\title{
Inventory models for production systems with constant/linear demand, time value of money, and perishable/non-perishable items
}

Karen N. Oganezov

West Virginia University

Follow this and additional works at: https://researchrepository.wvu.edu/etd

\section{Recommended Citation}

Oganezov, Karen N., "Inventory models for production systems with constant/linear demand, time value of money, and perishable/non-perishable items" (2006). Graduate Theses, Dissertations, and Problem Reports. 2756.

https://researchrepository.wvu.edu/etd/2756

This Dissertation is protected by copyright and/or related rights. It has been brought to you by the The Research Repository @ WVU with permission from the rights-holder(s). You are free to use this Dissertation in any way that is permitted by the copyright and related rights legislation that applies to your use. For other uses you must obtain permission from the rights-holder(s) directly, unless additional rights are indicated by a Creative Commons license in the record and/ or on the work itself. This Dissertation has been accepted for inclusion in WVU Graduate Theses, Dissertations, and Problem Reports collection by an authorized administrator of The Research Repository @ WVU.

For more information, please contact researchrepository@mail.wvu.edu. 


\title{
INVENTORY MODELS FOR PRODUCTION SYSTEMS WITH CONSTANT/LINEAR DEMAND, TIME VALUE OF MONEY, AND PERISHABLE/NON-PERISHABLE ITEMS
}

\author{
Karen N. Oganezov \\ Dissertation submitted to the \\ College of Engineering and Mineral Resources \\ at West Virginia University \\ in partial fulfillment of the requirements \\ for the degree of
}

Doctor of Philosophy

in

Industrial Engineering

\author{
Wafik H. Iskander, Ph.D., Chair \\ Bhaskaran Gopalakrishnan, Ph.D. \\ Majid Jaraiedi, Ph.D. \\ Alan R. McKendall, Jr., Ph.D. \\ Frances Van Scoy, Ph.D.
}

Department of Industrial and Management Systems Engineering

Morgantown, West Virginia

2006

Keywords: Inventory Control, Nonlinear Optimization, Time Value of Money, Linear Demand, Perishable Items 


\title{
ABSTRACT \\ INVENTORY MODELS FOR PRODUCTION SYSTEMS WITH CONSTANT/LINEAR DEMAND, TIME VALUE OF MONEY, AND PERISHABLE/NON-PERISHABLE ITEMS
}

\author{
Karen N. Oganezov
}

This research considers inventory systems for economic production models where the objective is to find the optimal cycle time, which minimizes the total cost, and optimal amount of shortage if it is allowed. Several aspects such as time value of money, inflation, constant and linear demand rates, shortages, and deterioration are considered in developing different models. Closed formulas are obtained for the optimal policy in one model. For others, more complex models where closed formulas cannot be obtained, search techniques are used to find the optimal solution.

First, a deterministic inventory control problem is considered for determination of optimal production quantities for an item with constant demand rate, while considering the effect of time value of money. Closed formulas are obtained to calculate the optimal cycle time and corresponding production quantity for the model without shortage. However, search procedures are used to find the optimal cycle time and maximum amount of shortage allowed for the models where shortage is allowed.

In the next inventory control problem, a deterministic model for items with linear demand rate over time, for a finite planning horizon, while considering the effect of time value of money, is considered. Search techniques are developed to find the optimal cycle time for the models without shortage, and the optimal cycle time and maximum amount of shortage for the models where shortage is allowed. A proof of the existence of a unique optimal point for the cost function is presented for the model without shortage.

A deterministic inventory control problem is also considered for items with constant rate of demand and exponentially decaying inventory over an infinite planning horizon, while considering the effect of time value of money. Two different search techniques are developed to find the optimal cycle time for the models without shortage, and the optimal cycle time and maximum amount of shortage allowed for the models where shortage is allowed. A proof of the existence of a unique optimal point for the cost function is presented for the model without shortage. 


\section{DEDICATION}

I would like to dedicate this thesis to my parents, and to my wife and son. Special thanks go to my mother for her continuous love and motivation. Without the support and encouragement of my family throughout my entire academic career, I would not be where I am today. 


\section{ACKNOWLEDGMENT}

I want to thank my advisor, Dr. Wafik Iskander, for his guidance, support and patience. I am grateful for the enormous time he spent reviewing every single page of the dissertation and providing constructive revision.

I also want to thank Dr. Alan McKendall, Dr. Bhaskaran Gopalakrishnan, Dr. Frances Van Scoy and Dr. Majid Jaraiedi for serving as members of my committee and for their help and support. 


\section{TABLE OF CONTENTS}

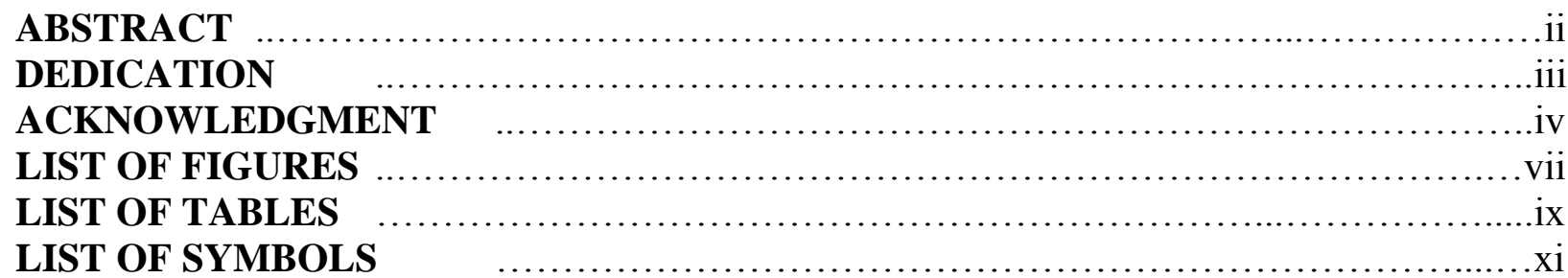

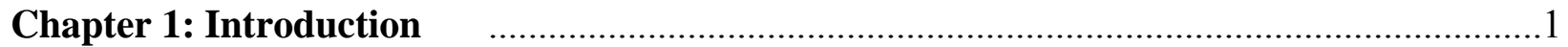

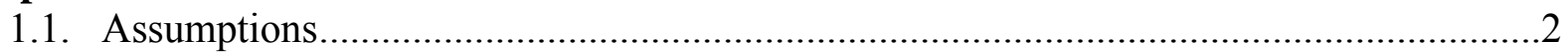

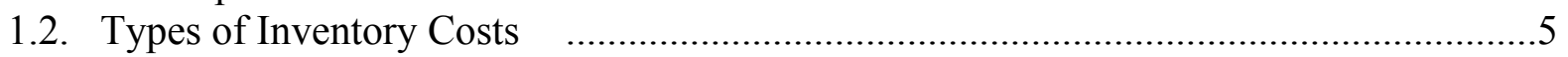

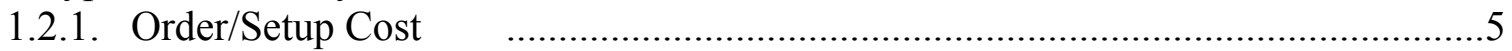

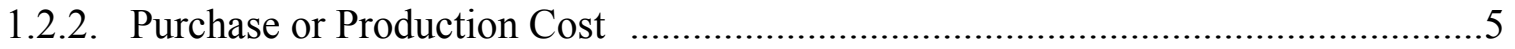

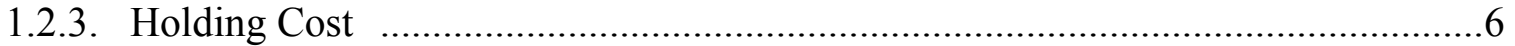

1.2.4. Shortage Cost ........................................................................................

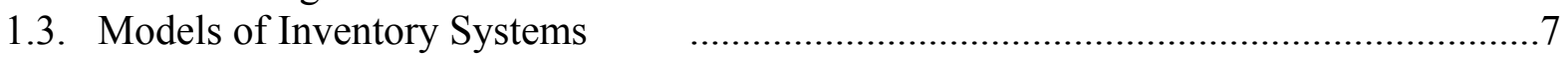

1.3.1. Economic Order Quantity (EOQ) for Single Item with Constant Demand

1.3.2. Economic Order Quantity (EOQ) for Single Item with Linear Demand ……............................................................................8

1.3.3. Economic Production Quantity (EPQ) for Single Item with Constant Demand

1.3.4. Economic Production Quantity (EPQ) for Single Item with Linear Demand .....................................................................................

1.4. Statement of the Problem and Research Objective ......................................................11

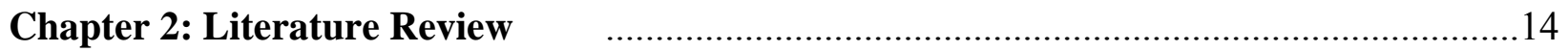

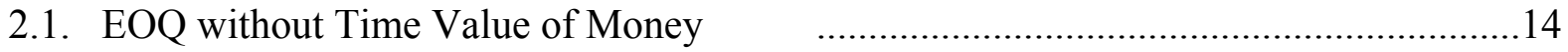

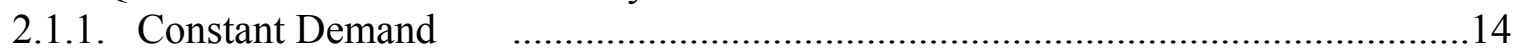

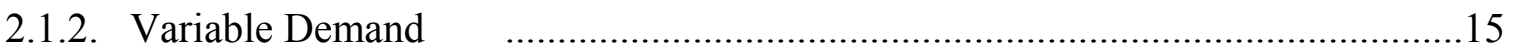

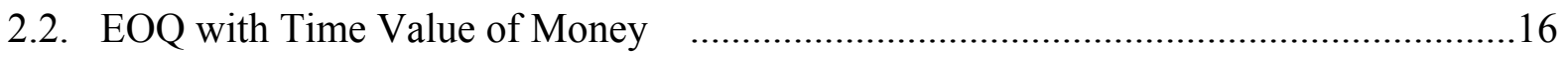

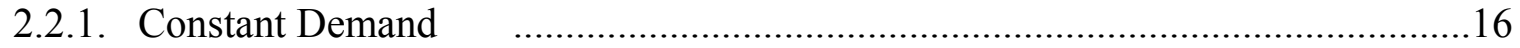

2.2.2. Variable Demand ……………………..............................................17

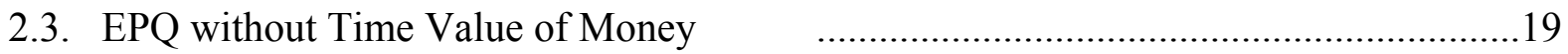

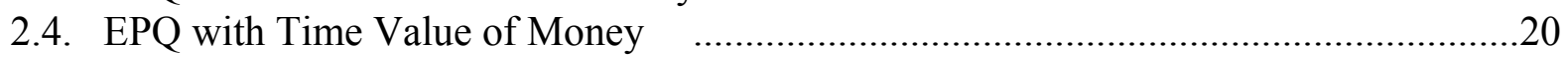

\section{Chapter 3: EPQ Models with and without Shortages} and Time Value of Money

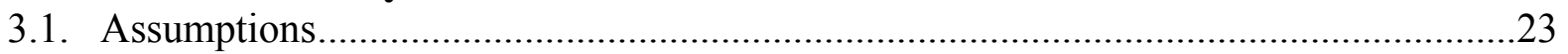

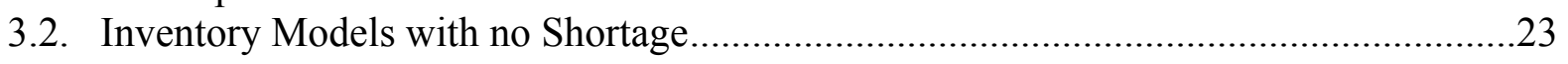

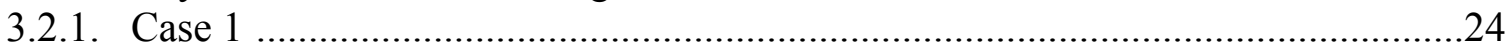

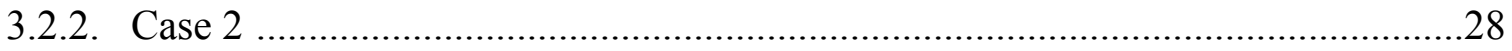

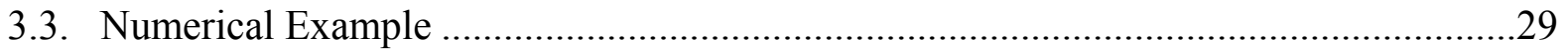

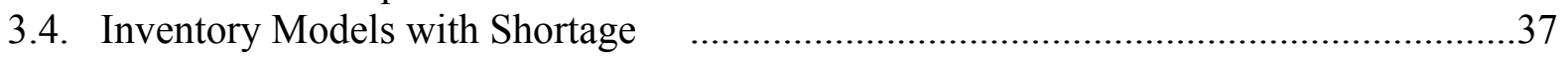

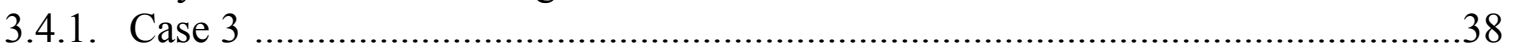




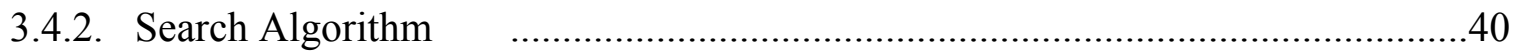

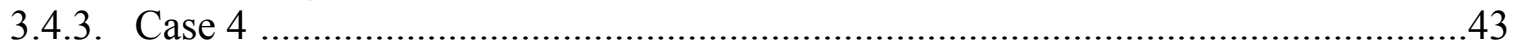

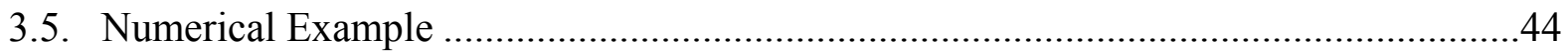

Chapter 4: EPQ Models with and without Shortages, with Linear Demand and Time Value of Money ……..................................................53

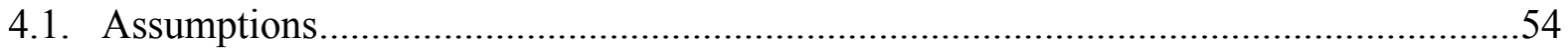

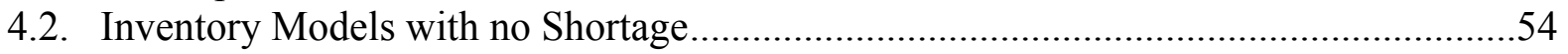

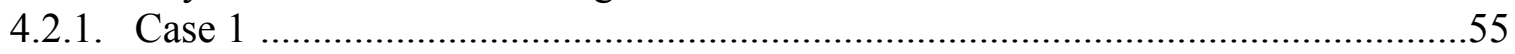

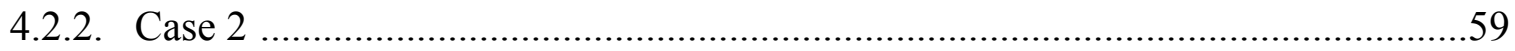

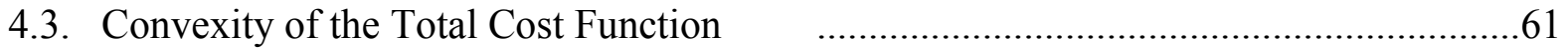

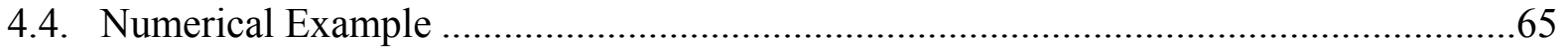

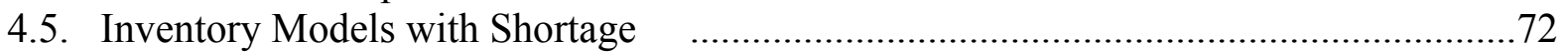

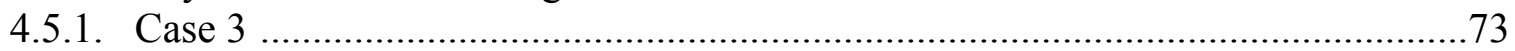

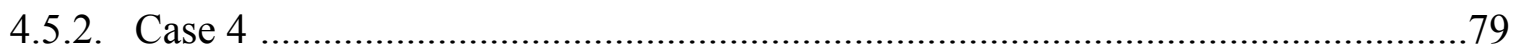

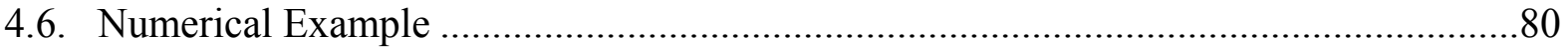

Chapter 5: EPQ Models with and without Shortages, with Constant Demand, Deterioration, and Time Value of Money $\quad$ ………....................91

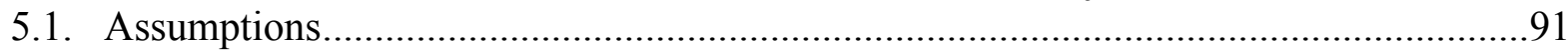

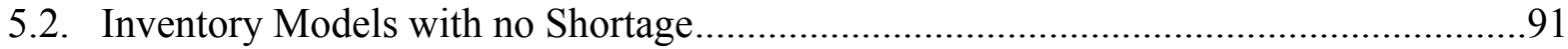

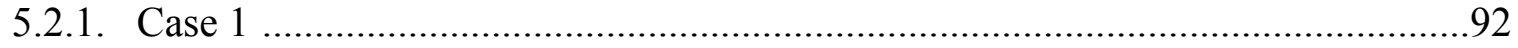

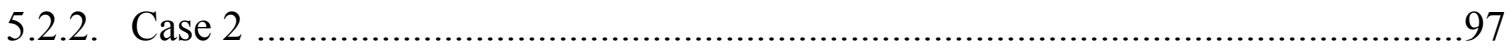

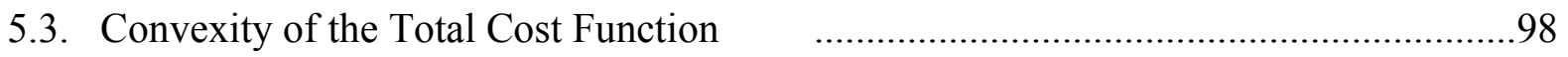

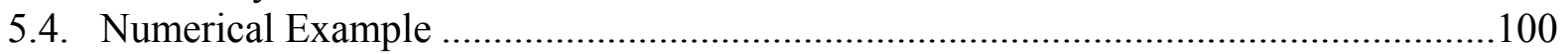

5.5. Inventory Models with Shortage ………….......................................................109

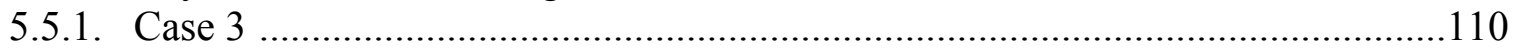

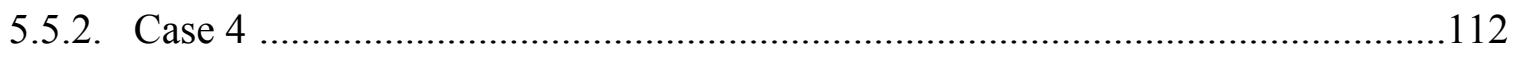

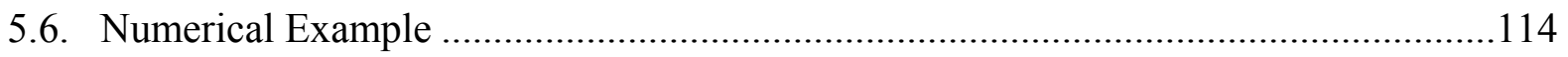

Chapter 6: Summary and Future Research

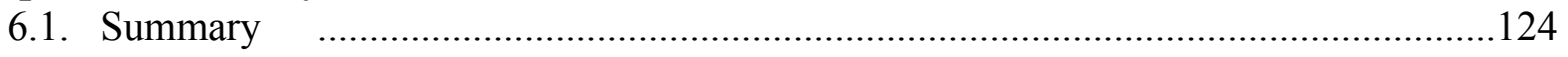

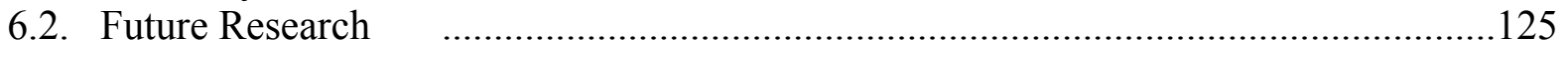

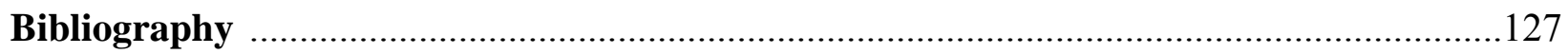

Appendix A. Computer program used for EPQ model

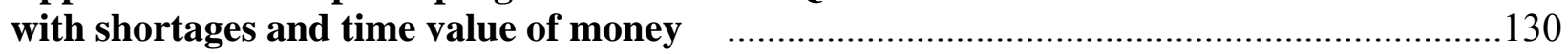

Appendix B. Computer program for EPQ model without shortages, with

linear demand and time value of money ................................................................138

Appendix C. Computer program for EPQ model with shortages,

linear demand, and time value of money 


\section{LIST OF FIGURES}

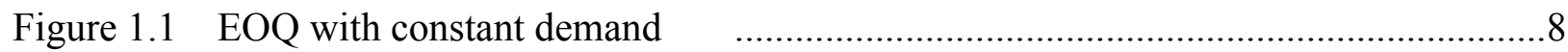

Figure 1.2 EOQ with linearly increasing demand ………................................................

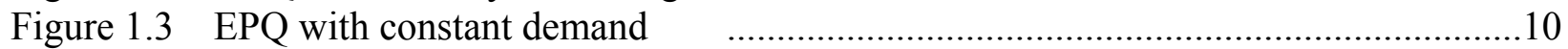

Figure 1.4 EPQ with linearly increasing demand ……...................................................

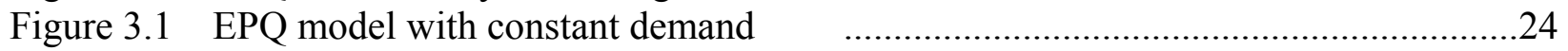

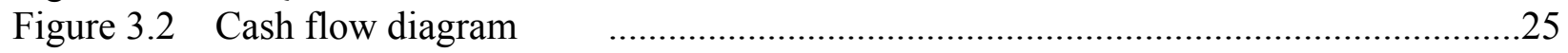

Figure 3.3 Effect of real interest rate $r$ on cycle time $T$

and present value of the total $\operatorname{cost} P_{t}$

Figure 3.4 Effect of carrying rate $F$ on cycle time $T$

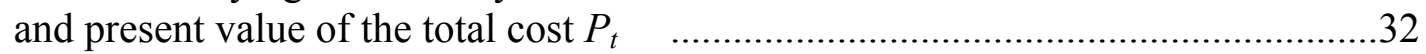

Figure 3.5 Effect of demand rate $D$ on cycle time $T$

and present value of the total cost $P_{t}$

Figure 3.6 Effect of setup $\operatorname{cost} A$ on cycle time $T$

Figure 3.7 Effect of changes in unit costs $c_{1}$ and $c_{2}$ and prest value of the total cost $P_{t}$

and present value of the total $\operatorname{cost} P_{t}$

Figure 3.8 Effect of changes in relative values of $c_{1}$ and $c_{2}$

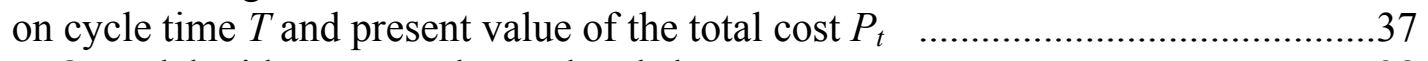

Figure 3.9 EPQ model with constant demand and shortages

Figure 3.10 Effect of real interest rate $r$ on ordering quantity $Q$, shortage $S$

and present value of the total cost $P_{t}$

Figure 3.11 Effect of carrying rate $F$ on ordering quantity $Q$, shortage $S$ and present value of the total $\operatorname{cost} P_{t}$

Figure 3.12 Effect of demand rate $D$ on ordering quantity $Q$, shortage $S$

and present value of the total cost $P_{t}$

Figure 3.13 Effect of shortage cost $K$ on ordering quantity $Q$, shortage $S$ and present value of the total cost $P_{t}$

Figure 3.14 Effect of setup cost $A$ on ordering quantity $Q$, shortage $S$ and present value of the total cost $P_{t}$

Figure 3.15 Effect of changes in unit costs $c_{1}$ and $c_{2}$ on ordering quantity $Q$, shortage $S$ and present value of the total cost $P_{t}$

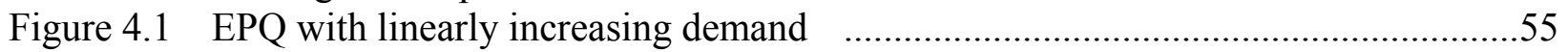

Figure 4.2 Shape of the TC function and its components when the polynomial function has no extremes

Figure 4.3 Shape of the TC function and its components when the polynomial function has two extremes

Figure 4.4 Effect of real interest rate $r$ on cycle time $T$ and present value of the total cost $P_{t}$

Figure 4.5 Effect of carrying rate $F$ on cycle time $T$ and present value of the total cost $P_{t}$

Figure 4.6 Effect of demand rate slope $b$ on cycle time $T$ and present value of the total cost $P_{t}$

Figure 4.7 Effect of setup cost $A$ on cycle time $T$ and present value of the total cost $P_{t}$ 
Figure 4.8 Effect of changes in unit costs $c_{1}$ and $c_{2}$ on cycle time $T$ and present value of the total $\operatorname{cost} P_{t}$ . .71

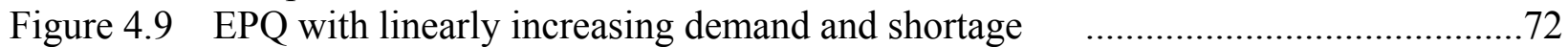

Figure 4.10 Effect of real interest rate $r$ on cycle time $T$ and shortage $S \quad \ldots \ldots \ldots \ldots \ldots \ldots \ldots \ldots \ldots \ldots . . . .11$

Figure 4.11 Effect of real interest rate $r$ on present value of the total cost $P_{t} \quad \ldots \ldots \ldots \ldots \ldots \ldots . . .82$

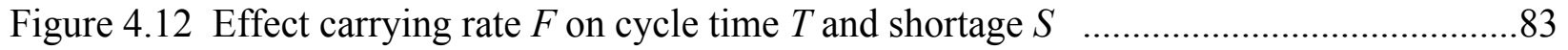

Figure 4.13 Effect of carrying rate $F$ on present value of the total cost $P_{t} \quad \ldots \ldots \ldots \ldots \ldots \ldots \ldots \ldots \ldots \ldots . . .83$

Figure 4.14 Effect of shortage cost $K$ on cycle time $T$ and shortage $S \quad \ldots$

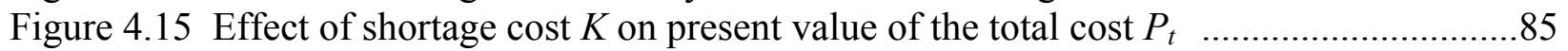

Figure 4.16 Effect of demand rate slope $b$ on cycle time $T$ and shortage $S \ldots \ldots \ldots \ldots \ldots \ldots \ldots \ldots \ldots \ldots . . . .86$

Figure 4.17 Effect of demand rate slope $b$ on present value of the total cost $P_{t} \quad \ldots \ldots \ldots \ldots \ldots \ldots . . . .86$

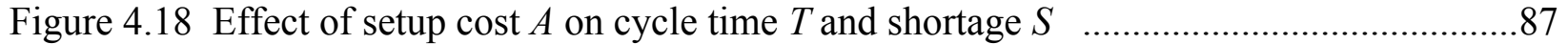

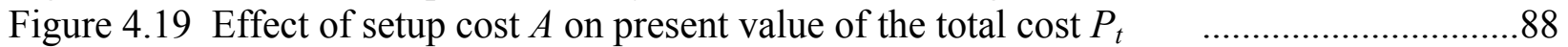

Figure 4.20 Effect of changes in unit costs $c_{1}$ and $c_{2}$ on

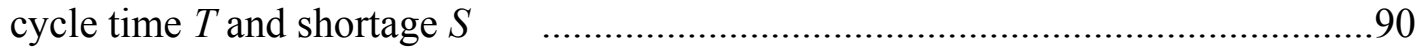

Figure 4.21 Effect of changes in unit $\operatorname{costs} c_{1}$ and $c_{2}$ on

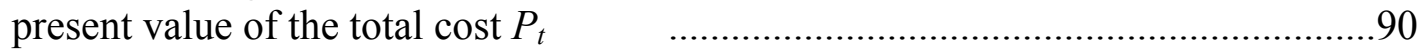

Figure 5.1 EPQ model for deteriorating items without shortage $\quad$........................................92

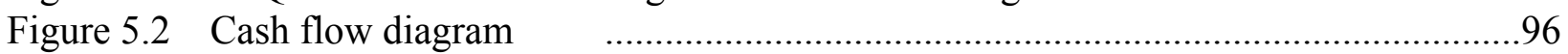

Figure 5.3 Effect of real interest rate $r$ on cycle time $T$ and present value of the total cost $P_{t}$

Figure 5.4 Effect of deterioration rate $\theta$ on cycle time $T$ and present value of the total $\operatorname{cost} P_{t}$

Figure 5.5 Effect of carrying rate $F$ on cycle time $T$ and present value of the total cost $P_{t}$

Figure 5.6 Effect of demand rate slope $b$ on cycle time $T$ and present value of the total cost $P_{t}$

Figure 5.7 Effect of setup cost $A$ on cycle time $T$ and present value of the total $\operatorname{cost} P_{t}$

Figure 5.8 Effect of changes in unit costs $c_{1}$ and $c_{2}$ on cycle time $T$ and present value of the total cost $P_{t}$

Figure 5.9 EPQ model with shortage for deteriorating items

Figure 5.10 Effect of real interest rate $r$ on ordering quantity $Q$, shortage $S$ and present value of the total cost $P_{t}$

Figure 5.11 Effect of deterioration rate $\theta$ on ordering quantity $Q$, shortage $S$ and present value of the total cost $P_{t}$

Figure 5.12 Effect of carrying rate $F$ on ordering quantity $Q$, shortage $S$ and present value of the total cost $P_{t}$

Figure 5.13 Effect of demand rate $D$ on ordering quantity $Q$, shortage $S$ and present value of the total cost $P_{t}$

Figure 5.14 Effect of shortage cost $K$ on ordering quantity $Q$, shortage $S$ and present value of the total cost $P_{t}$

Figure 5.15 Effect of setup cost $A$ on ordering quantity $Q$, shortage $S$ and present value of the total cost $P_{t}$

Figure 5.16 Effect of changes in unit costs $c_{1}$ and $c_{2}$ on ordering quantity $Q$, shortage $S$ and present value of the total $\operatorname{cost} P_{t}$ 


\section{LIST OF TABLES}

Table 3.1 Optimal ordering policies for different values of $r$ for Cases 1 and 2 ..................30

Table 3.2 Optimal ordering policies for different values of $F$ for Cases 1 and 2 .................32

Table 3.3 Optimal ordering policies for different values of $D$ for Cases 1 and 2 .................33

Table 3.4 Optimal ordering policies for different values of $A$ for Cases 1 and 2 ..................34

Table 3.5 Optimal ordering policies for different values of $c_{1}$ and $c_{2}$

increased simultaneously

Table 3.6 Optimal ordering policies for different values of $c_{1}$ and $c_{2} \quad$..............................36

Table 3.7 Optimal ordering policies for different values of $r$

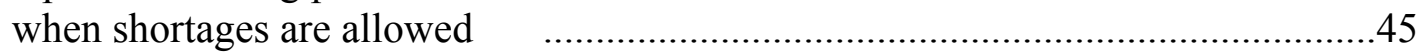

Table 3.8 Optimal ordering policies for different values of $F$

when shortages are allowed

Table 3.9 Optimal ordering policies for different values of $D$

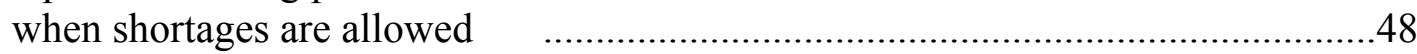

Table 3.10 Optimal ordering policies for different values of $K$ when shortages are allowed

Table 3.11 Optimal ordering policies for different values of $A$ when shortages are allowed . .50

Table 3.12 Optimal ordering policies for different values of $r$ and two separate costs when shortages are allowed $\quad$.........................................51

Table 3.13 Optimal ordering policies for simultaneous changes in

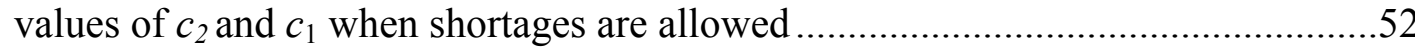

Table 4.1 Optimal ordering policies for different values of $r$

Table 4.2 Optimal ordering policies for different values of $F$

Table 4.3 Optimal ordering policies for different values of $b$

Table 4.4 Optimal ordering policies for different values of $A$

Table 4.5 Optimal ordering policies for different values of $r$ and two separate costs .70

Table 4.6 Optimal ordering policies for different values of $c_{1}$ and $c_{2} \quad$...............................71

Table 4.7 Optimal ordering policies for different values of $r$ for the models with shortages

Table 4.8 Optimal ordering policies for different values of $F$ for the models with shortages

Table 4.9 Optimal ordering policies for different values of $K$

for the models with shortages

Table 4.10 Optimal ordering policies for different values of $b$

for the models with shortages

Table 4.11 Optimal ordering policies for different values of $A$ for the models with shortages

Table 4.12 Optimal ordering policies for different values of $r$ and two separate costs for the models with shortages

Table 4.13 Optimal ordering policies for different values of $c_{1}$ and $c_{2}$

Table 5.1 Optimal ordering policies for different values of $r$

Table 5.2 Optimal ordering policies for different values of $\theta$ 
Table 5.3 Optimal ordering policies for different values of $F$ 104

Table 5.4 Optimal ordering policies for different values of $D$

Table 5.5 Optimal ordering policies for different values of $A$

Table 5.6 Optimal ordering policies for different values of $r$

Table 5.7 Optimal ordering policies for different values of $c_{1}$ and $c_{2} \quad \ldots \ldots \ldots \ldots \ldots \ldots \ldots \ldots \ldots . . . . .108$

Table 5.8 Optimal ordering policies for different values of $r$ when shortages are allowed

Table 5.9 Optimal ordering policies for different values of $\theta$

when shortages are allowed

Table 5.10 Optimal ordering policies for different values of $F$ when shortages are allowed

Table 5.11 Optimal ordering policies for different values of $D$ when shortages are allowed

Table 5.12 Optimal ordering policies for different values of $K$ when shortages are allowed

Table 5.13 Optimal ordering policies for different values of $A$ when shortages are allowed

Table 5.14 Optimal ordering policies for different values of $r$ and two separate costs when shortages are allowed

Table 5.15 Optimal ordering policies for different values of $c_{1}$ and $c_{2}$ when shortages are allowed 


\section{LIST OF SYMBOLS}

The following notation is used throughout the paper:

D demand rate (for constant demand rate models), unit per time unit

$D(t) \quad$ demand rate at time $t$ (for linear demand rate models), unit per time unit

$p \quad$ replenishment rate or production rate $(p>D)$, unit per time unit

$t_{p} \quad$ production time during a cycle (for constant demand rate models), time unit

$t_{p j} \quad$ end of the production time for cycle $j+1$ (for linear demand rate models), time unit

$\theta \quad$ deterioration rate, unit per unit per time unit

$c \quad$ unit production cost (for Cases I and III). For Cases II and IV, the unit production cost is divided into two components $c_{1}$ and $c_{2}$, where $c_{1}$ is the cost incurred at the beginning of cycle, and $c_{2}$ the cost incurred at the production time, $\$$ per unit

$R \quad$ interest rate. $R$ is assumed to have a constant value over time and is compounded continuously, \$ per \$ per time unit

$f \quad$ inflation rate, constant and less than the interest rate $R$, and is compounded continuously, \$ per \$ per time unit

$Q \quad$ economic production quantity, units

A fixed replenishment or setup cost incurred at the beginning of each cycle, $\$$ per setup

$T \quad$ length of the inventory cycle, time unit

$H \quad$ planning horizon, time unit

$m \quad$ number of cycles during the planning horizon, integer

$F \quad$ inventory carrying rate, $\$$ per $\$$ per time unit 
$K \quad$ shortage cost per unit short per time unit, \$ per unit per time unit

$K_{0} \quad$ shortage cost per unit short, \$ per unit

$P \quad$ present value of the total cost of the inventory system for the first cycle, $\$$

$P_{t} \quad$ present value of the total cost of the inventory system of all cycles over an infinite planning horizon, $\$$

$I(t) \quad$ level of inventory on-hand at time $t$, units 


\section{Chapter 1}

\section{Introduction}

Most organizations in any sectors of the economy have some type of inventory system. Inventories are common to agriculture, manufacture, retail, etc. A hospital, for example, has methods to control blood supplies and pharmaceuticals. For many small business owners, inventory is one of the most visible and tangible aspects of doing business. Raw materials, subassemblies, work in process, and finished goods all represent various forms of inventory. Government agencies, as well as production and manufacturing organizations are concerned with inventory planning and control. Inventories tie up money. Each type of inventory represents money tied up until the inventory leaves the company as products. Similarly, merchandise stocks in a retail store contribute to profits only when their sale puts money into the cash register. These stocks represent a large portion of the business investment and must be managed well in order to maximize profits. Investment in inventories represents a considerable amount of money. In fact, many small businesses cannot absorb the types of losses that arise from poor inventory management. A review of American industry reveals that in general, $20-40 \%$ of the total assets of companies are tied up in inventory (Tersine 1994). Unless inventories are controlled, they are unreliable, inefficient and costly. Cash invested in inventories could be used for other purposes, like paying debts or making capital investments.

Effective inventory management helps organizations to save money. Inventory management must determine how much and when to order/produce each item purchased/manufactured by the organization. Successful inventory management involves balancing the costs of inventory with its benefits. Many small business owners fail to fully 
realize the true costs of carrying inventory, which include not only direct costs of storage, insurance and taxes, but also the cost of money tied up in inventory. The fine line between keeping too much inventory and not enough is not the manager's only concern. Managers should consider keeping stocks low, without sacrificing performance or service. They should also guard against ending up with obsolete items.

One of the most important aspects of inventory control is to have the items in stock at the moment they are needed. This includes going into the market to buy the goods early enough to ensure delivery at the proper time. Thus, buying requires advance planning to determine inventory needs for each time period and then making the commitments without delay.

The objective of inventory management is to determine when to order, and how much should be ordered in order to minimize the related total costs. The following sections discuss relevant cost factors in inventory systems and review the most common inventory models. First, the most common assumptions and definitions found in the literature are presented, and then an explanation of the cost factors will follow.

\subsection{Assumptions}

In general, there are two types of assumptions encountered in the literature. First, general assumptions that are found in most inventory problems, and the second type is special assumptions that are unique to specific problems. The general assumptions are summarized below:

1. Initial inventory level is zero

2. Planning horizon is infinite 
3. Replenishment is either instantaneous or has a finite rate which is known with certainty

4. Shortages either are not allowed or may be allowed and satisfied when replenishments are received

5. On-hand inventory at time zero is zero when shortages are not allowed

6. Holding cost per unit per year (or any other unit of time) is known

7. For economic order quantity (EOQ) models order (or lot size) quantities are fixed at $Q$ items

8. Total cost $=$ Setup cost + Purchase $($ or Production cost $)+$ Holding cost. When shortages are allowed, Shortage cost is added to the Total cost

9. Demand rate is constant and known

Examples of special assumptions include:

1. Time value of money. The effect of inflation and time value of money is very important and it is now included in most of the recent papers concerning inventory. High inflation rates in some countries could undermine the entire economic development. Since money tied up in inventories could decrease their actual value over time, the effect of inflation rate should be reflected in the development of inventory policies.

2. Inventory items may deteriorate, perish or become obsolete. There are many industries where items such as dairy products, medicines and vegetables deteriorate at a considerable rate and the loss from deterioration cannot be ignored. The first attempt to derive optimal inventory policies for deteriorating items was made by 
Ghare et al. (1963), who developed an EOQ model for an item that deteriorates exponentially.

3. Demand rate may be linear and known with certainty, a deterministic function, or a random variable that follows some probability distribution. Different patterns of demand are commonly used to reflect sales in different phases of the product life cycle in the market. For example, demand can be increasing linearly when a product is in its growth phase, and then it becomes constant in its maturity period, and later it becomes a decreasing linear function when the product is in its decline phase. For cases that are more general, demand may not be known and is treated as a random variable that follows some probability distribution.

4. Permissible delay in payment. In general, the EOQ model assumes that the payment for the order is paid as soon as the items are received. However, in practice suppliers may allow for a certain delay in payment without charging interest. The delay in payment is advantageous to both customers and suppliers. For suppliers, it is some form of price discount to motivate customers to order more quantities from them. This assumption received some attention in the literature. Haley and Higgins (1973) first introduced the economic order quantity model where permissible delay in payment is allowed. Goyal (1985) developed a mathematical formulation for determining the EOQ with permissible delay in payment for a single item. Later, other authors applied permissible delay in payments for different inventory systems. As an example, Liao et al. (2000) applied delay in payments for inventory models for deteriorating items. 


\subsection{Types of Inventory Costs}

In the following sections, different types of costs incurred in an inventory system are discussed. Basically, there are four major inventory costs. These are: 1) Costs associated with ordering when inventories are ordered from external sources, or setup cost when inventories are

produced internally, 2) Costs associated with procuring or manufacturing the units, 3) Costs of carrying the items in inventory, 4) Shortage costs, which are associated with unsatisfied demands when the item is out of stock.

\subsubsection{Order/Setup Cost}

Ordering cost includes cost of forms, supplies, order processing, clerical support, etc. Thus, it includes all the cost components associated with a single order for the given item. When items are manufactured, setup costs are substituted for ordering costs. Operations managers can lower ordering costs by using efficient procedures such as electronic ordering and payment. The setup cost is mainly the cost incurred in preparing a machine or process for manufacturing an order. It includes the cost associated with the loss of production time, and labor cost for cleaning and changing tools or holders (Heizer 2001).

\subsubsection{Purchase or Production Cost}

Depending on the type of inventory model considered, there would be a cost associated with purchasing an item or a cost associated with producing it. For the purchasing case, purchasing cost simply represents the price of the purchased units. Besides, there are other costs incurred during procurement, such as transportation or freight cost. For the production case, production cost is the cost of the unit produced, which includes direct labor, direct material, etc. 
It may be appropriate and more practical to divide this cost into two parts. An initial cost, which occurs at the beginning of each cycle and is applied to the entire quantity produced during the production period, and a running cost which is occurred as production progresses and applies to the individual units produced. As an example, one may consider the situation where the initial cost is the cost of the raw material for the entire production quantity, which is paid at the beginning of the cycle, and the second is the labor cost associated with production process, paid continuously during production.

\subsubsection{Holding Cost}

Holding costs are the costs associated with holding or carrying inventory over time. They include several components such as obsolescence, warehouse rental or usage, costs related to storage such as light and cooling/heating, and costs paid out of pocket such as insurance, taxes, extra interest payments, breakage and pilferage at the storage site, etc. There is also another very important component: The opportunity cost. This is the cost incurred for having money tied up in inventory rather than investing it. In estimating this cost, one should use the largest rate of return that the company could have obtained from alternative investment (Hadley and Whitin 1963). It is very difficult to represent accurately all the costs of carrying inventory. The usual range of annual holding cost is $20 \%-40 \%$ of the inventory investment. Many firms fail to account for all

of the inventory holding costs. Consequently, inventory holding costs are often understated (Heizer 2001). 


\subsubsection{Shortage Cost}

Shortage cost occurs when the system is out of stock, but demand still exists. There are two types of shortage costs that depend on the reaction of the customer to the out-of-stock situation. First, when a company is out of stock and receives an order, it may take some costly steps to fill the order. This is the case of backorders, where the sale is not lost, but additional costs are incurred, such as special handling, shipping, and packaging costs. The second case is when the sale is lost. In this case, the company will lose potential profit from the sale, in addition to intangible loss of goodwill. A goodwill loss could cost the company a loss of future sales since the prospective customer might not come back to purchase other items in the future. For production companies, if the raw material is out-of-stock, the whole production process may have to shut down and the associated cost could be very high (Starr and Miller 1962).

\subsection{Models of Inventory Systems}

Based on the type of demand, whether it is constant or a function of some variables, and on the replenishment type, whether through production or by ordering, different models can be identified for deterministic single item inventory systems as discussed in the following sections.

\subsubsection{Economic Order Quantity (EOQ) for Single Item with Constant Demand}

This model is generally referred to as the classical inventory model (Tersine 1994). It assumes that demand rate for the item is constant and known with certainty. Although in the real world, demand is usually probabilistic and not constant, deterministic models are still a very good approximation and good starting point for describing the inventory system. Also, many products have relatively stable demands, such as toiletries, toothpaste, etc. 
As shown in Figure 1.1, after receiving an order, the inventory level becomes $Q$ units. These units are consumed with a constant demand rate $D$ until they are all gone. When the inventory level reaches the reorder point $R$, a new order is placed for $Q$ new units. The new items are received and placed in inventory just as the inventory level reaches zero. Models have been developed for cases with no shortage, or when shortage is allowed and fully satisfied from the new shipment.

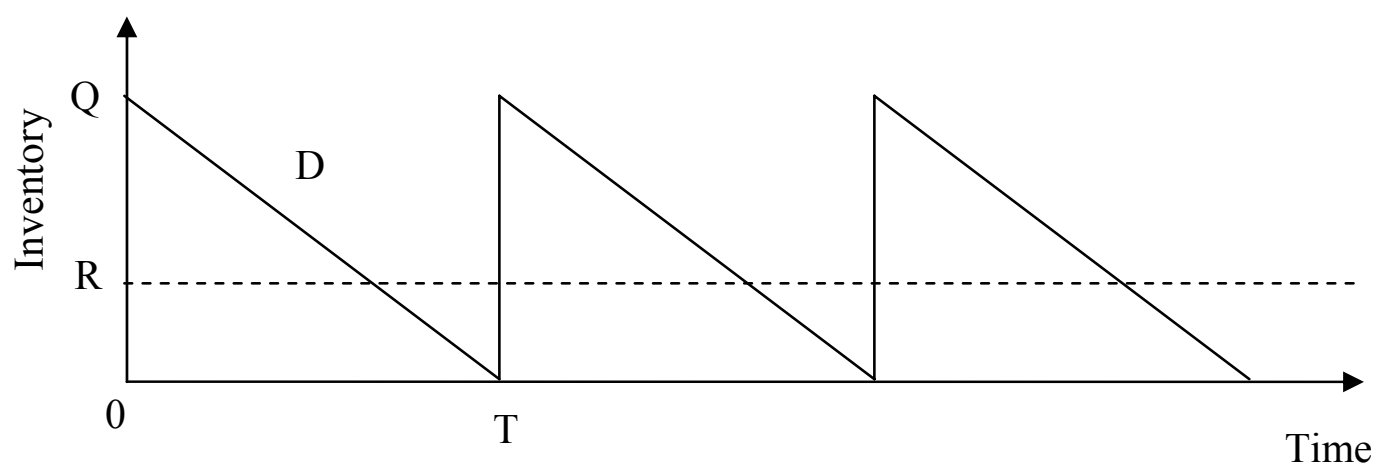

Figure 1.1 EOQ with constant demand

\subsubsection{Economic Order Quantity (EOQ) for Single Item with Linear Demand}

For many inventory systems, such as those for electronic products, clothes, and domestic goods, the demand rate may constantly increase after the successful introduction into the market.

The demand for the products could also drop at a constant rate after the maturity period. The demand rate of the product during its introduction or in its decline phase may be approximated as linearly increasing or decreasing functions, respectively. Many papers have considered EOQ models with demand as a linear function. Donaldson (1977) was the first to introduce and develop an EOQ model in which shortages were not allowed and the demand had a linearly increasing function over time over a finite time horizon, $H$. Figure 1.2 presents the EOQ model with linearly increasing demand, when demand at time $t, D(t)$, is equal to $a+b t$ where $a$ and $b$ are constant. Cycle time may be considered as either constant for all cycles, or it may vary 
between cycles. If order quantity, $Q$, is constant, then cycle time changes between cycles. This model can also be considered when shortages are allowed and satisfied from the new shipment.

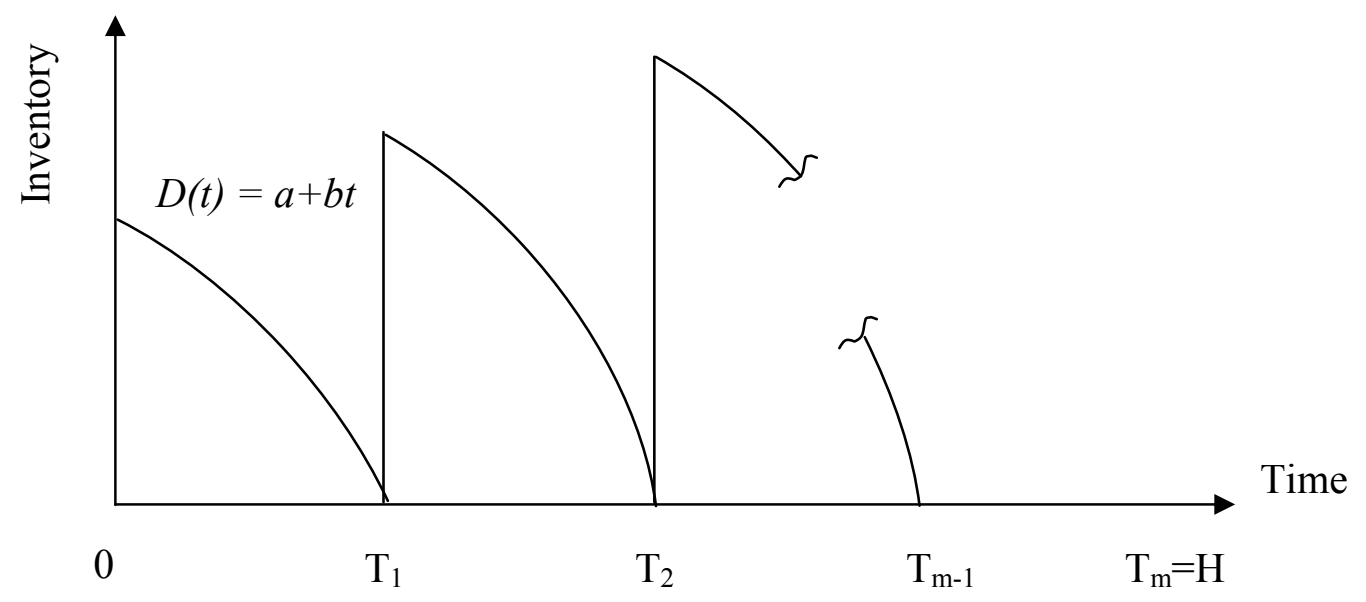

Figure 1.2 EOQ with linearly increasing demand

\subsubsection{Economic Production Quantity (EPQ) for Single Item with Constant Demand}

In EOQ models, it is assumed that the entire inventory order, $Q$, is received at one time. There are cases, however, where the firm receives its inventory over a period of time or where the item is produced locally rather than purchased. Such cases require a different model, one that does not assume instantaneous replenishment of the item. Because this model is especially suitable for the production environments, it is commonly called the production order quantity model. EPQ models, with and without shortages, have been addressed in many articles and textbooks, dating back to the early 1960s (e.g. Hadley and Whitin 1963). This model is useful when units are continuously added to inventory over time, while production is in process. The general EOQ assumptions are still valid (Heizer 2001). As shown in Figure 1.3, the inventory onhand increases at the rate $p-D$; this is the production rate minus the consumption rate during the production time. At $t_{p}$, the end of the production period, the production process stops and the inventory level reaches $Q_{l}$, its maximum. If there were no consumption from zero to $t_{p}$, the 
inventory level would have increased up to quantity $Q$ at the production rate $p$. After $t_{p}$, the inventory decreases at the consumption rate $D$ until the inventory level reaches zero at the end of the cycle $T$, where the production process resumes again. The model can also be considered with backordering, when system is out of stock but the demand still exists. Backorders accumulate until the end of the cycle, where the production process starts again.

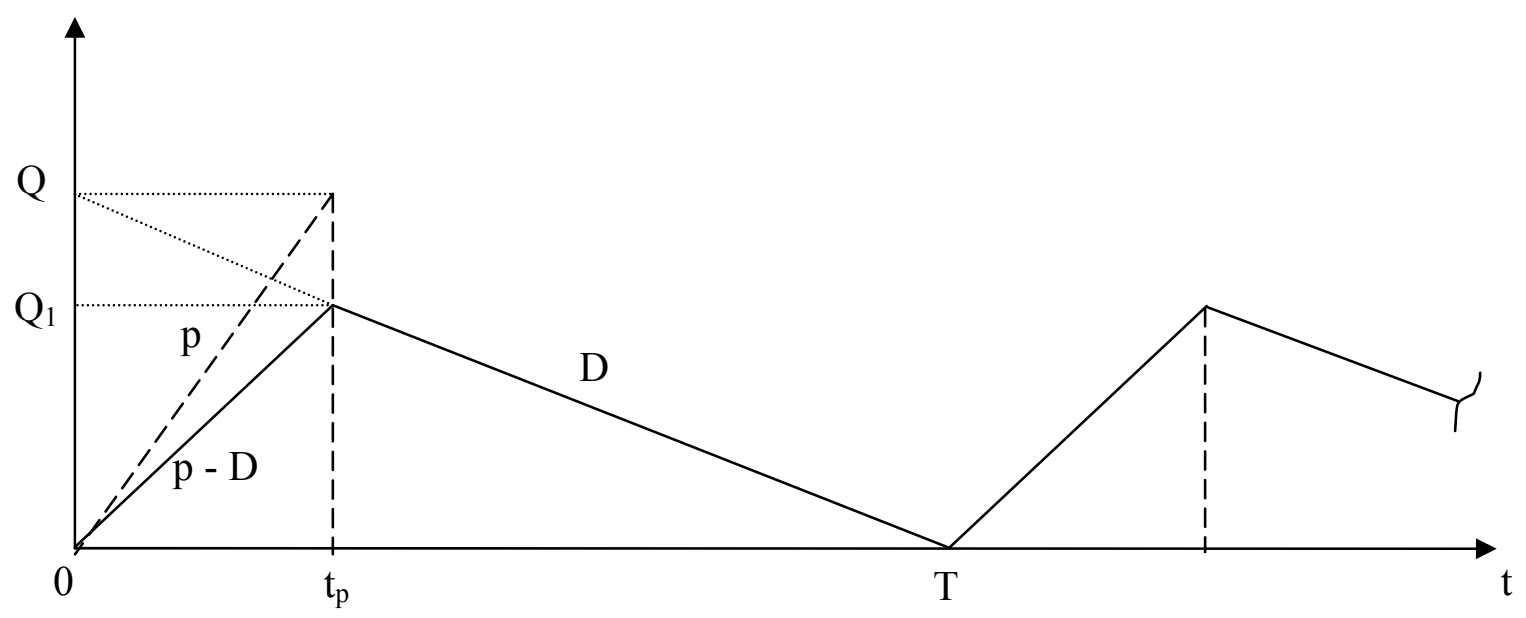

Figure 1.3 EPQ with constant demand

\subsubsection{Economic Production Quantity (EPQ) for Single Item with Linear Demand}

This model is applied for items manufactured and consumed at the same time with a linearly increasing or decreasing demand. The model is applied only for a finite planning horizon. Production time $t_{p}$, which is the length of the production period, would change for every cycle because of the linear change in demand while cycle time $T$ is considered to be constant over the planning horizon. Hong et al. (1990) introduced production policies for linearly increasing demand with finite and uniform production rate. The inventory scheme shown in Figure 1.4 is used to develop the details of the system. This model can also be considered while allowing for shortages. 


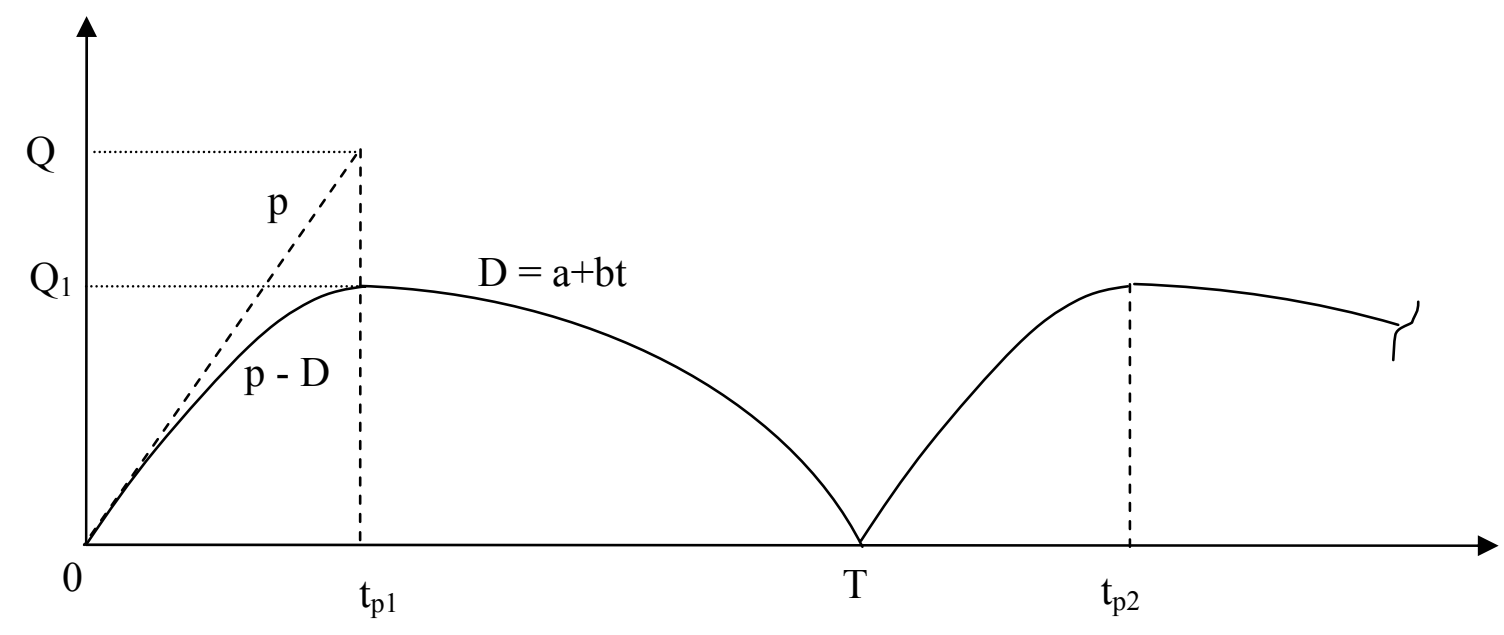

Figure 1.4 EPQ with linearly increasing demand

\subsection{Statement of the Problem and Research Objective}

The inventory models proposed in this research are for production inventory systems where items are manufactured within the organization and distributed or consumed simultaneously. The literature is very rich with discussion of inventory models. Many papers have been published where different inventory models were introduced and developed. Most of the published papers are concentrated around developing solutions for EOQ models. Different aspects of EOQ have been discussed and analyzed such as time value of money, allowable shortages and constant vs. non-constant demand rates. Not many authors, however, have addressed the problem of economic production quantities. No attempt could be found in the literature to develop inventory models for production policies with time value of money or linearly changing demand.

The objective of this study is to find the optimal cycle time (quantity of manufactured items), and optimal amount of backorders where different inventory concepts such as time value of money, inflation, constant or linear demand, shortages, and deterioration are considered. The 
planning horizon for the models in most of the cases is finite. For some cases where demand rate is constant, the optimal replenishment policy will be derived for an infinite planning horizon. For models with linear trend in demand production, the production time $t_{p}$ will change for every cycle because of the linear change in demand while the cycle time $T$ will be considered fixed over the planning horizon.

The first problem to be considered will investigate the EPQ models where time value of money is applied and demand is known and constant over time. Two different models are developed. In the first model, no shortage is allowed, while the second model allows for shortages. In each model, two different cost functions are considered. In the first case, the production cost is incurred at the beginning of the cycle. In the second case, two costs are applied in the production process, the first (initial cost) occurs at the beginning of the cycle and is applied to the entire quantity produced during the cycle, while the second cost (running cost) takes place at the time of production and applies only to the quantity produced at that time. Closed formulas are obtained to calculate the optimal cycle time and corresponding production quantity for the models without shortage. Search procedures are used to find the optimal cycle time and maximum amount of shortage allowed for the models where shortage is allowed.

The second problem to be investigated will consider the EPQ models with time value of money, known but variable demand that is a linear function of time. For this problem, again two models will be developed, with and without shortages and using two production cost functions as described above. Search techniques will be developed to search for the optimal cycle time for the models without shortage, and the optimal cycle time and maximum amount of shortage for the models where shortage is allowed. A proof of the existence of a unique optimal point for the cost function will be presented for the model without shortage. 
The last problem is similar to the first one, but it will investigate the EPQ models with time value of money and exponentially decaying inventory. Similar to the first two problems, models will be developed with and without shortages and using two production cost functions. Two different search techniques will be developed to search for the optimal cycle time for the models without shortage, and the optimal cycle time and maximum amount of shortage allowed for the models where shortage is allowed. A proof of the existence of a unique optimal point for the cost function will be presented for the model without shortage.

Chapter 2 of this document presents the literature related to the problem. Chapter 3 gives an introduction to inventory problems with and without shortages that take into account the effects of time value of money. Closed formulas are presented for the models without shortages. Chapter 4 gives a detailed formulation of the deterministic single item models with linearly increasing demand rate with and without shortages. Optimal solutions and numerical examples are presented as well. A proof of the existence of a unique optimal point for the cost function is presented for the model without shortage. Chapter 5 is concerned with developing the mathematical formulations related to models with inventory deterioration. Chapter 6 presents conclusions and suggestions for future research. 


\section{Chapter 2}

\section{Literature Review}

The study of inventory models has been widely discussed in the literature during the past several decades. Many papers have been published where different inventory models were introduced and developed. Most of the papers are concentrated on the development of solutions for economic order quantity models. Different aspects of EOQ models were discussed and analyzed, such as time value of money, allowable shortages, and different types of demand. In the following sections, a review of the recent literature for both EOQ and EPQ models is presented.

\subsection{EOQ without Time Value of Money}

Economic order quantity models were developed a long time ago and became very popular after World War II (Hadley and Whitin 1963). The basic EOQ model is presented in almost all books as a classical example of inventory management. Most of the papers found in the literature concentrate on developing inventory systems for EOQ models.

\subsubsection{Constant Demand}

Chung (1998) explored the problem of EOQ with the assumption of permissible delay in payment. His work was based on the paper by Goyal (1985) who initially presented the model. The article investigated an alternative approach for the determination of the EOQ. First, he showed that total annual cost is a convex function and then developed a simple theorem for determining the EOQ to simplify the solution procedure described by Goyal (1985). 
The economic ordering policy with constant demand rate for deteriorating items and permissible delay in payments was presented by Aggarwal and Jaggi (1995). In a few industries, there are items such as radioactive materials, highly volatile substances, etc., for which the rate of deterioration is significantly high and the loss associated with deterioration cannot be ignored. Chu et al. (1998) continued research on that model and investigated the convexity of the total cost function. They showed that the total cost function is piecewise-convex, and developed a better solution procedure than the one presented by Aggarwal and Jaggi (1995).

The EOQ model with a deterministic and continuous demand was applied to an inventory system for a recoverable item by Teunter (2001). A simple square root EOQ formula was derived for the inventory system with items that can be recovered (i.e. repaired, refurbished or remanufactured). Repair brings an item to a working condition. Refurbishing increases the quality of the product and brings it to a specified level. Remanufacturing makes the quality of an item as good as new.

\subsubsection{Variable Demand}

An inventory model for deteriorating items, linear trend in demand, and allowing shortages was presented by Bhunia and Maiti (1999). In this paper, the assumption of constant replenishment cost for the finite time horizon was relaxed. The replenishment cost includes transportation costs, and loading and unloading costs that depend on the lot size. Since the demand increases linearly, the optimal lot-size would change in every cycle. Therefore, the replenishment cost cannot be the same for the successive replenishments. The results for the model without shortages were also derived as a special case. 
Wang (2002) considered an inventory model with linear demand for deteriorating items, with shortages and partial backlogging. In earlier research it was assumed, that the shortages in inventory were either fully backordered or totally lost. In this paper, a more realistic scenario was assumed where part of the shortage was backordered and the rest was lost. The backordering rate was defined, as well as the opportunity cost due to lost sales. The backordering rate describes the percentage of customers who would like to wait for their order to be satisfied in the next cycle. This rate would decrease with the waiting time for the next replenishment. Numerical examples were presented to show the effects of changes of backordering rate and opportunity cost on the total cost and on the optimal number of replenishments.

\subsection{EOQ with Time Value of Money}

Consideration of the time value of money was one of the first "special concepts" applied to the basic EOQ model. In this section, literature review is presented for time value of money, with static and variable demands, along with other special concepts considered in inventory models.

\subsubsection{Constant Demand}

First, the EOQ model, with constant demand rate under inflationary conditions with an effect on all costs, was analyzed by Buzacott (1975). He showed that the effect of inflation results in cost increases. The effect of inflation was considered in the main cost components, and the optimal order quantity expression was developed.

The EOQ model has been expanded in many ways to improve Buzacott's model and bring it closer to real life problems. Moon and Lee (2000) discussed the EOQ model for a 
constant demand, where time value of money is considered and life of the product changes randomly. Normal and exponential distributions were considered for the product life cycle. Simulation models were developed for use with other probability distributions.

Liao et al. (2000) discussed an EOQ inventory model with time value of money, deteriorating items and permissible delay in payment, with a constant demand rate. In that study, the inventory model was developed and expressions were obtained for the inventory system's total cost under two different conditions. First, when the permissible credit period for payment is less than the cycle time, and second, when it is greater than the cycle time. Sarker et al. (2000) investigated a similar problem while allowing for shortages. The present value of the total cost was first developed, and then the optimal ordering quantity and maximum allowable shortage were obtained using a search technique. The purpose of the paper was to aid retailers of perishable products to determine the EOQ, where inflation is considered and a delay in payments for purchased products is allowed.

\subsubsection{Variable Demand}

In general, the classical EOQ models assume constant demand over an infinite planning horizon. This assumption is valid during the maturing phase of the product life cycle and for a finite period of time. In other phases of a product life demand for the product may increase after its successful introduction into the market or decrease due to, for example, introduction of new competitive products. The inventory model with a linear trend in demand was initially introduced by Donaldson (1977). Several other papers were also published with linearly increasing or decreasing demand. Time value of money and inflation were not considered in those papers. 
Hariga and Ben-Daya (1996) incorporated inflationary conditions into the inventory problem with linear trend in demand and developed optimal solution procedures with and without shortages. The models relax the assumptions of equal replenishment cycles and equal positive inventory periods in each cycle.

Ray and Chaudhuri (1997) considered an inventory model with shortages allowed and effects of inflation taken into account, where demand rate depends on the on-hand inventory level. The paper states that it was observed that the demand in supermarkets is usually influenced by the amount of inventory presented on the shelves. The paper claims that it is a common belief that consumers would have been tempted to buy more of some products if a large quantity of that product is placed on the shelves in the supermarkets. Hence, the demand is in direct relation to the level of inventory at any particular moment.

Chen (1998) introduced a model for a deteriorating item, where effects of inflation and time value of money were considered, shortages were permitted, and the demand rate was considered linear. The deterioration rate was considered a random variable, which follows the Weibull distribution. The solution of the model determines the optimal replenishment schedule over a finite planning horizon. The paper proposed a dynamic programming model for obtaining the optimal policy.

Another type of demand rate was considered by Yang et al. (2001), where this rate fluctuates over time. It is a more general case than increasing, decreasing or stable demand patterns. The inventory model considers the effect of inflation, deteriorating items and shortages. The model can also be applied to the cases with no shortages or no deterioration. Four possible scenarios for replenishment were analyzed to identify the least expensive policy to follow. These scenarios include models where the inventory is permitted to start and/or end with 
shortages. They finally showed that the cost function is a convex function of the number of replenishments, hence by searching for a local minimum, the optimal number of replenishments will be found. Later, a paper presented by Skouri and Papachristos (2002) showed by examples that the solution algorithm proposed by Yang et al. does not work for all cases and hence does not lead to the optimal replenishment schedule.

Linear trend in demand, shortages during the finite planning horizon, and time value of money were considered for an inventory model with deteriorating items by Chung and Tsai (2001). A solution algorithm using a line search was used to determine the optimal time interval or optimal order quantity. Hou (2006) developed a similar model in which he considered stockdependent consumption rate.

\subsection{EPQ without Time Value of Money}

In many industries, the products and supplies are not ordered and received by the companies, but rather produced within the company. In that case, the main decision for inventory management is how much to manufacture in each cycle so that the total cost is minimized. Balkhi and Benkherouf (1996) proved the uniqueness of the optimal replenishment schedule for a similar model in which the planning horizon is finite.

Balkhi (2001) discussed an inventory model for deteriorating items where demand and

production rate are known and continuous functions of time (e.g. linear function). A finite planning horizon was considered and shortages were allowed and fully backordered. A mathematical model was developed and the conditions under which the total cost of inventory system achieves its unique global minimum were obtained. 
Giri et al. (2005) introduced an EPQ model where demand rate increases with time (e.g. linear function), the production rate is finite and adjustable in each cycle over an infinite planning horizon, and shortages are permitted and partially backordered. They suggested a procedure to approximately find the minimum total cost of the system over a finite time horizon.

Teng and Chang (2005) developed an EPQ model for deteriorating items when the demand rate depends on both selling price per unit and on-display stock level. In addition, a restriction was imposed on the number of stocks on-display. An algorithm for finding the optimal solution to maximize the profit was proposed.

\subsection{EPQ with Time Value of Money}

Chandra and Bahner (1985) introduced the concept of time value of money for production inventory system. A search technique was suggested to use in order to obtain the optimal policy and the present worth of the total cost. Sensitivity analyses were performed for both cases, and it was concluded that optimum order policies of the economic order system and production system as well as total costs were significantly affected by inflation and time value of money. The effect becomes more significant when the inflation rate increases.

Dohi et al. (1992) proposed inventory policies for infinite time horizon, taking into account the time value of money. They assumed that items are uniformly delivered, and did not include production cost in their models. Chung (1996) proposed an algorithm to compute the optimal ordering time interval for the models developed by Dohi. Chung et al. (1998) developed a simple algorithm to solve the same problem, without some the assumptions that were made by Chung. 
Wee and Law (1999) developed a production inventory model for a deteriorating item with price-dependent demand. They also considered shortages and time value of money. The deterioration rate was assumed a random variable that follows the Weibull distribution. An optimization procedure was presented and applied to search for optimal production policies that maximize the total net present value of profit. 


\section{Chapter 3}

\section{EPQ Models with and without Shortages and Time Value of Money}

In general, production order quantity models are used for cases where the firm receives its inventory over a period of time or where the item is produced locally rather than purchased. These models are useful when units are continuously added to the inventory over time while the production is in process. In that case, the main decision for inventory management is to determine how much to manufacture so that the total cost is minimized. This chapter considers some of the aspects examined in the literature for EOQ models and applies them to economic production quantity (EPQ) models. The objective of this study is to find the optimal inventory policies when time value of money is considered and demand is constant over time.

Models are developed with and without shortages while using two production cost functions. In the first case, the production cost is incurred at the beginning of the cycle. In the second case, production cost is divided into two parts: an initial cost, which occurs at the beginning of each cycle and is applied to the entire quantity produced during the cycle, and a running cost that is incurred as production progresses and is applied to the individual units produced. As an example, one may consider the situation where the initial cost is the cost of the raw material for the entire production quantity, which is acquired at the beginning of the cycle, and the second (running cost) is the labor cost associated with the production process and is paid as the production takes place.

Time value of money was one of the first "special concepts" considered with the basic EOQ model. The effect of time value of money is very important and should be reflected in the development of inventory models. Since money tied up in inventories can change its actual value over time, the effect of inflation rate can affect the optimal policies. 
In this chapter, models are developed for an infinite planning horizon while considering time value of money. Closed formulas are obtained in models where shortage is not allowed, for the optimal policies and the corresponding costs, which has not been accomplished in the existing literature. Search techniques are developed to find the optimal cycle time and maximum amount of shortage for models where shortage is allowed.

\subsection{Assumptions}

The general assumptions presented in Chapter 1 are used in the mathematical models developed in this chapter. Additionally, the following assumptions are also made:

1. Replenishment rate is finite and constant during the production time.

2. Demand rate is constant and less than the production rate.

\subsection{Inventory Models with no Shortage}

The objective of the inventory models is to determine the optimal cycle time or the corresponding optimal production quantity in order to minimize the total relevant cost. Consequently, the production time and the maximum inventory level can be easily calculated. Figure 3.1 represents the EPQ model with constant demand. The inventory on-hand increases with the rate $p-D$, which is the production rate minus consumption rate, until time $t_{p}$ when the production process stops and the inventory on hand reaches its maximum level, $Q_{1}$. After that point, the inventory level decreases with the consumption rate, $D$, until it becomes zero at the end of the cycle, $T$, when the production process is resumed again.

The total cost TC(T) for this EPQ model consists of three elements:

$$
\mathrm{TC}(\mathrm{T})=\text { Setup Cost }+ \text { Production Cost }+ \text { Holding Cost }
$$




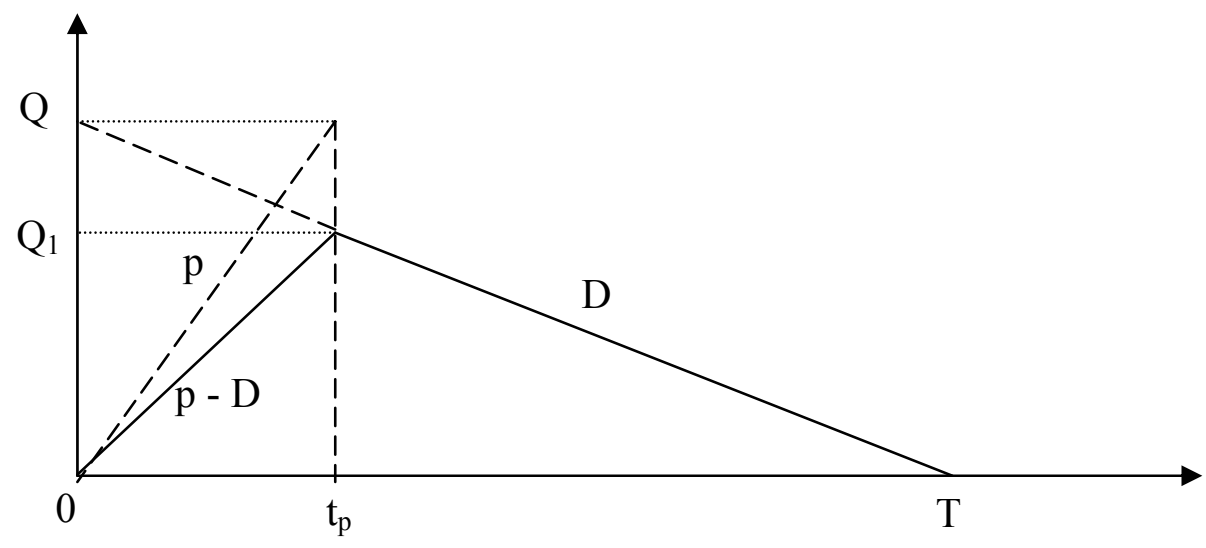

Figure 3.1 EPQ model with constant demand

\subsubsection{Case 1}

For this case, the setup cost and the production cost are assumed to be incurred at the beginning of each cycle, and the inventory holding cost is incurred continuously during the period $T$.

During the first cycle, the inventory level, $I(t)$, at time $t$ is equal to:

$$
\begin{array}{ll}
I(t)=t(p-D) & \text { for } 0<t<t_{p} \\
I(t)=D(T-t) & \text { for } t_{p}<t<T
\end{array}
$$

where

$$
T=\frac{Q}{D}, \quad \quad \text { and } \quad t_{p}=\frac{Q}{p}=\frac{D T}{p}
$$

The inventory carrying cost during an infinitely small period $d t$ at time $t$ is equal to:

\section{FcI $(t) d t$}

where $F$ is inventory carrying rate and $c$ is unit production cost.

To incorporate the effect of time value of money into the equations, the difference between the interest rate and inflation rate is calculated as $r$, the inflation free or real interest rate representing the time value of money:

$$
r=R-f
$$


Assuming continuous compounding and a constant setup cost, $A$, the present value of the total cost of the inventory system for the first cycle, $P$, can be expressed as:

$$
P=A+c D T+F c \int_{0}^{t_{p}}(p-D) t e^{-r t} d t+F c \int_{t_{p}}^{T}(D T-D t) e^{-r t} d t
$$

Integrating by parts, we get, after some simplifications:

$$
F_{c} \int_{0}^{t_{p}}(p-D) t e^{-r t} d t=\frac{F c(p-D)}{r}\left(\frac{1}{r}-t_{p} e^{-r t_{p}}-\frac{e^{-r t_{p}}}{r}\right)
$$

and

$$
F_{c} \int_{t_{p}}^{T}(D T-D t) e^{-r t} d t=\frac{F c D}{r}\left[e^{-r T}+e^{-r t_{p}}\left(T-t_{p}-\frac{1}{r}\right)\right]
$$

Substituting these expressions into Equation (3.1) and simplifying, we get the present value of the total cost for the first period:

$$
P=A+c D T+\frac{F c}{r^{2}}\left[p-p e^{\frac{-r D T}{p}}-D\left(1-e^{-r T}\right)\right]
$$

According to Figure 3.2, the present value, $P$, for the first period is repeated at the start of each of the subsequent cycles. The present value of the total cost for $N$ cycles, $P_{t}$, can then be calculated as follows:

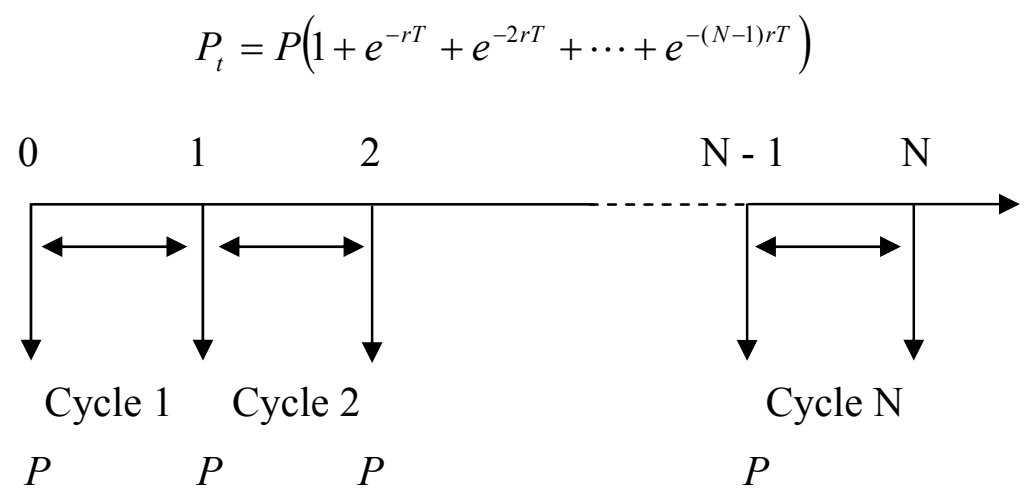

Figure 3.2 Cash flow diagram 
For an infinite planning horizon, $N \rightarrow \infty$, and $P_{t}$ can be expressed as:

$$
P_{t}=P\left(\frac{1}{1-e^{-r T}}\right)
$$

Substituting Equation (3.2) into Equation (3.3) we get the present value, $P_{t}$, of the total cost:

$$
\begin{gathered}
P_{t}=\frac{A}{1-e^{-r T}}+\frac{c D T}{1-e^{-r T}}+\frac{F c p}{r^{2}\left(1-e^{-r T}\right)}-\frac{F c p e^{-\frac{r D T}{p}}}{r^{2}\left(1-e^{-r T}\right)}-\frac{F c D}{r^{2}} \\
P_{t}=\frac{A+c D T}{1-e^{-r T}}+\frac{F c p\left(1-e^{-\frac{r D T}{p}}\right)}{r^{2}\left(1-e^{-r T}\right)}-\frac{F c D}{r^{2}}
\end{gathered}
$$

The present value of the total cost function, $P_{t}$, is a function of the length of the cycle, $T$. Taking the first derivative of $P_{t}$ with respect to $T$ and equating to zero, we get:

$$
\frac{d P_{t}}{d T}=\frac{c D\left(1-e^{-r T}\right)-(A+c D T) r e^{-r T}}{\left(1-e^{-r T}\right)^{2}}+\frac{F c D e^{-\frac{r D T}{p}}\left(1-e^{-r T}\right)-F c p e^{-r T}\left(1-e^{-\frac{r D T}{p}}\right)}{r\left(1-e^{-r T}\right)^{2}}=0
$$

Using a common denominator and after some simplifications, the equation can be written as follows:

$$
e^{r T}=1+\frac{r A}{c D}+r T-\frac{F}{r} e^{r T\left(\frac{p-D}{p}\right)}+\frac{F p}{r D}-e^{\frac{-r D T}{p}}\left[\frac{F}{r}\left(\frac{p-D}{D}\right)\right]
$$

For simplicity, the following constants are defined:

$$
\begin{gathered}
K=1+\frac{r A}{c D}+\frac{F p}{r D}, \\
U=\left(\frac{p-D}{D}\right) \text { and } V=\left(\frac{p-D}{p}\right), \text { hence } V=\frac{U D}{p}
\end{gathered}
$$

Equation (3.6) can then be written as follows: 


$$
e^{r T}=K+r T-\frac{F}{r} e^{r T V}-e^{-\frac{r D T}{p}}\left(\frac{F}{r} U\right)
$$

In general, $e^{x}$ can be expressed as the following series:

$$
e^{x}=1+x+\frac{(x)^{2}}{2 !}+\frac{(x)^{3}}{3 !}+\frac{(x)^{4}}{4 !}+\cdots
$$

Applying this expansion to each of $e^{r T}, e^{r T V}$ and $e^{-\frac{r D T}{p}}$, and ignoring the cubic and higher terms, which are very close to zero, Equation (3.7) becomes:

$$
1+r T+\frac{r^{2} T^{2}}{2 !}=K+r T-\frac{F}{r}\left(1+r T V+\frac{r^{2} T^{2} V^{2}}{2 !}\right)-\frac{F U}{r}\left(1-\frac{r D T}{p}+\frac{r^{2} D^{2} T^{2}}{2 ! p^{2}}\right)
$$

It should be noted that the value of $r T$ is usually smaller than 0.01 , and since $V$ and $\frac{D}{p}$ are always smaller than one (in fact, their sum is equal to one), the values of $r T V$ and $\frac{r D T}{p}$ are even smaller. The cubic terms are hence smaller than $\frac{1}{6} * 10^{-6}$. Higher terms are even much smaller.

After some simplifications, and using the original values of $K, U$ and $V$, the following equation is obtained:

$$
T^{2}(p r+F p-F D)=\frac{2 p A}{c D}
$$

and the optimal cycle time can be defined as:

$$
T^{*}=\sqrt{\frac{2 A p}{c D(p r+F p-F D)}}
$$

The corresponding production quantity is: 


$$
Q^{*}=D T^{*}=\sqrt{\frac{2 A D p}{c(p r+F p-F D)}}
$$

The above formulas reduce to the standard equations of optimal production quantity and cycle time when the value of $r$ is equal to zero:

$$
\begin{aligned}
& T^{*}=\sqrt{\frac{2 A p}{F c D(p-D)}} \\
& Q^{*}=D T^{*}=\sqrt{\frac{2 A D p}{F c(p-D)}}
\end{aligned}
$$

\subsubsection{Case 2}

In the second case, the production cost, $c$, has two components. A cost, $c_{1}$, that is incurred at the beginning of each cycle and is applied to the total quantity produced during the cycle, and a second cost, $c_{2}$, which is incurred as the production process takes place.

The total cost for this model consists of the same three elements as in the first model:

$$
\mathrm{TC}(\mathrm{T})=\text { Setup Cost }+ \text { Production Cost }+ \text { Holding Cost }
$$

The difference between the two cases is only in the production cost. With continuous compounding, the present value of the production cost of the system during the first cycle is now defined as follows:

$$
\text { Production Cost }=c_{1} Q+c_{2} p \int_{0}^{t_{p}} e^{-r t} d t
$$

The present value of the total cost of the inventory system for the first period becomes:

$$
P=A+c_{1} Q+c_{2} p \int_{0}^{t_{p}} e^{-r t} d t+F c_{3} \int_{0}^{t_{p}}(p-D) t e^{-r t} d t+F c_{3} \int_{t_{p}}^{T}(Q-D t) e^{-r t} d t
$$

where $c_{3}=c_{1}+c_{2}$ 
The procedure followed in Case 1 is repeated and leads to the following value for the total cost for all cycles:

$$
P_{t}=\frac{A}{1-e^{-r T}}+\frac{c_{1} D T}{1-e^{-r T}}+\frac{c_{2} p\left(1-e^{\frac{-r D T}{p}}\right)}{r\left(1-e^{-r T}\right)}+\frac{F c_{3} p}{r^{2}\left(1-e^{-r T}\right)}-\frac{F c_{3} p e^{\frac{-r D T}{p}}}{r^{2}\left(1-e^{-r T}\right)}-\frac{F c_{3} D}{r^{2}}
$$

Taking the derivative of $P_{t}$ with respect to $T$ and equating it to zero, then following the same procedure used in Case 1, the optimal cycle time is obtained as:

$$
T^{*}=\sqrt{\frac{2 A p}{D\left[c_{1} p r+\left(F\left(c_{1}+c_{2}\right)+c_{2} r\right)(p-D)\right]}}
$$

The corresponding production quantity is:

$$
Q^{*}=D T^{*}=\sqrt{\frac{2 A D p}{\left[c_{1} p r+\left(F\left(c_{1}+c_{2}\right)+c_{2} r\right)(p-D)\right]}}
$$

\subsection{Numerical Example and Sensitivity Analysis}

A numerical example is presented below to illustrate the application of the models developed. The following data are used:

$$
p=4500 \text { units/yr, } D=1500 \text { units/yr, } A=50 \$ / \text { order, } F=0.15 \$ / \$ / \mathrm{yr}, c=2 \$ / \text { unit }
$$

The model was applied for Case 1, using different values for the real interest rate, and the results obtained are summarized in Table 3.1. When the value of $r$ is equal to zero, the standard equations for optimal production quantity and cycle time were used to calculate $T$ and $Q$. Since the present value of the total cost, with infinite horizon, approaches infinity as $r$ approaches zero, the present value of the total relevant cost for the first year was calculated using the results of the infinite horizon policy, and pro-rating the value for the partial cycle at the end of the year. Figure 3.3 shows the relation between cycle time and the real interest rate. As expected, the cycle time 
decreases as the real interest rate increases. Accordingly, the optimal production quantity, $Q$, decreases with high real interest rates. The present value of the total cost also decreases as the real interest rate increases.

For Case 2, the same example was used, with the same parameters. The only difference is that the production cost, $c$, is substituted with a raw material cost $c_{1}=1.5 \$ /$ unit, and a labor cost $c_{2}=0.5 \$$ unit. The results are summarized in Table 3.1. As in Case 1, the cycle time and order quantity decrease as the real interest rate increases. The results obtained for the two cases are almost identical.

\begin{tabular}{|c|c|c|c|c|c|c|c|c|}
\hline \multirow{2}{*}{$\begin{array}{c}\text { Real } \\
\text { interest }\end{array}$} & \multicolumn{3}{|c|}{ Case 1 } & \multicolumn{3}{|c|}{ Case 2 } \\
\cline { 2 - 9 } \\
$\begin{array}{c}\text { (\%) } \boldsymbol{r} \\
\mathbf{\%}\end{array}$ & $\begin{array}{c}\boldsymbol{T} \\
\mathbf{( m )}\end{array}$ & $\begin{array}{c}\boldsymbol{Q} \\
\mathbf{( u n i t s )}\end{array}$ & $\begin{array}{c}\boldsymbol{P}_{\boldsymbol{t}} \\
\mathbf{( \$ )}\end{array}$ & $\begin{array}{c}\text { PV for } \\
\text { first year } \\
\mathbf{( \$ )}\end{array}$ & $\begin{array}{c}\boldsymbol{T} \\
\mathbf{( m )}\end{array}$ & $\begin{array}{c}\boldsymbol{Q} \\
\mathbf{( u n i t s )}\end{array}$ & $\begin{array}{c}\boldsymbol{P}_{\boldsymbol{t}} \\
\mathbf{( \$ )}\end{array}$ & $\begin{array}{c}\text { PV for } \\
\text { first year } \\
\mathbf{( \$ )}\end{array}$ \\
\hline $0 \%$ & 6.93 & 866.03 & - & $3,173.21$ & 6.93 & 866.03 & - & $3,173.21$ \\
\hline $1 \%$ & 6.61 & 825.72 & $318,194.20$ & $3,165.37$ & 6.63 & 828.87 & $318,125.14$ & $3,164.66$ \\
\hline $2 \%$ & 6.32 & 790.57 & $159,515.57$ & $3,157.82$ & 6.37 & 796.12 & $159,449.24$ & $3,156.40$ \\
\hline $3 \%$ & 6.08 & 759.55 & $106,611.92$ & $3,150.56$ & 6.14 & 766.96 & $106,548.01$ & $3,148.45$ \\
\hline $4 \%$ & 5.86 & 731.93 & $80,152.91$ & $3,142.16$ & 5.93 & 740.80 & $80,091.18$ & $3,140.06$ \\
\hline $5 \%$ & 5.66 & 707.11 & $64,272.35$ & $3,132.80$ & 5.74 & 717.14 & $64,212.59$ & $3,130.24$ \\
\hline $6 \%$ & 5.48 & 684.65 & $53,681.44$ & $3,123.25$ & 5.56 & 695.61 & $53,623.46$ & $3,120.22$ \\
\hline $7 \%$ & 5.31 & 664.21 & $46,113.49$ & $3,113.62$ & 5.41 & 675.91 & $46,057.14$ & $3,110.11$ \\
\hline $8 \%$ & 5.16 & 645.50 & $40,435.11$ & $3,103.98$ & 5.26 & 657.79 & $40,380.26$ & $3,099.98$ \\
\hline $9 \%$ & 5.03 & 628.28 & $36,016.62$ & $3,094.37$ & 5.13 & 641.06 & $35,963.16$ & $3,089.87$ \\
\hline $10 \%$ & 4.90 & 612.37 & $32,480.20$ & $3,084.85$ & 5.00 & 625.54 & $32,428.02$ & $3,079.84$ \\
\hline $11 \%$ & 4.78 & 597.61 & $29,585.38$ & $3,075.42$ & 4.89 & 611.10 & $29,534.39$ & $3,069.90$ \\
\hline $12 \%$ & 4.67 & 583.87 & $27,171.85$ & $3,066.12$ & 4.78 & 597.61 & $27,121.98$ & $3,060.07$ \\
\hline $13 \%$ & 4.57 & 571.04 & $25,128.63$ & $3,056.95$ & 4.68 & 584.98 & $25,079.80$ & $3,050.37$ \\
\hline $14 \%$ & 4.47 & 559.02 & $23,376.42$ & $3,047.91$ & 4.58 & 573.12 & $23,328.56$ & $3,040.80$ \\
\hline $15 \%$ & 4.38 & 547.72 & $21,857.06$ & $3,039.02$ & 4.50 & 561.95 & $21,810.13$ & $3,031.37$ \\
\hline
\end{tabular}

Table 3.1 Optimal ordering policies for different values of $r$ for Cases 1 and 2 


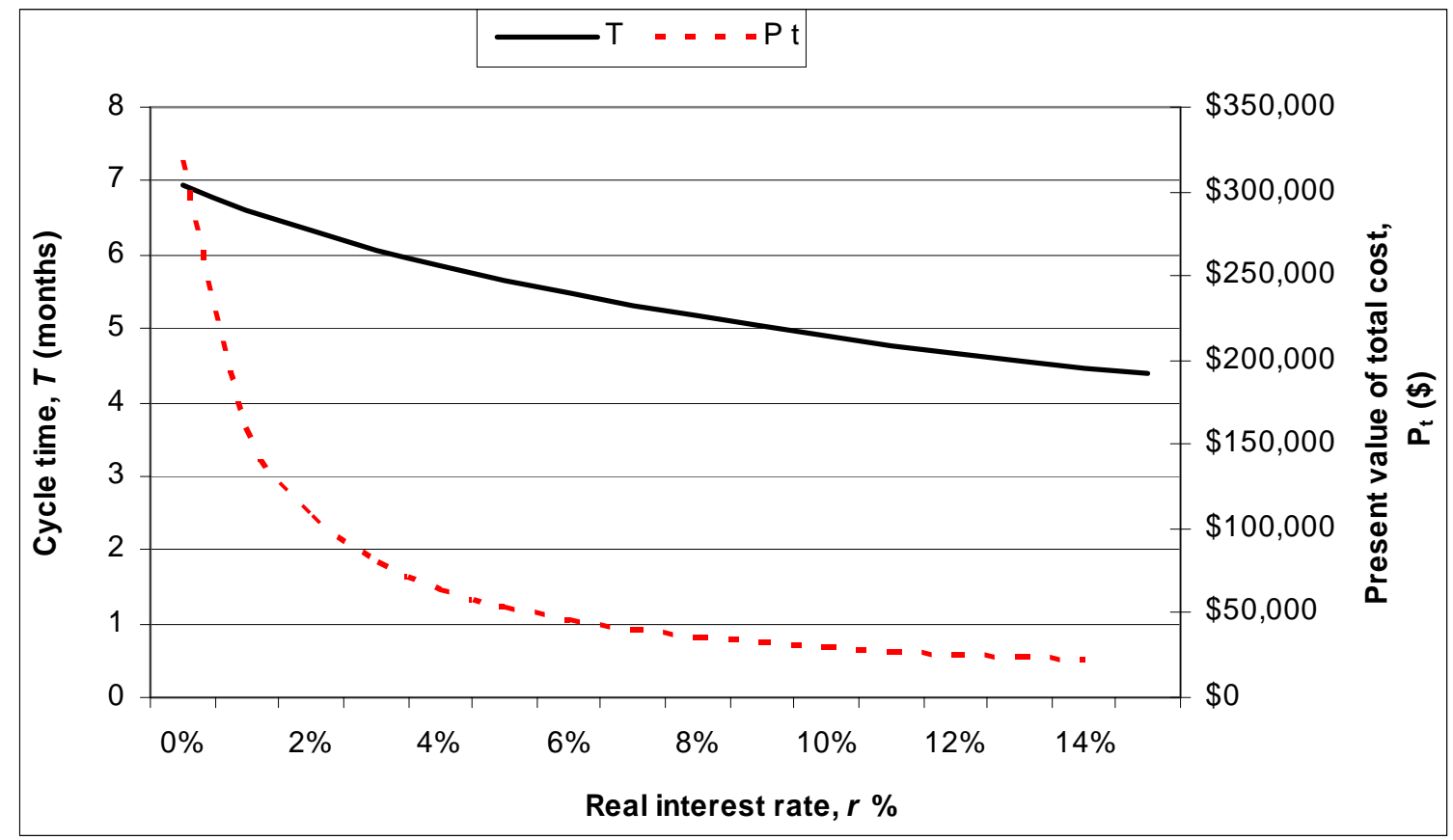

Figure 3.3 Effect of real interest rate $r$ on cycle time $T$ and present value of the total cost $P_{t}$

Tables 3.2, 3.3, and 3.4 along with Figures 3.4, 3.5, and 3.6 show the results obtained for different values of carrying rate, $F$, demand rate, $D$, and setup cost, $A$, and the behavior of $T$ and $P_{t}$ with respect to those parameters. As expected, with the increase in $F$ and $D$ the cycle time gets smaller. The increase in setup cost leads to increase in the value of $T$. The present value of the total cost increases with the increase of these parameters. It increases significantly with the increase in $D$, increases with a lesser degree with the increase in $A$, and remains relatively flat with changes in $F$. 


\begin{tabular}{|c|c|c|c|c|c|c|}
\hline \multirow{2}{*}{$\begin{array}{c}\text { Carrying } \\
\text { rate } \boldsymbol{F} \\
\mathbf{( \% )}\end{array}$} & $\begin{array}{c}\boldsymbol{T} \\
\mathbf{( m )}\end{array}$ & $\begin{array}{c}\boldsymbol{Q} \\
\text { (units) }\end{array}$ & $\begin{array}{c}\boldsymbol{P}_{\boldsymbol{t}} \\
\mathbf{( \$ )}\end{array}$ & $\begin{array}{c}\boldsymbol{T} \\
\mathbf{( m )}\end{array}$ & $\begin{array}{c}\boldsymbol{Q} \\
\text { (units) }\end{array}$ & $\begin{array}{c}\boldsymbol{P}_{\boldsymbol{t}} \\
\mathbf{( \$ )}\end{array}$ \\
\hline $5 \%$ & 6.51 & 813.49 & $39,836.75$ & 6.71 & 838.53 & $39,767.14$ \\
\hline $6 \%$ & 6.32 & 790.57 & $39,903.35$ & 6.51 & 813.49 & $39,835.77$ \\
\hline $7 \%$ & 6.16 & 769.48 & $39,968.14$ & 6.32 & 790.57 & $39,902.42$ \\
\hline $8 \%$ & 6.00 & 750.00 & $40,031.26$ & 6.16 & 769.48 & $39,967.26$ \\
\hline $9 \%$ & 5.86 & 731.93 & $40,092.84$ & 6.00 & 750.00 & $40,030.42$ \\
\hline $10 \%$ & 5.72 & 715.10 & $40,152.97$ & 5.86 & 731.93 & $40,092.04$ \\
\hline $11 \%$ & 5.60 & 699.38 & $40,211.77$ & 5.72 & 715.10 & $40,152.21$ \\
\hline $12 \%$ & 5.48 & 684.65 & $40,269.30$ & 5.60 & 699.38 & $40,211.04$ \\
\hline $13 \%$ & 5.37 & 670.82 & $40,325.66$ & 5.48 & 684.65 & $40,268.60$ \\
\hline $14 \%$ & 5.26 & 657.79 & $40,380.91$ & 5.37 & 670.82 & $40,324.99$ \\
\hline $15 \%$ & 5.16 & 645.50 & $40,435.11$ & 5.26 & 657.79 & $40,380.26$ \\
\hline $16 \%$ & 5.07 & 633.87 & $40,488.32$ & 5.16 & 645.50 & $40,434.49$ \\
\hline $17 \%$ & 4.98 & 622.84 & $40,540.60$ & 5.07 & 633.87 & $40,487.72$ \\
\hline $18 \%$ & 4.90 & 612.37 & $40,591.98$ & 4.98 & 622.84 & $40,540.02$ \\
\hline $19 \%$ & 4.82 & 602.41 & $40,642.52$ & 4.90 & 612.37 & $40,591.42$ \\
\hline $20 \%$ & 4.74 & 592.93 & $40,692.25$ & 4.82 & 602.41 & $40,641.98$ \\
\hline
\end{tabular}

Table 3.2 Optimal ordering policies for different values of $\boldsymbol{F}$ for Cases 1 and 2

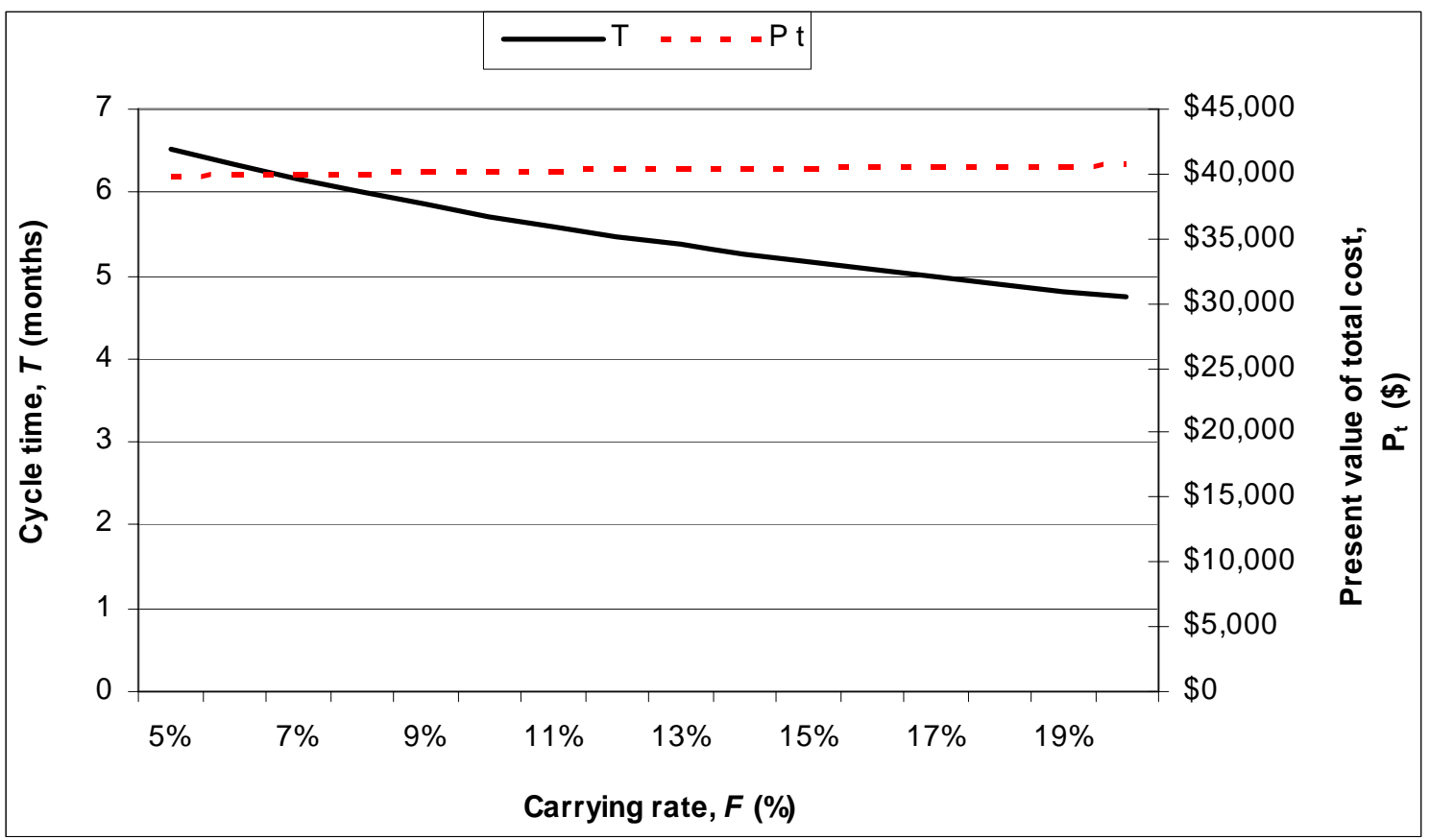

Figure 3.4 Effect of carrying rate $F$ on cycle time $T$ and present value of the total cost $P_{t}$ 


\begin{tabular}{|c|c|c|c|c|c|c|}
\hline Demand & \multicolumn{4}{|c|}{ Case 1 } & \multicolumn{3}{c|}{ Case 2 } \\
\cline { 2 - 7 } $\begin{array}{c}\text { rate } \boldsymbol{D} \\
\text { (units) }\end{array}$ & $\begin{array}{c}\boldsymbol{T} \\
\text { (m) }\end{array}$ & $\begin{array}{c}\boldsymbol{Q} \\
\text { (units) }\end{array}$ & $\begin{array}{c}\boldsymbol{P}_{\boldsymbol{t}} \\
\mathbf{( \$ )}\end{array}$ & $\begin{array}{c}\boldsymbol{T} \\
\mathbf{( m )}\end{array}$ & $\begin{array}{c}\boldsymbol{Q} \\
\text { (units) }\end{array}$ & $\begin{array}{c}\boldsymbol{P}_{\boldsymbol{t}} \\
\mathbf{( \$ )}\end{array}$ \\
\hline 1,000 & 6.05 & 504.22 & $27,510.37$ & 6.12 & 510.02 & $27,481.84$ \\
\hline 1,100 & 5.82 & 533.37 & $30,109.04$ & 5.89 & 540.24 & $30,075.85$ \\
\hline 1,200 & 5.62 & 561.95 & $32,700.17$ & 5.70 & 570.01 & $32,662.01$ \\
\hline 1,300 & 5.45 & 590.10 & $35,284.50$ & 5.53 & 599.45 & $35,241.08$ \\
\hline 1,400 & 5.30 & 617.91 & $37,862.65$ & 5.39 & 628.67 & $37,813.67$ \\
\hline 1,500 & 5.16 & 645.50 & $40,435.11$ & 5.26 & 657.79 & $40,380.26$ \\
\hline 1,600 & 5.05 & 672.93 & $43,002.31$ & 5.15 & 686.89 & $42,941.29$ \\
\hline 1,700 & 4.94 & 700.27 & $45,564.59$ & 5.05 & 716.05 & $45,497.08$ \\
\hline 1,800 & 4.85 & 727.61 & $48,122.25$ & 4.97 & 745.36 & $48,047.94$ \\
\hline 1,900 & 4.77 & 754.98 & $50,675.55$ & 4.89 & 774.87 & $50,594.12$ \\
\hline 2,000 & 4.69 & 782.46 & $53,224.72$ & 4.83 & 804.66 & $53,135.81$ \\
\hline
\end{tabular}

Table 3.3 Optimal ordering policies for different values of $\boldsymbol{D}$ for Cases 1 and 2

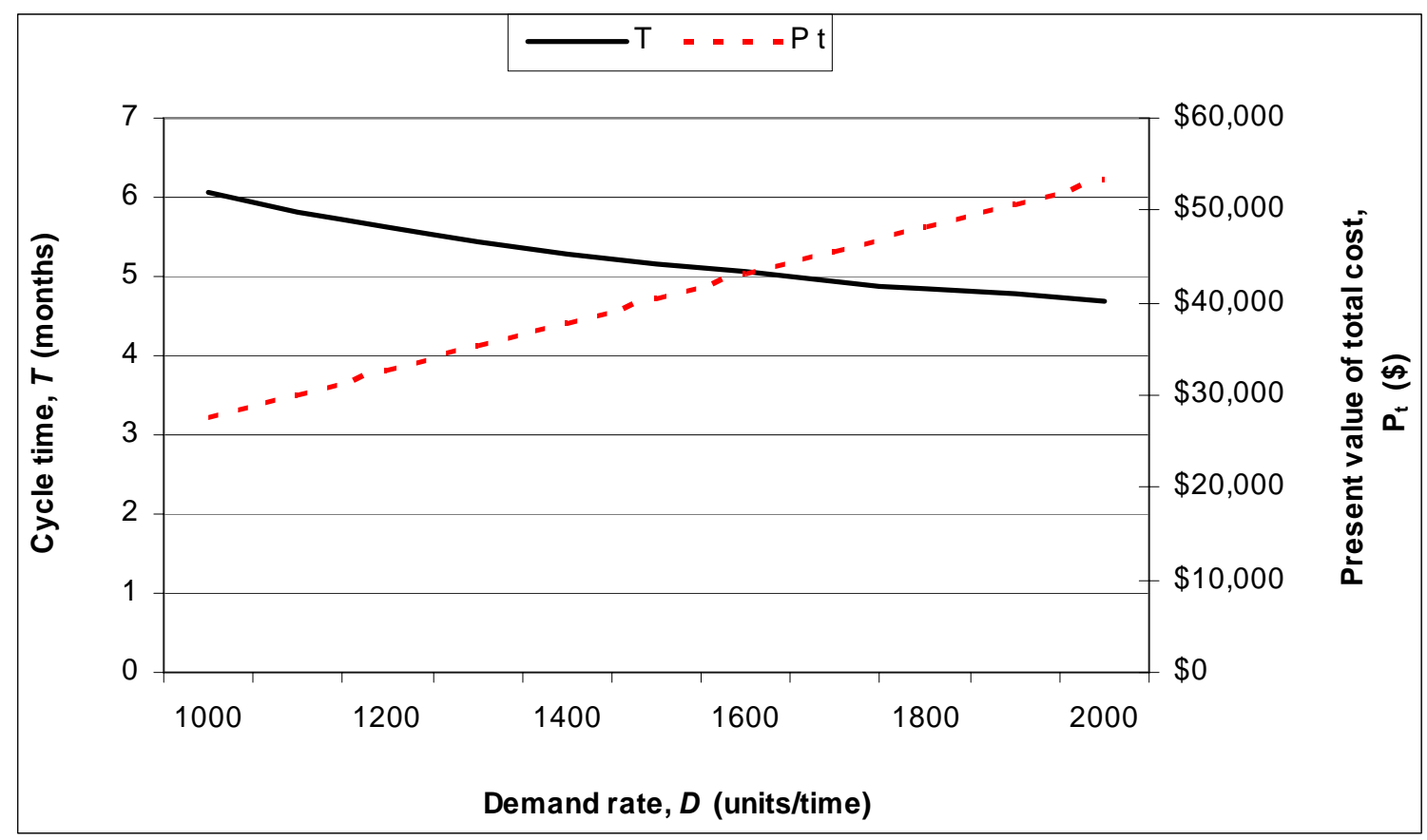

Figure 3.5 Effect of demand rate $D$ on cycle time $T$ and present value of the total $\operatorname{cost} P_{t}$ 


\begin{tabular}{|c|c|c|c|c|c|c|}
\hline \multirow{2}{*}{$\begin{array}{c}\text { Setup } \\
\text { Cost } \boldsymbol{A}\end{array}$} & \multicolumn{3}{|c|}{ Case 1 } & \multicolumn{3}{c|}{ Case 2 } \\
\cline { 2 - 7 } $\mathbf{\$} / \mathbf{o r d e r})$ & $\begin{array}{c}\boldsymbol{T} \\
(\mathbf{m})\end{array}$ & $\begin{array}{c}\boldsymbol{Q} \\
\text { (units) }\end{array}$ & $\begin{array}{c}\boldsymbol{P}_{\boldsymbol{t}} \\
\mathbf{( \$ )}\end{array}$ & $\begin{array}{c}\boldsymbol{T} \\
\mathbf{( m )}\end{array}$ & $\begin{array}{c}\boldsymbol{Q} \\
\text { (units) }\end{array}$ & $\begin{array}{c}\boldsymbol{P}_{\boldsymbol{t}} \\
\mathbf{( \$ )}\end{array}$ \\
\hline 10 & 2.31 & 288.68 & $38,805.10$ & 2.35 & 294.17 & $38,780.71$ \\
\hline 20 & 3.27 & 408.25 & $39,349.25$ & 3.33 & 416.03 & $39,314.69$ \\
\hline 30 & 4.00 & 500.00 & $39,768.21$ & 4.08 & 509.52 & $39,725.82$ \\
\hline 40 & 4.62 & 577.35 & $40,122.36$ & 4.71 & 588.35 & $40,073.36$ \\
\hline 50 & 5.16 & 645.50 & $40,435.11$ & 5.26 & 657.79 & $40,380.26$ \\
\hline 60 & 5.66 & 707.11 & $40,718.44$ & 5.76 & 720.58 & $40,658.30$ \\
\hline 70 & 6.11 & 763.76 & $40,979.49$ & 6.23 & 778.31 & $40,914.47$ \\
\hline 80 & 6.53 & 816.50 & $41,222.88$ & 6.66 & 832.05 & $41,153.33$ \\
\hline 90 & 6.93 & 866.03 & $41,451.86$ & 7.06 & 882.52 & $41,378.03$ \\
\hline 100 & 7.30 & 912.87 & $41,668.77$ & 7.44 & 930.26 & $41,590.88$ \\
\hline 110 & 7.66 & 957.43 & $41,875.37$ & 7.81 & 975.67 & $41,793.63$ \\
\hline 120 & 8.00 & $1,000.00$ & $42,073.06$ & 8.15 & $1,019.05$ & $41,987.63$ \\
\hline 130 & 8.33 & $1,040.83$ & $42,262.92$ & 8.49 & $1,060.66$ & $42,173.94$ \\
\hline
\end{tabular}

Table 3.4 Optimal ordering policies for different values of $\boldsymbol{A}$ for Cases 1 and 2

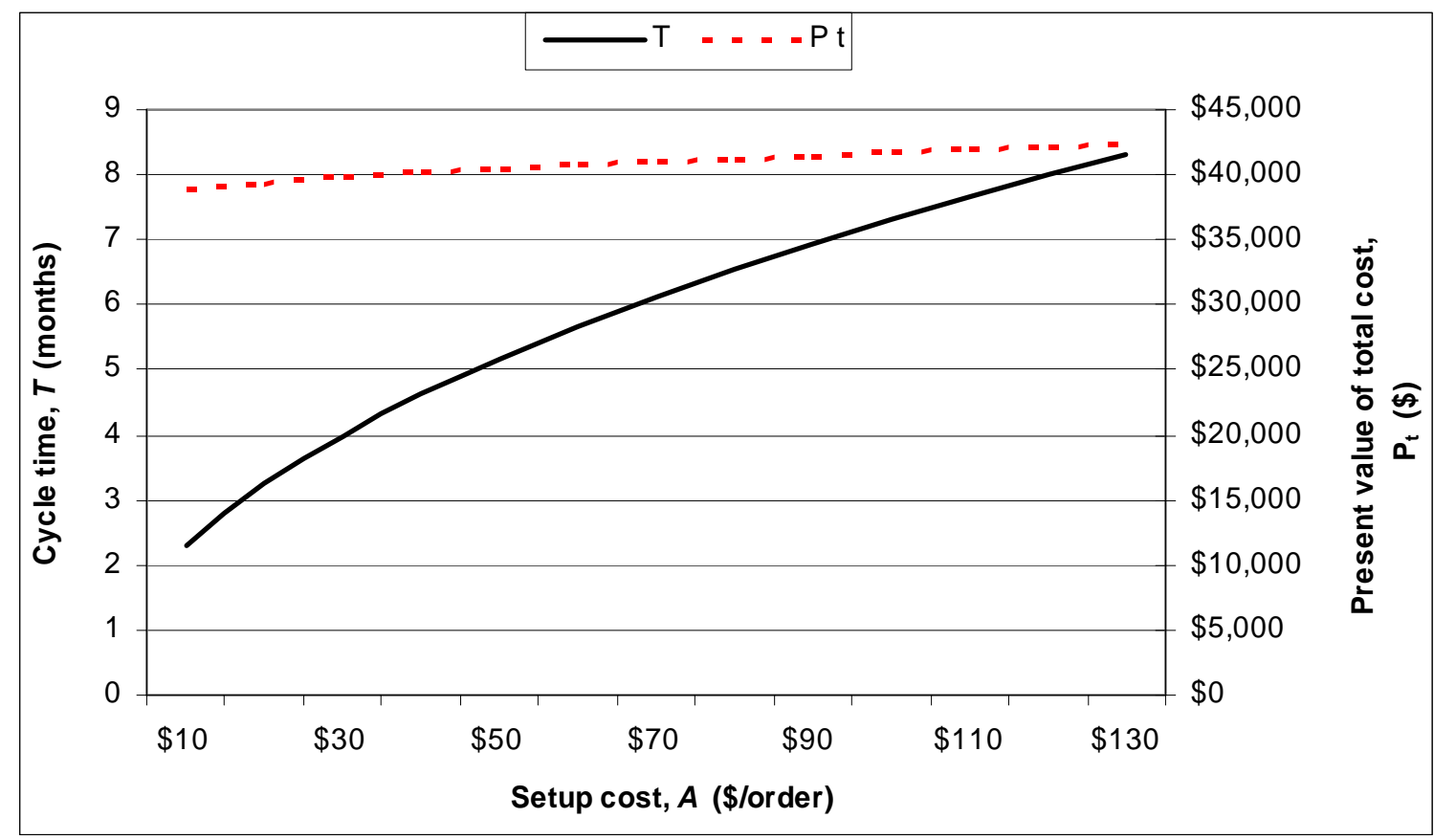

Figure 3.6 Effect of setup cost $\boldsymbol{A}$ on cycle time $T$ and present value of the total cost $P_{t}$ 
Computational experience has also shown that any increase in any of the two components of the production cost for Case 2 would lead to shorter cycle times and smaller production quantities, and considerably increases the present value of the total cost. Table 3.5 and Figure 3.7 show the results and behavior of cycle time, $T$, and present value of he total cost, $P_{t}$, with respect to simultaneous changes in both $\operatorname{costs} c_{1}$ and $c_{2}$. These behaviors are attributed to the fact that higher unit costs result in increases of the holding cost, which force the cycle time to get smaller and make the total cost higher.

\begin{tabular}{|c|c|c|c|c|c|}
\hline $\begin{array}{c}\text { Raw material cost } \boldsymbol{c}_{\mathbf{1}}, \\
\mathbf{\$} \mathbf{u n i t}\end{array}$ & $\begin{array}{c}\text { Labor cost } \boldsymbol{c}_{\mathbf{2}}, \\
\mathbf{\$} / \mathbf{u n i t}\end{array}$ & $\boldsymbol{c}=\boldsymbol{c}_{\mathbf{1}}+\boldsymbol{c}_{\mathbf{2}}$ & $\begin{array}{c}\boldsymbol{T} \\
\text { (months) }\end{array}$ & $\begin{array}{c}\boldsymbol{Q} \\
\text { (units) }\end{array}$ & $\begin{array}{c}\boldsymbol{P}_{\boldsymbol{t}} \\
\mathbf{( \$ )}\end{array}$ \\
\hline$\$ 0.30$ & $\$ 0.10$ & $\$ 0.40$ & 11.77 & $1,470.87$ & $8,804.73$ \\
\hline$\$ 0.60$ & $\$ 0.20$ & $\$ 0.80$ & 8.32 & $1,040.06$ & $16,832.67$ \\
\hline$\$ 0.90$ & $\$ 0.30$ & $\$ 1.20$ & 6.79 & 849.21 & $24,737.80$ \\
\hline$\$ 1.20$ & $\$ 0.40$ & $\$ 1.60$ & 5.88 & 735.44 & $32,579.35$ \\
\hline$\$ 1.50$ & $\$ 0.50$ & $\$ 2.00$ & 5.26 & 657.79 & $40,380.26$ \\
\hline$\$ 1.80$ & $\$ 0.60$ & $\$ 2.40$ & 4.80 & 600.48 & $48,152.31$ \\
\hline$\$ 2.10$ & $\$ 0.70$ & $\$ 2.80$ & 4.45 & 555.94 & $55,902.49$ \\
\hline$\$ 2.40$ & $\$ 0.80$ & $\$ 3.20$ & 4.16 & 520.03 & $63,635.35$ \\
\hline$\$ 2.70$ & $\$ 0.90$ & $\$ 3.60$ & 3.92 & 490.29 & $71,354.06$ \\
\hline$\$ 3.00$ & $\$ 1.00$ & $\$ 4.00$ & 3.72 & 465.13 & $79,060.92$ \\
\hline$\$ 3.30$ & $\$ 1.10$ & $\$ 4.40$ & 3.55 & 443.48 & $86,757.67$ \\
\hline$\$ 3.60$ & $\$ 1.20$ & $\$ 4.80$ & 3.40 & 424.60 & $94,445.66$ \\
\hline$\$ 3.90$ & $\$ 1.30$ & $\$ 5.20$ & 3.26 & 407.95 & $102,125.97$ \\
\hline$\$ 4.20$ & $\$ 1.40$ & $\$ 5.60$ & 3.14 & 393.11 & $109,799.47$ \\
\hline$\$ 4.50$ & $\$ 1.50$ & $\$ 6.00$ & 3.04 & 379.78 & $117,466.88$ \\
\hline
\end{tabular}

Table 3.5 Optimal ordering policies for different values of $c_{1}$ and $c_{2}$ increased simultaneously

Table 3.6 and Figure 3.8 show the effect of changing the relative weights of the unit production cost components $c_{1}$ and $c_{2}$ for Case 2 while maintaining their total as a constant. The present value of the total cost is increases when $c_{1}$ increases and $c_{2}$ decreases; which is expected as the present value decreases when most of the cost is increased at later stages. 


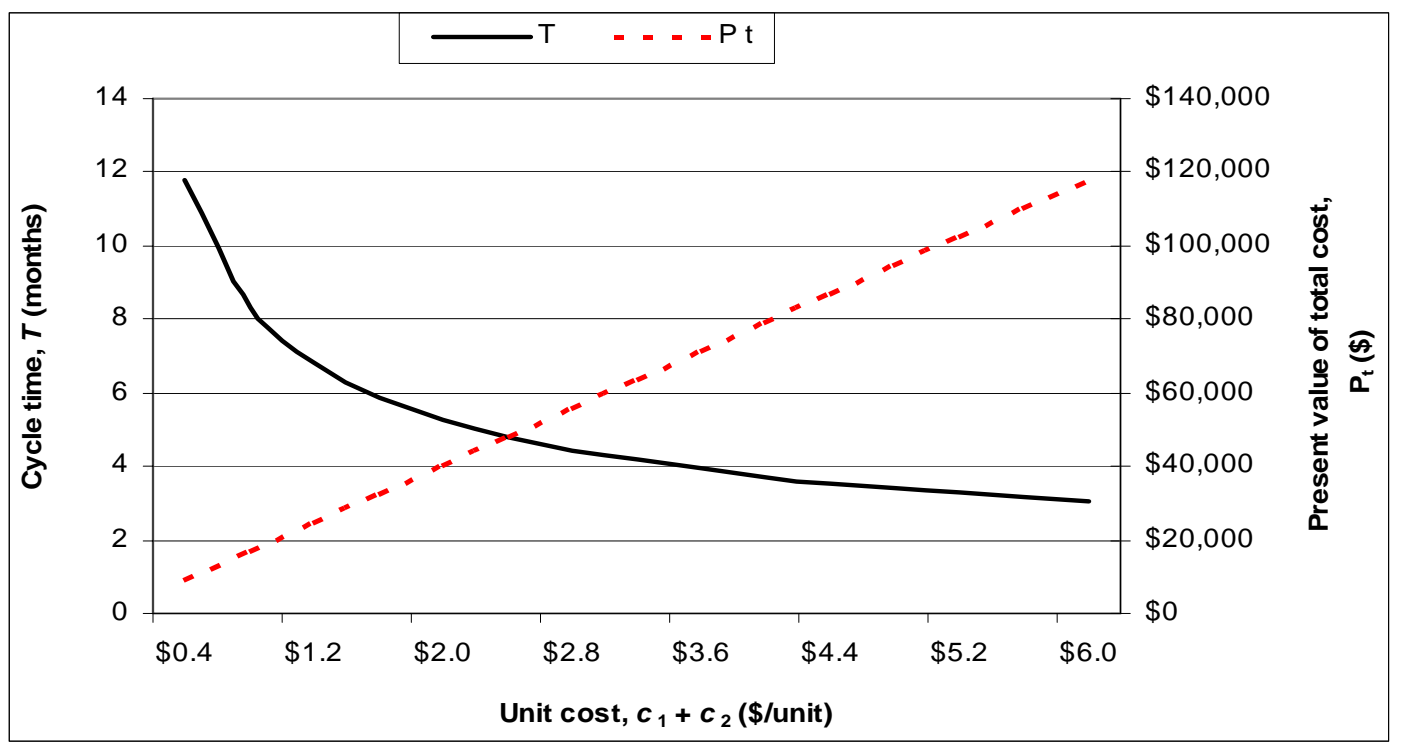

Figure 3.7 Effect of changes in unit costs $c_{1}$ and $c_{2}$ on cycle time $T$ and present value of the total $\operatorname{cost} \boldsymbol{P}_{t}$

\begin{tabular}{|c|c|c|c|c|}
\hline $\begin{array}{c}\text { Raw material cost } \boldsymbol{c}_{\mathbf{1}}, \\
\$ \mathbf{u n i t}\end{array}$ & $\begin{array}{c}\text { Labor cost } \boldsymbol{c}_{\mathbf{2}}, \\
\$ \mathbf{\text { unit }}\end{array}$ & $\begin{array}{c}\boldsymbol{T} \\
\text { (months) }\end{array}$ & $\begin{array}{c}\boldsymbol{Q} \\
\text { (units) }\end{array}$ & $\begin{array}{c}\boldsymbol{P}_{\boldsymbol{t}} \\
\text { (\$) }\end{array}$ \\
\hline$\$ 0.00$ & $\$ 2.00$ & 5.60 & 699.38 & $40,208.85$ \\
\hline$\$ 0.10$ & $\$ 1.90$ & 5.57 & 696.36 & $40,220.62$ \\
\hline$\$ 0.20$ & $\$ 1.80$ & 5.55 & 693.38 & $40,232.35$ \\
\hline$\$ 0.30$ & $\$ 1.70$ & 5.52 & 690.43 & $40,244.02$ \\
\hline$\$ 0.40$ & $\$ 1.60$ & 5.50 & 687.52 & $40,255.64$ \\
\hline$\$ 0.50$ & $\$ 1.50$ & 5.48 & 684.65 & $40,267.21$ \\
\hline$\$ 0.60$ & $\$ 1.40$ & 5.45 & 681.82 & $40,278.73$ \\
\hline$\$ 0.70$ & $\$ 1.30$ & 5.43 & 679.02 & $40,290.20$ \\
\hline$\$ 0.80$ & $\$ 1.20$ & 5.41 & 676.25 & $40,301.62$ \\
\hline$\$ 0.90$ & $\$ 1.10$ & 5.39 & 673.52 & $40,312.99$ \\
\hline$\$ 1.00$ & $\$ 1.00$ & 5.37 & 670.82 & $40,324.32$ \\
\hline$\$ 1.10$ & $\$ 0.90$ & 5.35 & 668.15 & $40,335.60$ \\
\hline$\$ 1.20$ & $\$ 0.80$ & 5.32 & 665.52 & $40,346.83$ \\
\hline$\$ 1.30$ & $\$ 0.70$ & 5.30 & 662.91 & $40,358.02$ \\
\hline$\$ 1.40$ & $\$ 0.60$ & 5.28 & 660.34 & $40,369.17$ \\
\hline$\$ 1.50$ & $\$ 0.50$ & 5.26 & 657.79 & $40,380.26$ \\
\hline$\$ 1.60$ & $\$ 0.40$ & 5.24 & 655.28 & $40,391.32$ \\
\hline$\$ 1.70$ & $\$ 0.30$ & 5.22 & 652.79 & $40,402.33$ \\
\hline$\$ 1.80$ & $\$ 0.20$ & 5.20 & 650.33 & $40,413.30$ \\
\hline$\$ 1.90$ & $\$ 0.10$ & 5.18 & 647.90 & $40,424.23$ \\
\hline$\$ 2.00$ & $\$ 0.00$ & 5.16 & 645.50 & $40,435.11$ \\
\hline
\end{tabular}

Table 3.6 Optimal ordering policies for different values of $c_{1}$ and $c_{2}$ 


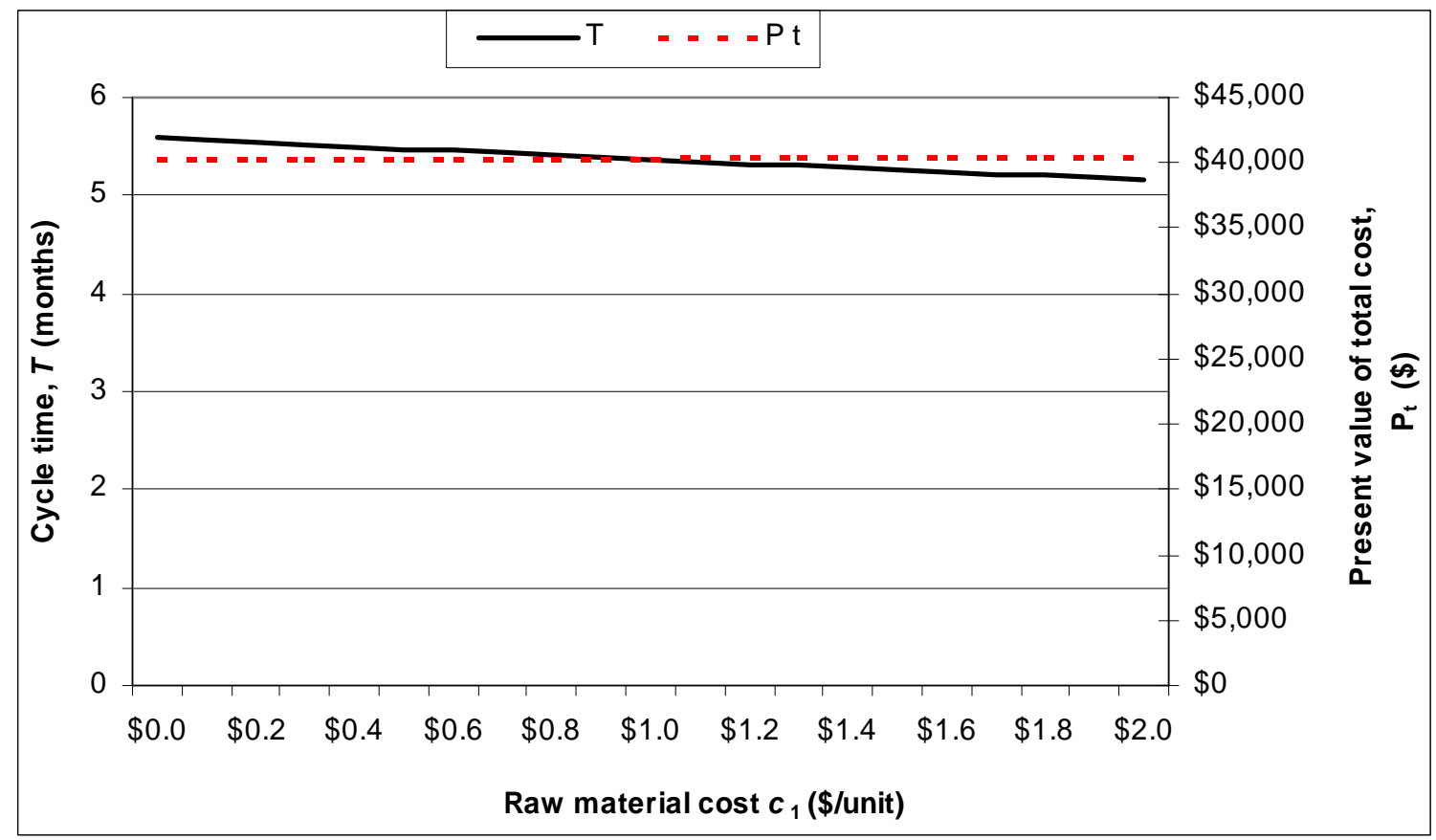

Figure 3.8 Effect of changes in relative values of $c_{1}$ and $c_{2}$ on cycle time $T$ and present value of the total $\operatorname{cost} \boldsymbol{P}_{t}$

\subsection{Inventory Models with Shortage}

The objective of the inventory models where shortage is allowed is to determine the optimal cycle time and the optimal quantity of allowed shortage in order to minimize the total relevant cost. Consequently, the production time and the maximum inventory level can be determined. The models are applied for an infinite planning horizon. Figure 3.9 gives a graphical representation of the first cycle in the system. The inventory production starts at time zero and the amount of shortage is reduced at the rate of $p-D$, which is the production rate minus consumption rate, until time $t_{1}$ when all the shortage is satisfied. After $t_{1}$, the inventory builds up at the same rate of $p-D$ until time $t_{p}$ when the production process stops and the inventory on hand reaches its maximum level. After time $t_{p}$, the inventory level decreases with the consumption rate, $D$, until it becomes zero at time $t_{2}$. After $t_{2}$, the system is out of stock but the 
demand still exists, and backorders accumulate until the end of the cycle, $T$, when the production process is resumed again.

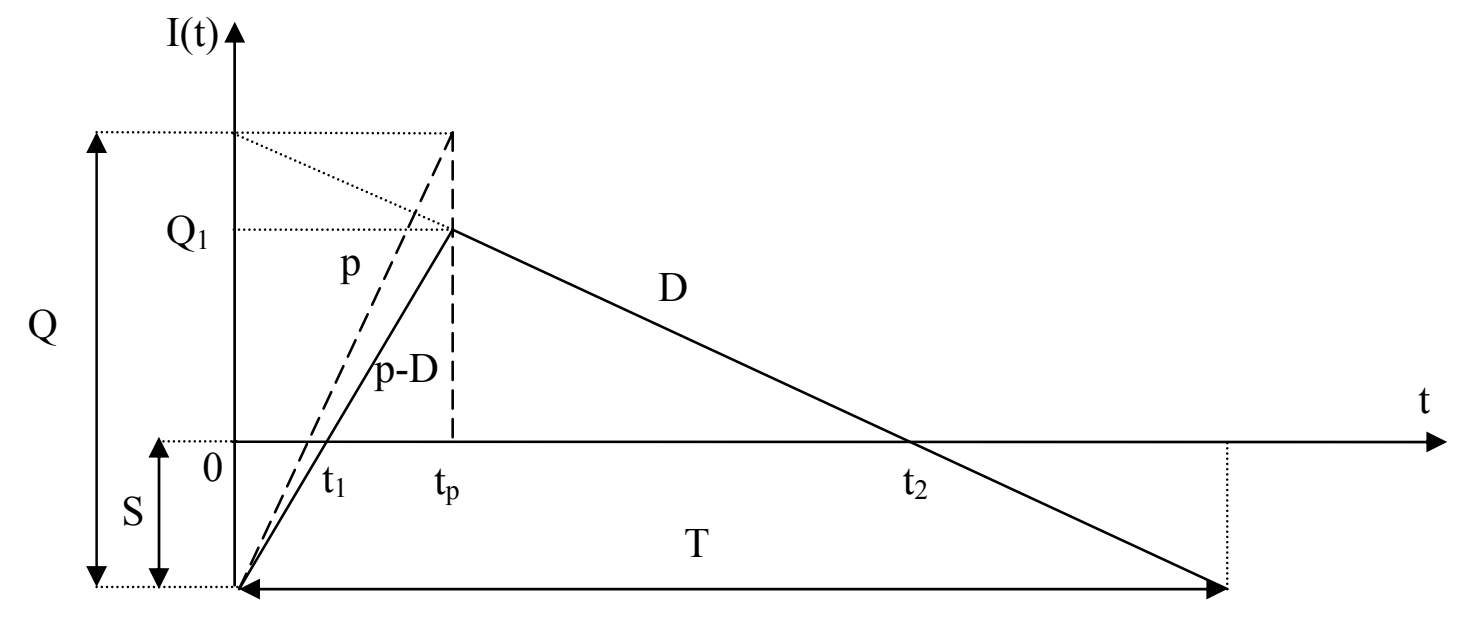

Figure 3.9 EPQ model with constant demand and shortages

The total cost TC for this EPQ model consists of four elements:

$$
\mathrm{TC}=\text { Setup Cost }+ \text { Production Cost }+ \text { Holding Cost }+ \text { Shortage Cost }
$$

\subsubsection{Case 3}

For this case, the setup cost and the production cost are assumed to be incurred at the beginning of each cycle, and the inventory holding cost is incurred continuously during the cycle. A shortage cost will also be incurred.

During the first cycle, the inventory level, $I(t)$, at time $t$ is equal to:

$$
\begin{array}{ll}
-I(t)=S-t(p-D) & \text { for } 0<t<t_{1} \\
I(t)=(p-D)\left(t-t_{1}\right) & \text { for } t_{1}<t<t_{p} \\
I(t)=(Q-S)-D t & \text { for } t_{p}<t<t_{2} \\
-I(t)=D\left(t-t_{2}\right) & \text { for } t_{2}<t<T
\end{array}
$$
where

$$
t_{1}=\frac{S}{p-D}
$$$$
t_{2}=T-\frac{S}{D}
$$$$
t_{p}=\frac{Q}{p}
$$$$
T=\frac{Q}{D}
$$ 
The shortage cost is assumed to consist of two components: $K_{0}$ times the maximum amount of shortage, $S$, where $K_{0}$ is shortage cost per unit short. This component is incurred at the beginning of the cycle. The second component is $K$ times duration of the shortage, for each unit short, where $K$ is shortage cost per unit short per time unit. This component is incurred during the shortage time of the individual units. Assuming continuous compounding, the present value of the total cost of the inventory system for the first cycle can be expressed as:

$$
\begin{aligned}
P= & A+c Q+K \int_{0}^{t_{1}}[S-(p-D) t] e^{-r t} d t+F c \int_{t_{1}}^{t_{p}}(p-D)\left(t-t_{1}\right) e^{-r t} d t+F c \int_{t_{p}}^{t_{2}}(Q-S-D t) e^{-r t} d t \\
& +K \int_{t_{2}}^{T} D\left(t-t_{2}\right) e^{-r t} d t+K_{0} S
\end{aligned}
$$

Integrating by parts, we get, after some simplifications:

$$
\begin{gathered}
K \int_{0}^{t_{1}}[S-(p-D) t] e^{-r t} d t=K\left(\frac{S}{r}+\frac{(p-D) e^{-r t_{1}}}{r^{2}}-\frac{(p-D)}{r^{2}}\right) \\
F c \int_{t_{1}}^{t_{p}}(p-D)\left(t-t_{1}\right) e^{-r t} d t=F c\left[\frac{e^{-r t_{p}}}{r}\left(S-\frac{(p-D)}{r}-Q+\frac{D Q}{p}\right)+\frac{e^{-r t_{1}}(p-D)}{r^{2}}\right] \\
F c \int_{t_{p}}^{t_{2}}(Q-S-D t) e^{-r t} d t=F c\left[\frac{e^{-r t_{p}}}{r}\left(Q-S-\frac{D Q}{p}-\frac{D}{r}\right)+\frac{D e^{-r t_{2}}}{r^{2}}\right] \\
K \int_{t_{2}}^{T} D\left(t-t_{2}\right) e^{-r t} d t=K D\left[\frac{e^{-r T}}{r}\left(\frac{Q-S}{D}-\frac{1}{r}-\frac{Q}{D}\right)+\frac{e^{-r t_{2}}}{r^{2}}\right]
\end{gathered}
$$

Substituting these expressions into Equation (3.18) and simplifying, we get the present value of the total cost for the first period as: 


$$
\begin{aligned}
P= & A+c Q+\frac{K S}{r}-\frac{K(p-D)}{r^{2}}+K_{0} S-\frac{F c p e^{-r t_{p}}}{r^{2}}+\frac{(p-D) e^{-r t_{1}}}{r^{2}}(K+F c)+ \\
& \frac{D e^{-r t_{2}}}{r^{2}}(K+F c)-\frac{K e^{-r T}}{r}\left(S+\frac{D}{r}\right)
\end{aligned}
$$

For an infinite planning horizon, $N \rightarrow \infty$, and $P_{t}$ can be expressed as:

$$
P_{t}=P\left(\frac{1}{1-e^{-r T}}\right)
$$

Substituting Equation (3.19) into (3.20) and representing $T, t_{1}, t_{2}$ and $t_{p}$ in terms of $Q$ and $S$, we get the present value, $P_{t}$, of the total cost:

$$
\begin{aligned}
P_{t}= & \left(\frac{1}{1-e^{-\frac{r Q}{D}}}\right)\left[A+c Q+\frac{K S}{r}-\frac{K(p-D)}{r^{2}}+K_{0} S-\frac{F c p e^{-\frac{r Q}{p}}}{r^{2}}+\frac{(p-D) e^{-\frac{r S}{(p-D)}}}{r^{2}}(K+F c)+\right. \\
& \left.\frac{D e^{-r\left(\frac{Q-S}{D}\right)}}{r^{2}}(K+F c)-\frac{K e^{-\frac{r Q}{D}}}{r}\left(S+\frac{D}{r}\right)\right]
\end{aligned}
$$

The total inventory cost in Equation (3.21) is a function of the production quantity, $Q$, and shortage, $S$. Closed formulas could not be obtained for the optimal values of $Q$ and $S$. A search technique needs to be applied to find the optimal policy.

\subsubsection{Search Algorithm}

An iterative search procedure was developed using a combination of a modified version of the Simplex Evolutionary Operation (EVOP) (Spendley et al., 1962) and a Univariate Walk. The search starts by applying the modified EVOP until no further improvement can be achieved then the Univariate Walk is used to obtain the solution. 
The modified EVOP search tries to minimize the objective function, $f(x)$, of $k$ variables. The algorithm builds a regular simplex with $k+1$ vertices, in $k$ dimensions around the starting point. The coordinates of the vertices are defined in the following matrix, $S_{0}$, in which each of the $k+1$ rows represents a vertex, and the $k$ columns represent coordinates of these vertices.

$$
S_{0}=\left[\begin{array}{ccccc}
0 & 0 & 0 & \ldots \ldots & 0 \\
p & q & q & \ldots . . & q \\
q & p & q & \ldots . . & q \\
\ldots & \ldots & \ldots & \ldots \ldots & \ldots \\
q & q & q & \ldots \ldots & p
\end{array}\right]
$$

where $\quad p=\frac{1}{k \sqrt{2}}[(k-1)+\sqrt{k+1}] \quad$ and $\quad q=\frac{1}{k \sqrt{2}}(\sqrt{k+1}-1)$

The centroid of the matrix is defined by the point

$$
C_{0}=\left(\frac{p+(k-1) q}{k+1}, \frac{p+(k-1) q}{k+1} \ldots, \frac{p+(k-1) q}{k+1}\right)
$$

For two variables, $k=2$, the vertices of the simplex are $(0,0),(p, q),(q, p)$ and the simplex is an equilateral triangle. For a simplex with a centroid at point $\left(X_{1}, X_{2}, \ldots X_{k}\right)$ and an edge length, $L$, the matrix can be defined as:

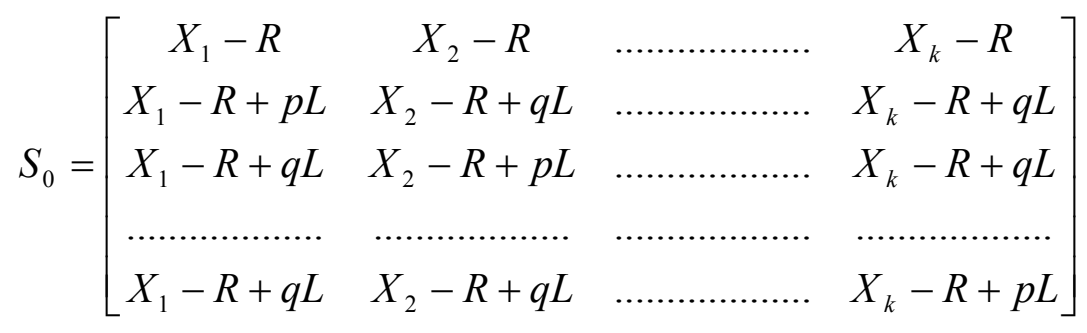

$$
\begin{aligned}
& \text { where } \quad R=\left(\frac{p L+(k-1) q L}{k+1}\right)
\end{aligned}
$$

After defining the initial Simplex, $S_{0}$, with any point in the acceptable range of the variables as the centroid, and $L$ as the initial edge length, the objective function can be evaluated at each of the vertices of the simplex. For a minimization problem, the vertex, $V_{j}, j=1,2, \ldots, k+1$, 
with the highest value of the objective function is selected and a projection is made from that vertex through the centroid. The rotation of the simplex gives a new vertex, $V_{j}^{*}$, located along the projection line on the opposite side of $V_{j}$. The old vertex is deleted and a new simplex is formed, with the new vertex replacing the old one, and all other vertices kept unchanged. The coordinates of the new vertex, $V_{j}^{*}$, can be calculated by subtracting the coordinates of $V_{j}$ from twice the average of the coordinates of all the other vertices. The general formula for the new vertex, $V_{j}^{*}$, is:

$$
V_{j}^{*}=2 \times \frac{\left(V_{1}+V_{2}+\ldots+V_{j-1}+V_{j+1}+\ldots+V_{k+1}\right)}{k}-V_{j}
$$

The objective function is evaluated at the new vertex, and the search continues until the value of the objective function at the new vertex, $V_{j}^{*}$, is more than or equal to the value at the old vertex, $V_{j}$, or until the new vertex, $V_{j}^{*}$, falls outside the acceptable range for one or more variables. In either case, the process stops and the centroid of the current simplex is determined. The edge length is then reduced and a new simplex is constructed around the centroid. The search continues until the edge length becomes smaller than a stoppage value that is predetermined by the user. The centroid of the last simplex would give the optimal or near optimal solution.

To assure that the optimal value is attained, the search continues with a Univariate Walk that starts with the final centroid obtained with EVOP. In this case, the value of the first variable, $X_{1}$, is changed to a new value, $X_{1}+L$, while keeping all other variables constant. If the objective function improves at the new point, the move continues at the same direction with the same edge length, $L$. Otherwise, the search proceeds in opposite direction. If no improvement is attained in either direction, the search continues with another variable. When all variables are exhausted, the length of the step, $L$, is reduced and the process continues. The search stops when no more 
improvement can be achieved and the value of $L$ becomes smaller than a stoppage value defined by the user.

\subsubsection{Case 4}

As in the models with no shortage, the production cost, $c$, for this case, has two components. A cost, $c_{1}$, that is incurred at the beginning of each cycle and is applied to the total quantity produced during the production period and a second cost, $c_{2}$, that is incurred as the production process takes place.

The main difference between Cases 3 and 4 is in the production cost. For Case 4, the production cost for the model with shortages is similar to the one used with the model with no shortage, and expressed in Equation (3.13). In addition, for the holding cost, the unit production cost $c$, is replaced with the sum of two cost components, $c_{1}$ and $c_{2}$.

For the inventory system where shortages are allowed, the present value of the total cost for the first period becomes:

$$
\begin{aligned}
& P=A+c_{1} Q+c_{2} p \int_{0}^{t_{p}} e^{-r t} d t+K \int_{0}^{t_{1}}[S-(p-D) t] e^{-r t} d t+ \\
& F c_{3}\left(\int_{t_{1}}^{t_{p}}(p-D)\left(t-t_{1}\right) e^{-r t} d t+\int_{t_{p}}^{t_{2}}(Q-S-D t) e^{-r t} d t\right)+K \int_{t_{2}}^{T} D\left(t-t_{2}\right) e^{-r t} d t+K_{0} S
\end{aligned}
$$

where $c_{3}=c_{1}+c_{2}$

The procedure followed in Case 3 is repeated and leads to the following value for the total cost for all cycles: 


$$
\begin{aligned}
P_{t}= & \left(\frac{1}{1-e^{-\frac{r Q}{D}}}\right)\left[A+c_{1} Q+\frac{c_{2} p}{r}+\frac{K S}{r}-\frac{K(p-D)}{r^{2}}+K_{0} S-\frac{p e^{-\frac{r Q}{p}}}{r}\left(\frac{F c_{3}}{r}+c_{2}\right)+\right. \\
& \left.\frac{(p-D) e^{-\frac{r S}{(p-D)}}}{r^{2}}\left(K+F c_{3}\right)+\frac{D e^{-r\left(\frac{Q-S}{D}\right)}}{r^{2}}\left(K+F c_{3}\right)-\frac{K e^{-\frac{r Q}{D}}}{r}\left(S+\frac{D}{r}\right)\right]
\end{aligned}
$$

Similar to Case 3, the total inventory cost is a function of $Q$ and $S$ and a search procedure is used to find the optimal policy.

\subsection{Numerical Example and Sensitivity Analysis}

A numerical example is presented to illustrate the application of the models developed for the inventory system when shortage is allowed and items are fully backordered. A software was developed, using Visual Basic Applications, to apply the search technique.

Consider an inventory system with the following data:

$p=4500$ units/yr, $D=1500$ units/yr, $A=50 \$ /$ order, $F=0.15 \$ / \$ / y r, c=2 \$ /$ unit, $K=1 \$ /$ unit/yr, $K_{0}=0 \$$ unit.

The model was applied for Case 3, using different values for the real interest rate, and the results obtained are summarized in Table 3.7. The table shows the relations between the optimal values of the cycle time, order quantity, shortage, maximum inventory on hand, and the real interest rate. As expected, the cycle time decreases as the real interest rate increases. Accordingly, the optimal production quantity, $Q$, shortage, $S$, and maximum inventory on hand, $I_{\max }$, decrease with higher real interest rates. The present value of the total cost also decreases as the real interest rate increases. When the value of $r$ is equal to zero, the standard equation for optimal production quantity and cycle time were used to calculate $T$ and $Q$. Since the present 
value of the total cost, with infinite horizon, approaches infinity as $r$ approaches zero, the last column in Table 3.7 was calculated for the present value of the total relevant cost for the first year, using the results of the infinite horizon policy, and pro-rating the value for the partial cycle at the end of the year. Figure 3.10 shows the behavior of optimal production quantity, $Q$, shortage, $S$, and present value of the total cost, $P_{t}$, with respect to real interest rate, $r$.

\begin{tabular}{|c|c|c|c|c|c|c|}
\hline $\begin{array}{c}\text { Real interest } \\
\text { rate } \boldsymbol{r}, \mathbf{( \% )}\end{array}$ & $\begin{array}{c}\boldsymbol{Q} \\
\text { (units) }\end{array}$ & $\begin{array}{c}\boldsymbol{S} \\
\text { (units) }\end{array}$ & $\begin{array}{c}\boldsymbol{I}_{\max } \\
\text { (units) }\end{array}$ & $\begin{array}{c}\boldsymbol{T} \\
\text { (months) }\end{array}$ & $\begin{array}{c}\boldsymbol{P}_{\boldsymbol{t}} \\
\mathbf{( \$ )}\end{array}$ & $\begin{array}{c}\text { PV for first } \\
\text { year, (\$) }\end{array}$ \\
\hline $0 \%$ & 987.42 & 151.91 & 506.37 & 7.90 & - & $3,151.91$ \\
\hline $1 \%$ & 928.62 & 142.98 & 476.10 & 7.43 & $316,175.66$ & $3,144.58$ \\
\hline $2 \%$ & 879.06 & 135.44 & 450.60 & 7.03 & $158,553.93$ & $3,137.36$ \\
\hline $3 \%$ & 836.56 & 128.98 & 428.73 & 6.69 & $105,998.48$ & $3,130.36$ \\
\hline $4 \%$ & 799.59 & 123.35 & 409.71 & 6.40 & $79,711.12$ & $3,123.62$ \\
\hline $5 \%$ & 767.05 & 118.39 & 392.97 & 6.14 & $63,931.94$ & $3,117.15$ \\
\hline $6 \%$ & 738.13 & 113.98 & 378.10 & 5.91 & $53,407.50$ & $3,109.53$ \\
\hline $7 \%$ & 712.20 & 110.03 & 364.77 & 5.70 & $45,886.23$ & $3,099.97$ \\
\hline $8 \%$ & 688.78 & 106.46 & 352.73 & 5.51 & $40,242.26$ & $3,090.34$ \\
\hline $9 \%$ & 667.50 & 103.21 & 341.79 & 5.34 & $35,850.08$ & $3,080.72$ \\
\hline $10 \%$ & 648.05 & 100.24 & 331.79 & 5.18 & $32,334.35$ & $3,071.16$ \\
\hline $11 \%$ & 630.18 & 97.52 & 322.60 & 5.04 & $29,456.18$ & $3,061.71$ \\
\hline $12 \%$ & 613.68 & 95.00 & 314.12 & 4.91 & $27,056.30$ & $3,052.39$ \\
\hline $13 \%$ & 598.40 & 92.66 & 306.27 & 4.79 & $25,024.44$ & $3,043.21$ \\
\hline $14 \%$ & 584.19 & 90.49 & 298.97 & 4.67 & $23,281.82$ & $3,034.18$ \\
\hline $15 \%$ & 570.92 & 88.46 & 292.15 & 4.57 & $21,770.64$ & $3,025.30$ \\
\hline
\end{tabular}

Table 3.7 Optimal ordering policies for different values of $r$ when shortages are allowed 


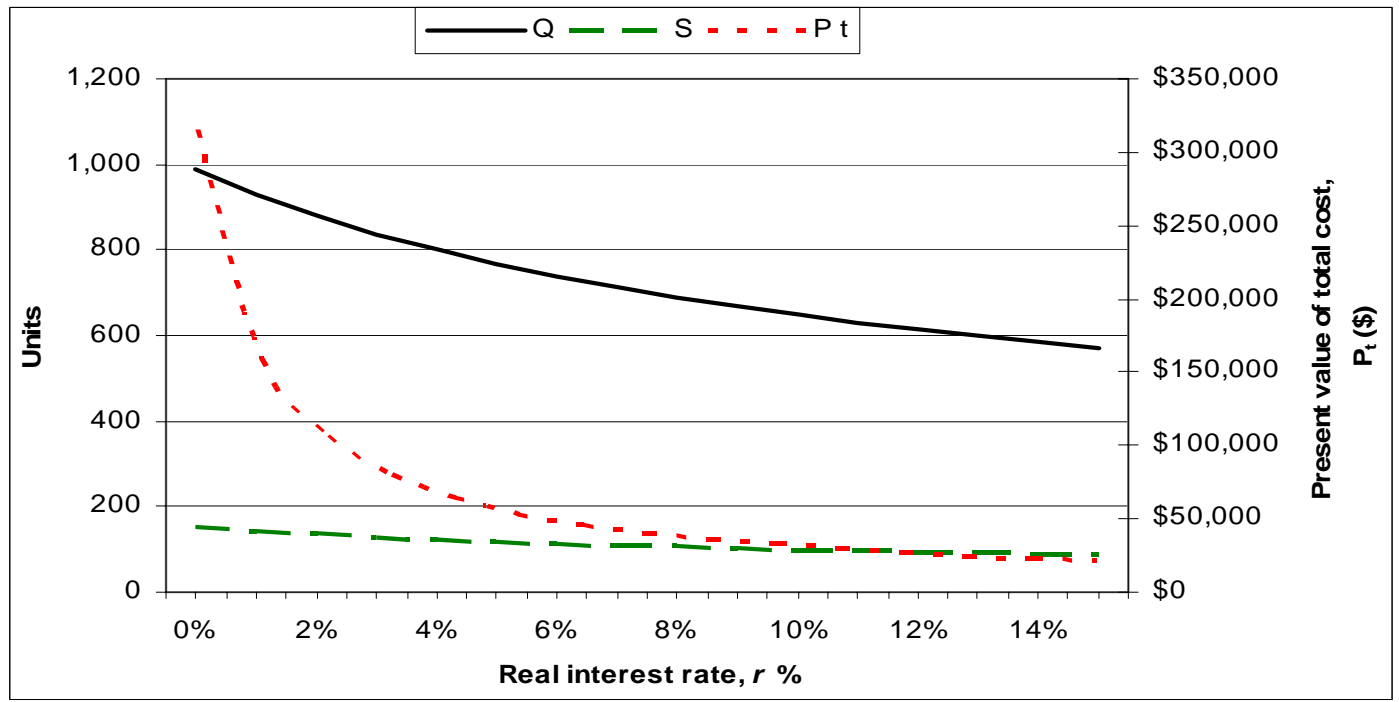

Figure 3.10 Effect of real interest rate $r$ on ordering quantity $Q$, shortage $S$ and present value of the total $\operatorname{cost} \boldsymbol{P}_{t}$

Tables 3.8, 3.9, 3.10, and 3.11 along with Figures 3.11, 3.12, 3.13, and 3.14 show the results obtained for different values of carrying rate, $F$, demand rate, $D$, shortage cost, $K$, and setup cost, $A$, and the behavior of $Q, S$ and $P_{t}$ with respect to those parameters. The production quantity decreases with an increase in $F$, but increases with the increase in $D$ or $A$. The shortage, $S$, increases with the increase in carrying rate, $F$, and setup cost, $A$, and it decreases when shortage cost increases. High carrying rate results in smaller value of $Q$ and drives the amount of shortage to a higher value. Increasing demand results in more production, hence in higher value of $Q$. High setup costs result in fewer but larger orders and also in larger shortages. The increase in shortage cost obviously reduces shortages. When the demand rate increases, shortages increase at the beginning, but after some point, they start decreasing. When demand is low, there is no reason to have high amount of shortages. Also, when the demand is equal to the production rate, the amount of shortage is equal to zero. However, the amount of shortage increases between these two extremes. The present value of the total cost follows the same patterns encountered in the model without shortage. 


\begin{tabular}{|c|c|c|c|c|c|}
\hline $\begin{array}{c}\text { Carrying rate } \boldsymbol{F} \\
(\mathbf{\%})\end{array}$ & $\begin{array}{c}\boldsymbol{Q} \\
\text { (units) }\end{array}$ & $\begin{array}{c}\boldsymbol{S} \\
\text { (units) }\end{array}$ & $\begin{array}{c}\boldsymbol{I}_{\max } \\
\text { (units) }\end{array}$ & $\begin{array}{c}\boldsymbol{T} \\
\text { (months) }\end{array}$ & $\begin{array}{c}\boldsymbol{P}_{\boldsymbol{t}} \\
\text { (\$) }\end{array}$ \\
\hline $5 \%$ & 819.77 & 50.01 & 496.50 & 6.56 & $39,805.67$ \\
\hline $6 \%$ & 800.64 & 57.55 & 476.21 & 6.41 & $39,860.54$ \\
\hline $7 \%$ & 783.40 & 64.52 & 457.74 & 6.27 & $39,912.29$ \\
\hline $8 \%$ & 767.76 & 71.01 & 440.83 & 6.14 & $39,961.21$ \\
\hline $9 \%$ & 753.52 & 77.06 & 425.29 & 6.03 & $40,007.56$ \\
\hline $10 \%$ & 740.47 & 82.72 & 410.93 & 5.92 & $40,051.55$ \\
\hline $11 \%$ & 728.48 & 88.04 & 397.62 & 5.83 & $40,093.39$ \\
\hline $12 \%$ & 717.42 & 93.04 & 385.24 & 5.74 & $40,133.23$ \\
\hline $13 \%$ & 707.17 & 97.76 & 373.69 & 5.66 & $40,171.23$ \\
\hline $14 \%$ & 697.65 & 102.23 & 362.87 & 5.58 & $40,207.54$ \\
\hline $15 \%$ & 688.78 & 106.46 & 352.73 & 5.51 & $40,242.26$ \\
\hline $16 \%$ & 680.50 & 110.48 & 343.19 & 5.44 & $40,275.51$ \\
\hline $17 \%$ & 672.74 & 114.30 & 334.20 & 5.38 & $40,307.39$ \\
\hline $18 \%$ & 665.46 & 117.94 & 325.70 & 5.32 & $40,337.98$ \\
\hline $19 \%$ & 658.62 & 121.41 & 317.67 & 5.27 & $40,367.37$ \\
\hline $20 \%$ & 652.16 & 124.73 & 310.05 & 5.22 & $40,395.63$ \\
\hline
\end{tabular}

Table 3.8 Optimal ordering policies for different values of $\boldsymbol{F}$ when shortages are allowed

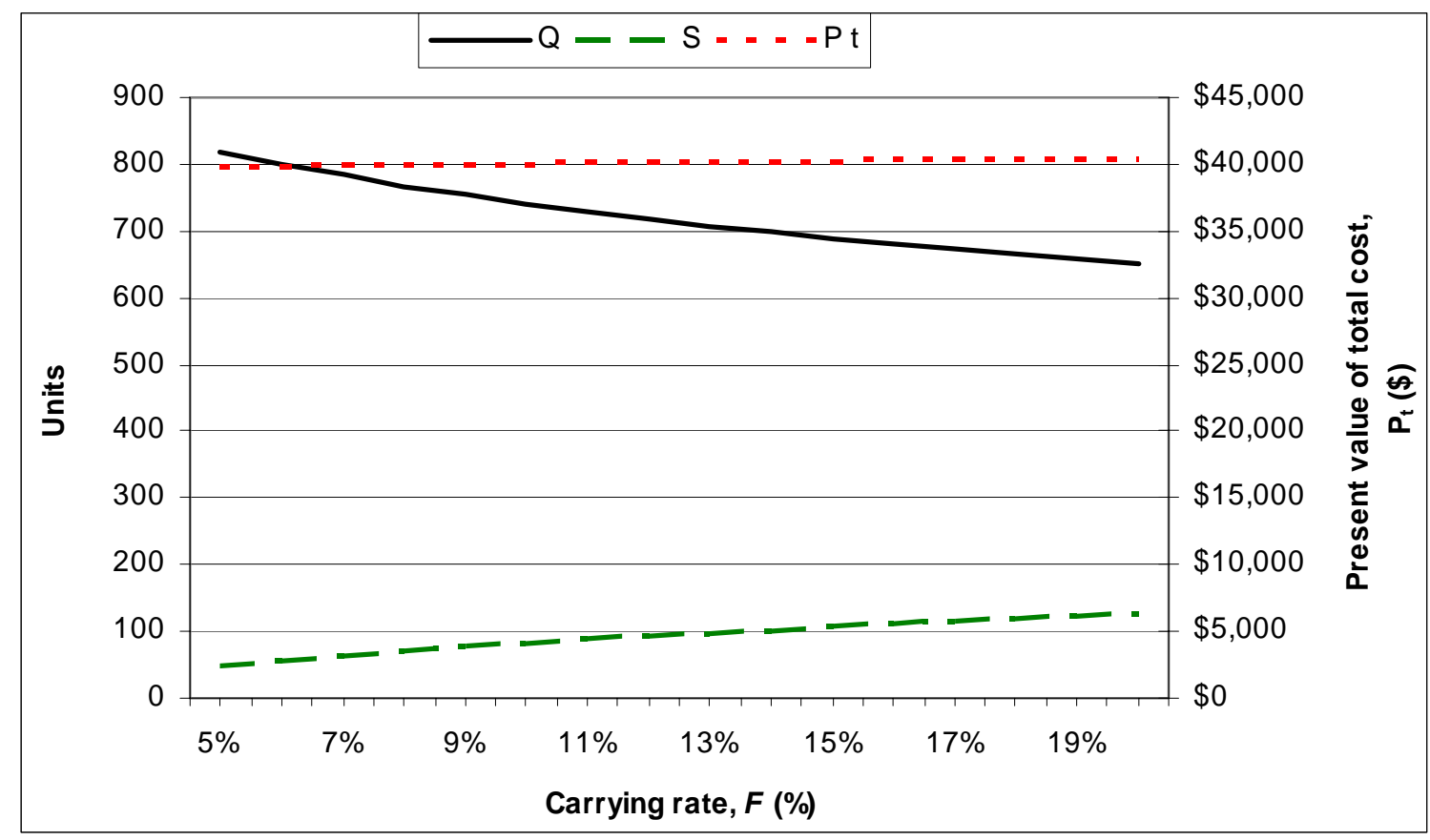

Figure 3.11 Effect of carrying rate $F$ on ordering quantity $Q$, shortage $S$ and present value of the total cost $\boldsymbol{P}_{t}$ 


\begin{tabular}{|c|c|c|c|c|c|}
\hline $\begin{array}{c}\text { Demand rate } \boldsymbol{D} \\
\text { (units) }\end{array}$ & $\begin{array}{c}\boldsymbol{Q} \\
\text { (units) }\end{array}$ & $\begin{array}{c}\boldsymbol{S} \\
\text { (units) }\end{array}$ & $\begin{array}{c}\boldsymbol{I}_{\text {max }} \\
\text { (units) }\end{array}$ & $\begin{array}{c}\boldsymbol{T} \\
\text { (months) }\end{array}$ & $\begin{array}{c}\boldsymbol{P}_{\boldsymbol{t}} \\
\text { (\$) }\end{array}$ \\
\hline 200 & 226.82 & 51.63 & 165.11 & 13.61 & $6,121.58$ \\
\hline 400 & 326.24 & 70.02 & 227.22 & 9.79 & $11,552.10$ \\
\hline 600 & 405.80 & 82.40 & 269.29 & 8.12 & $16,867.81$ \\
\hline 800 & 475.81 & 91.34 & 299.87 & 7.14 & $22,121.41$ \\
\hline 1,000 & 540.26 & 97.86 & 322.34 & 6.48 & $27,333.53$ \\
\hline 1,200 & 601.23 & 102.47 & 338.43 & 6.01 & $32,514.83$ \\
\hline 1,400 & 659.97 & 105.49 & 349.16 & 5.66 & $37,671.66$ \\
\hline 1,600 & 717.34 & 107.10 & 355.19 & 5.38 & $42,808.19$ \\
\hline 1,800 & 773.96 & 107.44 & 356.94 & 5.16 & $47,927.28$ \\
\hline 2,000 & 830.33 & 106.60 & 354.70 & 4.98 & $53,031.03$ \\
\hline 2,200 & 886.87 & 104.63 & 348.66 & 4.84 & $58,120.99$ \\
\hline 2,400 & 943.95 & 101.57 & 338.94 & 4.72 & $63,198.33$ \\
\hline 2,600 & $1,001.90$ & 97.44 & 325.59 & 4.62 & $68,263.96$ \\
\hline 2,800 & $1,061.07$ & 92.24 & 308.61 & 4.55 & $73,318.59$ \\
\hline 3,000 & $1,121.79$ & 85.96 & 287.97 & 4.49 & $78,362.78$ \\
\hline
\end{tabular}

Table 3.9 Optimal ordering policies for different values of $D$ when shortages are allowed

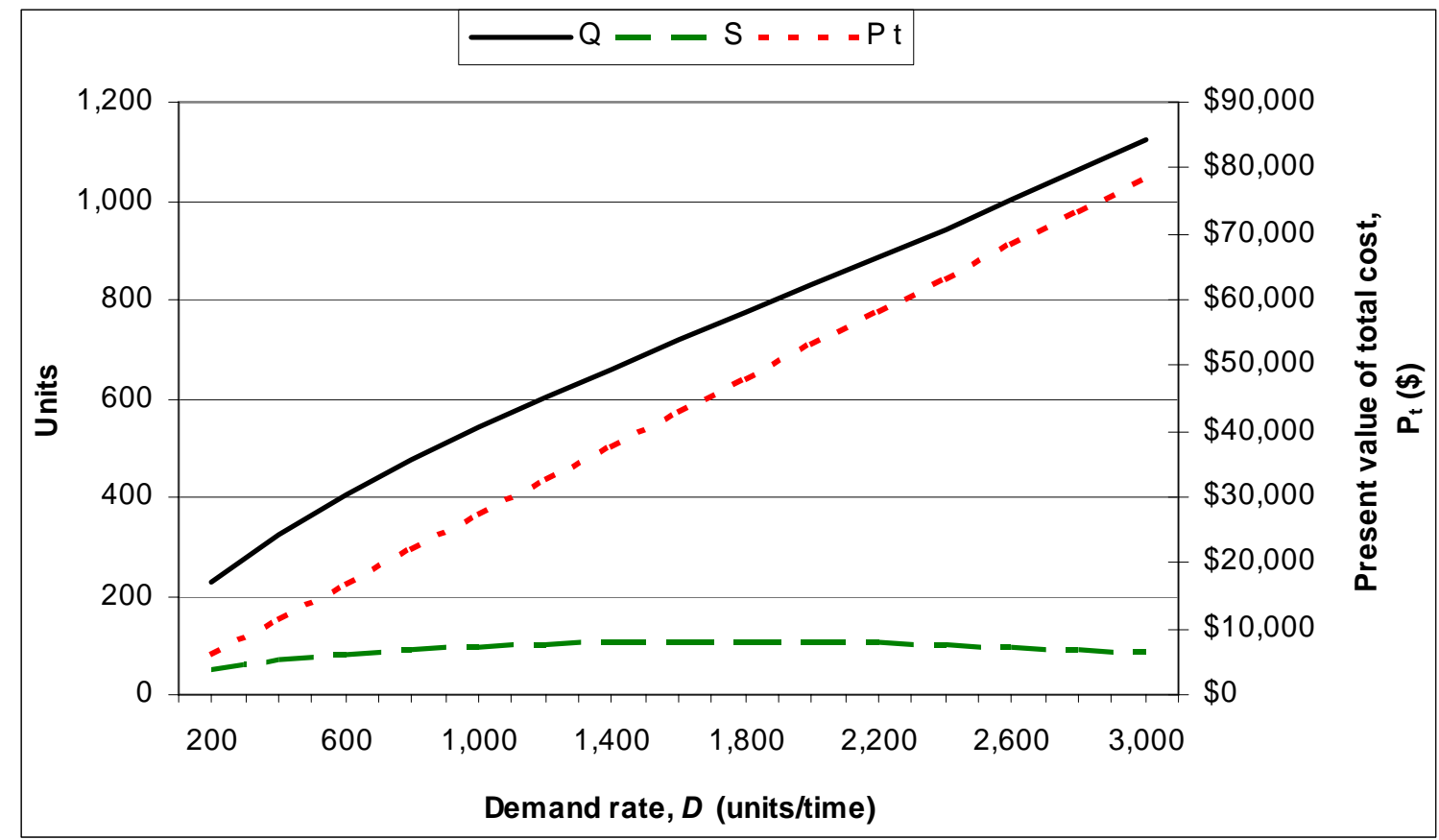

Figure 3.12 Effect of demand rate $D$ on ordering quantity $Q$, shortage $S$ and present value of the total $\operatorname{cost} \boldsymbol{P}_{t}$ 


\begin{tabular}{|c|c|c|c|c|c|}
\hline $\begin{array}{c}\text { Shortage cost } \boldsymbol{K} \\
\text { (\$/unit/time) }\end{array}$ & $\begin{array}{c}\boldsymbol{Q} \\
\text { (units) }\end{array}$ & $\begin{array}{c}\boldsymbol{S} \\
\text { (units) }\end{array}$ & $\begin{array}{c}\boldsymbol{I}_{\text {max }} \\
\text { (units) }\end{array}$ & $\begin{array}{c}\boldsymbol{T} \\
\text { (months) }\end{array}$ & $\begin{array}{c}\boldsymbol{P}_{\boldsymbol{t}} \\
\text { (\$) }\end{array}$ \\
\hline 1 & 688.78 & 106.46 & 352.73 & 5.51 & $40,242.26$ \\
\hline 2 & 667.81 & 58.37 & 386.84 & 5.34 & $40,327.69$ \\
\hline 3 & 660.05 & 40.21 & 399.82 & 5.28 & $40,360.66$ \\
\hline 4 & 656.01 & 30.68 & 406.66 & 5.25 & $40,378.14$ \\
\hline 5 & 653.53 & 24.80 & 410.89 & 5.23 & $40,388.97$ \\
\hline 6 & 651.85 & 20.81 & 413.76 & 5.21 & $40,396.34$ \\
\hline 7 & 650.64 & 17.92 & 415.84 & 5.21 & $40,401.68$ \\
\hline 8 & 649.72 & 15.74 & 417.41 & 5.20 & $40,405.72$ \\
\hline 9 & 649.01 & 14.03 & 418.64 & 5.19 & $40,408.89$ \\
\hline 10 & 648.44 & 12.66 & 419.63 & 5.19 & $40,411.45$ \\
\hline
\end{tabular}

Table 3.10 Optimal ordering policies for different values of $\boldsymbol{K}$ when shortages are allowed

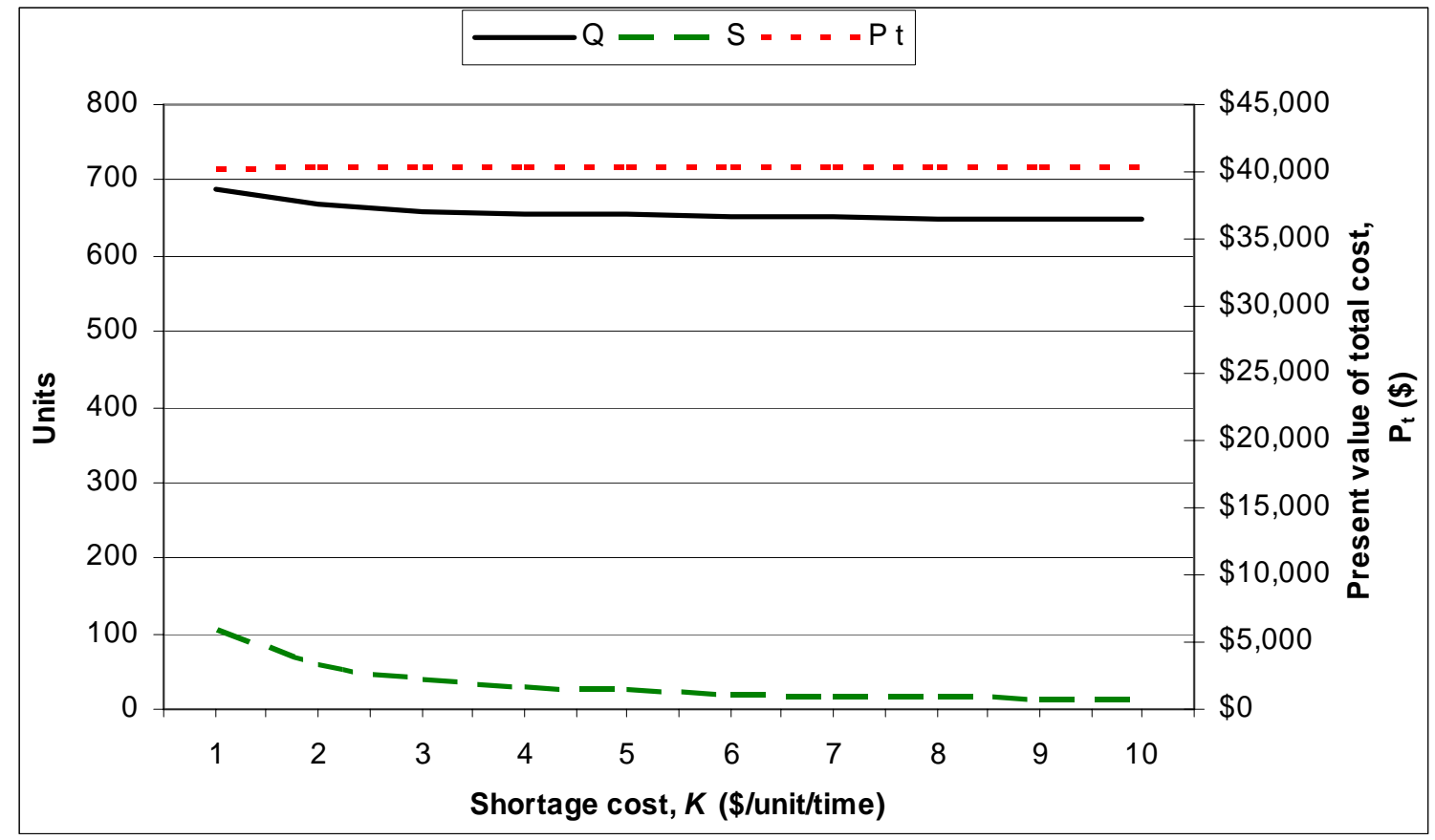

Figure 3.13 Effect of shortage cost $K$ on ordering quantity $Q$, shortage $S$ and present value of the total cost $\boldsymbol{P}_{t}$ 


\begin{tabular}{|c|c|c|c|c|c|}
\hline $\begin{array}{c}\text { Setup cost } \boldsymbol{A} \\
\text { (\$/order) }\end{array}$ & $\begin{array}{c}\boldsymbol{Q} \\
\text { (units) }\end{array}$ & $\begin{array}{c}\boldsymbol{S} \\
\text { (units) }\end{array}$ & $\begin{array}{c}\boldsymbol{I}_{\max } \\
\text { (units) }\end{array}$ & $\begin{array}{c}\boldsymbol{T} \\
\text { (months) }\end{array}$ & $\begin{array}{c}\boldsymbol{P}_{\boldsymbol{t}} \\
\text { (\$) }\end{array}$ \\
\hline 10 & 308.67 & 47.59 & 158.19 & 2.47 & $38,718.92$ \\
\hline 20 & 436.22 & 67.31 & 223.50 & 3.49 & $39,227.34$ \\
\hline 30 & 533.98 & 82.45 & 273.54 & 4.27 & $39,618.87$ \\
\hline 40 & 616.31 & 95.21 & 315.66 & 4.93 & $39,949.90$ \\
\hline 50 & 688.78 & 106.46 & 352.73 & 5.51 & $40,242.26$ \\
\hline 60 & 754.26 & 116.63 & 386.21 & 6.03 & $40,507.16$ \\
\hline 70 & 814.43 & 125.98 & 416.97 & 6.52 & $40,751.24$ \\
\hline 80 & 870.39 & 134.69 & 445.57 & 6.96 & $40,978.86$ \\
\hline 90 & 922.93 & 142.87 & 472.42 & 7.38 & $41,193.00$ \\
\hline 100 & 972.59 & 150.61 & 497.79 & 7.78 & $41,395.88$ \\
\hline
\end{tabular}

Table 3.11 Optimal ordering policies for different values of $\boldsymbol{A}$ when shortages are allowed

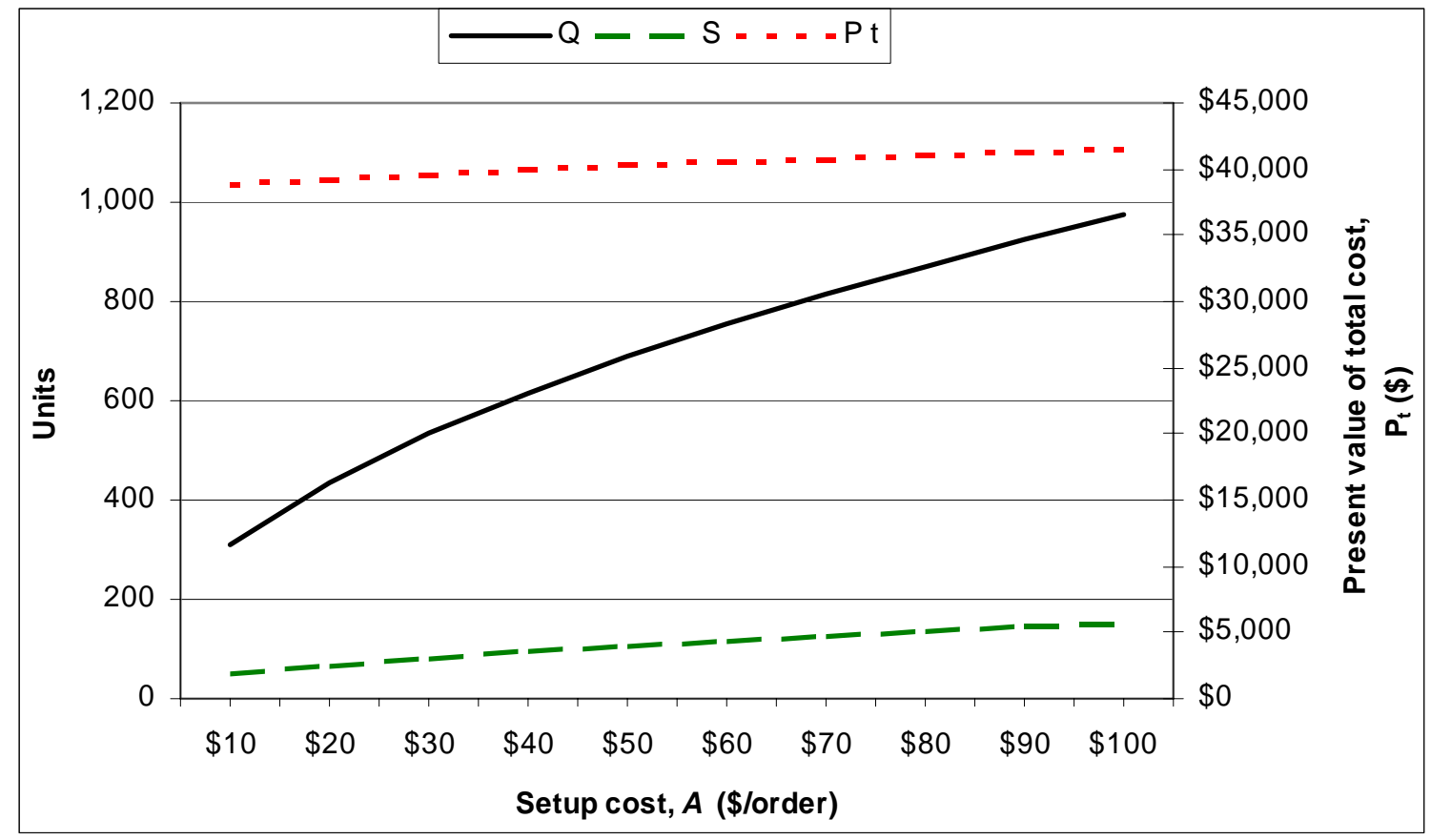

Figure 3.14 Effect of setup cost $A$ on ordering quantity $Q$, shortage $S$ and present value of the total cost $P_{t}$

For Case 4, the same example was used with the same parameters, except that the production cost, $c$, was substituted with a raw material $\operatorname{cost} c_{1}=1.5 \$$ unit, and a labor cost $c_{2}=$ 
0.5 \$/unit. The results are summarized in Table 3.12. As in Case 3, the optimal values of the cycle time, order quantity, shortage, and maximum inventory on hand decrease as the real interest rate increases. The present value of the total cost also decreases as the real interest rate increases. The results were very close to the case with one cost, hence the detailed tables and figures are not repeated.

The results of simultaneous changes in unit $\operatorname{costs} c_{1}$ and $c_{2}$ are summarized in Table 3.13 and their graphical representation is illustrated in Figure 3.15.

\begin{tabular}{|c|c|c|c|c|c|c|}
\hline $\begin{array}{c}\text { Real interest } \\
\text { rate } \boldsymbol{r}, \mathbf{( \% / y r )}\end{array}$ & $\begin{array}{c}\boldsymbol{Q} \\
\text { (units) }\end{array}$ & $\begin{array}{c}\boldsymbol{S} \\
\text { (units) }\end{array}$ & $\begin{array}{c}\boldsymbol{I}_{\text {max }} \\
\text { (units) }\end{array}$ & $\begin{array}{c}\boldsymbol{T} \\
\text { (months) }\end{array}$ & $\begin{array}{c}\boldsymbol{P}_{\boldsymbol{t}} \\
\mathbf{( \$ )}\end{array}$ & $\begin{array}{c}\text { PV for first } \\
\text { year, (\$) }\end{array}$ \\
\hline $\mathbf{0 \%}$ & 987.42 & 151.91 & 506.37 & 7.90 & - & $3,151.91$ \\
\hline $1 \%$ & 933.12 & 143.67 & 478.41 & 7.46 & $316,097.90$ & $3,143.78$ \\
\hline $2 \%$ & 886.78 & 136.63 & 454.55 & 7.09 & $158,480.01$ & $3,135.79$ \\
\hline $3 \%$ & 846.61 & 130.53 & 433.88 & 6.77 & $105,927.90$ & $3,128.04$ \\
\hline $4 \%$ & 811.37 & 125.17 & 415.75 & 6.49 & $79,643.44$ & $3,120.55$ \\
\hline $5 \%$ & 780.14 & 120.42 & 399.67 & 6.24 & $63,866.83$ & $3,113.35$ \\
\hline $6 \%$ & 752.20 & 116.16 & 385.30 & 6.02 & $53,344.69$ & $3,106.42$ \\
\hline $7 \%$ & 727.02 & 112.33 & 372.35 & 5.82 & $45,825.48$ & $3,096.64$ \\
\hline $8 \%$ & 704.18 & 108.85 & 360.60 & 5.63 & $40,183.39$ & $3,086.51$ \\
\hline $9 \%$ & 683.33 & 105.67 & 349.88 & 5.47 & $35,792.92$ & $3,076.37$ \\
\hline $10 \%$ & 664.20 & 102.76 & 340.05 & 5.31 & $32,278.75$ & $3,066.28$ \\
\hline $11 \%$ & 646.57 & 100.07 & 330.98 & 5.17 & $29,402.02$ & $3,056.28$ \\
\hline $12 \%$ & 630.26 & 97.58 & 322.59 & 5.04 & $27,003.48$ & $3,046.40$ \\
\hline $13 \%$ & 615.10 & 95.27 & 314.80 & 4.92 & $24,972.85$ & $3,036.65$ \\
\hline $14 \%$ & 600.96 & 93.11 & 307.53 & 4.81 & $23,231.38$ & $3,027.05$ \\
\hline $15 \%$ & 587.75 & 91.09 & 300.74 & 4.70 & $21,721.28$ & $3,017.60$ \\
\hline
\end{tabular}

Table 3.12 Optimal ordering policies for different values of $r$ and two separate costs when shortages are allowed 


\begin{tabular}{|c|c|c|c|c|c|c|c|}
\hline $\begin{array}{c}\text { Raw } \\
\text { material } \\
\text { cost } \boldsymbol{c}_{\mathbf{1}}, \\
\$ / \mathbf{u n i t}\end{array}$ & $\begin{array}{c}\text { Labor } \\
\text { cost } \boldsymbol{c}_{\mathbf{2}}, \\
\$ / \mathbf{u n i t}\end{array}$ & $\boldsymbol{c}=\boldsymbol{c}_{\mathbf{1}}+\boldsymbol{c}_{\mathbf{2}}$ & $\begin{array}{c}\boldsymbol{Q} \\
\text { (units) }\end{array}$ & $\begin{array}{c}\boldsymbol{S} \\
\text { (units) }\end{array}$ & $\begin{array}{c}\boldsymbol{I}_{\boldsymbol{m a x}} \\
\text { (units) }\end{array}$ & $\begin{array}{c}\boldsymbol{T} \\
\text { (months) }\end{array}$ & $\begin{array}{c}\boldsymbol{P}_{\boldsymbol{t}} \\
\mathbf{( \$ )}\end{array}$ \\
\hline$\$ 0.30$ & $\$ 0.10$ & $\$ 0.40$ & $1,484.50$ & 56.70 & 932.97 & 11.88 & $8,783.61$ \\
\hline$\$ 0.60$ & $\$ 0.20$ & $\$ 0.80$ & $1,068.22$ & 76.94 & 635.21 & 8.55 & $16,775.86$ \\
\hline$\$ 0.90$ & $\$ 0.30$ & $\$ 1.20$ & 885.48 & 90.64 & 499.68 & 7.08 & $24,638.14$ \\
\hline$\$ 1.20$ & $\$ 0.40$ & $\$ 1.60$ & 777.43 & 100.86 & 417.42 & 6.22 & $32,432.48$ \\
\hline$\$ 1.50$ & $\$ 0.50$ & $\$ 2.00$ & 704.18 & 108.85 & 360.60 & 5.63 & $40,183.39$ \\
\hline$\$ 1.80$ & $\$ 0.60$ & $\$ 2.40$ & 650.39 & 115.26 & 318.33 & 5.20 & $47,903.63$ \\
\hline$\$ 2.10$ & $\$ 0.70$ & $\$ 2.80$ & 608.74 & 120.49 & 285.34 & 4.87 & $55,600.88$ \\
\hline$\$ 2.40$ & $\$ 0.80$ & $\$ 3.20$ & 575.26 & 124.81 & 258.70 & 4.60 & $63,280.17$ \\
\hline$\$ 2.70$ & $\$ 0.90$ & $\$ 3.60$ & 547.57 & 128.40 & 236.64 & 4.38 & $70,944.99$ \\
\hline$\$ 3.00$ & $\$ 1.00$ & $\$ 4.00$ & 524.16 & 131.42 & 218.02 & 4.19 & $78,597.90$ \\
\hline$\$ 3.30$ & $\$ 1.10$ & $\$ 4.40$ & 504.02 & 133.95 & 202.06 & 4.03 & $86,240.82$ \\
\hline$\$ 3.60$ & $\$ 1.20$ & $\$ 4.80$ & 486.44 & 136.09 & 188.21 & 3.89 & $93,875.25$ \\
\hline$\$ 3.90$ & $\$ 1.30$ & $\$ 5.20$ & 470.91 & 137.89 & 176.05 & 3.77 & $101,502.35$ \\
\hline$\$ 4.20$ & $\$ 1.40$ & $\$ 5.60$ & 457.05 & 139.41 & 165.29 & 3.66 & $109,123.07$ \\
\hline$\$ 4.50$ & $\$ 1.50$ & $\$ 6.00$ & 444.58 & 140.68 & 155.70 & 3.56 & $116,738.19$ \\
\hline
\end{tabular}

Table 3.13 Optimal ordering policies for simultaneous changes in values of $c_{2}$ and $c_{1}$ when shortages are allowed

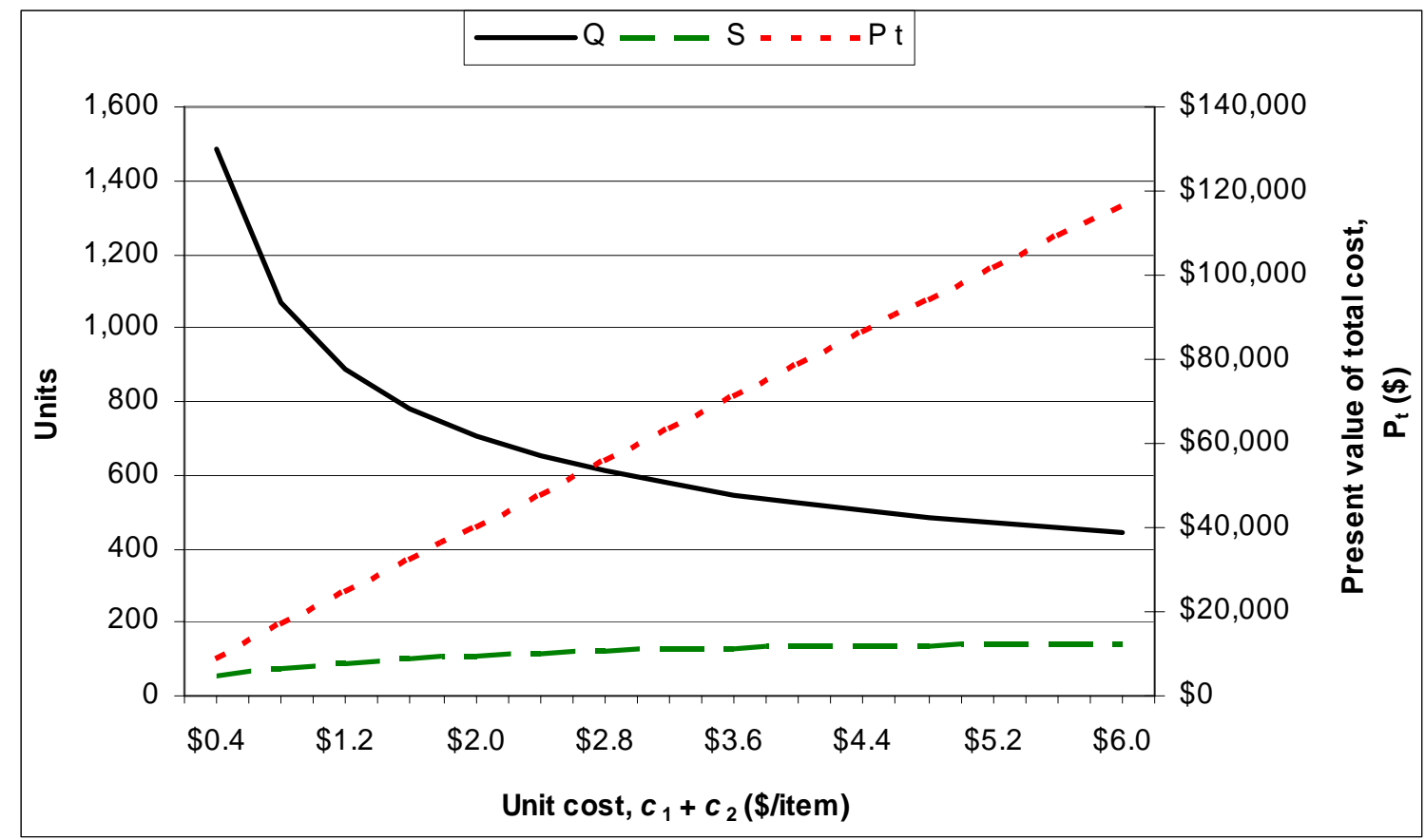

Figure 3.15 Effect of changes in unit $\operatorname{costs} c_{1}$ and $c_{2}$ on ordering quantity $Q$, shortage $S$ and present value of the total $\operatorname{cost} \boldsymbol{P}_{t}$ 


\section{Chapter 4}

\section{EPQ Models with and without Shortages, with Linear Demand and Time Value of Money}

In general, the classical EOQ and EPQ models assume constant demand over an infinite planning horizon. This assumption is valid during the mature phase of the product life cycle and for a finite period of time. In other phases of the product life, demand for the product may increase after its successful introduction into the market or decrease due to, for example, introduction of new competitive products. This chapter considers a linear function for the demand rate over a finite horizon, and develops inventory models for the economic production quantity (EPQ) problem. In many practical cases, items may be out of stock while demand still exists, so models are also considered where shortages are allowed, and items are backordered and used during the following cycle. The objective of this part of this research is to find the optimal inventory cycle time (or quantity of manufactured items), where time value of money is considered and demand is in the form of a linearly increasing function over time for a finite time horizon. Models are developed with and without allowing shortages while using two production cost functions.

In this chapter, models are developed for a finite planning horizon while considering time value of money and linearly increasing demand rate. A search technique is developed to find the optimal policies for these models, and the corresponding costs. 


\subsection{Assumptions}

The general assumptions presented earlier are still valid for the mathematical models developed in this chapter. Additional assumptions are presented below:

1. Replenishment rate is finite and constant during the production time

2. Planning horizon is finite

3. Demand rate is a linear function of time and is always less than the production rate over the planning horizon, i.e.,

$$
D(t)=a+b t, \quad a, b>0 \text { and } 0 \leq t \leq H
$$

\subsection{Inventory Models with no Shortage}

These models are developed for items manufactured and consumed during the same cycle, with a linearly increasing demand over time. They are applied only for a finite planning horizon. Production time for cycle $j, t_{p j}$, would change in every cycle because of the linear change in demand while the cycle time, $T$, is considered to be constant over the planning horizon. The inventory scheme shown in Figure 4.1 is used to develop the details of the model for cycle $j+1$. The inventory on-hand increases with the rate $p-D(t)$, which is the production rate minus consumption rate, until time $t_{p j}$ when the production process stops and the inventory on hand reaches its maximum level. After that point, the inventory level decreases with the consumption rate, $D(t)$, which increases linearly, until it becomes zero at the end of the cycle, $(j+1) T$, when cycle $(j+1)$ starts and the production process is resumed again.

The total cost $T C(T)$ for this EPQ model consists of three elements:

$$
\mathrm{TC}(\mathrm{T})=\text { Setup Cost }+ \text { Production Cost }+ \text { Holding Cost }
$$




\subsubsection{Case 1}

For this case, the setup cost and the production cost are assumed to be incurred at the beginning of each cycle, and the inventory holding cost is incurred continuously during the cycle.

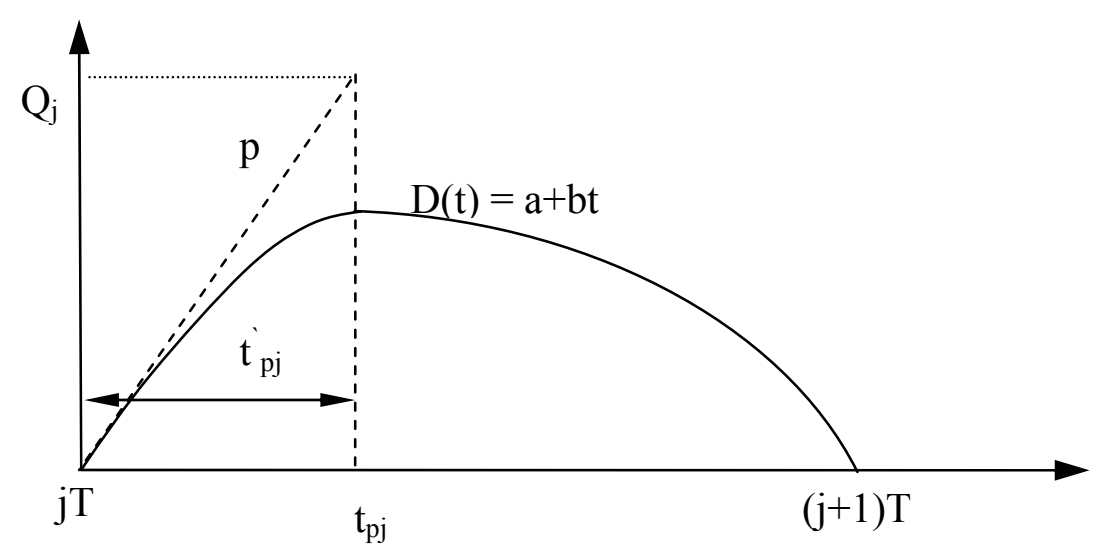

Figure 4.1 EPQ with linearly increasing demand

As in the previous models, time value of money, which is the inflation free or real interest rate, $r$, is represented by the difference between the interest rate and inflation rate:

$$
r=R-f
$$

There are $m$ cycles in the planning horizon. The first cycle starts at time zero, and the last one starts at time $(m-1) T$. Hence, the present value of the total setup cost during the planning horizon is given by:

$$
S C=A \sum_{j=0}^{m-1} e^{-r j T}=A\left(1+e^{-r T}+e^{-2 r T}+\ldots e^{-(m-1) r T}\right)=\frac{A\left(e^{-m r T}-1\right)}{e^{-r T}-1}=\frac{A\left(e^{-r H}-1\right)}{e^{-r \frac{H}{m}}-1}
$$

where $H=m T$.

The present value of production cost is equal to:

$$
P C=c \sum_{j=0}^{m-1} p\left(t_{p j}-j T\right) e^{-r j T}
$$


To find production time, $t_{p j}-j T$, during cycle $j+1$, we equate the total number of items produced during this time to the total number of items consumed during the entire cycle:

$$
p\left(t_{p j}-j T\right)=\int_{j T}^{(j+1) T}(a+b t) d t=a T+b j T^{2}+\frac{b T^{2}}{2}
$$

Substituting Equation (4.3) into (4.2) we get:

$$
\begin{gathered}
P C=c \sum_{j=0}^{m-1}\left(a T+b j T^{2}+\frac{b T^{2}}{2}\right) e^{-r j T}=c a T\left(1+e^{-r T}+e^{-2 r T}+\ldots+e^{-(m-1) r T}\right)+ \\
\frac{c b T^{2}}{2}\left(1+e^{-r T}+e^{-2 r T}+\ldots+e^{-(m-1) r T}\right)+c b T^{2} \sum_{j=0}^{m-1} j e^{-r j T} \\
P C=\frac{c a T\left(e^{-r H}-1\right)}{e^{-r T}-1}+\frac{c b T^{2}\left(e^{-r H}-1\right)}{2\left(e^{-r T}-1\right)}+c b T^{2} \sum_{j=0}^{m-1} j e^{-r j T}
\end{gathered}
$$

To calculate the present value of the holding cost for the planning horizon, first the present value of the holding cost for the $(j+1)$-th cycle $(j=0,1,2, \ldots, m-1))$ needs to be calculated, and then the summation of all $m$ cycles would equal the present value of the total holding cost. The present value of the holding cost during the $(j+1)$-th cycle is calculated as:

$$
H C_{j}=F c \int_{j T}^{t_{p j}} I_{1}(t) e^{-r t} d t+F c \int_{t_{p j}}^{(j+1) T} I_{2}(t) e^{-r t} d t
$$

$I_{1}(t)$, the amount of inventory on hand at time $t$, for the time period starting from the beginning of the cycle, $j T$, till the end of production time, $t_{p j}$, is equal to:

$$
I_{1}(t)=\int_{j T}^{t}(p-a-b \tau) d \tau=p t-a t-\frac{b t^{2}}{2}-p j T+a j T+\frac{b j^{2} T^{2}}{2}
$$

Starting from the end of the production time, $t_{p j}$, till the end of the cycle, $(j+1) T$, the inventory level, $I_{2}(t)$, at time $t$ is equal to: 


$$
I_{2}(t)=\int_{t}^{(j+1) T}(a+b \tau) d \tau=a j T+a T+\frac{b j^{2} T^{2}}{2}+b j T^{2}+\frac{b T^{2}}{2}-a t-\frac{b t^{2}}{2}
$$

Substituting Equations (4.6) and (4.7) into (4.5), integrating it by parts and simplifying, we get:

$$
\begin{aligned}
H C_{j}= & F c\left\{\left(\frac{a T}{r}+\frac{b T^{2}}{2 r}-\frac{p}{r^{2}}\right) e^{-r t_{p j}}+\left(\frac{b T^{2}}{r}+\frac{p T}{r}\right) j e^{-r t_{p j}}-\frac{p t_{p j}}{r} e^{-r t_{p j}}+\frac{b T}{r^{2}}\left(e^{-r T}-1\right) j e^{-r j T}+\right. \\
& {\left.\left[\frac{\left(e^{-r T}-1\right)\left(a+\frac{b}{r}\right)+b T e^{-r T}+p}{r^{2}}\right] e^{-r j T}\right\} }
\end{aligned}
$$

From Equation (4.3), the value of $t_{p j}$ is defined as:

$$
t_{p j}=j T+\frac{a T}{p}+\frac{b j T^{2}}{p}+\frac{b T^{2}}{2 p}
$$

Substituting this value in Equation (4.8), and after some simplifications we get:

$$
\begin{aligned}
H C_{j}= & F c\left\{-\frac{p e^{\frac{-r T}{2 p}(2 a+b T)}}{r^{2}} e^{-r j T\left(1+\frac{b T}{p}\right)}+\left[\frac{\left(e^{-r T}-1\right)\left(a+\frac{b}{r}\right)+b T e^{-r T}+p}{r^{2}}\right] e^{-r j T}+\right. \\
& \left.\frac{b T}{r^{2}}\left(e^{-r T}-1\right) \sum_{j=0}^{m-1} j e^{-r j T}\right\}
\end{aligned}
$$

The present value of holding cost for $m$ cycles during the planning horizon is:

$$
H C=\sum_{j=0}^{m-1} H C_{j}
$$

Since:

$$
1+e^{x}+e^{2 x}+\ldots+e^{(n-1) x}=\frac{e^{n x}-1}{e^{x}-1}
$$


The present value of the total cost, $H C$, in Equation (4.11) can be written, after some simplifications, as:

$$
\begin{aligned}
& H C=F c\left\{\frac{\left[\left(e^{-r T}-1\right)\left(a+\frac{b}{r}\right)+b T e^{-r T}+p\right]\left(e^{-m r T}-1\right)}{r^{2}\left(e^{-r T}-1\right)}-\frac{p e^{\frac{-r T}{2 p}(2 a+b T)}\left(e^{-m r T\left(1+\frac{b T}{p}\right)}-1\right)}{r^{2}\left(e^{-r T\left(1+\frac{b T}{p}\right)}-1\right)}+\right. \\
&\left.\frac{b T}{r^{2}}\left(e^{-r T}-1\right) \sum_{j=0}^{m-1} j e^{-r j T}\right\}
\end{aligned}
$$

Now, combining all the inventory costs into one equation, using $H=m T$, and after some simplifications, we get the following function for the present value of the total cost:

$$
\begin{aligned}
& T C=\frac{\left(2 A m^{2}+2 c a H m+c b H^{2}\right)\left(e^{-r H}-1\right)}{2 m^{2}\left(e^{-r \frac{H}{m}}-1\right)}-\frac{F c p e^{-r \frac{H}{2 p m^{2}}(2 a m+b H)}\left(e^{-r \frac{H}{p m}(p m+b H)}-1\right)}{r^{2}\left(e^{-r \frac{H}{p m^{2}}(p m+b H)}-1\right)}+ \\
& \frac{F c\left[\left(e^{-r \frac{H}{m}}-1\right)\left(a+\frac{b}{r}\right) m+b H e^{-r \frac{H}{m}}+p m\right]\left(e^{-r H}-1\right)}{m r^{2}\left(e^{-r \frac{H}{m}}-1\right)}+ \\
& \frac{H c b}{m^{2} r^{2}}\left[H r^{2}+F m\left(e^{-r \frac{H}{m}}-1\right)\right] \sum_{j=0}^{m-1} j e^{-r j \frac{H}{m}}
\end{aligned}
$$

This total cost is a function of $m$, which is a discrete variable. To find the optimal value of $m$ when the total cost function is convex, the Golden Search technique (Bazaraa and Shetty, 1979) can be used. However, the search has to be slightly modified to work with discrete values. At the first iteration, $k=1$, the initial interval $\left[a_{k}, b_{k}\right]$ for the variable $m$ is identified as $[1, m$ '], where $m$ ' is the maximum value of $m$ as defined by the user. The values of $\lambda_{k}=a_{k}+(1-\alpha)\left(b_{k}-\right.$ 
$\left.a_{k}\right)$ and $\mu_{k}=a_{k}+\alpha\left(b_{k}-a_{k}\right)$ are then calculated, where $\alpha=0.618$. The total costs at points $\lambda_{k}$ and $\mu_{k}$ are evaluated. If $T C\left(\lambda_{k}\right)>T C\left(\mu_{k}\right)$, then the new interval becomes $\left[a_{k+1}, b_{k+1}\right]$, where $a_{k+1}$ $=\lambda_{k}$ and $b_{k+1}=b_{k}$. Furthermore, $\lambda_{k+1}=\mu_{k}$ and $\mu_{k+1}=a_{k+1}+\alpha\left(b_{k+1}-a_{k+1}\right)$. Only the total cost for $\mu_{k+1}$ has to be calculated since the total cost for $\lambda_{k+1}$ is the same as for $\mu_{k}$. If $T C\left(\lambda_{k}\right)<T C\left(\mu_{k}\right)$, then the new interval is $\left[a_{k+1}, b_{k+1}\right]$, where $a_{k+1}=a_{k}$ and $b_{k+1}=\mu_{k} ; \mu_{k+1}=\lambda_{k}$ and $\lambda_{k+1}=a_{k+1}+$ $(1-\alpha)\left(b_{k+1}-a_{k+1}\right)$. In this case, only the total cost for $\lambda_{k+1}$ has to be calculated since the total cost for $\mu_{k+1}$ is the same as for $\lambda_{k}$. After evaluating the total costs, $k$ is replaced by $k+1$ and the procedure is repeated until a stopping criterion is met. A typical stopping criterion is when $\left(b_{k}-a_{k}\right)<l$, where $l>0$ is the allowable accuracy; then the procedure stops and the optimal solution lies in the interval $\left[a_{k}, b_{k}\right]$.

Following this procedure with a discrete variable $m$, and working with integer values of $\lambda$ and $\mu$, the optimal value of $m$ and the corresponding total cost can be obtained when the accuracy level, $l$, is equal to one.

\subsubsection{Case 2}

In the second case, the production cost, $c$, has two components. A cost, $c_{1}$, that is incurred at the beginning of each cycle and is applied to the total quantity produced during the production time, and. a second cost, $c_{2}$, which is incurred as the production process takes place.

The total cost for this model consists of the same three elements as in the first model:

$$
\mathrm{TC}(\mathrm{T})=\text { Setup Cost }+ \text { Production Cost }+ \text { Holding Cost }
$$

The only differences between the two cases are in the production cost and holding cost. The present value of the production cost of the system during the planning horizon is now defined as follows: 


$$
P C=c_{1} p \sum_{j=0}^{m-1}\left(t_{p j}-j T\right) e^{-r j T}+c_{2} p \sum_{j=0}^{m-1} \int_{j T}^{t_{p j}} e^{-r t} d t
$$

After integration and substituting expression for $t_{p j}$ from Equation (4.3) we get:

$$
P C=\frac{c_{1} a T\left(e^{-r H}-1\right)}{e^{-r T}-1}+\frac{c_{1} b T^{2}\left(e^{-r H}-1\right)}{2\left(e^{-r T}-1\right)}+c_{1} b T^{2} \sum_{j=0}^{m-1} j e^{-r j T}+\frac{c_{2} p}{r} \sum_{j=0}^{m-1}\left(e^{-r j T}-e^{-r\left(j T+\frac{a T}{p}+\frac{b j T^{2}}{p}+\frac{b T^{2}}{2 p}\right)}\right)
$$

The procedure followed in Case 1 is repeated and the following function is obtained for the present value of the production cost for the entire planning horizon:

$$
\begin{aligned}
P C= & \frac{\left(2 c_{1} a T r+c_{1} b T^{2} r+2 c_{2} p\right)\left(e^{-m r T}-1\right)}{2 r\left(e^{-r T}-1\right)}-\frac{c_{2} p e^{-r \frac{T}{p}\left(a+\frac{b T}{2}\right)}\left(e^{-m r T\left(1+\frac{b T}{p}\right)}-1\right)}{r\left(e^{-r T\left(1+\frac{b T}{p}\right)}-1\right)}+ \\
& c_{1} b T^{2} \sum_{j=0}^{m-1} j e^{-r j T}
\end{aligned}
$$

The present value of the holding cost of the system during the planning horizon is defined

as:

$$
\begin{aligned}
& H C=F\left(c_{1}+c_{2}\right)\left\{\frac{\left[\left(e^{-r T}-1\right)\left(a+\frac{b}{r}\right)+b T e^{-r T}+p\right]\left(e^{-m r T}-1\right)}{r^{2}\left(e^{-r T}-1\right)}-\frac{p e^{\frac{-r T}{2 p}(2 a+b T)}\left(e^{-m r T\left(1+\frac{b T}{p}\right)}-1\right)}{r^{2}\left(e^{-r T\left(1+\frac{b T}{p}\right)}-1\right)}+\right. \\
&\left.\frac{b T}{r^{2}}\left(e^{-r T}-1\right) \sum_{j=0}^{m-1} j e^{-r j T}\right\}
\end{aligned}
$$

Adding all inventory costs and using $H=m T$, we get the following present value of the total cost for the entire planning horizon: 


$$
\begin{aligned}
T C= & \frac{\left(2 r A m^{2}+2 c_{1} a H r m+c_{1} b H^{2} r+2 c_{2} p m^{2}\right)\left(e^{-r H}-1\right)}{2 r m^{2}\left(e^{-r \frac{H}{m}}-1\right)}- \\
& \frac{p e^{-r \frac{H}{2 p m^{2}}(2 a m+b H)}\left(e^{-r \frac{H}{p m}(p m+b H)}-1\right)\left(c_{2} r+F c_{1}+F c_{2}\right)}{r^{2}\left(e^{-r \frac{H}{p m^{2}}(p m+b H)}-1\right)}+ \\
& \frac{F\left(c_{1}+c_{2}\right)\left[\left(e^{-r \frac{H}{m}}-1\right)\left(a+\frac{b}{r}\right) m+b H e^{-r \frac{H}{m}}+p m\right]\left(e^{-r H}-1\right)}{m r^{2}\left(e^{-r \frac{H}{m}}-1\right)}+ \\
& \frac{b H}{m^{2} r^{2}}\left[H c_{1} r^{2}+F m\left(c_{1}+c_{2}\right)\left(e^{-r \frac{H}{m}}-1\right)\right] \sum_{j=0}^{m-1} j e^{-r j \frac{H}{m}}
\end{aligned}
$$

Similar to Case 1, the above total inventory cost is a function of $m$, and the Golden Search technique can be used to find the minimum total inventory cost. The corresponding $m$ would be the optimal number of equal length cycles during the planning horizon.

\subsection{Convexity of the Total Cost Function}

To show that the total cost function has no local minima, so the search technique would indeed find the optimal point, a similar inventory model was developed without considering the time value of money. This was done for simplicity, and with the assumption that the time value of money does not affect the convexity of the total cost function. Otherwise, the equations become too cumbersome, and the proof becomes very hard. 
Considering each of the three cost components, the setup cost is paid at the beginning of each cycle, for $m$ cycles during planning horizon, hence:

$$
S C=m A
$$

Since there is no time value of money, the production cost for all cycles is simply equal to:

$$
P C=c \int_{0}^{m T}(a+b t) d t=c a H+\frac{c b H^{2}}{2}
$$

where $H=m T$

The holding cost for cycle $(j+1)$ is equal to:

$$
H C_{j}=F c \int_{j T}^{t_{p j}} I_{1}(t) d t+F c \int_{t_{p j}}^{(j+1) T} I_{2}(t) d t
$$

The expressions for inventory on hand, $I_{1}(t)$ and $I_{2}(t)$, were presented in Equations (4.6) and (4.7). Substituting them into Equation (4.18), using the value $t_{p j}$ from Equation (4.9), and after some simplifications, we get:

$$
H C_{j}=F c\left\{j^{2}\left(-\frac{b^{2} T^{4}}{2 p}\right)+j\left(\frac{b T^{3}}{2}-\frac{a b T^{3}}{p}-\frac{b^{2} T^{4}}{2 p}\right)+\frac{a T^{2}}{2}-\frac{b^{2} T^{4}}{8 p}-\frac{a^{2} T^{2}}{2 p}+\frac{b T^{3}}{3}-\frac{a b T^{3}}{2 p}\right\}
$$

For simplicity, the following variables are defined:

$$
S_{1}=-\frac{b^{2} T^{4}}{2 p}, \quad S_{2}=\frac{b T^{3}}{2}-\frac{a b T^{3}}{p}-\frac{b^{2} T^{4}}{2 p}, \quad S_{3}=\frac{a T^{2}}{2}-\frac{b^{2} T^{4}}{8 p}-\frac{a^{2} T^{2}}{2 p}+\frac{b T^{3}}{3}-\frac{a b T^{3}}{2 p}
$$

Equation (4.18) can then be written as follows:

$$
H C_{j}=F c\left(S_{1} j^{2}+S_{2} j+S_{3}\right)
$$

The holding cost for $m$ cycles during the planning horizon is the summation of Equation (4.20) for the $m$ cycles: 


$$
\begin{aligned}
& H C=\sum_{j=0}^{m-1} H C_{j}=F c\left\{S_{1}\left[1+2^{2}+3^{2}+\ldots+(m-1)^{2}\right]+S_{2}[1+2+3+\ldots+(m-1)]+m S_{3}\right\}= \\
& F_{c}\left\{\frac{m(m-1)(2 m-1)}{6} S_{1}+\frac{m(m-1)}{2} S_{2}+m S_{3}\right\}
\end{aligned}
$$

Hence, adding all inventory costs and substituting back the values of $S_{1}, S_{2}$ and $S_{3}$ and simplifying, the total inventory cost during the entire planning horizon is equal to:

$$
\begin{aligned}
T C= & \frac{F c b^{2} H}{24 p} T^{3}+\frac{F c b H}{12} T^{2}-\frac{F c b^{2} H^{3}}{6 p} T+\frac{F c b H^{2}}{4} T-\frac{F c a b H^{2}}{2 p} T+\frac{F c a H}{2} T-\frac{F c a^{2} H}{2 p} T+ \\
& \frac{H A}{T}+c a H+\frac{c b H^{2}}{2}
\end{aligned}
$$

The feasible region for this function is on the positive side of the $T$ axis. The total cost function consists of two parts: a third order polynomial, and an inverse function. In general, the third order polynomial function is represented as follows:

$$
Y=A X^{3}+B X^{2}+C X+D
$$

The graph of this function can have different shapes, depending on the values of the coefficients $A, B, C$, and $D$ (Bronshtein and Semendyaev, 1980). If $A>0$, then $Y \rightarrow+\infty$ when $X$ $\rightarrow+\infty$, and $Y \rightarrow-\infty$ when $X \rightarrow-\infty$. If $A<0$, then $Y \rightarrow-\infty$ when $X \rightarrow+\infty$, and $Y \rightarrow+\infty$ when $X \rightarrow-\infty$. It is clear from the total cost function that the coefficients $A$ and $B$ have positive values. Hence the polynomial function either has two extreme points, one maximum and one minimum, or does not have any at all. If there are no extreme points, the point of deflection would have the coordinates $\left(-\frac{B}{3 A}, \frac{2 B^{2}-9 A B C}{27 A^{2}}+D\right)$, i.e. on the negative side of $T$. After that point, the slope of the function increases. After $T=0$, with the increase of $T$, the rate of increase of the polynomial function gets larger, while the rate of decrease of the inverse function gets 
smaller. This condition leads to only one minimum point for the $T C$ function on the positive side of $T$. Figure 4.2 gives a representation of these functions.

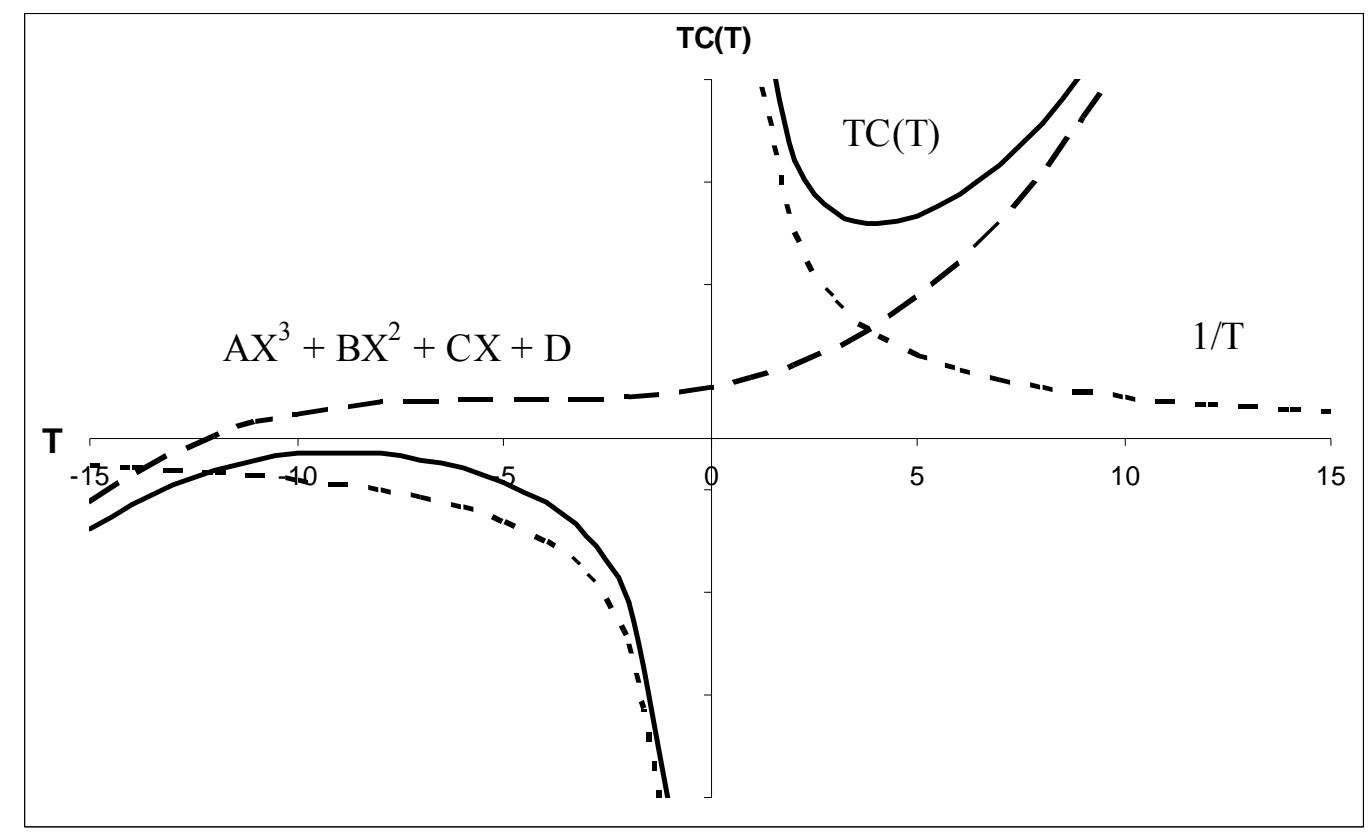

\section{Figure 4.2 Shape of the TC function and its components when the polynomial function has no extremes}

If the polynomial function has two extreme values, and $A>0$, then $\Delta=B^{2}-3 A C>0$, and the maximum would be at point $\frac{-B-\sqrt{\Delta}}{3 A}$ and the minimum at $\frac{-B+\sqrt{\Delta}}{3 A}$. Since $\mathrm{B}$ has a positive value, the maximum point will always be on the negative side of $T$. Depending on the value of $C$ (positive or negative), the minimum point can be either on the positive or the negative side of $T$. In the case when both extremes are on the negative side, the shape of the $T C$ function after $T=0$ is similar to the case when there is no extreme points in the polynomial part of the function (see Figure 4.2). When the extreme points are on both sides of $T=0$, both the polynomial and inverse functions decrease, when $T>0$, as $T$ increases up to a certain point when the polynomial function starts increasing while the inverse function keeps on decreasing. However, the rate of increase of the polynomial function gets larger while the rate of decrease of 
the inverse function continues to get smaller. At some point both rates become equal and that is the point where the $T C$ function has its minimum point. Figure 4.3 illustrates this case.

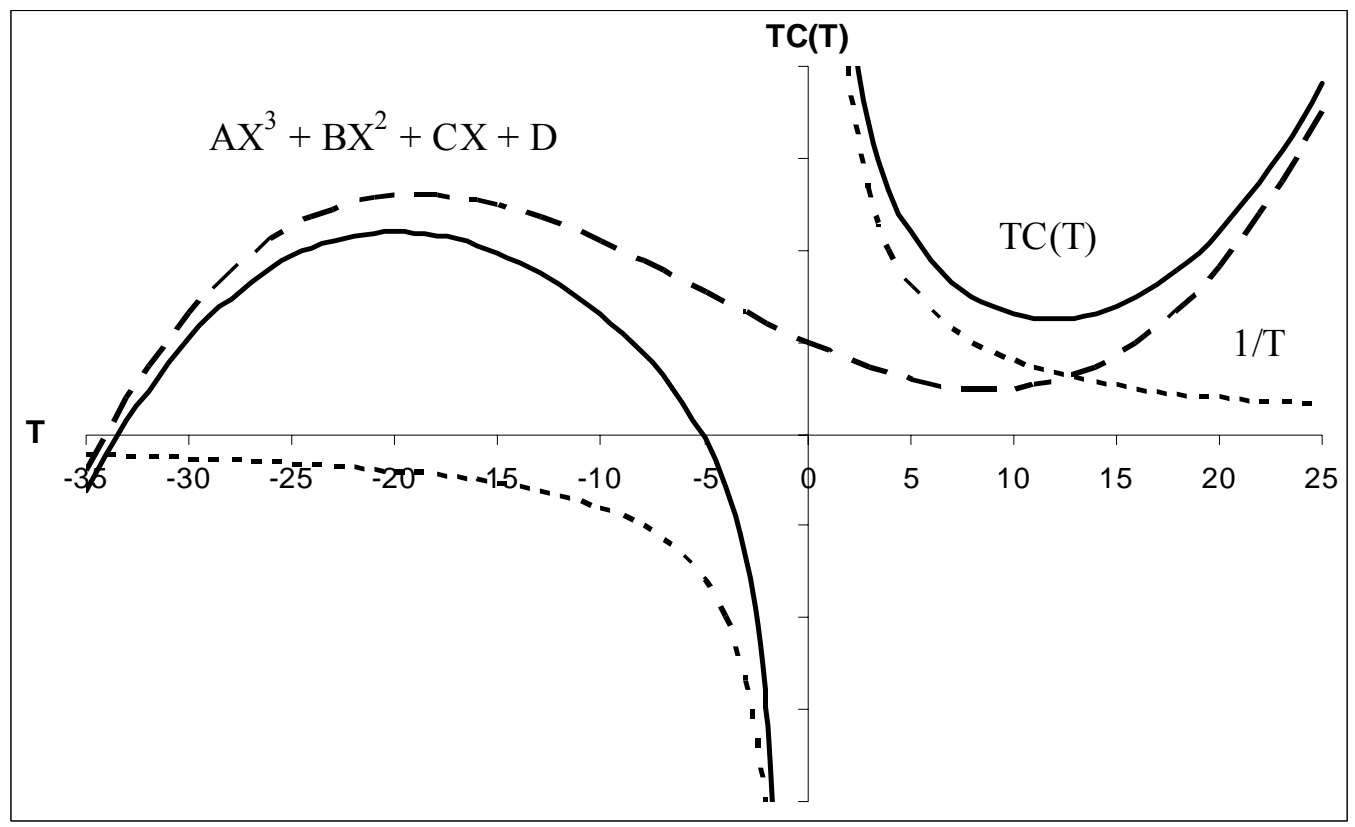

Figure 4.3 Shape of the TC function and its components when the polynomial function has two extremes

Hence, in all cases, the total cost function will always have one unique minimum point on the positive side of the $T$ axis; i.e. the function is convex.

Consequently, the Golden Search technique will always find the optimal policy and there is no need for complete enumeration.

\subsection{Numerical Example and Sensitivity Analysis}

A numerical example is presented to illustrate the application of the models developed. Consider an inventory system with a linear increasing rate of demand and the following data:

$$
p=4500 \text { units } / \mathrm{yr}, a=1500 \text { units } / \mathrm{yr}, b=300 \text { units/yr/yr, } A=50 \$ / \text { order, } F=0.15 \$ / \$ / \mathrm{yr},
$$
$c=2 \$ /$ unit, $H=5$ yrs. 
A software was developed with Visual Basic Applications to apply the Golden Search technique and find the optimal policies for the models developed. The model was applied for Case 1, using different values for the real interest rate, and the results obtained are summarized in Table 4.1.

\begin{tabular}{|c|c|c|c|}
\hline $\begin{array}{c}\text { Real interest rate } \boldsymbol{r} \\
\mathbf{( \% )}\end{array}$ & $\boldsymbol{m}$ & $\begin{array}{c}\boldsymbol{T} \\
\text { (months) }\end{array}$ & $\begin{array}{c}\boldsymbol{P}_{\boldsymbol{t}} \\
\mathbf{( \$ )}\end{array}$ \\
\hline $0 \%$ & 9 & 6.67 & $23,413.18$ \\
\hline $1 \%$ & 10 & 6.00 & $22,835.65$ \\
\hline $2 \%$ & 10 & 6.00 & $22,274.35$ \\
\hline $3 \%$ & 11 & 5.46 & $21,727.28$ \\
\hline $4 \%$ & 11 & 5.46 & $21,197.02$ \\
\hline $5 \%$ & 12 & 5.00 & $20,680.66$ \\
\hline $6 \%$ & 12 & 5.00 & $20,180.39$ \\
\hline $7 \%$ & 13 & 4.62 & $19,694.13$ \\
\hline $8 \%$ & 13 & 4.62 & $19,222.56$ \\
\hline $9 \%$ & 14 & 4.29 & $18,765.29$ \\
\hline $10 \%$ & 14 & 4.29 & $18,321.01$ \\
\hline $11 \%$ & 14 & 4.29 & $17,890.91$ \\
\hline $12 \%$ & 15 & 4.00 & $17,472.97$ \\
\hline $13 \%$ & 15 & 4.00 & $17,067.82$ \\
\hline $14 \%$ & 15 & 4.00 & $16,675.47$ \\
\hline $15 \%$ & 16 & 3.75 & $16,293.91$ \\
\hline
\end{tabular}

Table 4.1 Optimal ordering policies for different values of $\boldsymbol{r}$

As expected, the increase in real interest rate leads to a smaller cycle time, larger number of inventory cycles, and reduction in the present value of the total cost of the system. For $r=0 \%$, Equation (4.22), which was developed with no time value of money, was used to find the optimal policy.

The tables and figures presented below represent the relations between parameters and the optimal policies. Increases in inventory carrying rate, $F$, slope of the demand, $b$, or production cost, $c$, make the cycle time smaller, but lead to an increase in the total cost of the system. On the other hand, an increase in the setup cost, $A$, leads to an increase in the cycle time, 
decrease in the number of cycles during the planning horizon, and an increase in the total cost of the system.

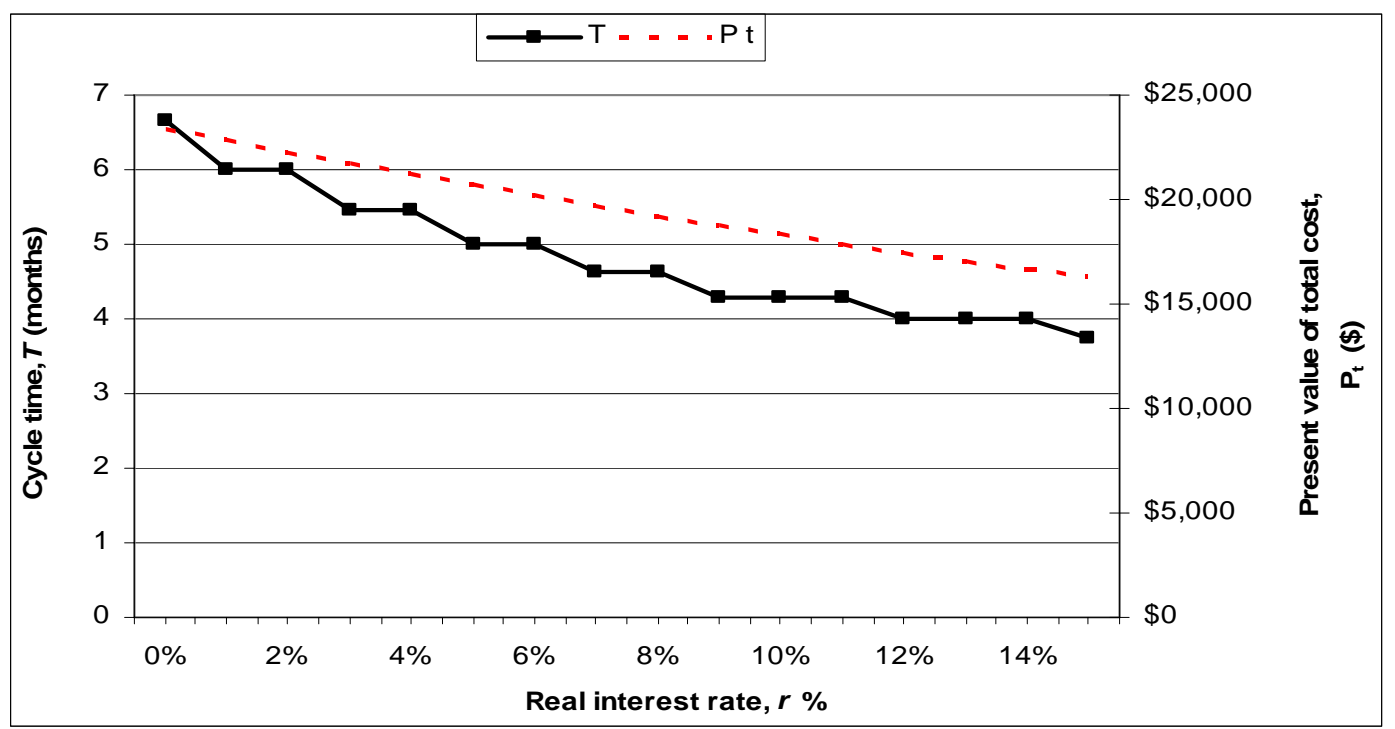

Figure 4.4 Effect of real interest rate $r$ on cycle time $T$ and present value of the total cost $P_{t}$

\begin{tabular}{|c|c|c|c|}
\hline $\begin{array}{c}\text { Carrying rate } \boldsymbol{F} \\
\text { (\%) }\end{array}$ & $\boldsymbol{m}$ & $\begin{array}{c}\boldsymbol{T} \\
\text { (months) }\end{array}$ & $\begin{array}{c}\boldsymbol{P}_{\boldsymbol{t}} \\
\mathbf{( \$ )}\end{array}$ \\
\hline $3 \%$ & 10 & 6.00 & $18,991.71$ \\
\hline $4 \%$ & 11 & 5.45 & $19,013.15$ \\
\hline $5 \%$ & 11 & 5.45 & $19,033.88$ \\
\hline $6 \%$ & 11 & 5.45 & $19,054.60$ \\
\hline $7 \%$ & 11 & 5.45 & $19,075.32$ \\
\hline $8 \%$ & 12 & 5.00 & $19,094.81$ \\
\hline $9 \%$ & 12 & 5.00 & $19,113.78$ \\
\hline $10 \%$ & 12 & 5.00 & $19,132.74$ \\
\hline $11 \%$ & 12 & 5.00 & $19,151.70$ \\
\hline $12 \%$ & 13 & 4.62 & $19,170.12$ \\
\hline $13 \%$ & 13 & 4.62 & $19,187.60$ \\
\hline $14 \%$ & 13 & 4.62 & $19,205.08$ \\
\hline $15 \%$ & 13 & 4.62 & $19,222.56$ \\
\hline $16 \%$ & 13 & 4.62 & $19,240.03$ \\
\hline $17 \%$ & 14 & 4.29 & $19,256.67$ \\
\hline $18 \%$ & 14 & 4.29 & $19,272.88$ \\
\hline $19 \%$ & 14 & 4.29 & $19,289.09$ \\
\hline
\end{tabular}

Table 4.2 Optimal ordering policies for different values of $F$ 


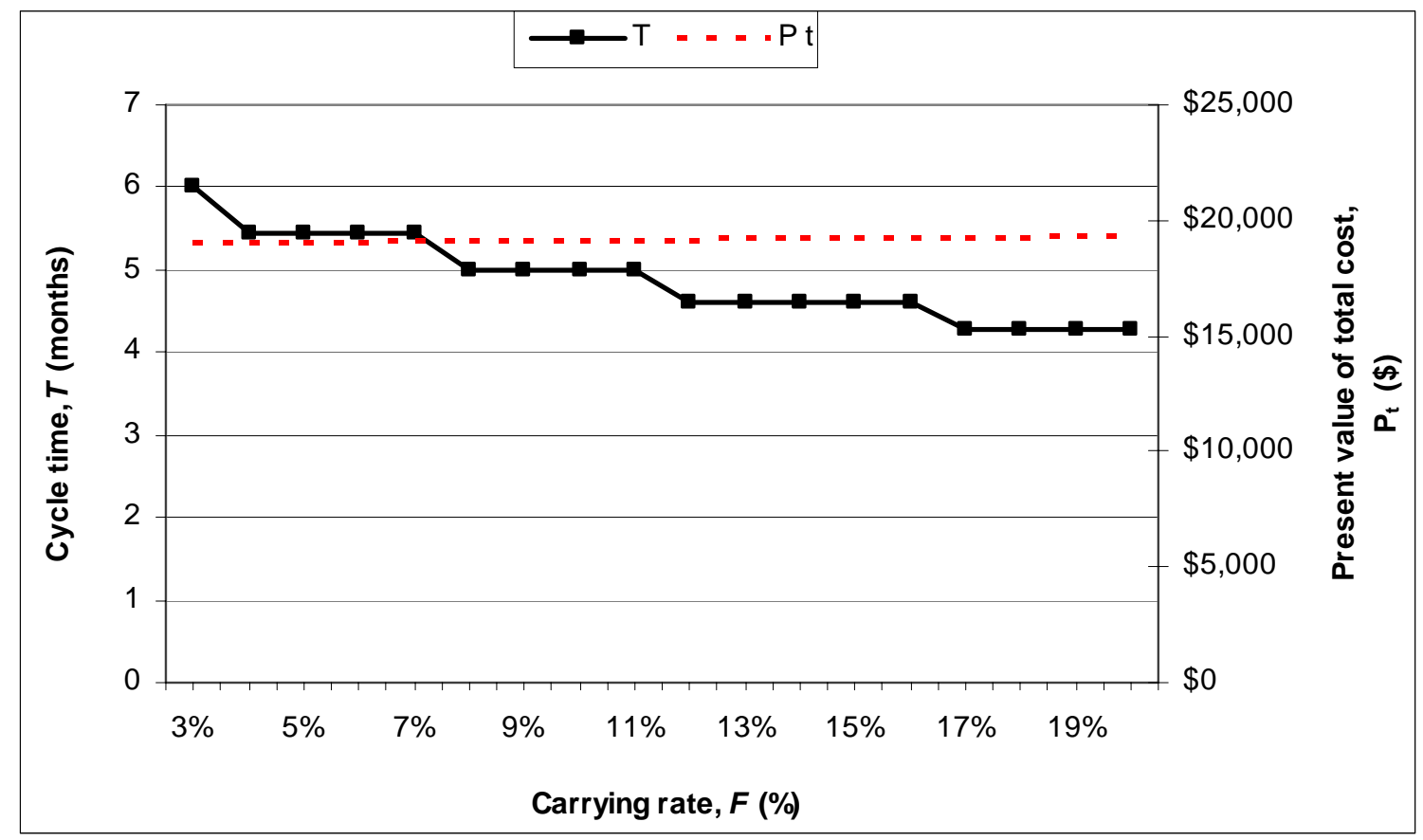

Figure 4.5 Effect of carrying rate $F$ on cycle time $T$ and present value of the total $\operatorname{cost} \boldsymbol{P}_{t}$

\begin{tabular}{|c|c|c|c|}
\hline $\begin{array}{c}\text { Demand rate } \\
\text { slope } \boldsymbol{b} \\
\text { (units/time/time) }\end{array}$ & $\boldsymbol{m}$ & $\begin{array}{c}\boldsymbol{T} \\
\text { (months) }\end{array}$ & $\begin{array}{c}\boldsymbol{P}_{\boldsymbol{t}} \\
\mathbf{( \$ )}\end{array}$ \\
\hline 50 & 12 & 5.00 & $14,319.17$ \\
\hline 100 & 12 & 5.00 & $15,305.15$ \\
\hline 150 & 13 & 4.62 & $16,288.38$ \\
\hline 200 & 13 & 4.62 & $17,268.42$ \\
\hline 250 & 13 & 4.62 & $18,246.48$ \\
\hline 300 & 13 & 4.62 & $19,222.56$ \\
\hline 350 & 13 & 4.62 & $20,196.65$ \\
\hline 400 & 14 & 4.29 & $21,168.69$ \\
\hline 450 & 14 & 4.29 & $22,138.16$ \\
\hline
\end{tabular}

Table 4.3 Optimal ordering policies for different values of $\boldsymbol{b}$ 


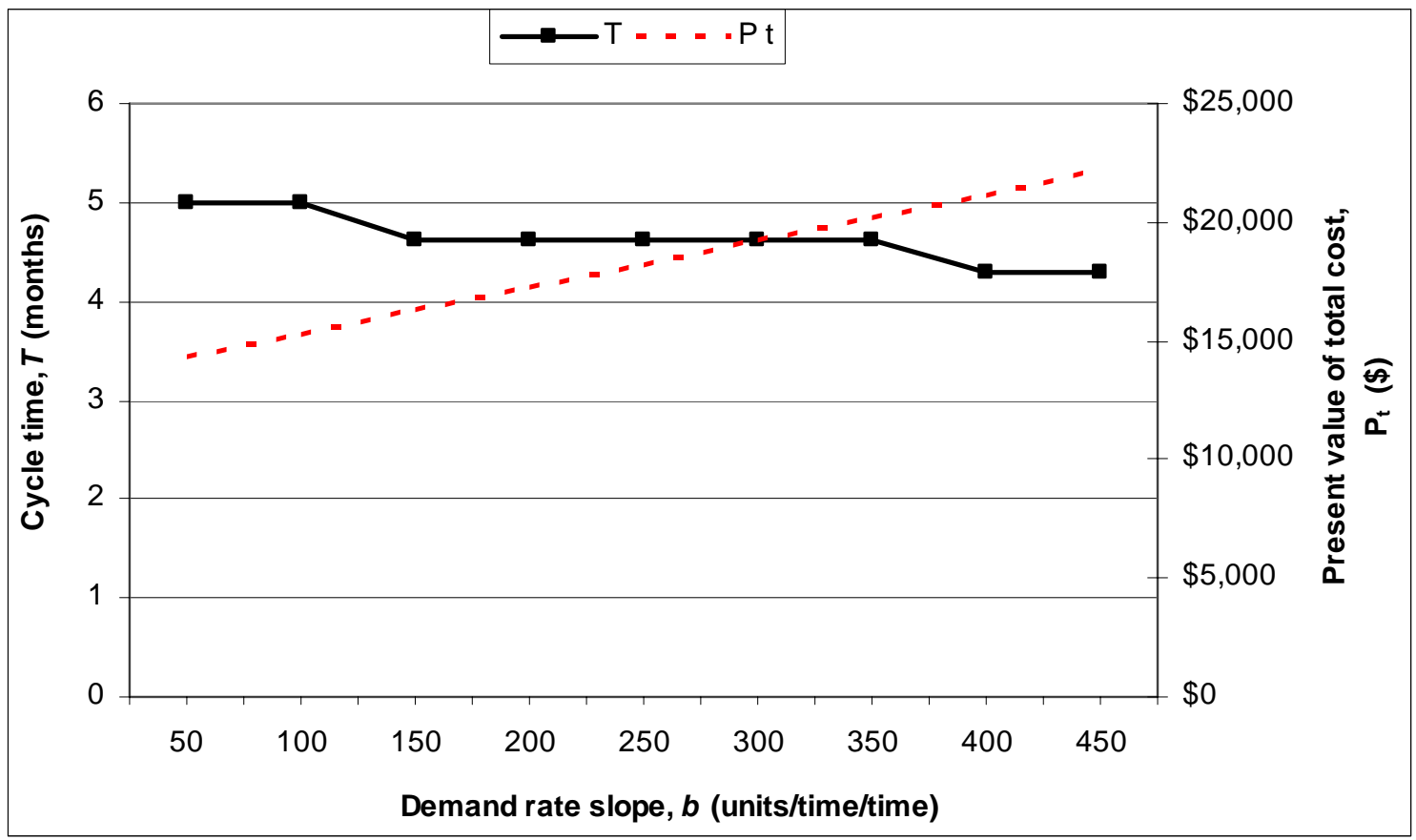

Figure 4.6 Effect of demand rate slope $b$ on cycle time $T$ and present value of the total $\operatorname{cost} \boldsymbol{P}_{\boldsymbol{t}}$

\begin{tabular}{|c|c|c|c|}
\hline $\begin{array}{c}\text { Setup cost } \boldsymbol{A} \\
\text { (\$/order) }\end{array}$ & $\boldsymbol{m}$ & $\begin{array}{c}\boldsymbol{T} \\
\text { (months) }\end{array}$ & $\begin{array}{c}\boldsymbol{P}_{\boldsymbol{t}} \\
\mathbf{( \$ )}\end{array}$ \\
\hline$\$ 10$ & 29 & 2.07 & $18,616.37$ \\
\hline$\$ 20$ & 21 & 2.86 & $18,818.34$ \\
\hline$\$ 30$ & 17 & 3.53 & $18,974.05$ \\
\hline$\$ 40$ & 15 & 4.00 & $19,106.01$ \\
\hline$\$ 50$ & 13 & 4.62 & $19,222.56$ \\
\hline$\$ 60$ & 12 & 5.00 & $19,328.11$ \\
\hline$\$ 70$ & 11 & 5.45 & $19,425.75$ \\
\hline$\$ 80$ & 11 & 5.45 & $19,518.07$ \\
\hline$\$ 90$ & 10 & 6.00 & $19,602.16$ \\
\hline$\$ 100$ & 9 & 6.67 & $19,684.75$ \\
\hline$\$ 110$ & 9 & 6.67 & $19,760.59$ \\
\hline$\$ 120$ & 9 & 6.67 & $19,836.43$ \\
\hline$\$ 130$ & 8 & 7.50 & $19,906.82$ \\
\hline$\$ 140$ & 8 & 7.50 & $19,974.42$ \\
\hline$\$ 150$ & 8 & 7.5 & $20,042.02$ \\
\hline$\$ 160$ & 7 & 8.57 & $20,109.36$ \\
\hline & & & \\
\hline
\end{tabular}

Table 4.4 Optimal ordering policies for different values of $\boldsymbol{A}$ 


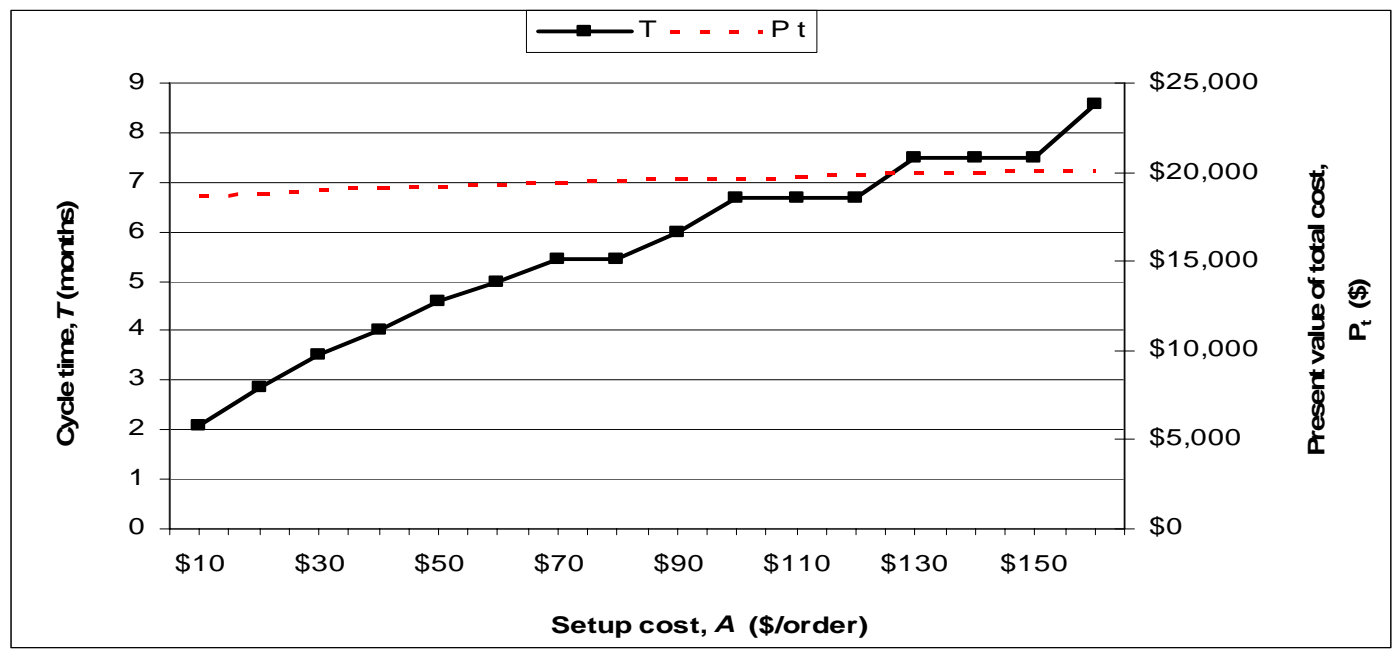

Figure 4.7 Effect of setup cost $A$ on cycle time $T$ and present value of the total cost $P_{t}$

For Case 2, the same example was used with the same parameters, but the production cost, $c$, was replaced with a raw material $\cos t c_{1}=1.5 \$ /$ unit, and a labor cost $c_{2}=0.5 \$$ unit. Results are summarized in Table 4.5.

\begin{tabular}{|c|c|c|c|}
\hline $\begin{array}{c}\text { Real interest rate } \boldsymbol{r} \\
\mathbf{( \% )}\end{array}$ & $\boldsymbol{m}$ & $\begin{array}{c}\boldsymbol{T} \\
\text { (months) }\end{array}$ & $\begin{array}{c}\boldsymbol{T C} \\
\mathbf{( \$ )}\end{array}$ \\
\hline $0 \%$ & 9 & 6.67 & $23,413.18$ \\
\hline $1 \%$ & 10 & 6.00 & $22,828.57$ \\
\hline $2 \%$ & 10 & 6.00 & $22,260.58$ \\
\hline $3 \%$ & 11 & 5.46 & $21,709.03$ \\
\hline $4 \%$ & 11 & 5.46 & $21,173.36$ \\
\hline $5 \%$ & 12 & 5.00 & $20,654.32$ \\
\hline $6 \%$ & 12 & 5.00 & $20,149.65$ \\
\hline $7 \%$ & 12 & 5.00 & $19,661.33$ \\
\hline $8 \%$ & 13 & 4.62 & $19,186.79$ \\
\hline $9 \%$ & 13 & 4.62 & $18,726.95$ \\
\hline $10 \%$ & 14 & 4.29 & $18,281.75$ \\
\hline $11 \%$ & 14 & 4.29 & $17,848.87$ \\
\hline $12 \%$ & 14 & 4.29 & $17,429.83$ \\
\hline $13 \%$ & 15 & 4.00 & $17,023.92$ \\
\hline $14 \%$ & 15 & 4.00 & $16,629.44$ \\
\hline $15 \%$ & 15 & 4.00 & $16,247.44$ \\
\hline & & &
\end{tabular}

Table 4.5 Optimal ordering policies for different values of $r$ and two separate costs 
As in Case 1, the cycle time decreases as the real interest rate increases. The effects of all other parameters on the optimal policy are similar to Case 1 and are not repeated here.

The results of simultaneous changes in unit costs $c_{1}$ and $c_{2}$ are summarized in Table 4.6 and their graphical representation is illustrated in Figure 4.8.

\begin{tabular}{|c|c|c|c|c|c|}
\hline $\begin{array}{c}\text { Raw material cost } \boldsymbol{c}_{\mathbf{1}}, \\
\text { \$/unit }\end{array}$ & $\begin{array}{c}\text { Labor cost } \boldsymbol{c}_{\mathbf{2}}, \\
\mathbf{\$} / \mathbf{u n i t}\end{array}$ & $\boldsymbol{c}=\boldsymbol{c}_{\mathbf{1}}+\boldsymbol{c}_{\mathbf{2}}$ & $\boldsymbol{m}$ & $\begin{array}{c}\boldsymbol{T} \\
\text { (months) }\end{array}$ & $\begin{array}{c}\boldsymbol{P}_{\boldsymbol{t}} \\
\mathbf{( \$ )}\end{array}$ \\
\hline$\$ 0.30$ & $\$ 0.10$ & $\$ 0.40$ & 10 & 6.00 & $4,107.23$ \\
\hline$\$ 0.60$ & $\$ 0.20$ & $\$ 0.80$ & 8 & 7.50 & $7,925.82$ \\
\hline$\$ 0.90$ & $\$ 0.30$ & $\$ 1.20$ & 10 & 6.00 & $11,699.68$ \\
\hline$\$ 1.20$ & $\$ 0.40$ & $\$ 1.60$ & 11 & 5.45 & $15,451.33$ \\
\hline$\$ 1.50$ & $\$ 0.50$ & $\$ 2.00$ & 13 & 4.62 & $19,186.79$ \\
\hline$\$ 1.80$ & $\$ 0.60$ & $\$ 2.40$ & 14 & 4.29 & $22,912.24$ \\
\hline$\$ 2.10$ & $\$ 0.70$ & $\$ 2.80$ & 15 & 4.00 & $26,629.91$ \\
\hline$\$ 2.40$ & $\$ 0.80$ & $\$ 3.20$ & 16 & 3.75 & $30,341.27$ \\
\hline$\$ 2.70$ & $\$ 0.90$ & $\$ 3.60$ & 17 & 3.53 & $34,047.46$ \\
\hline$\$ 3.00$ & $\$ 1.00$ & $\$ 4.00$ & 18 & 3.33 & $37,749.35$ \\
\hline$\$ 3.30$ & $\$ 1.10$ & $\$ 4.40$ & 19 & 3.16 & $41,447.62$ \\
\hline$\$ 3.60$ & $\$ 1.20$ & $\$ 4.80$ & 20 & 3.00 & $45,142.82$ \\
\hline$\$ 3.90$ & $\$ 1.30$ & $\$ 5.20$ & 20 & 3.00 & $48,835.35$ \\
\hline$\$ 4.20$ & $\$ 1.40$ & $\$ 5.60$ & 21 & 2.86 & $52,524.76$ \\
\hline$\$ 4.50$ & $\$ 1.50$ & $\$ 6.00$ & 22 & 2.73 & $56,212.19$ \\
\hline
\end{tabular}

Table 4.6 Optimal ordering policies for different values of $c_{1}$ and $c_{2}$

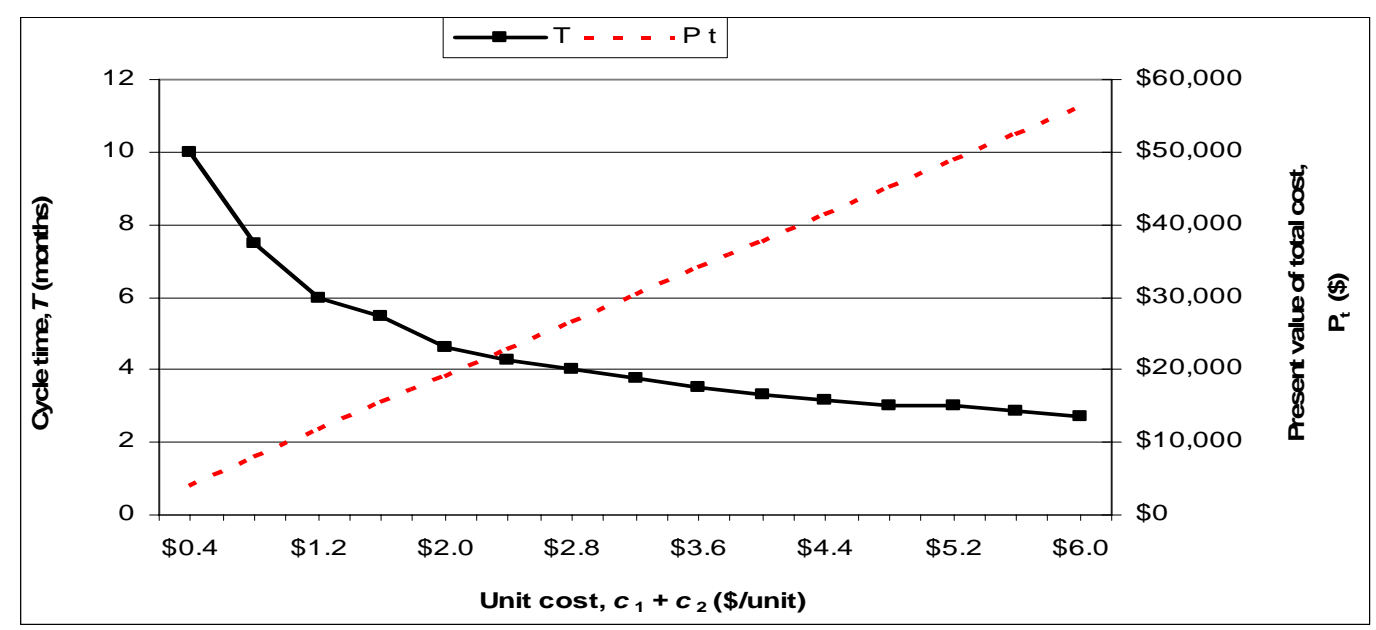

Figure 4.8 Effect of changes in unit $\operatorname{costs} c_{1}$ and $c_{2}$ on cycle time $T$ and present value of the total $\operatorname{cost} \boldsymbol{P}_{t}$ 


\subsection{Inventory Models with Shortage}

The objective of the inventory models where shortage is allowed is to determine the optimal cycle time and the optimal quantity of allowed shortage in order to minimize the total relevant cost. Consequently, the production time and the maximum inventory level can be determined.

The models are applied for items manufactured, and consumed with a linearly increasing demand. They apply only for a finite planning horizon. The inventory scheme shown in Figure 4.9 is used to develop the details of the system.

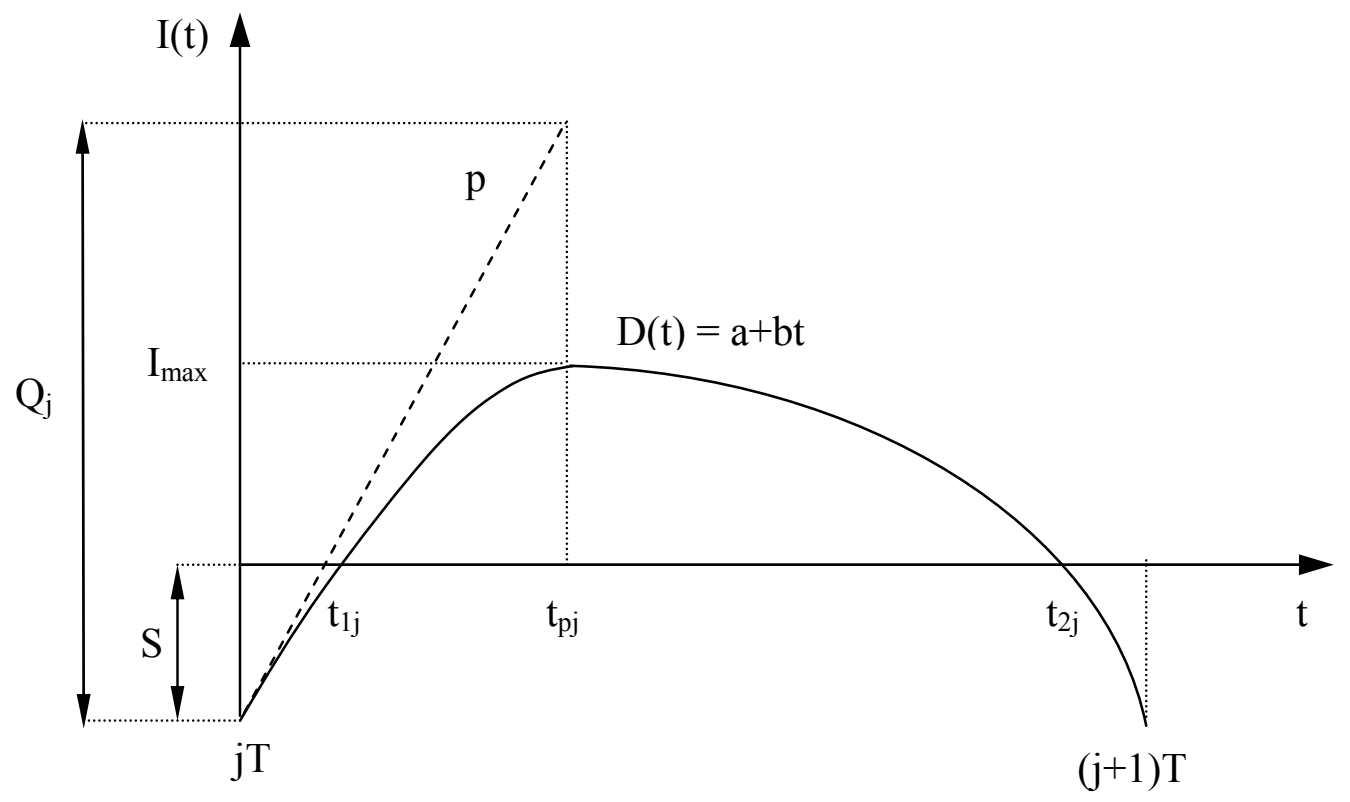

Figure 4.9 EPQ with linearly increasing demand and shortage

For cycle $j+1$, production starts at time $j T$, and the negative inventory increases with the rate $p-D(t)$, until time $t_{1 j}$ of each cycle. After $t_{1 j}$, the inventory continues to increase with the same rate and the inventory on hand starts building up until time $t_{p j}$, when the production process stops and the inventory on hand reaches its maximum level. After that point, the inventory level decreases with the consumption rate, $D(t)$, until it becomes zero at time $t_{2 j}$. After $t_{2 j}$, the system is 
out of stock but the demand still exists and the system continues to receive orders until the end of the cycle, $(j+1) T$, when the production process resumes again. Production time, $t_{p j}-j T$, for cycle $j+1$ would change from cycle to cycle because of the linear change in demand, while the cycle time of each cycle, $T$, and amount of shortage, $S$, allowed during the cycle are assumed to be constant over the planning horizon.

The total cost $T C$ for this EPQ model consists of four elements:

$$
\mathrm{TC}=\text { Setup Cost }+ \text { Production Cost }+ \text { Holding Cost }+ \text { Shortage Cost }
$$

\subsubsection{Case 3}

For this case, the setup cost and the production cost are assumed to be incurred at the beginning of each cycle, and the inventory holding cost is incurred continuously during the time period from $t_{1 j}$ to $t_{2 j}$. A shortage cost is also incurred and is addressed below.

The present value for the total setup cost during the planning horizon and the present value of the total production cost are the same as in the model without shortage and are given by:

$$
S C=A \sum_{j=0}^{m-1} e^{-r j T}=\frac{A\left(e^{-r H}-1\right)}{e^{-r \frac{H}{m}}-1}
$$

where $H=m T$, and:

$$
P C=c \sum_{j=0}^{m-1} p\left(t_{p j}-j T\right) e^{-r j T}=\frac{c a T\left(e^{-r H}-1\right)}{e^{-r T}-1}+\frac{c b T^{2}\left(e^{-r H}-1\right)}{2\left(e^{-r T}-1\right)}+c b T^{2} \sum_{j=0}^{m-1} j e^{-r j T}
$$

The production time, $t_{p j}-j T$, was calculated earlier for the models without shortage and it remains the same for the models with shortage as well. Time $t_{1 j}$, when inventory on hand becomes zero during the production period, can be derived from the following equation:

$$
S=p\left(t_{1 j}-j T\right)-\int_{j T}^{t_{1 j}}(a+b t) d t
$$


Integrating and solving the resulting quadratic equation for $t_{1 j}$, we get two possible solutions:

$$
t_{1 j}=\frac{p-a}{b} \pm \frac{1}{b} \sqrt{(p-a)^{2}-2 j T b(p-a)+b\left(j^{2} T^{2} b-2 S\right)}
$$

To determine the sign in front of the square root, the first cycle $(j=0)$ is considered:

$$
t_{10}=\frac{p-a}{b} \pm \frac{1}{b} \sqrt{(p-a)^{2}-2 b S}
$$

According to the assumptions of the model, the production rate is always greater than the demand rate during the entire planning horizon, including time $t_{1}$. Hence, $p>a+b t_{10}$, which means that $t_{10}<\frac{p-a}{b}$ and the unique solution for Equations (4.26) and (4.27) has a negative sign for the square root. Since it is true for $j=0$, it will also be true for all $j=0,1,2, \ldots, m-1$. Hence, the final equation for time $t_{1 j}$ is:

$$
t_{1 j}=\frac{p-a}{b}-\frac{1}{b} \sqrt{(p-a)^{2}-2 j T b(p-a)+b\left(j^{2} T^{2} b-2 S\right)}
$$

Time $t_{2 j}$, when the inventory level reaches zero during the consumption period, can be obtained from the following expression:

$$
S=\int_{t_{2 j}}^{(j+1) T}(a+b t) d t
$$

Integrating and solving the resulting quadratic equation for $t_{2 j}$, we get the following solution:

$$
t_{2 j}=-\frac{a}{b}+\sqrt{\frac{a^{2}}{b^{2}}+\frac{2 a T(j+1)}{b}+T^{2}(j+1)^{2}-\frac{2 S}{b}}
$$


To calculate the holding cost for the planning horizon, the present value of the holding cost for the $(j+1)$-th cycle $(j=0,1,2, \ldots, m-1)$ is calculated, and then summed for all $m$ cycles. The present value of the holding cost during the $(j+1)$-th cycle is calculated as:

$$
H C_{j}=F c \int_{t_{1 j}}^{t_{p j}} I_{1}(t) e^{-r t} d t+F c \int_{t_{p j}}^{t_{2 j}} I_{2}(t) e^{-r t} d t
$$

$I_{1}(t)$, the amount of inventory on hand at time $t$, for the time between $t_{1 j}$ and $t_{p j}$ is equal to:

$$
I_{1}(t)=\int_{t_{1 j}}^{t}(p-a-b \tau) d \tau=p t-a t-\frac{b t^{2}}{2}-p t_{1 j}+a t_{1 j}+\frac{b t_{1 j}{ }^{2}}{2}
$$

Starting from the end of the production time, $t_{p j}$, till $t_{2 j}$ when the on-hand inventory becomes zero, the inventory level, $I_{2}(t)$, at time $t$ is equal to:

$$
I_{2}(t)=\int_{t}^{t_{2 j}}(a+b \tau) d \tau=a t_{2 j}+\frac{b t_{2 j}{ }^{2}}{2}-a t-\frac{b t^{2}}{2}
$$

Substituting Equations (4.32) and (4.33) into (4.31), integrating by parts and simplifying, we get:

$$
\begin{aligned}
H C_{j}= & \frac{F c}{r}\left[e^{-r t_{p j}}\left(a t_{2 j}+\frac{b t_{2 j}{ }^{2}}{2}+p t_{1 j}-a t_{1 j}-\frac{b t_{1 j}{ }^{2}}{2}-p t_{p j}-\frac{p}{r}\right)+\right. \\
& \left.\frac{e^{-r t_{2 j}}}{r}\left(a+b t_{2 j}+\frac{b}{r}\right)+\frac{e^{-r t_{1 j}}}{r}\left(p-a-b t_{1 j}-\frac{b}{r}\right)\right]
\end{aligned}
$$

The present value of the holding cost for all cycles during the planning horizon is the summation of Equation (4.34):

$$
H C=\sum_{j=0}^{m-1} H C_{j}
$$

The shortage cost is obtained following a similar procedure. Assuming that the shortage cost during cycle $j+1$ consists of two components: $K_{0}$ times the maximum amount of shortage, 
$S$, which is incurred at the beginning of the cycle, and $K$ times duration of the shortage, for each unit short, and is incurred during the shortage time of the individual units, the present value of the shortage cost for the $(j+1)$-th cycle $(j=0,1,2, \ldots, m-1)$ is calculated as:

$$
B C_{j}=K \int_{j T}^{t_{1 j}}\left|I_{3}(t)\right| e^{-r t} d t+K \int_{t_{2 j}}^{(j+1) T}\left|I_{4}(t)\right| e^{-r t} d t+K_{0} S e^{-r j T}
$$

$I_{3}(t)$ for time between the beginning of the cycle, $j T$, till time $t_{1 j}$ is given by:

$$
\left|I_{3}(t)\right|=S-\int_{j T}^{t}(p-a-b \tau) d \tau=S-p t+a t+\frac{b t^{2}}{2}+p j T-a j T-\frac{b j^{2} T^{2}}{2}
$$

Starting from time $t_{2 j}$ till the end of the inventory cycle, $(j+1) T$, the inventory level, $I_{4}(t)$, at time $t$ is given by:

$$
\left|I_{4}(t)\right|=S-\int_{t}^{(j+1) T}(a+b \tau) d \tau=S-a j T-a T-\frac{b j^{2} T^{2}}{2}-b j T^{2}-\frac{b T^{2}}{2}+a t+\frac{b t^{2}}{2}
$$

Substituting Equations (4.37) and (4.38) into (4.36), integrating by parts, and simplifying, we get:

$$
\begin{aligned}
B C_{j}= & \frac{K}{r}\left[e^{-r t_{1 j}}\left(-S-p j T+a j T+\frac{b j^{2} T^{2}}{2}-a t_{1 j}-\frac{a}{r}+p t_{1 j}+\frac{p}{r}-\frac{b t_{1 j}{ }^{2}}{2}-\frac{b t_{1 j}}{r}-\frac{b}{r^{2}}\right)+\right. \\
& e^{-r t_{2 j}}\left(-a j T-a T-\frac{b j^{2} T^{2}}{2}-b j T^{2}-\frac{b T^{2}}{2}+a t_{2 j}+\frac{a}{r}+\frac{b t_{2 j}{ }^{2}}{2}+\frac{b t_{2 j}}{r}+\frac{b}{r^{2}}+S\right)+ \\
& \left.e^{-r j T}\left(S+\frac{a}{r}-\frac{p}{r}+\frac{b j T}{r}+\frac{b}{r^{2}}-\frac{a e^{-r T}}{r}-\frac{b T(j+1) e^{-r T}}{r}-\frac{b e^{-r T}}{r^{2}}-S e^{-r T}\right)\right]+K_{0} S e^{-r j T}
\end{aligned}
$$

The present value of holding cost for all cycles during the planning horizon is the summation of Equation (4.39):

$$
B C=\sum_{j=0}^{m-1} B C_{j}
$$


The present value of the total cost function is the sum of all the cost components:

$$
T C=S C+P C+H C+B C
$$

Using $H=m T$, the total inventory cost becomes a function of $m$, which is a discrete variable, and $S$. Assuming the total cost to be a convex function, simple search techniques may be used to find the optimal policy. Since $m$ is an integer and $S$ is continuous, the Golden Search technique needs to be modified and used to find the optimal policy. The search procedure needs to be performed twice. For each $m$ used in the first search, the optimal value of $S$ is found in the second search, which gives the minimum total cost corresponding to $m$. At the first iteration, $k=$ 1 , the initial interval $\left[a_{k}, b_{k}\right]$ for variable $m$ is identified as $\left[1, m^{\prime}\right]$, where $m^{`}$ is the maximum value of $m$ as defined by the user. Then the values of $\lambda_{m k}=a_{k}+(1-\alpha)\left(b_{k}-a_{k}\right)$ and $\mu_{m k}=a_{k}+$ $\alpha\left(b_{k}-a_{k}\right)$ are calculated, where $\alpha=0.618$. Next, for each of the points $\lambda_{m k}$ and $\mu_{m k}$, the initial interval $\left[a_{2 k}, b_{2 k}\right]$ for variable $S$ is identified as $\left[0, S^{\prime}\right]$, where $S^{`}$ is maximum value of $S$ as defined by the user. The corresponding $\lambda_{s k}$ and $\mu_{s k}$ are calculated and a second Golden Search procedure is performed to find the minimum total cost for each of $\lambda_{m k}$ and $\mu_{m k}$. The first Golden Search procedure is then continued by comparing the minimum total costs obtained for $\lambda_{m k}$ and $\mu_{m k}$. A new interval $\left[a_{k+1}, b_{k+1}\right]$ is then selected for variable $m$ and the corresponding $\lambda_{m k+1}$ and $\mu_{m k+1}$ are calculated. The second Golden Search is then invoked. This double search is continued until the stopping criteria are met.

During the search procedure, one important detail needs to be noted. In the process of selecting the initial intervals $\left[a_{2 k}, b_{2 k}\right]$ for variable $S$, a specific requirement has to be considered. Since the models have a linearly increasing rate of demand, as the demand increases in the later cycles, time $t_{1 j}-j T$ increases and gets closer to the production time, $t_{p j}-j T$, which means that the inventory on hand gets smaller. If the value of $S$ is too large, a situation may arise where the 
production during the cycle may not be enough to satisfy the shortage. To avoid this situation, the following restriction may be added, using the last cycle (the most critical cycle in this case):

$$
S<\int_{(m-1) T}^{t_{p, m-1}}(p-a-b t) d t
$$

From equation (4.3), we have:

$$
t_{p, m-1}-(m-1) T=\frac{1}{p} \int_{(m-1) T}^{m T}(a+b t) d t=\frac{a T}{p}+\frac{m b T^{2}}{p}-\frac{b T^{2}}{2 p}
$$

Hence,

$$
t_{p, m-1}=H\left(1-\frac{1}{m}+\frac{a}{p m}+\frac{b H}{p m}-\frac{b H}{2 p m^{2}}\right)
$$

Substituting Equation (4.42) into Equation (4.41) we get the following inequality:

$$
S<\frac{a H}{m}\left(1-\frac{a}{p}\right)-b H^{2}\left(\frac{a}{p m}-\frac{a}{2 p m^{2}}-\frac{1}{2}\right)-\frac{b H^{2}}{2}\left(1-\frac{1}{m}+\frac{a}{p m}+\frac{b H}{p m}-\frac{b H}{2 p m^{2}}\right)^{2}
$$

This condition should be considered when the initial interval $\left[a_{2 k}, b_{2 k}\right]$ for variable $S$ is determined. For each $k$ in the modified Golden Search, the maximum value allowed for $S$ has to be calculated from Equation (4.43) and should not be exceeded when defining the initial interval $\left[a_{2 k}, b_{2 k}\right]$

The models developed are too complex to prove the convexity of the total cost function. However, a complete enumeration for the values of $m$ and an exhaustive search technique were applied for the intervals specified for variables $m$ and $S$ and the results obtained were always the same as those obtained using the modified Golden Search procedure. 


\subsubsection{Case 4}

In this case, as in the models without shortage, the production cost, $c$, has two components. A cost, $c_{1}$, which is incurred at the beginning of each cycle and is applied to the total quantity produced during the production period and a second cost, $c_{2}$, is incurred as the production process takes place.

The total cost for this model consists of the same four elements as in Case 3. The main difference between the two cases is in the production cost. However, the production cost for this model is the same as for the model where shortages are not allowed. This cost is given in Equation (4.14). Also for the holding cost, the unit production cost, $c$, used in Case 3 is replaced with the sum of two cost components, $c_{1}$ and $c_{2}$ :

$$
\begin{aligned}
H C_{j}= & \frac{F\left(c_{1}+c_{2}\right)}{r}\left[e^{-r t_{p j}}\left(a t_{2 j}+\frac{b t_{2 j}{ }^{2}}{2}+p t_{1 j}-a t_{1 j}-\frac{b t_{1 j}{ }^{2}}{2}-p t_{p j}-\frac{p}{r}\right)+\right. \\
& \left.\frac{e^{-r t_{2 j}}}{r}\left(a+b t_{2 j}+\frac{b}{r}\right)+\frac{e^{-r t_{1 j}}}{r}\left(p-a-b t_{1 j}-\frac{b}{r}\right)\right]
\end{aligned}
$$

As in Case 3, the present value of total cost function is the summation of the all cost components:

$$
T C=S C+P C+H C+B C
$$

Similar to Case 3, the total inventory cost is a function of $m$ and $S$ and the modified Golden Search procedure used in Case 3 is used here to find the minimum total inventory cost and the corresponding policy. 


\subsection{Numerical Example and Sensitivity Analysis}

A numerical example is presented to illustrate the application of the inventory models developed for cases with shortage. A software was developed with Visual Basic Applications to apply the modified Golden Search procedure. Consider an inventory system with a linear increasing rate of demand and the following data:

$$
p=4500 \text { units } / \mathrm{yr}, a=1500 \text { units } / \mathrm{yr}, b=300 \text { units } / \mathrm{yr}, A=50 \$ / \text { order, } F=0.15 \$ / \$ / \mathrm{yr},
$$
$c=2 \$ /$ unit, $H=5$ yrs.

The model was applied for Case 3, using different values of real interest rate, and the results obtained are summarized in Table 4.7.

\begin{tabular}{|c|c|c|c|c|}
\hline $\begin{array}{c}\text { Real interest rate } \boldsymbol{r} \\
\mathbf{( \% )}\end{array}$ & $\boldsymbol{m}$ & $\begin{array}{c}\boldsymbol{T} \\
\text { (months) }\end{array}$ & $\begin{array}{c}\boldsymbol{S} \\
\text { (units) }\end{array}$ & $\begin{array}{c}\boldsymbol{P}_{\boldsymbol{m}, \boldsymbol{S}} \\
\mathbf{( \$ )}\end{array}$ \\
\hline $1 \%$ & 9 & 6.67 & 143.65 & $22,734.09$ \\
\hline $2 \%$ & 9 & 6.67 & 143.66 & $22,181.33$ \\
\hline $3 \%$ & 10 & 6.00 & 128.84 & $21,641.32$ \\
\hline $4 \%$ & 11 & 5.45 & 116.80 & $21,117.52$ \\
\hline $5 \%$ & 11 & 5.45 & 116.80 & $20,606.26$ \\
\hline $6 \%$ & 12 & 5.00 & 106.81 & $20,111.10$ \\
\hline $7 \%$ & 12 & 5.00 & 106.81 & $19,628.54$ \\
\hline $8 \%$ & 12 & 5.00 & 106.81 & $19,161.45$ \\
\hline $9 \%$ & 13 & 4.62 & 98.39 & $18,706.60$ \\
\hline $10 \%$ & 13 & 4.62 & 98.40 & $18,266.06$ \\
\hline $11 \%$ & 14 & 4.29 & 91.21 & $17,838.23$ \\
\hline $12 \%$ & 14 & 4.29 & 91.21 & $17,422.97$ \\
\hline $13 \%$ & 14 & 4.29 & 91.21 & $17,020.85$ \\
\hline $14 \%$ & 15 & 4.00 & 85.00 & $16,629.58$ \\
\hline $15 \%$ & 15 & 4.00 & 85.00 & $16,250.58$ \\
\hline & & & \multicolumn{2}{|c}{} \\
\hline
\end{tabular}

Table 4.7 Optimal ordering policies for different values of $r$ for the models with shortages

As expected, the increase in real interest rate leads to a smaller cycle time, larger number of inventory cycles, smaller value for shortage, and reduction in the present value of the total cost of the system. The total costs for the system were also smaller than the corresponding ones 
in the system with no shortage (Table 4.1), which is expected. As in the model without shortages, increases in inventory carrying rate, $F$, slope of the demand, $b$, or production cost, $c$, shorten the cycle time and lead to increase in the total cost of the system. Increases in inventory carrying rate, $F$, lead to an increase in the value of $S$ within the same number of cycles. Also, as in the no shortage models, an increase in the setup cost, $A$, leads to an increase in the cycle time, a decrease in the number of cycles during the planning horizon, an increase in the value of $S$, and an increase in the total cost of the system. Increase in the slope of the demand, $b$, first increases the value of $S$ and then it decreases it back, again within the same number of cycles. The results in Table 4.10 do not show this behavior, but further calculations showed that the shortage $S$ follows this pattern when the number of cycles remains the same. The following tables and figures show the results obtained and the effect of the individual parameters on the optimal policies.

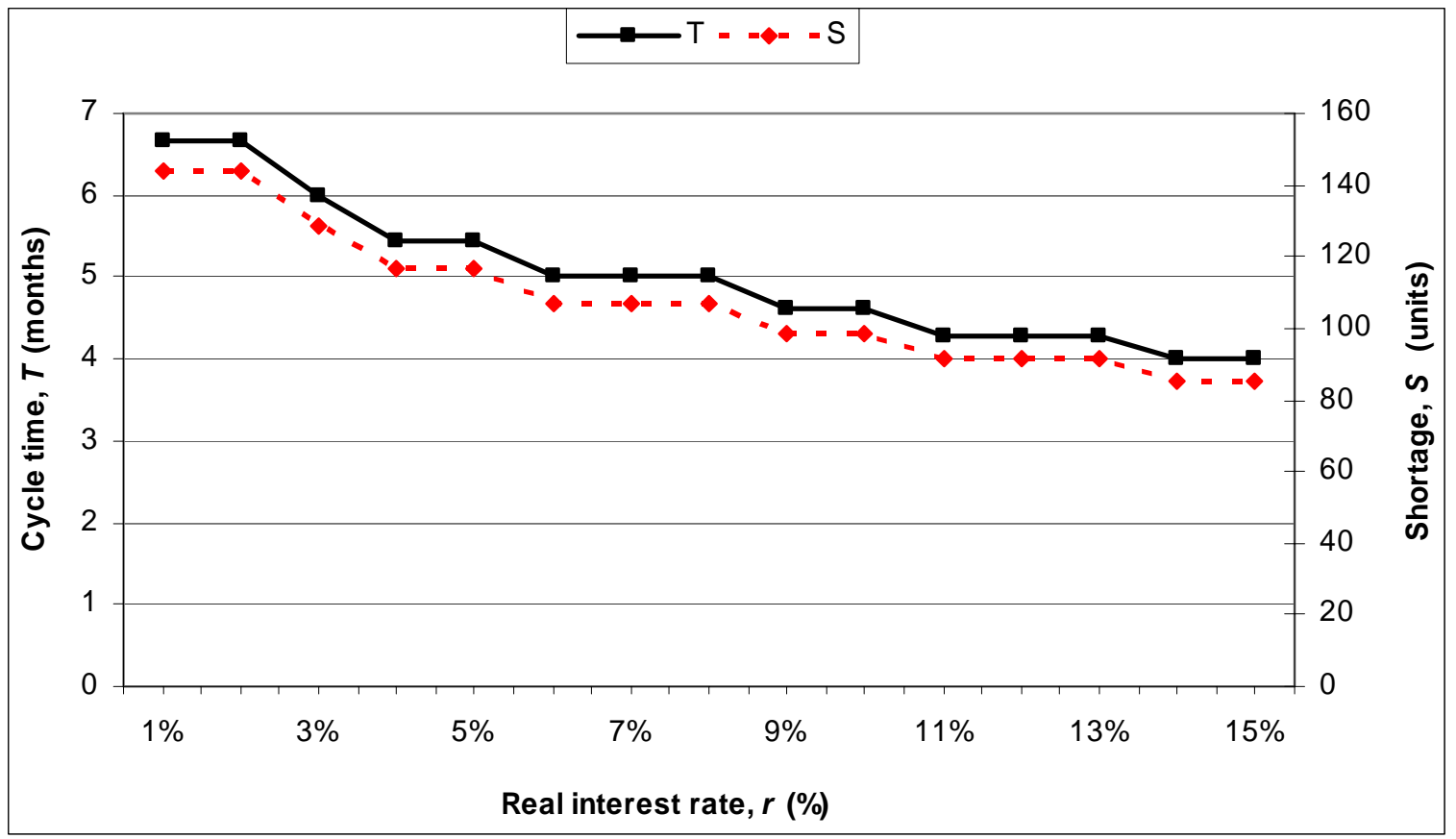

Figure 4.10 Effect of real interest rate $\boldsymbol{r}$ on cycle time $\boldsymbol{T}$ and shortage $S$ 


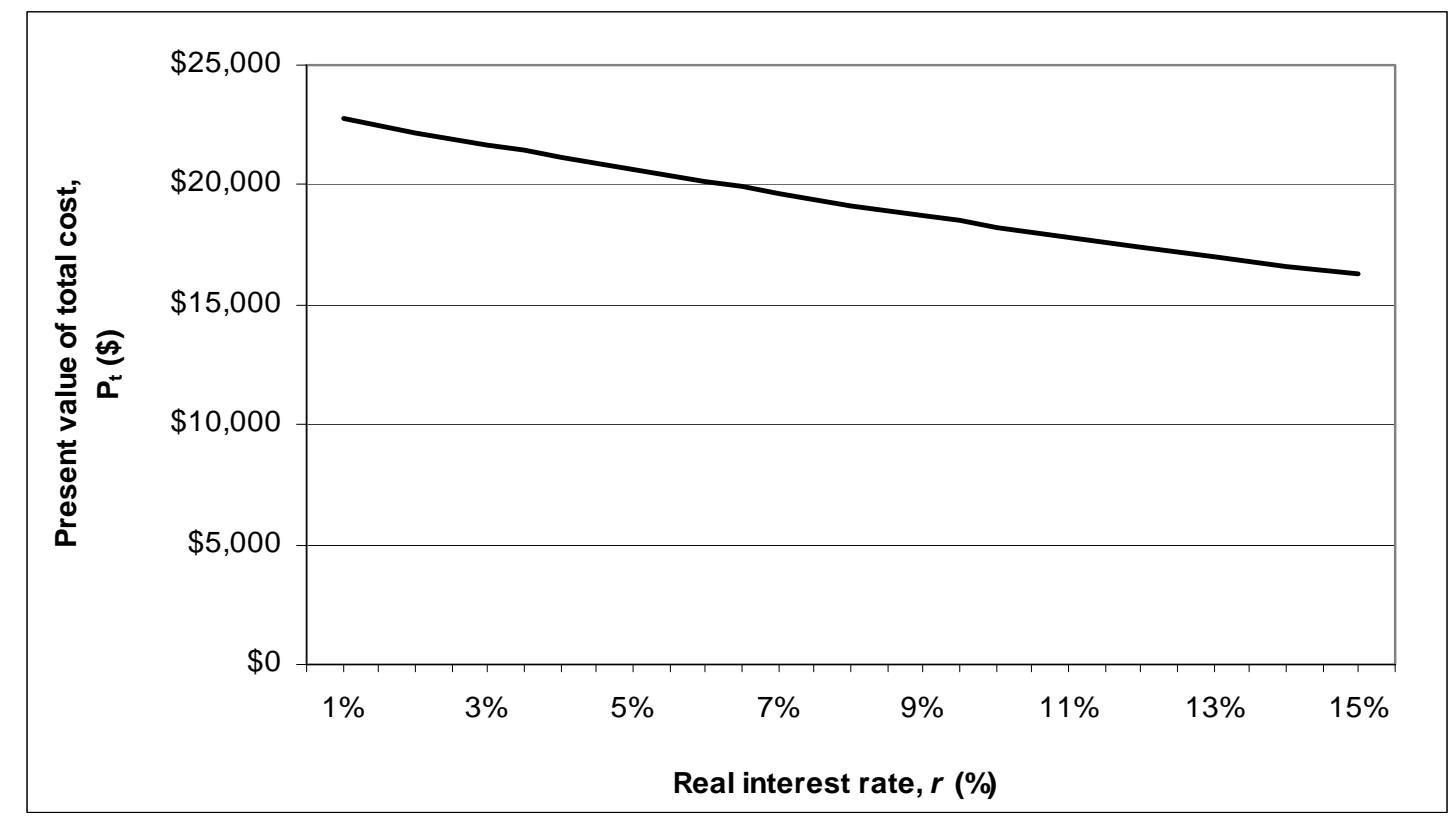

Figure 4.11 Effect of real interest rate $r$ on present value of the total $\operatorname{cost} \boldsymbol{P}_{t}$

\begin{tabular}{|c|c|c|c|c|}
\hline $\begin{array}{c}\text { Carrying rate } \boldsymbol{F} \\
(\%)\end{array}$ & $\boldsymbol{m}$ & $\begin{array}{c}\boldsymbol{T} \\
\text { (months) }\end{array}$ & $\begin{array}{c}\boldsymbol{S} \\
\text { (units) }\end{array}$ & $\begin{array}{c}\boldsymbol{P}_{\boldsymbol{m}, \boldsymbol{S}} \\
\mathbf{( \$ )}\end{array}$ \\
\hline $3 \%$ & 10 & 6.00 & 31.71 & $18,987.79$ \\
\hline $4 \%$ & 11 & 5.45 & 37.59 & $19,006.95$ \\
\hline $5 \%$ & 11 & 5.45 & 46.12 & $19,024.37$ \\
\hline $6 \%$ & 11 & 5.45 & 54.34 & $19,041.15$ \\
\hline $7 \%$ & 11 & 5.45 & 62.27 & $19,057.34$ \\
\hline $8 \%$ & 11 & 5.45 & 69.92 & $19,072.97$ \\
\hline $9 \%$ & 12 & 5.00 & 70.69 & $19,087.54$ \\
\hline $10 \%$ & 12 & 5.00 & 77.22 & $19,100.89$ \\
\hline $11 \%$ & 12 & 5.00 & 83.53 & $19,113.80$ \\
\hline $12 \%$ & 12 & 5.00 & 89.64 & $19,126.29$ \\
\hline $13 \%$ & 12 & 5.00 & 95.55 & $19,138.38$ \\
\hline $14 \%$ & 12 & 5.00 & 101.27 & $19,150.10$ \\
\hline $15 \%$ & 12 & 5.00 & 106.81 & $19,161.45$ \\
\hline $16 \%$ & 13 & 4.62 & 103.35 & $19,171.81$ \\
\hline $17 \%$ & 13 & 4.62 & 108.15 & $19,181.65$ \\
\hline $18 \%$ & 13 & 4.62 & 112.81 & $19,191.20$ \\
\hline $19 \%$ & 13 & 4.62 & 117.33 & $19,200.47$ \\
\hline $20 \%$ & 13 & 4.62 & 121.72 & $19,209.48$ \\
\hline
\end{tabular}

Table 4.8 Optimal ordering policies for different values of $\boldsymbol{F}$ for the models with shortages 


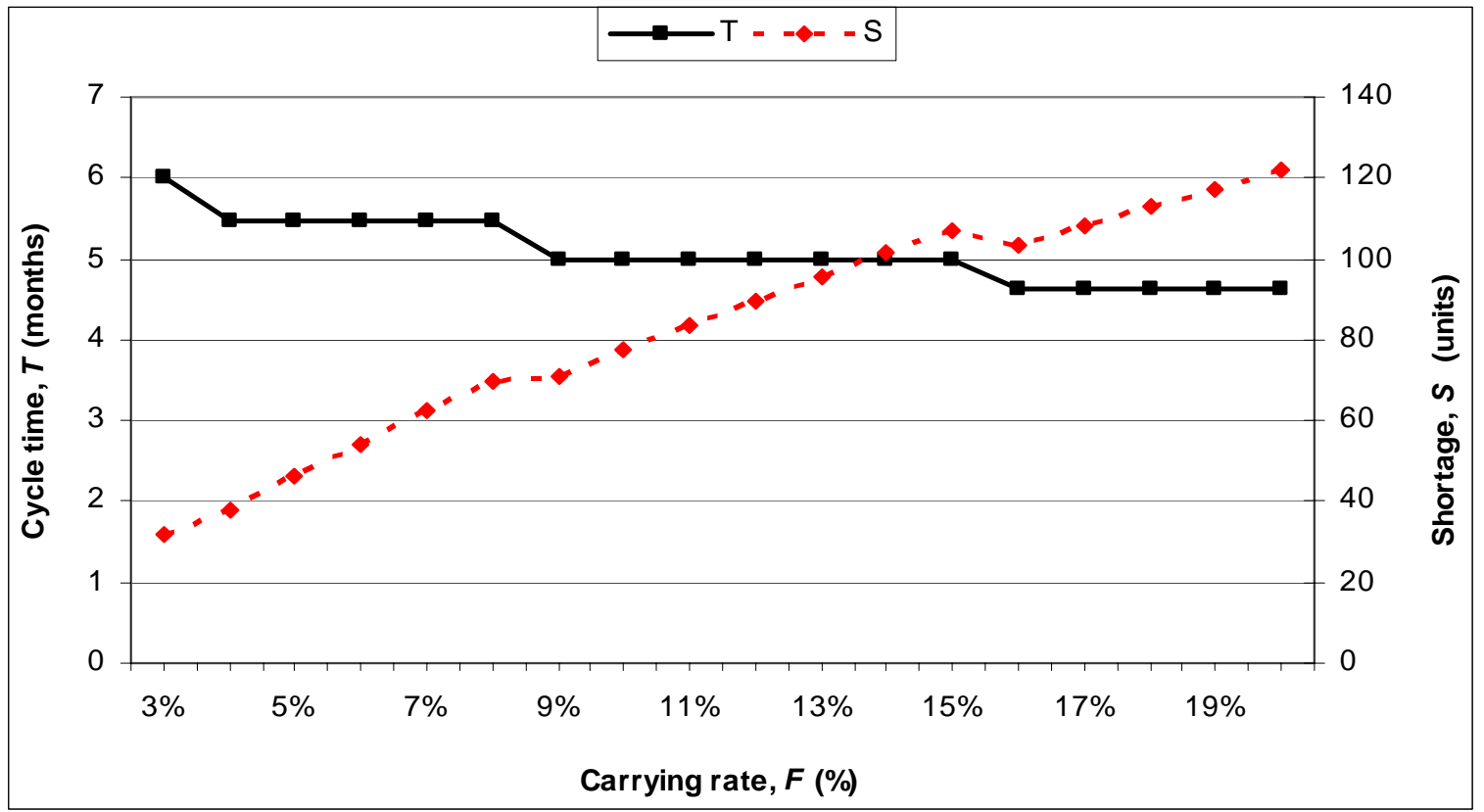

Figure 4.12 Effect carrying rate $F$ on cycle time $T$ and shortage $S$

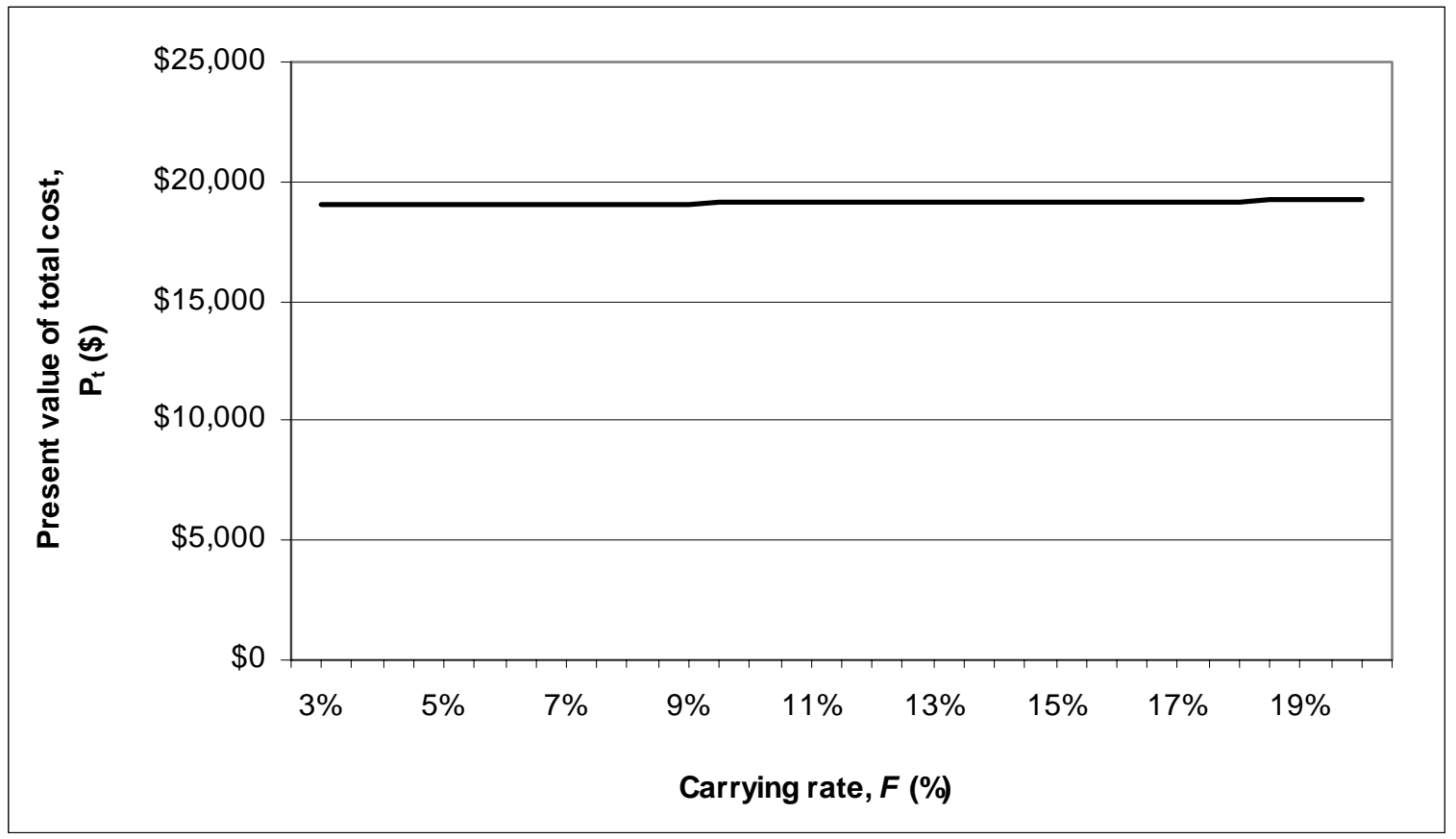

Figure 4.13 Effect of carrying rate $F$ on present value of the total cost $P_{t}$ 


\begin{tabular}{|c|c|c|c|c|}
\hline $\begin{array}{c}\text { Shortage cost } \boldsymbol{K} \\
\text { (\$/unit/time) }\end{array}$ & $\boldsymbol{m}$ & $\begin{array}{c}\boldsymbol{T} \\
\text { (months) }\end{array}$ & $\begin{array}{c}\boldsymbol{S} \\
\text { (units) }\end{array}$ & $\begin{array}{c}\boldsymbol{P}_{\boldsymbol{m}, \boldsymbol{S}} \\
\mathbf{( \$ )}\end{array}$ \\
\hline 1 & 12 & 5.00 & 106.8107 & $19,161.45$ \\
\hline 2 & 13 & 4.62 & 55.6964 & $19,188.10$ \\
\hline 3 & 13 & 4.62 & 38.8412 & $19,198.53$ \\
\hline 4 & 13 & 4.62 & 29.8181 & $19,204.12$ \\
\hline 5 & 13 & 4.62 & 24.1968 & $19,207.59$ \\
\hline 6 & 13 & 4.62 & 20.3585 & $19,209.97$ \\
\hline 7 & 13 & 4.62 & 17.5721 & $19,211.69$ \\
\hline 8 & 13 & 4.62 & 15.4556 & $19,213.00$ \\
\hline 9 & 13 & 4.62 & 13.7946 & $19,214.03$ \\
\hline 10 & 13 & 4.62 & 12.4552 & $19,214.85$ \\
\hline
\end{tabular}

Table 4.9 Optimal ordering policies for different values of $K$ for the models with shortages

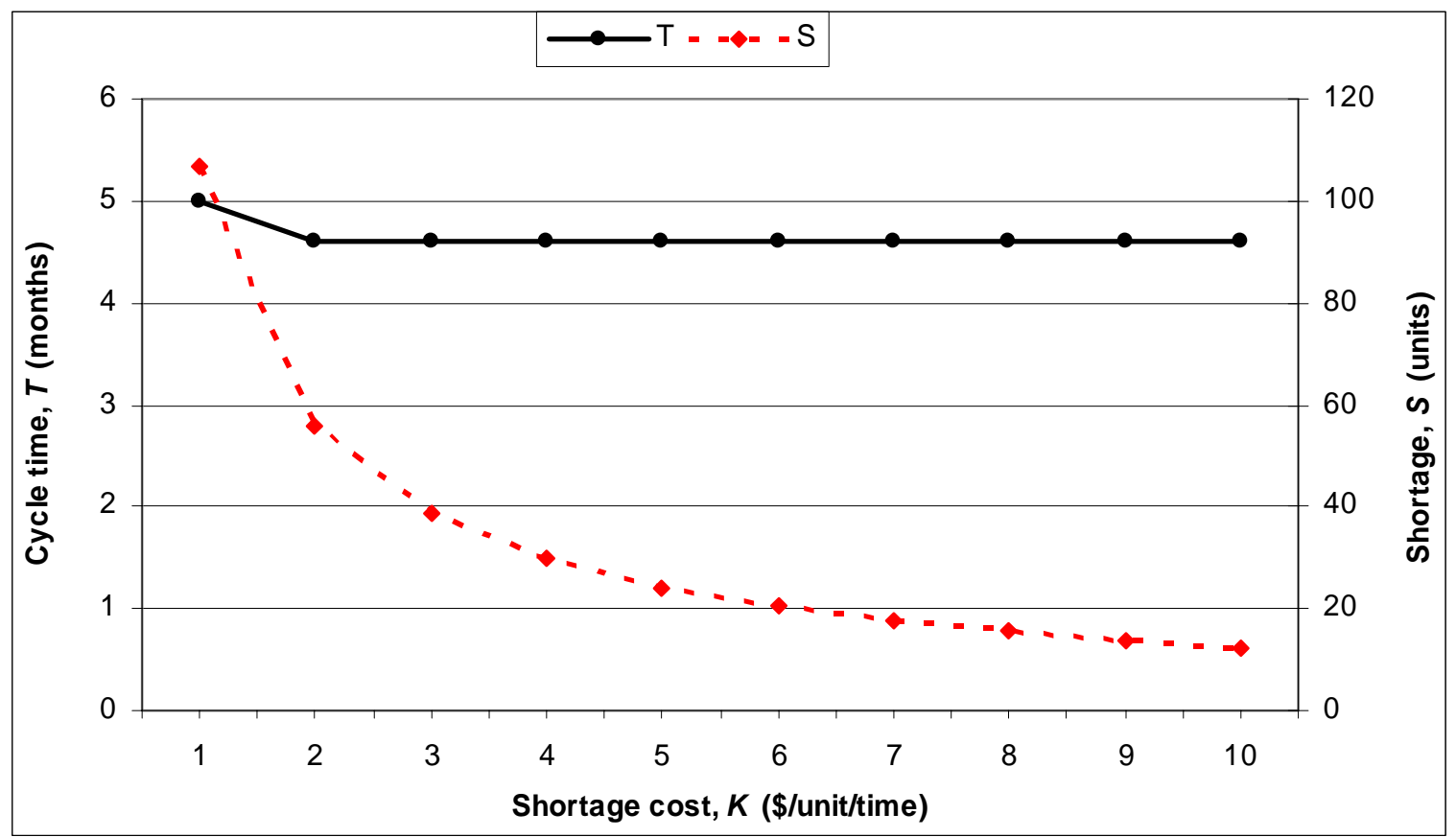

Figure 4.14 Effect of shortage cost $K$ on cycle time $T$ and shortage $S$ 


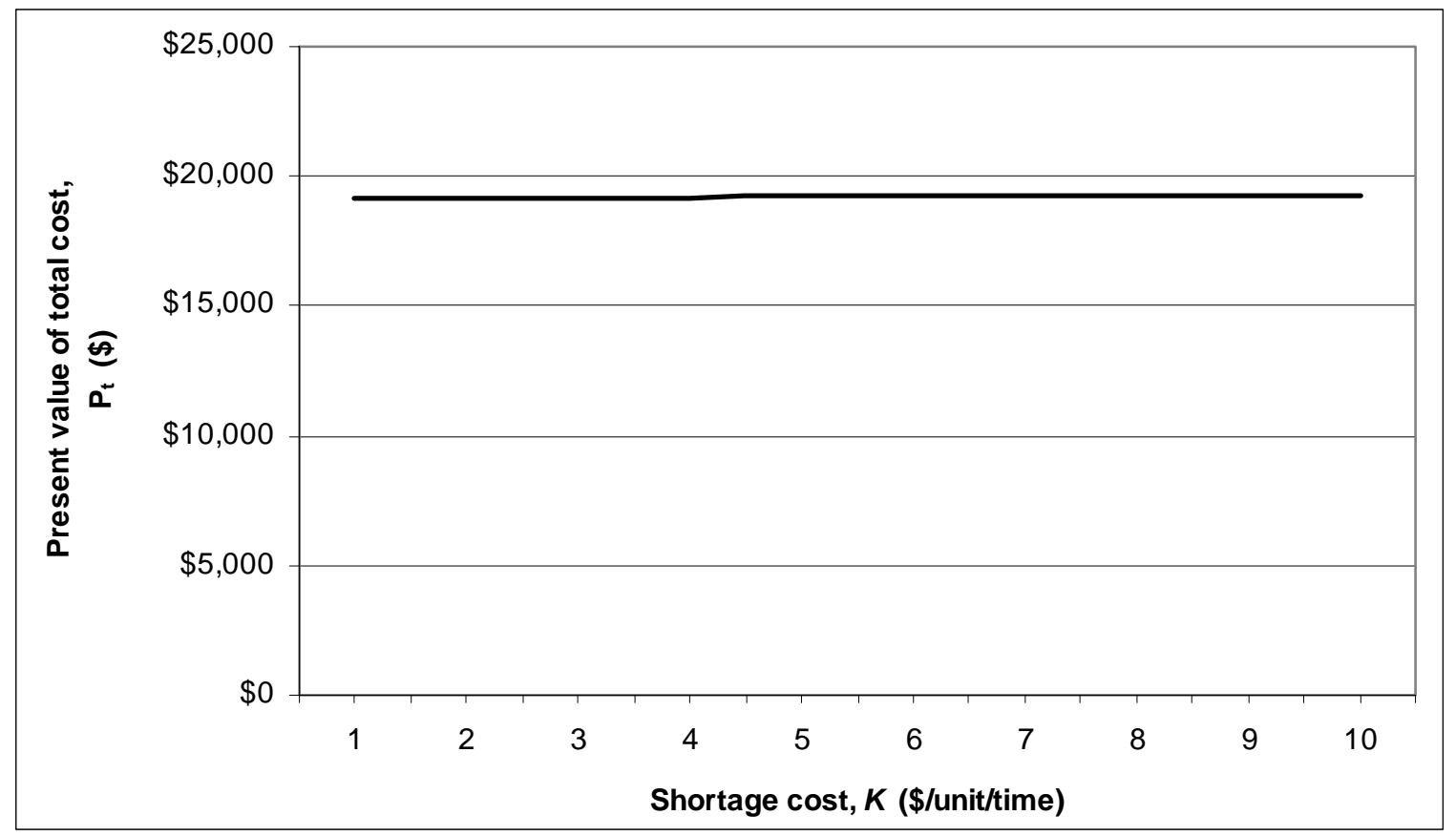

Figure 4.15 Effect of shortage cost $K$ on present value of the total $\operatorname{cost} \boldsymbol{P}_{t}$

\begin{tabular}{|c|c|c|c|c|}
\hline $\begin{array}{c}\text { Demand rate slope } \boldsymbol{b} \\
\text { (units/time) }\end{array}$ & $\boldsymbol{m}$ & $\begin{array}{c}\boldsymbol{T} \\
\text { (months) }\end{array}$ & $\begin{array}{c}\boldsymbol{S} \\
\text { (units) }\end{array}$ & $\begin{array}{c}\boldsymbol{P}_{\boldsymbol{m}, \boldsymbol{S}} \\
\mathbf{( \$ )}\end{array}$ \\
\hline 50 & 11 & 5.45 & 109.48 & $14,255.24$ \\
\hline 100 & 12 & 5.00 & 103.16 & $15,241.33$ \\
\hline 150 & 12 & 5.00 & 105.25 & $16,223.86$ \\
\hline 200 & 12 & 5.00 & 106.56 & $17,204.71$ \\
\hline 250 & 12 & 5.00 & 107.10 & $18,183.89$ \\
\hline 300 & 12 & 5.00 & 106.81 & $19,161.45$ \\
\hline 350 & 13 & 4.62 & 97.25 & $20,136.46$ \\
\hline 400 & 13 & 4.62 & 95.09 & $21,109.90$ \\
\hline 450 & 13 & 4.62 & 91.67 & $22,082.14$ \\
\hline
\end{tabular}

Table 4.10 Optimal ordering policies for different values of $b$ for the models with shortages 


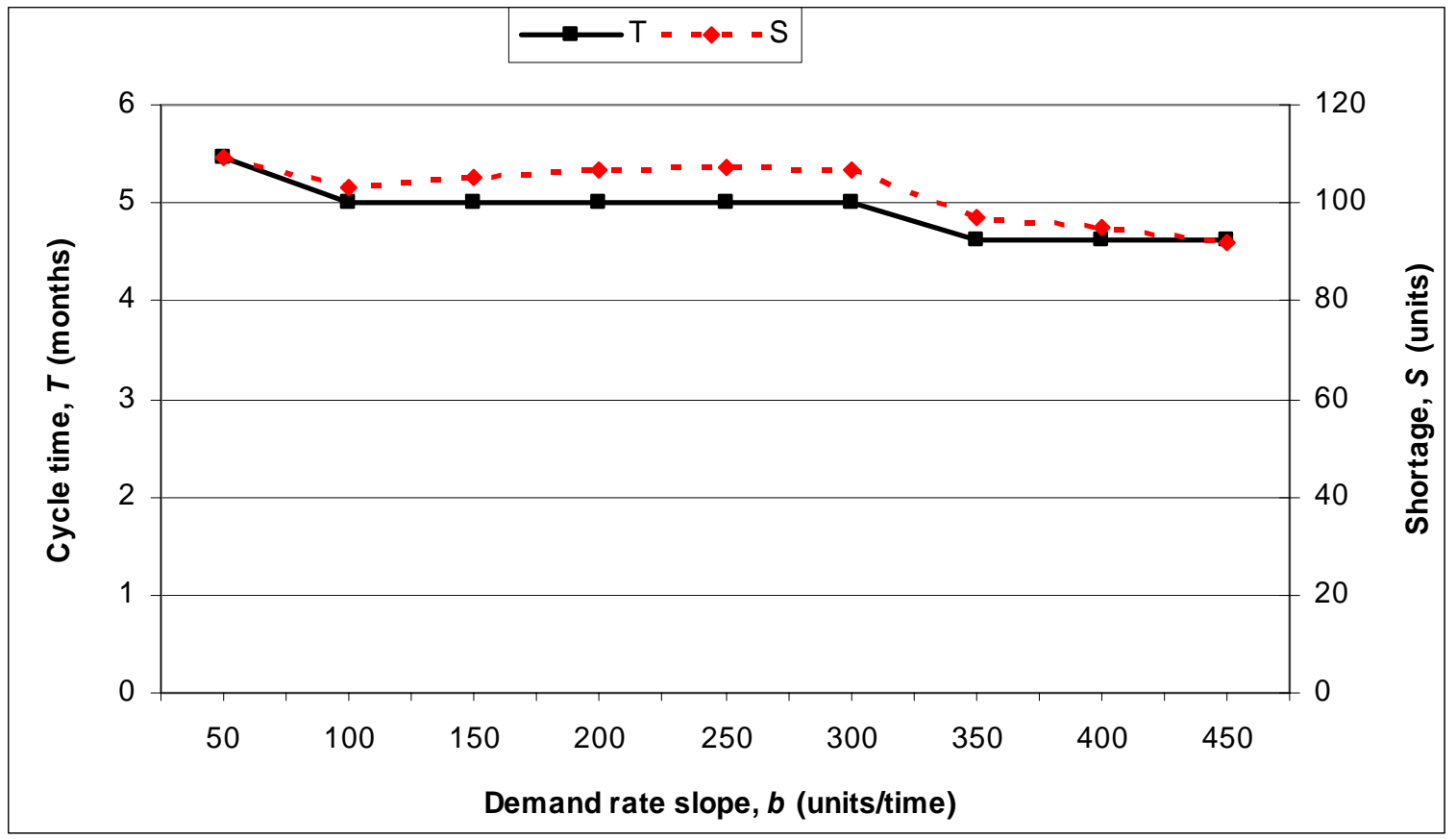

Figure 4.16 Effect of demand rate slope $b$ on cycle time $T$ and shortage $S$

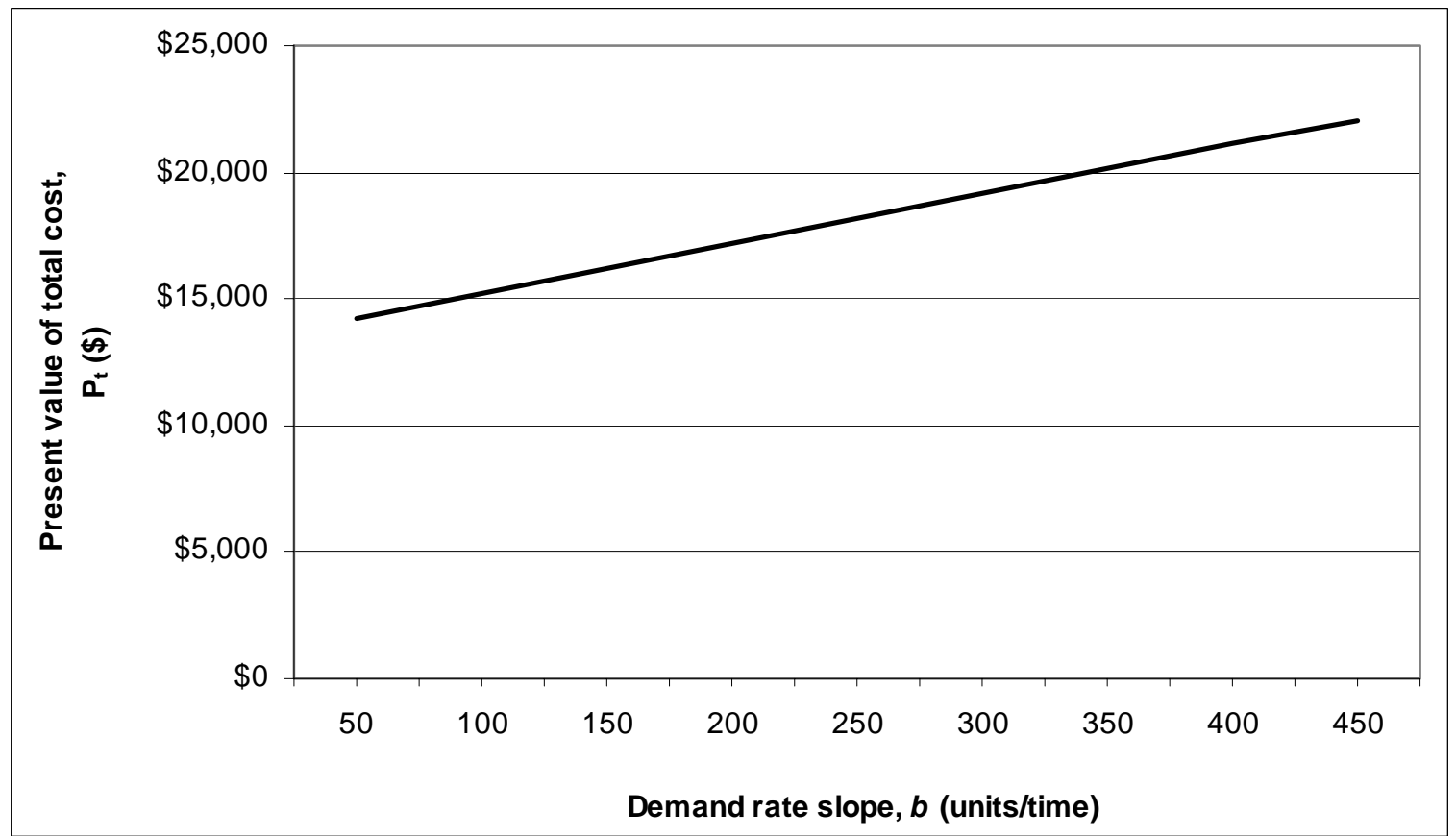

Figure 4.17 Effect of demand rate slope $b$ on present value of the total $\operatorname{cost} \boldsymbol{P}_{t}$ 


\begin{tabular}{|c|c|c|c|c|}
\hline $\begin{array}{c}\text { Setup cost } \boldsymbol{A} \\
\text { (\$/order) }\end{array}$ & $\boldsymbol{m}$ & $\begin{array}{c}\boldsymbol{T} \\
\text { (months) }\end{array}$ & $\begin{array}{c}\boldsymbol{S} \\
\text { (units) }\end{array}$ & $\begin{array}{c}\boldsymbol{P}_{\boldsymbol{m}, \boldsymbol{S}} \\
\text { (\$) }\end{array}$ \\
\hline$\$ 10$ & 28 & 2.14 & 45.09 & $18,588.95$ \\
\hline$\$ 20$ & 20 & 3.00 & 63.41 & $18,779.57$ \\
\hline$\$ 30$ & 16 & 3.75 & 79.58 & $18,926.37$ \\
\hline$\$ 40$ & 14 & 4.29 & 91.21 & $19,050.77$ \\
\hline$\$ 50$ & 12 & 5.00 & 106.81 & $19,161.45$ \\
\hline$\$ 60$ & 11 & 5.45 & 116.80 & $19,261.13$ \\
\hline$\$ 70$ & 11 & 5.45 & 116.80 & $19,353.45$ \\
\hline$\$ 80$ & 10 & 6.00 & 128.85 & $19,438.31$ \\
\hline$\$ 90$ & 9 & 6.67 & 143.67 & $19,519.96$ \\
\hline$\$ 100$ & 9 & 6.67 & 143.67 & $19,595.80$ \\
\hline
\end{tabular}

Table 4.11 Optimal ordering policies for different values of $\boldsymbol{A}$ for the models with shortages

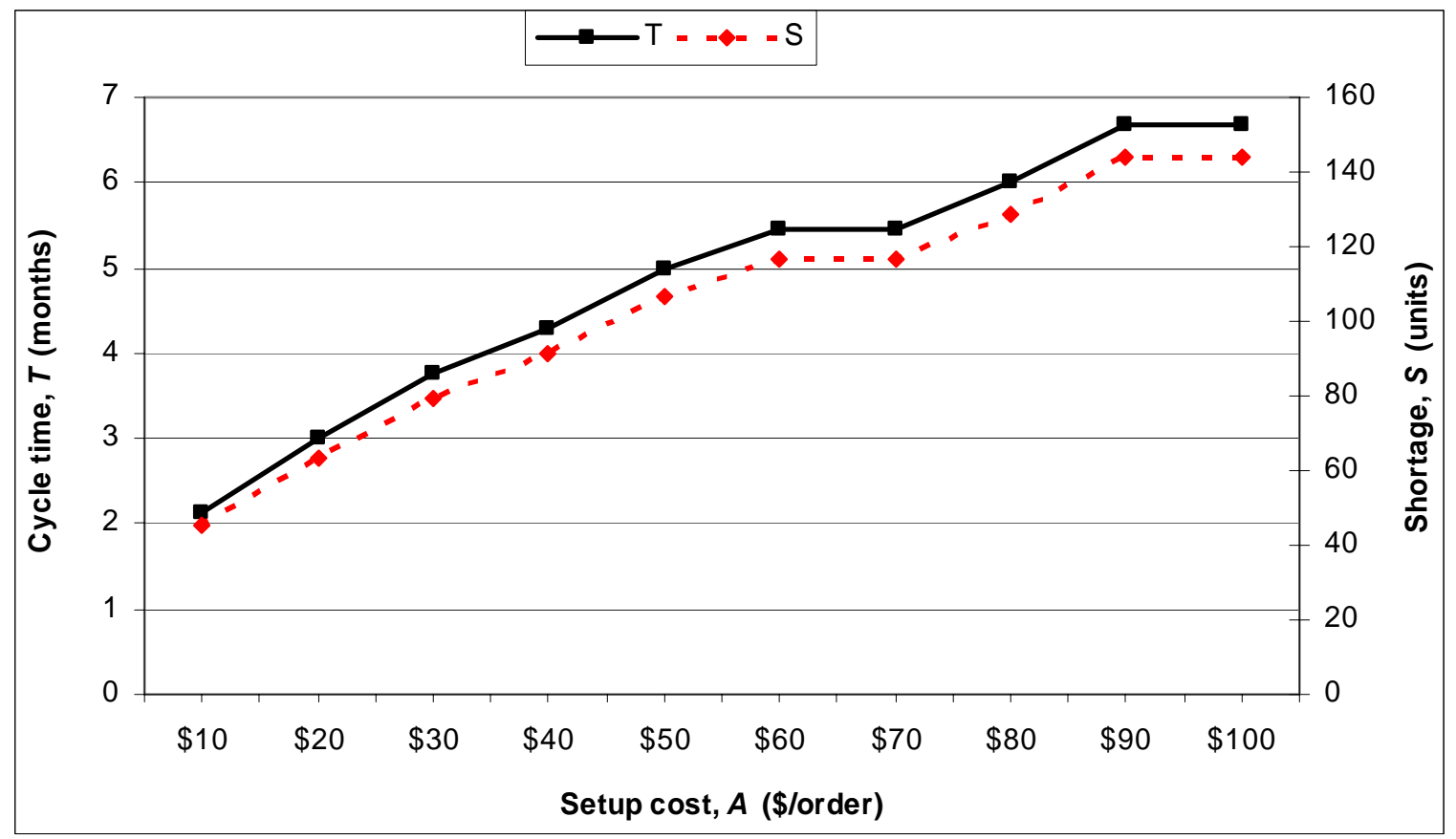

Figure 4.18 Effect of setup cost $\boldsymbol{A}$ on cycle time $\boldsymbol{T}$ and shortage $S$ 


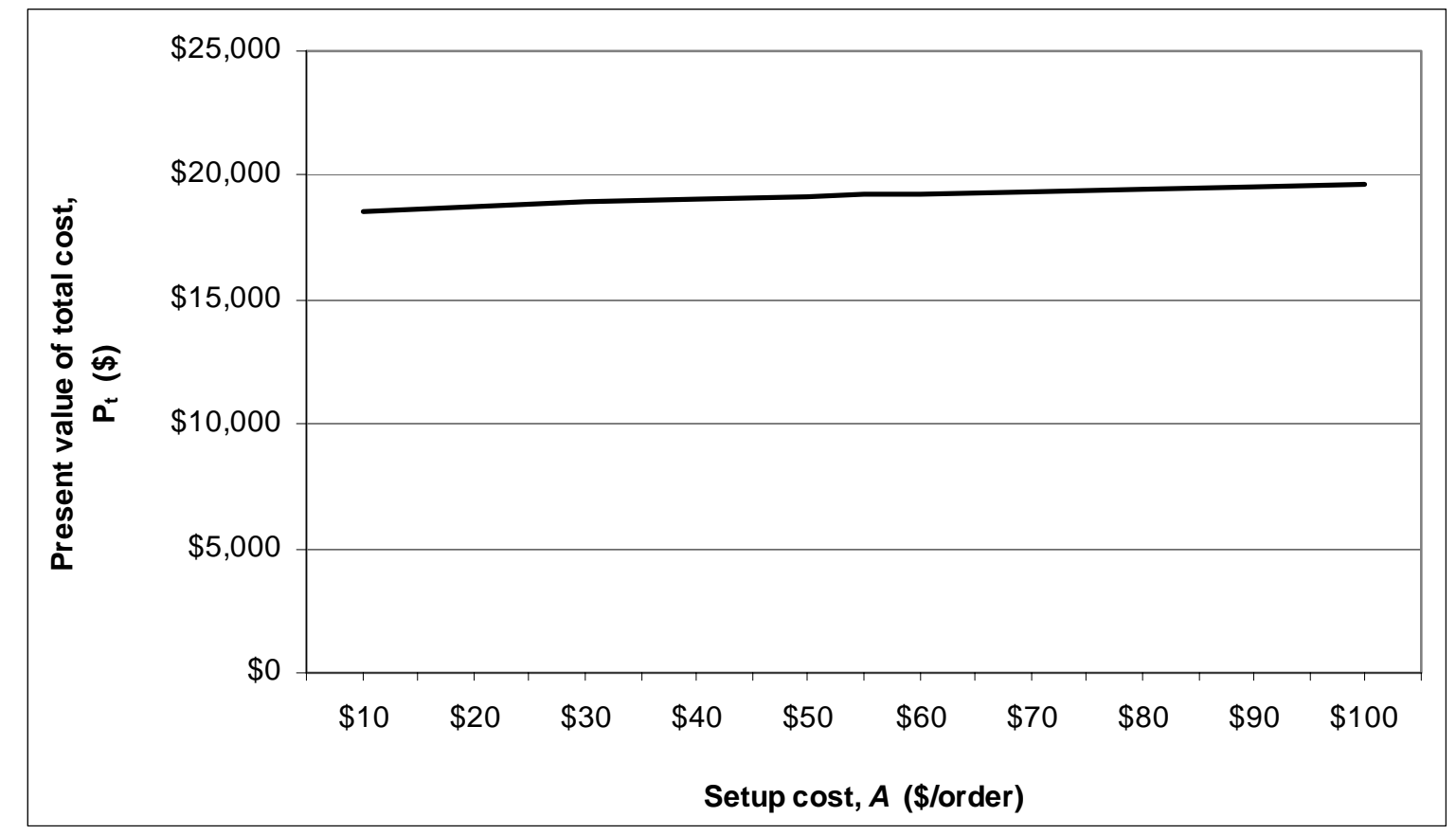

Figure 4.19 Effect of setup $\operatorname{cost} A$ on present value of the total $\operatorname{cost} P_{t}$

For Case 4, the same example was used with the same parameters. The only difference is that the production cost, $c$, was replaced with a raw material $\operatorname{cost} c_{1}=1.5 \$$ unit, and a labor cost $c_{2}=0.5 \$ /$ unit. The results obtained are summarized in Table 4.12. As in Case 3, the cycle time decreases as the real interest rate increases. Also all other measures follow patterns similar to Case 3.

Table 4.13 and Figures 4.20 and 4.21 show the results and the effect of simultaneous changes in both $\operatorname{costs} c_{1}$ and $c_{2}$ on cycle time, $T$, and present value of the total cost, $P_{t}$. As in the model without shortages, increases in production cost, $c$, shorten the cycle time, because of higher holding cost, and lead to increase in the total cost of the system. Shortages increase within the same number of cycles, but drop again after a certain point, when the number of cycles increases. 


\begin{tabular}{|c|c|c|c|c|}
\hline $\begin{array}{c}\text { Real interest rate } \boldsymbol{r} \\
\mathbf{( \% )}\end{array}$ & $\boldsymbol{m}$ & $\begin{array}{c}\boldsymbol{T} \\
\text { (months) }\end{array}$ & $\begin{array}{c}\boldsymbol{S} \\
\text { (units) }\end{array}$ & $\begin{array}{c}\boldsymbol{P}_{\boldsymbol{m}, \boldsymbol{S}} \\
\mathbf{( \$ )}\end{array}$ \\
\hline $1 \%$ & 9 & 6.67 & 143.65 & $22,726.21$ \\
\hline $2 \%$ & 9 & 6.67 & 143.66 & $22,166.02$ \\
\hline $3 \%$ & 10 & 6.00 & 128.84 & $21,621.24$ \\
\hline $4 \%$ & 10 & 6.00 & 128.84 & $21,091.79$ \\
\hline $5 \%$ & 11 & 5.45 & 116.80 & $20,577.51$ \\
\hline $6 \%$ & 11 & 5.45 & 116.80 & $20,077.89$ \\
\hline $7 \%$ & 12 & 5.00 & 106.81 & $19,593.66$ \\
\hline $8 \%$ & 12 & 5.00 & 106.81 & $19,122.67$ \\
\hline $9 \%$ & 12 & 5.00 & 106.81 & $18,666.82$ \\
\hline $10 \%$ & 13 & 4.62 & 98.40 & $18,223.73$ \\
\hline $11 \%$ & 13 & 4.62 & 98.40 & $17,794.22$ \\
\hline $12 \%$ & 14 & 4.29 & 91.21 & $17,378.33$ \\
\hline $13 \%$ & 14 & 4.29 & 91.21 & $16,973.77$ \\
\hline $14 \%$ & 14 & 4.29 & 91.21 & $16,582.03$ \\
\hline $15 \%$ & 15 & 4.00 & 85.00 & $16,202.54$ \\
\hline & & & &
\end{tabular}

Table 4.12 Optimal ordering policies for different values of $r$ and two separate costs for the models with shortages

\begin{tabular}{|c|c|c|c|c|c|c|}
\hline $\begin{array}{c}\text { Raw material } \\
\text { cost } \boldsymbol{c}_{\mathbf{1}} \\
\mathbf{\$} / \mathbf{u n i t}\end{array}$ & $\begin{array}{c}\text { Labor cost } \\
\boldsymbol{c}_{\mathbf{2}}, \\
\mathbf{\$} / \mathbf{u n i t}\end{array}$ & $\boldsymbol{c}=\boldsymbol{c}_{\mathbf{1}}+\boldsymbol{c}_{\mathbf{2}}$ & $\boldsymbol{m}$ & $\begin{array}{c}\boldsymbol{T} \\
\text { (months) }\end{array}$ & $\begin{array}{c}\boldsymbol{S} \\
\text { (units) }\end{array}$ & $\begin{array}{c}\boldsymbol{P}_{\boldsymbol{t}} \\
\mathbf{( \$ )}\end{array}$ \\
\hline$\$ 0.30$ & $\$ 0.10$ & $\$ 0.40$ & 6 & 10.00 & 54.08 & $4,100.54$ \\
\hline$\$ 0.60$ & $\$ 0.20$ & $\$ 0.80$ & 8 & 7.50 & 75.59 & $7,907.11$ \\
\hline$\$ 0.90$ & $\$ 0.30$ & $\$ 1.20$ & 10 & 6.00 & 85.30 & $11,668.01$ \\
\hline$\$ 1.20$ & $\$ 0.40$ & $\$ 1.60$ & 11 & 5.45 & 98.03 & $15,402.80$ \\
\hline$\$ 1.50$ & $\$ 0.50$ & $\$ 2.00$ & 12 & 5.00 & 106.81 & $19,122.67$ \\
\hline$\$ 1.80$ & $\$ 0.60$ & $\$ 2.40$ & 13 & 4.62 & 112.81 & $22,831.56$ \\
\hline$\$ 2.10$ & $\$ 0.70$ & $\$ 2.80$ & 14 & 4.29 & 116.79 & $26,532.20$ \\
\hline$\$ 2.40$ & $\$ 0.80$ & $\$ 3.20$ & 15 & 4.00 & 119.31 & $30,226.52$ \\
\hline$\$ 2.70$ & $\$ 0.90$ & $\$ 3.60$ & 15 & 4.00 & 128.95 & $33,915.77$ \\
\hline$\$ 3.00$ & $\$ 1.00$ & $\$ 4.00$ & 16 & 3.75 & 129.09 & $37,599.84$ \\
\hline$\$ 3.30$ & $\$ 1.10$ & $\$ 4.40$ & 17 & 3.53 & 128.65 & $41,280.83$ \\
\hline$\$ 3.60$ & $\$ 1.20$ & $\$ 4.80$ & 17 & 3.53 & 135.42 & $44,959.12$ \\
\hline$\$ 3.90$ & $\$ 1.30$ & $\$ 5.20$ & 18 & 3.33 & 133.73 & $48,633.87$ \\
\hline$\$ 4.20$ & $\$ 1.40$ & $\$ 5.60$ & 19 & 3.16 & 131.85 & $52,307.14$ \\
\hline$\$ 4.50$ & $\$ 1.50$ & $\$ 6.00$ & 19 & 3.16 & 136.79 & $55,977.67$ \\
\hline
\end{tabular}

Table 4.13 Optimal ordering policies for different values of $c_{1}$ and $c_{2}$ 


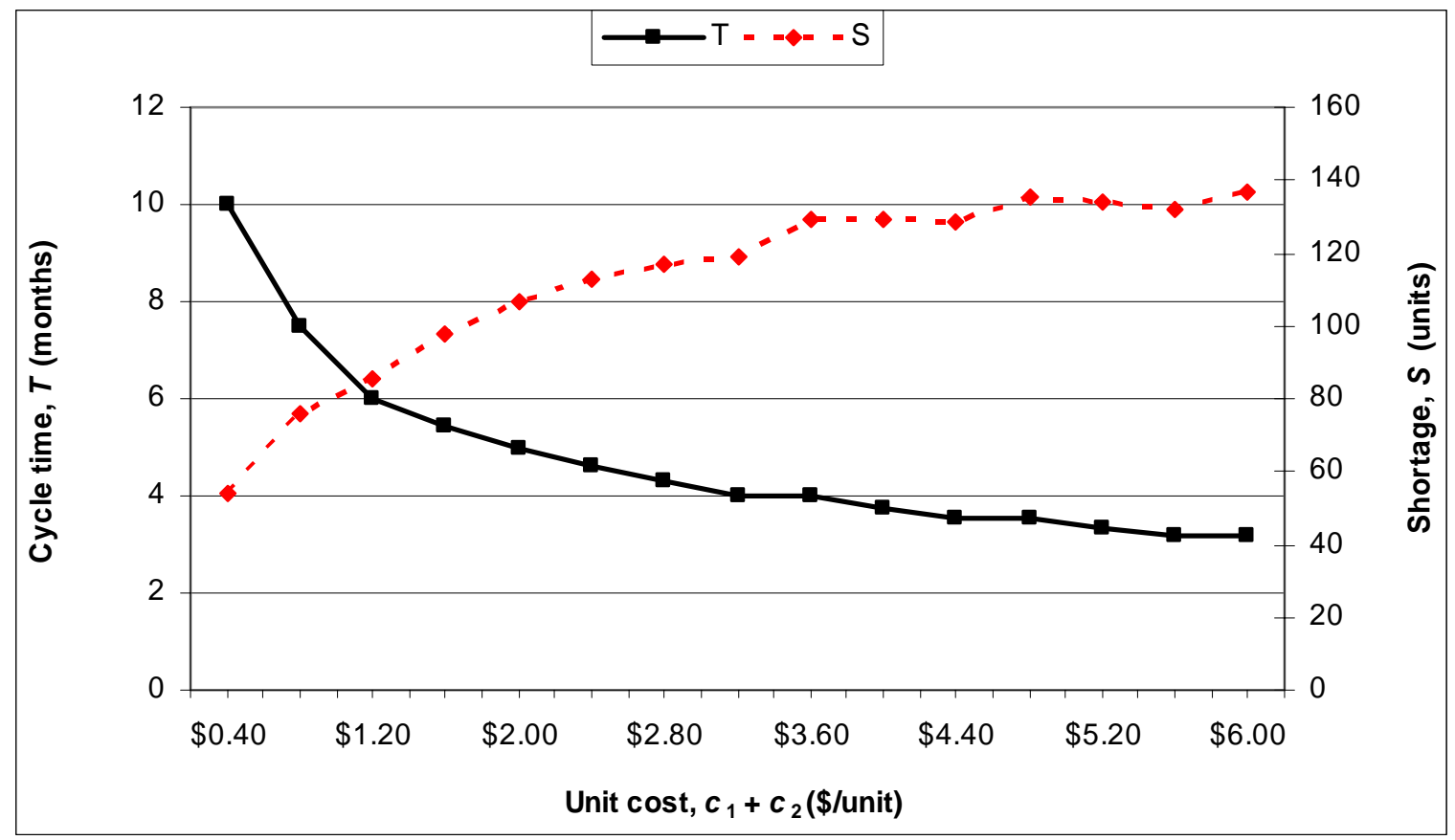

Figure 4.20 Effect of changes in unit $\cos t s c_{1}$ and $c_{2}$ on cycle time $T$ and shortage $S$

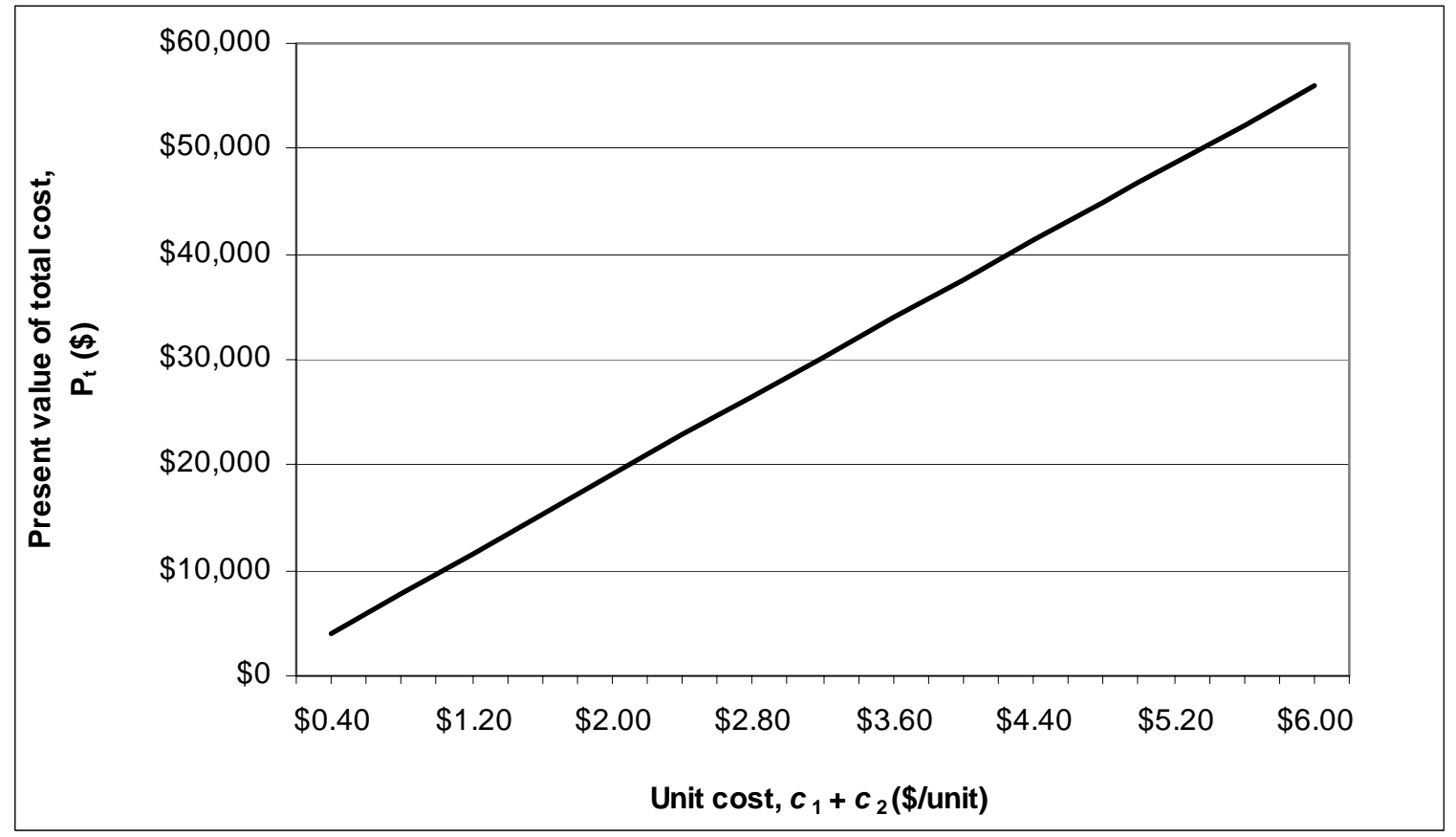

Figure 4.21 Effect of changes in unit costs $c_{1}$ and $c_{2}$ on present value of the total $\operatorname{cost} P_{t}$ 


\section{Chapter 5}

\section{EPQ Models with and without Shortages, with Constant Demand, Deterioration, and Time Value of Money}

There are many industries where items such as dairy products, medicines and vegetables deteriorate at a considerable rate, and the loss from deterioration cannot be ignored. The models presented in this chapter investigate the economic production quantity for systems with time value of money and exponentially decaying inventory. Models are developed with and without shortage and using two different production cost functions.

\subsection{Assumptions}

The mathematical models developed for finding the optimal cycle time and optimal shortage quantity, and the corresponding production quantity are based on the general assumptions presented earlier and the following additional assumptions:

1. Items have a constant deterioration rate

2. Replenishment rate is finite and constant during the production time

3. Demand rate is constant and less than the production rate

\subsection{Inventory Models with no Shortage}

These models are developed for items manufactured and consumed during the same cycle, with constant rate of demand and exponentially decaying inventory, over an infinite planning horizon, while considering the effect of time value of money. The objective of these models is to determine the optimal cycle time, $T$, or the corresponding optimal production 
quantity, $Q$, in order to minimize the total relevant cost. Consequently, the production time and the maximum inventory level can be easily calculated. Figure 5.1 gives a graphical representation of the first cycle in this system. The inventory on-hand increases with a rate that is equal to the difference between $p-D$, the production rate minus the consumption rate, and a decay rate, $\theta$, until time $t_{p}$ when the production process stops and the inventory on hand reaches its maximum level. After that point, the inventory level decreases with the consumption rate, $D$, and the decay rate, $\theta$, until it becomes zero at the end of the cycle, $T$, when the production process is resumed again.

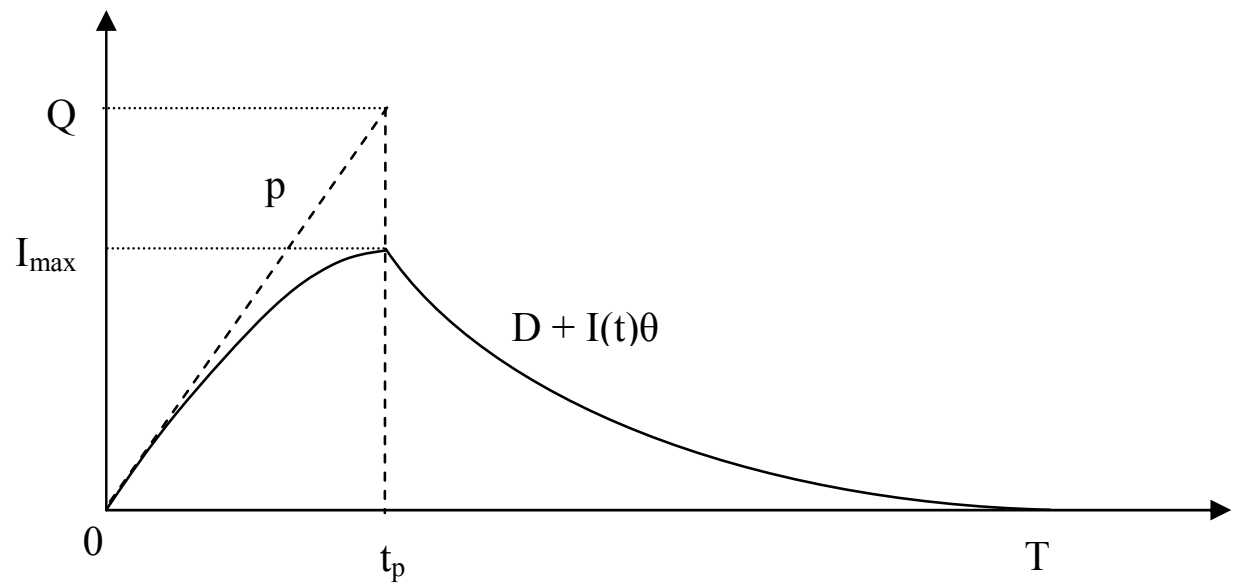

Figure 5.1 EPQ model for deteriorating items without shortage

The total cost TC (T) for this EPQ model, consists of three elements:

$$
\mathrm{TC}(\mathrm{T})=\text { Setup Cost }+ \text { Production Cost }+ \text { Holding Cost }
$$

\subsubsection{Case 1}

For this case, the setup cost and the production cost are assumed to be incurred at the beginning of each cycle, and the inventory holding cost is incurred continuously during the cycle, $T$. 
As in previous chapters, the inflation free or real interest rate, $r$, represents the time value of money. Assuming continuous compounding, the present value of the total cost of the inventory system for the first cycle can be expressed as:

$$
P=A+c p t_{p}+F c \int_{0}^{t_{p}} I_{1}(t) e^{-r t} d t+F c \int_{t_{p}}^{T} I_{2}(t) e^{-r t} d t
$$

According to Ghare et al. (1963), starting with an initial inventory, $I_{0}$, the inventory level after time $t$ during the consumption period is equal to:

$$
I_{t}=I_{0} e^{-\theta t}-e^{-\theta t} \int_{0}^{t} D(x) e^{\theta x} d x
$$

where $D(x)$ is the demand rate at time $x$.

With zero inventory at the beginning of the cycle, and a constant demand rate, $D$, the inventory level, $I_{1}(t)$, at time $t$ during the production time, can be written, based on Ghare's formula, as follows:

$$
I_{1}(t)=(p-D) e^{-\theta t} \int_{0}^{t} e^{\theta x} d x=\frac{p-D}{\theta}\left(1-e^{-\theta t}\right) \quad \text { for } 0<t<t_{p}
$$

From Equation (5.3), the inventory level at the end of production cycle time, $t_{p}$, can be determined as:

$$
I_{t_{p}}=\frac{p-D}{\theta}\left(1-e^{-\theta t_{p}}\right)
$$

Again, using the formula developed by Ghare et al. (1963), the inventory level, $I_{2}(t)$, at time $t$, during the pure consumption period, can be written as:

$$
I_{2}(t)=I_{t_{p}} e^{-\theta\left(t-t_{p}\right)}-D e^{-\theta\left(t-t_{p}\right)} \int_{0}^{t-t_{p}} e^{\theta x} d x=I_{t_{p}} e^{-\theta\left(t-t_{p}\right)}-\frac{D}{\theta}\left(1-e^{-\theta\left(t-t_{p}\right)}\right) \quad \text { for } t_{p}<t<T
$$


To proceed with the model development, we need to determine the value of the production time, $t_{p}$. This value is determined such that the inventory level at time $T$ is equal to zero. Equating $I_{2}(T)$ from Equation (5.5) to zero, and substituting the value of $I_{t_{p}}$ from Equation (5.4), we have:

$$
\begin{aligned}
I_{2}(T)= & I_{t_{p}} e^{-\theta\left(T-t_{p}\right)}-\frac{D}{\theta}\left(1-e^{-\theta\left(T-t_{p}\right)}\right)=\left(I_{t_{p}}+\frac{D}{\theta}\right) e^{-\theta\left(T-t_{p}\right)}-\frac{D}{\theta}= \\
& {\left[\frac{p-D}{\theta}\left(1-e^{-\theta t_{p}}\right)+\frac{D}{\theta}\right] e^{-\theta\left(T-t_{p}\right)}-\frac{D}{\theta}=0 } \\
& e^{\theta\left(T-t_{p}\right)}=1+\frac{p-D}{D}\left(1-e^{-\theta t_{p}}\right)
\end{aligned}
$$

In general, $e^{x}$ can be expressed as the following series:

$$
e^{x}=1+x+\frac{(x)^{2}}{2 !}+\frac{(x)^{3}}{3 !}+\frac{(x)^{4}}{4 !}+
$$

Applying this expansion to each of $e^{\theta\left(T-t_{p}\right)}$ and $e^{-\theta t_{p}}$, and ignoring the cubic and higher terms, which are very close to zero, especially when $\theta<1, T<1$, and $t_{p}<T<1$, Equation (5.6) becomes:

$$
1+\theta\left(T-t_{p}\right)+\frac{\theta^{2}}{2}\left(T^{2}-2 T t_{p}+t_{p}{ }^{2}\right)=1+\frac{(p-D)}{D}\left[1-\left(1-t_{p} \theta+\frac{t_{p}{ }^{2} \theta^{2}}{2}\right)\right]
$$

This is a quadratic equation in $t_{p}$, which after simplification is solved to give two solutions for $t_{p}$, expressed in terms of $T$ :

$$
t_{p}=\frac{D T}{p}+\frac{1}{\theta} \pm \sqrt{\frac{D T^{2}}{p}\left(\frac{D}{p}-1\right)+\frac{1}{\theta^{2}}}
$$

To determine which of the two solutions is the correct one for the problem on hand, let us consider the extreme case when the production rate, $p$, is equal to consumption rate, $D$. In this 
case the time for the end of the production, $t_{p}$, will be equal to the cycle time, $T$, and Equation (5.7) becomes:

$$
t_{p}=T+\frac{1}{\theta} \pm \sqrt{\frac{1}{\theta^{2}}}
$$

It is clear that the sign of the square root has to be negative in order for $t_{p}$ to be equal to $T$. If we consider the case where the demand, $D$, is slightly less than the production rate, $p$, such that $D=p-\delta$ and substitute this value into the first part of Equation (5.7), the equation becomes:

$$
t_{p}=T-\frac{\delta T}{p}+\frac{1}{\theta} \pm \sqrt{\frac{D T^{2}}{p}\left(\frac{D}{p}-1\right)+\frac{1}{\theta^{2}}}
$$

As long as the expression $-\frac{\delta T}{p}+\frac{1}{\theta}$ is positive, i.e. $\delta<\frac{p}{\theta T}$ or $p>\delta \theta T$, the sign of the square root in Equation (5.7) has to be negative, since $t_{p}$ is always less than the cycle time, $T$. Since $p>\delta, \theta<1$, and $T<1$, the expression $p>\delta \theta T$ will always hold, and the sign of the square root is always negative. Hence, the unique solution to the quadratic equation for time $t_{p}$ is:

$$
t_{p}=\frac{D T}{p}+\frac{1}{\theta}-\sqrt{\frac{D T^{2}}{p}\left(\frac{D}{p}-1\right)+\frac{1}{\theta^{2}}}
$$

Substituting the expressions defined above in Equation (5.1), we get the present value of the total cost for the first cycle:

$$
P=A+c p t_{p}+F c \int_{0}^{t_{p}} \frac{p-D}{\theta}\left(1-e^{-\theta t}\right) e^{-r t} d t+F c \int_{t_{p}}^{T}\left[I_{t_{p}} e^{-\theta\left(t-t_{p}\right)}-\frac{D}{\theta}\left(1-e^{-\theta\left(t-t_{p}\right)}\right)\right] e^{-r t} d t
$$

Integrating by parts and simplifying, we get: 


$$
\begin{aligned}
P= & A+c p t_{p}+F c\left[\frac{\left(p-D-p e^{-r t_{p}}+D e^{-r T}\right)}{r \theta}+\frac{e^{-(\theta+r) T}}{\theta(\theta+r)}\left(p-D-p e^{\theta t_{p}}\right)+\right. \\
& \left.\frac{\left(p e^{-r t_{p}}-p+D\right)}{\theta(\theta+r)}\right]
\end{aligned}
$$

As shown in Figure 5.2, the present value, $P$, for the first cycle is repeated at the beginning of each of the following cycles. The present value of the total cost for $N$ cycles, $P_{t}$, can then be calculated as follows:

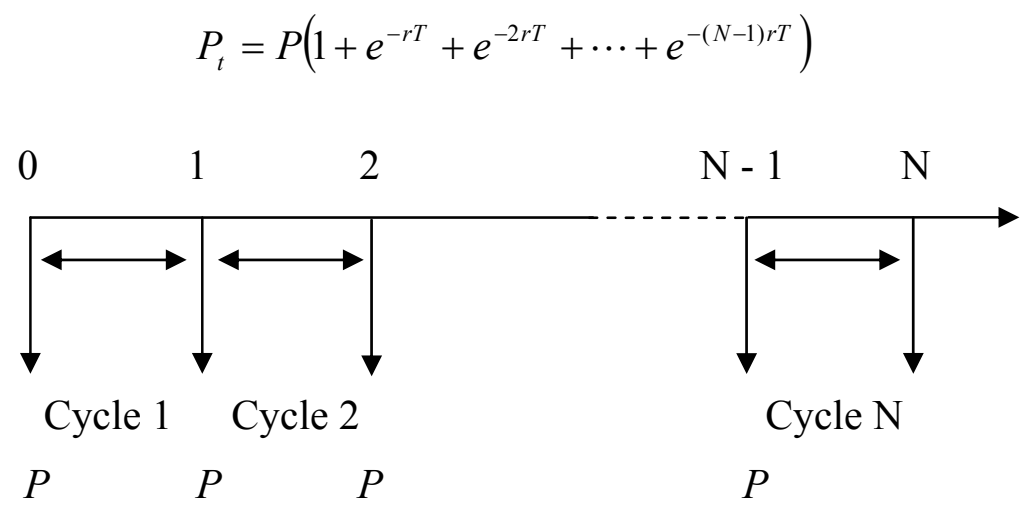

Figure 5.2 Cash flow diagram

For an infinite planning horizon, $N \rightarrow \infty$ and $P_{t}$ can be expressed as:

$$
P_{t}=P\left(\frac{1}{1-e^{-r T}}\right)
$$

Substituting Equation (5.9) into (5.10), we get the present value, $P_{t}$, of the total cost:

$$
\begin{aligned}
P_{t}= & \left(\frac{1}{1-e^{-r T}}\right)\left\{A+c p t_{p}+F c\left[\frac{\left(p-D-p e^{-r t_{p}}+D e^{-r T}\right)}{r \theta}+\right.\right. \\
& \left.\left.\frac{e^{-(\theta+r) T}}{\theta(\theta+r)}\left(p-D-p e^{\theta t_{p}}\right)+\frac{\left(p e^{-r t_{p}}-p+D\right)}{\theta(\theta+r)}\right]\right\}
\end{aligned}
$$


The above cost is a function of $T$. The Golden Search technique can be used to find the optimal policy for the system. Following the search procedure described earlier, the optimal value of $T$ and the corresponding total cost value can be obtained.

\subsubsection{Case 2}

In the second case, the production cost, $c$, has two components. A cost, $c_{1}$, that is incurred at the beginning of each cycle and is applied to the total quantity produced during the production time, and a second cost, $c_{2}$, which is incurred as the production process takes place.

The total cost for this model consists of the same three elements as in the first model:

$$
\mathrm{TC}(\mathrm{T})=\text { Setup Cost }+ \text { Production Cost }+ \text { Holding Cost }
$$

The only difference between the two cases is in the production cost. With continuous compounding, the present value of the production cost during the first cycle is now defined as follows:

$$
P C=c_{1} Q+c_{2} p \int_{0}^{t_{p}} e^{-r t} d t
$$

The present value of the total cost of the inventory system for the first cycle becomes:

$$
P=A+c_{1} Q+c_{2} p \int_{0}^{t_{p}} e^{-r t} d t+F c_{3} \int_{0}^{t_{p}} I_{1}(t) e^{-r t} d t+F c_{3} \int_{t_{p}}^{T} I_{2}(t) e^{-r t} d t
$$

where $c_{3}=c_{1}+c_{2}$

The procedure followed in Case 1 is repeated and leads to the following value for the present value of the total cost for an infinite number of cycles: 


$$
\begin{aligned}
P_{t}= & \left(\frac{1}{1-e^{-r T}}\right)\left\{A+c_{1} p t_{p}+\frac{c_{2} p}{r}\left(1-e^{-r t_{p}}\right)+F\left(c_{1}+c_{2}\right)\left[\frac{\left(p-D-p e^{-r t_{p}}+D e^{-r T}\right)}{r \theta}+\right.\right. \\
& \left.\left.\frac{e^{-(\theta+r) T}}{\theta(\theta+r)}\left(p-D-p e^{\theta t_{p}}\right)+\frac{\left(p e^{-r t_{p}}-p+D\right)}{\theta(\theta+r)}\right]\right\}
\end{aligned}
$$

As in Case 1, the above cost is a function of $T$ and the Golden Search technique can be used to find the minimum cost and the corresponding cycle time, $T$.

\subsection{Convexity of the Total Cost Function}

To show that the total cost function has no local minima, so the search technique would find the optimal point, a similar inventory model was developed without considering the time value of money. This was done for simplicity, and with the assumption that the time value of money does not affect the convexity of the total cost function. Balkhi and Benkherouf (1996) proved the uniqueness of the optimal replenishment schedule for a similar model in which the planning horizon is finite.

Similar to the models developed above, the total cost of the inventory system per unit time can be expressed as (see Equation (5.1)):

$$
T C=\frac{A}{T}+\frac{c p t_{p}}{T}+\frac{F c}{T} \int_{0}^{t_{p}} I_{1}(t) d t+\frac{F c}{T} \int_{t_{p}}^{T} I_{2}(t) d t
$$

The expressions for the inventory on hand, $I_{1}(t)$ and $I_{2}(t)$, remain the same as in Equations (5.3) and (5.5). Substituting their values into Equation (5.15) and integrating, we get:

$$
T C=\frac{A}{T}+\frac{c p t_{p}}{T}+F c\left[\frac{1}{\theta}\left(\frac{p t_{p}}{T}-D\right)+\frac{1}{T \theta^{2}}\left(D-p e^{\theta\left(t_{p}-T\right)}+(p-D) e^{-\theta T}\right)\right]
$$

The equation for $t_{p}$ remains the same as in (5.8): 


$$
t_{p}=\frac{D T}{p}+\frac{1}{\theta}-\sqrt{\frac{D T^{2}}{p}\left(\frac{D}{p}-1\right)+\frac{1}{\theta^{2}}}
$$

Substituting the expression for $t_{p}$ into Equation (5.16), and substituting the exponential expressions as sums of series while ignoring cubic and higher terms, which have very small values, we get, after some simplification, the total cost per unit time for the inventory model for an exponentially decaying item, without considering the time value of money:

$$
\begin{gathered}
T C=\frac{1}{T}\left[A+\frac{c p}{\theta}\left(1-\frac{F}{\theta}\right)\right]+T\left[F c D\left(1-\frac{D}{p}\right)\right]-\frac{c p}{\theta}\left(1-\frac{F}{\theta}\right) \sqrt{\frac{1}{T^{2}}-\frac{D \theta^{2}(p-D)}{p^{2}}}- \\
\sqrt{-\frac{F^{2} c^{2} D(p-D)^{3}}{p^{2}} T^{2}+\frac{F^{2} c^{2}(p-D)^{2}}{\theta^{2}}}+c D+F c \frac{(p-D)}{\theta}
\end{gathered}
$$

The total cost function consists of the following four components as functions of $T$, and a constant part:

$$
\begin{aligned}
& T\left[F c D\left(1-\frac{D}{p}\right)\right] \\
& \sqrt{-\frac{F^{2} c^{2} D(p-D)^{3}}{p^{2}} T^{2}+\frac{F^{2} c^{2}(p-D)^{2}}{\theta^{2}}} \\
& \frac{1}{T}\left[A+\frac{c p}{\theta}\left(1-\frac{F}{\theta}\right)\right] \\
& \frac{c p}{\theta}\left(1-\frac{F}{\theta}\right) \sqrt{\frac{1}{T^{2}}-\frac{D \theta^{2}(p-D)}{p^{2}}}
\end{aligned}
$$

The first component is a linear function of $T$, with a positive slope. The second is a square root of a quadratic equation, which is in general represented as follows:

$$
Y= \pm \sqrt{A x^{2}+B x+C}
$$


For that component, the square root has a negative sign, coefficient $A$ is negative, $B$ is equal to zero, and $C$ is positive. This function, where $A<0$ and $\Delta=4 A C-B^{2}<0$, has a convex shape (Bronshtein and Semendyaev, 1980).

The other two components of the total cost function are the inverse function and the square root of inverse quadratic equation. Grouping these two components gives us:

$$
\begin{aligned}
& \frac{1}{T}\left[A+\frac{c p}{\theta}\left(1-\frac{F}{\theta}\right)\right]-\frac{c p}{\theta}\left(1-\frac{F}{\theta}\right) \sqrt{\frac{1}{T^{2}}-\frac{D \theta^{2}(p-D)}{p^{2}}} \\
\text { or } \quad & \frac{A}{T}+\frac{c p}{\theta}\left(1-\frac{F}{\theta}\right)\left(\frac{1}{T}-\sqrt{\frac{1}{T^{2}}-\frac{D \theta^{2}(p-D)}{p^{2}}}\right)
\end{aligned}
$$

Under the square root, we have the expression $\frac{D \theta^{2}(p-D)}{p^{2}}$, which can be written as $\theta^{2} \frac{D}{p}\left(1-\frac{D}{p}\right)$. Since $\theta<1, \frac{D}{p}<1$, and $T<1$, the value of this expression is very small when compared to $\frac{1}{T^{2}}$ and is considered negligible. In this case, the sum of these two components becomes equal to $\frac{A}{T}$, which is a convex function.

Since all the functions are convex, their summation is also a convex function, which yields a global minimum on the positive part of the $T$ axis. Hence, the Golden Search technique can be applied to find the optimal policy and will always reach the global minimum.

\subsection{Numerical Example and Sensitivity Analysis}

A numerical example is presented to illustrate the application of the models developed. Consider an inventory system with the following data: 
$p=4500$ units/yr, $\quad D=1500$ units/yr, $\quad A=50 \$ /$ order, $\quad F=0.15 \$ / \$ / \mathrm{yr}, \quad c=2 \$ /$ unit, $\theta=0.05$ unit/unit/yr.

A software was developed with Visual Basic Applications to apply the Golden Search technique and find the optimal policies for the models developed. The model was applied for Case 1, using different values of real interest rate, and the results obtained are summarized in Table 5.1. They show the relations between cycle time, $T$, order quantity, $Q$, maximum inventory on hand, $I_{\max }$, and the real interest rate $r$. Figure 5.3 shows the effect of $r$ on the optimal values of the cycle time, $T$, and present value of the total cost $P_{t}$. As expected, the cycle time decreases as the real interest rate increases. Accordingly, the optimal production quantity and maximum inventory on hand decrease with higher real interest rates. The present value of the total cost also decreases as the real interest rate increases.

\begin{tabular}{|c|c|c|c|c|c|}
\hline $\begin{array}{c}\text { Real interest } \\
\text { rate } \boldsymbol{r} \\
\text { (\%) }\end{array}$ & $\begin{array}{c}\boldsymbol{T} \\
\text { (months) }\end{array}$ & $\begin{array}{c}\boldsymbol{Q} \\
\text { (units) }\end{array}$ & $\begin{array}{c}\boldsymbol{I}_{\text {max }} \\
\text { (units) }\end{array}$ & $\begin{array}{c}\boldsymbol{P}_{\boldsymbol{t}} \\
\mathbf{( \$ )}\end{array}$ & $\begin{array}{c}\text { PV for first } \\
\text { year, } \\
\mathbf{( \$ )}\end{array}$ \\
\hline $0 \%$ & 5.93 & 746.92 & 495.88 & - & $3,201.23$ \\
\hline $1 \%$ & 5.77 & 727.31 & 482.92 & $320,788.74$ & $3,191.64$ \\
\hline $2 \%$ & 5.58 & 702.41 & 466.45 & $160,766.02$ & $3,182.50$ \\
\hline $3 \%$ & 5.4 & 680.00 & 451.63 & $107,417.56$ & $3,173.03$ \\
\hline $4 \%$ & 5.24 & 660.00 & 438.39 & $80,738.17$ & $3,163.32$ \\
\hline $5 \%$ & 5.09 & 640.88 & 425.74 & $64,726.76$ & $3,153.61$ \\
\hline $6 \%$ & 4.96 & 623.70 & 414.36 & $54,049.60$ & $3,143.79$ \\
\hline $7 \%$ & 4.83 & 608.06 & 404.01 & $46,420.77$ & $3,135.80$ \\
\hline $8 \%$ & 4.71 & 593.15 & 394.13 & $40,697.29$ & $3,124.31$ \\
\hline $9 \%$ & 4.61 & 579.41 & 385.03 & $36,244.15$ & $3,114.77$ \\
\hline $10 \%$ & 4.5 & 566.44 & 376.44 & $32,680.35$ & $3,105.25$ \\
\hline $11 \%$ & 4.41 & 554.45 & 368.50 & $29,763.41$ & $3,095.94$ \\
\hline $12 \%$ & 4.32 & 542.86 & 360.82 & $27,331.69$ & $3,086.74$ \\
\hline $13 \%$ & 4.23 & 532.27 & 353.80 & $25,273.25$ & $3,077.65$ \\
\hline $14 \%$ & 4.16 & 522.41 & 347.26 & $23,508.15$ & $3,068.72$ \\
\hline $15 \%$ & 4.08 & 512.88 & 340.94 & $21,977.77$ & $3,059.96$ \\
\hline
\end{tabular}

Table 5.1 Optimal ordering policies for different values of $r$ 


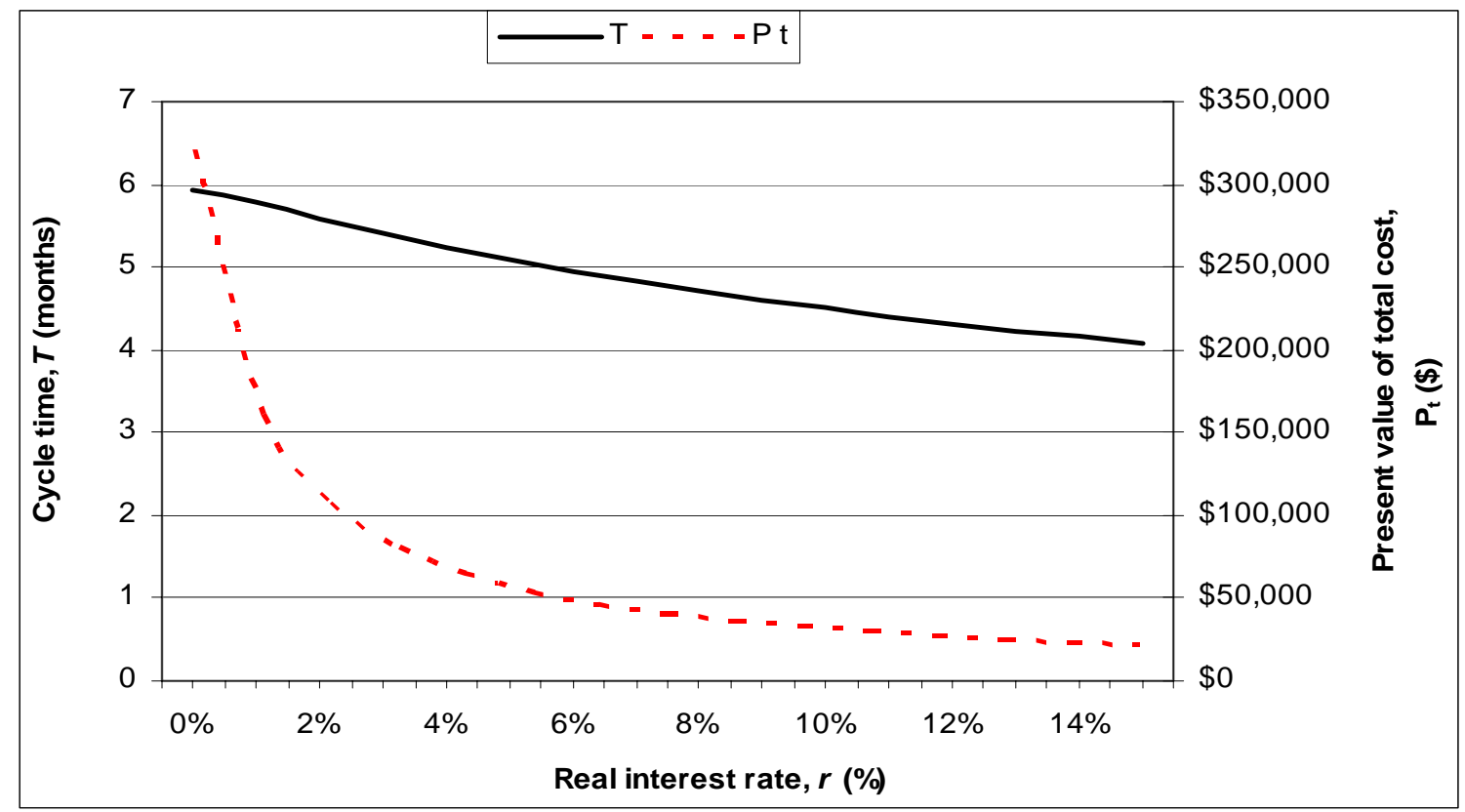

Figure 5.3 Effect of real interest rate $r$ on cycle time $T$ and present value of the total $\operatorname{cost} \boldsymbol{P}_{t}$

The results obtained using different values of deterioration rate, $\theta$, are summarized in Table 5.2.

\begin{tabular}{|c|c|c|c|c|}
\hline $\begin{array}{c}\text { Deterioration rate } \boldsymbol{\theta} \\
\text { (\%) }\end{array}$ & $\begin{array}{c}\boldsymbol{T} \\
\text { (months) }\end{array}$ & $\begin{array}{c}\boldsymbol{Q} \\
\text { (units) }\end{array}$ & $\begin{array}{c}\boldsymbol{I}_{\text {max }} \\
\text { (units) }\end{array}$ & $\begin{array}{c}\boldsymbol{P}_{\boldsymbol{t}} \\
\mathbf{( \$ )}\end{array}$ \\
\hline $1 \%$ & 5.05 & 631.98 & 421.02 & $40,489.46$ \\
\hline $2 \%$ & 4.96 & 621.48 & 413.75 & $40,542.82$ \\
\hline $3 \%$ & 4.87 & 611.46 & 406.81 & $40,595.20$ \\
\hline $4 \%$ & 4.79 & 601.89 & 400.19 & $40,646.68$ \\
\hline $5 \%$ & 4.71 & 593.15 & 394.13 & $40,697.29$ \\
\hline $6 \%$ & 4.64 & 584.36 & 388.06 & $40,747.07$ \\
\hline $7 \%$ & 4.57 & 576.36 & 382.52 & $40,796.08$ \\
\hline $8 \%$ & 4.50 & 568.56 & 377.13 & $40,844.33$ \\
\hline $9 \%$ & 4.44 & 561.03 & 371.93 & $40,891.88$ \\
\hline $10 \%$ & 4.38 & 553.81 & 366.95 & $40,938.74$ \\
\hline $11 \%$ & 4.32 & 546.75 & 362.07 & $40,984.95$ \\
\hline $12 \%$ & 4.26 & 540.33 & 357.64 & $41,030.54$ \\
\hline $13 \%$ & 4.21 & 534.08 & 353.32 & $41,075.53$ \\
\hline $14 \%$ & 4.16 & 527.81 & 349.00 & $41,119.93$ \\
\hline $15 \%$ & 4.10 & 521.84 & 344.88 & $41,163.79$ \\
\hline
\end{tabular}

Table 5.2 Optimal ordering policies for different values of $\theta$ 
Figure 5.4 shows the effect of $\theta$ on the optimal values of $T$ and $P_{t}$. As expected, the cycle time gets smaller with the increase in deterioration rate. Although the present value of the total cost increases, the changes are not significant.

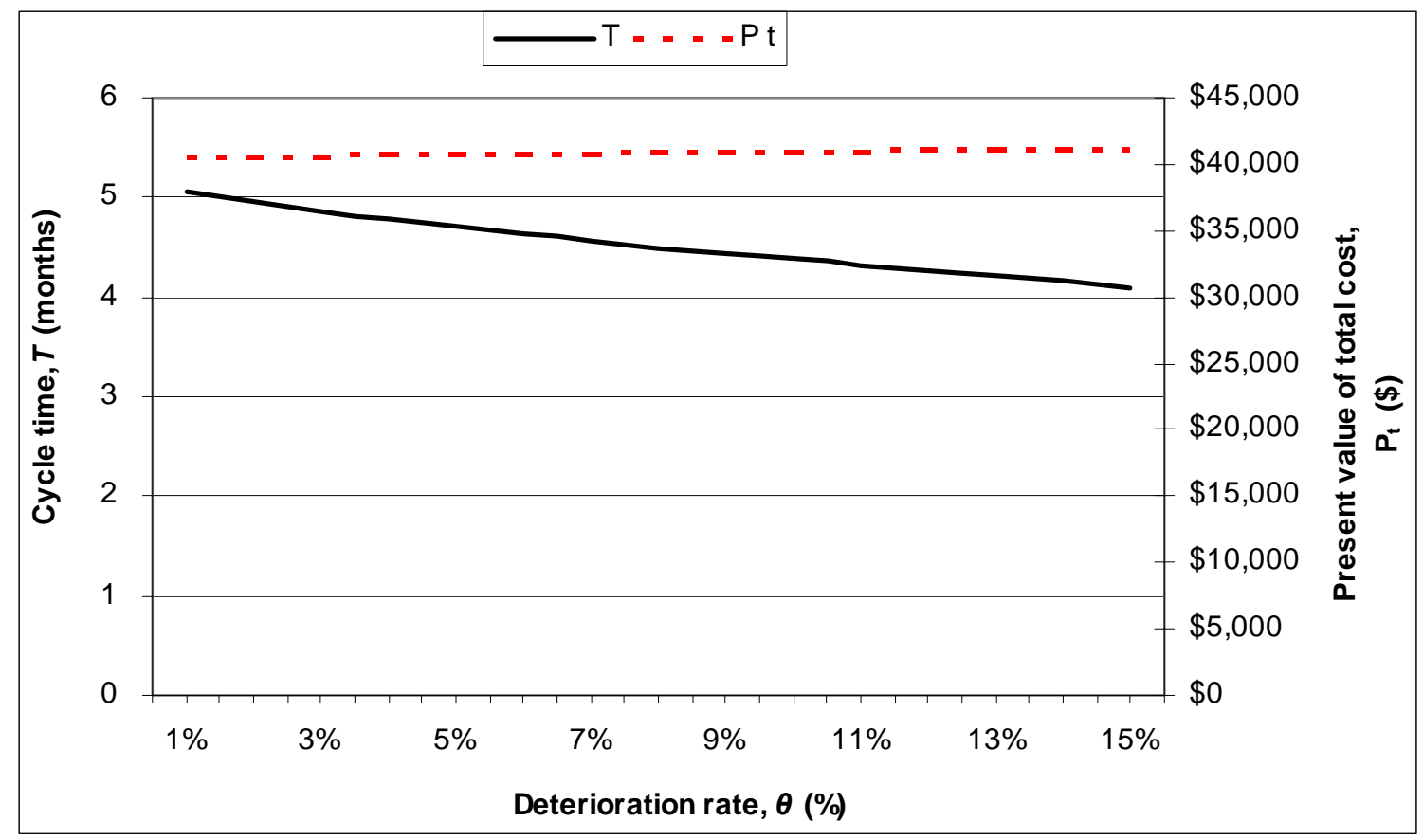

Figure 5.4 Effect of deterioration rate $\theta$ on cycle time $T$ and present value of the total $\operatorname{cost} \boldsymbol{P}_{t}$

Tables 5.3, 5.4, and 5.5 along with Figures 5.5, 5.6 and 5.7 show the results obtained for different values of carrying rate, $F$, demand rate, $D$, and setup cost, $A$, and effect of these parameters on the optimal values of $T$ and $P_{t}$. Similar to the results presented in previous chapters, the cycle time gets smaller with the increase in $F$ and $D$. Increases in the setup cost result in higher values of $T$. The present value of the total cost increases significantly with the increase in $D$ and $A$, and remains relatively flat with the changes in $F$. 


\begin{tabular}{|c|c|c|c|c|}
\hline $\begin{array}{c}\text { Carrying rate } \boldsymbol{F} \\
\text { (\%) }\end{array}$ & $\begin{array}{c}\boldsymbol{T} \\
\text { (months) }\end{array}$ & $\begin{array}{c}\boldsymbol{Q} \\
\text { (units) }\end{array}$ & $\begin{array}{c}\boldsymbol{I}_{\text {max }} \\
\text { (units) }\end{array}$ & $\begin{array}{c}\boldsymbol{P}_{\boldsymbol{t}} \\
\mathbf{( \$ )}\end{array}$ \\
\hline $6 \%$ & 5.55 & 698.80 & 464.06 & $40,217.43$ \\
\hline $7 \%$ & 5.43 & 684.16 & 454.38 & $40,274.88$ \\
\hline $8 \%$ & 5.32 & 670.43 & 445.29 & $40,331.15$ \\
\hline $9 \%$ & 5.22 & 657.75 & 436.90 & $40,386.32$ \\
\hline $10 \%$ & 5.13 & 645.41 & 428.73 & $40,440.44$ \\
\hline $11 \%$ & 5.03 & 633.61 & 420.92 & $40,493.59$ \\
\hline $12 \%$ & 4.95 & 622.66 & 413.68 & $40,545.80$ \\
\hline $13 \%$ & 4.87 & 612.26 & 406.79 & $40,597.12$ \\
\hline $14 \%$ & 4.79 & 602.68 & 400.45 & $40,647.60$ \\
\hline $15 \%$ & 4.71 & 593.15 & 394.13 & $40,697.29$ \\
\hline $16 \%$ & 4.64 & 584.13 & 388.16 & $40,746.20$ \\
\hline $17 \%$ & 4.57 & 575.42 & 382.39 & $40,794.39$ \\
\hline $18 \%$ & 4.51 & 567.29 & 377.00 & $40,841.87$ \\
\hline $19 \%$ & 4.45 & 559.15 & 371.61 & $40,888.69$ \\
\hline $20 \%$ & 4.39 & 551.86 & 366.78 & $40,934.87$ \\
\hline
\end{tabular}

Table 5.3 Optimal ordering policies for different values of $\boldsymbol{F}$

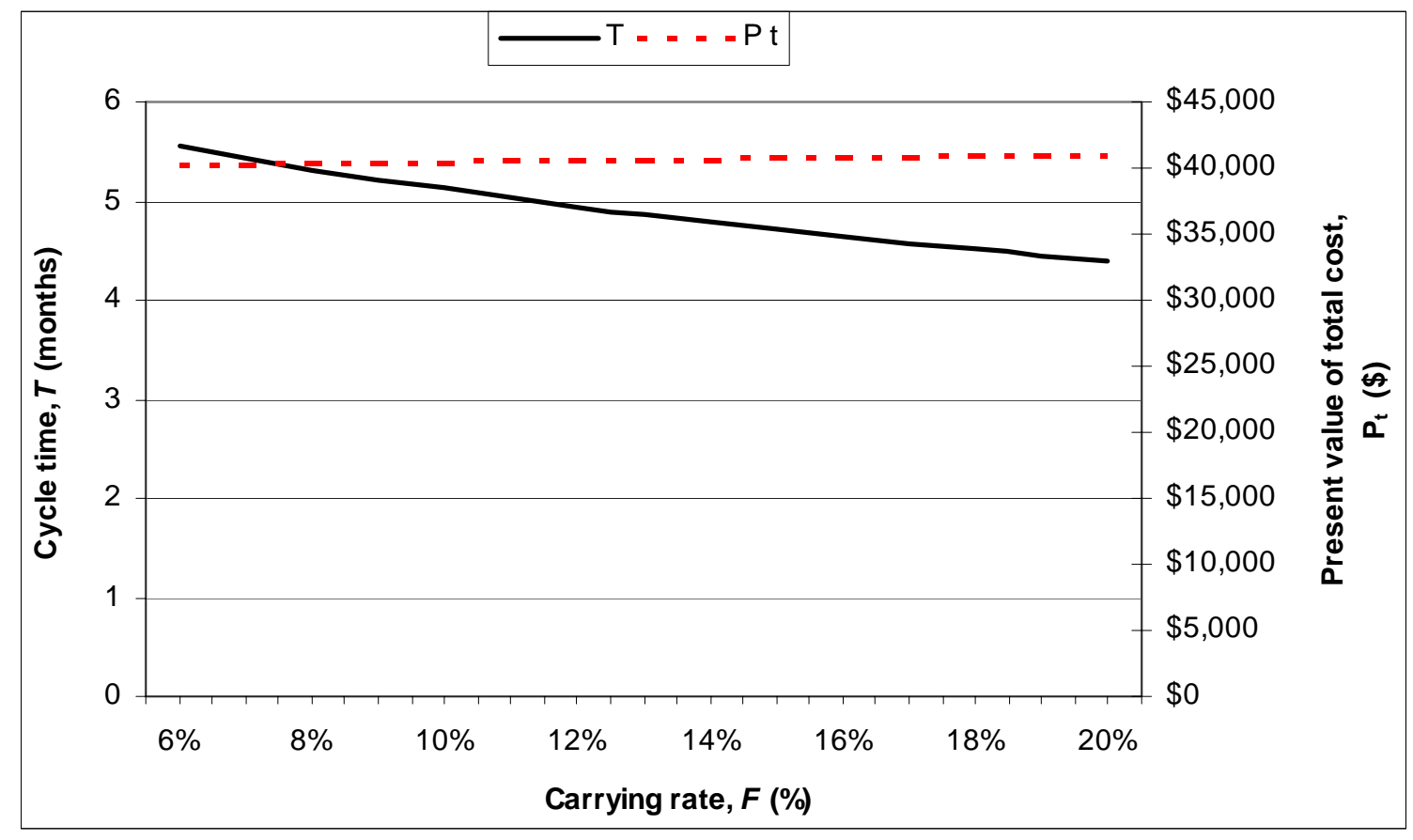

Figure 5.5 Effect of carrying rate $F$ on cycle time $T$ and present value of the total cost $P_{t}$ 


\begin{tabular}{|c|c|c|c|c|}
\hline $\begin{array}{c}\text { Demand rate } \boldsymbol{D} \\
\text { (units/time) }\end{array}$ & $\begin{array}{c}\boldsymbol{T} \\
\text { (months) }\end{array}$ & $\begin{array}{c}\boldsymbol{Q} \\
\text { (units) }\end{array}$ & $\begin{array}{c}\boldsymbol{I}_{\max } \\
\text { (units) }\end{array}$ & $\begin{array}{c}\boldsymbol{P}_{\boldsymbol{t}} \\
\text { (\$) }\end{array}$ \\
\hline 1,000 & 5.48 & 460.63 & 357.35 & $27,750.27$ \\
\hline 1,100 & 5.28 & 487.80 & 367.56 & $30,355.28$ \\
\hline 1,200 & 5.11 & 514.61 & 376.31 & $32,951.74$ \\
\hline 1,300 & 4.96 & 541.08 & 383.61 & $35,540.46$ \\
\hline 1,400 & 4.83 & 566.85 & 389.27 & $38,122.13$ \\
\hline 1,500 & 4.71 & 593.15 & 394.13 & $40,697.29$ \\
\hline 1,600 & 4.61 & 619.03 & 397.56 & $43,266.39$ \\
\hline 1,700 & 4.53 & 645.20 & 400.02 & $45,829.83$ \\
\hline 1,800 & 4.45 & 670.97 & 401.09 & $48,387.93$ \\
\hline 1,900 & 4.38 & 697.38 & 401.37 & $50,940.97$ \\
\hline 2,000 & 4.32 & 723.54 & 400.36 & $53,489.17$ \\
\hline 2,100 & 4.27 & 750.13 & 398.41 & $56,032.75$ \\
\hline 2,200 & 4.22 & 777.08 & 395.46 & $58,571.88$ \\
\hline 2,300 & 4.18 & 804.56 & 391.59 & $61,106.70$ \\
\hline 2,400 & 4.14 & 832.20 & 386.57 & $63,637.34$ \\
\hline
\end{tabular}

Table 5.4 Optimal ordering policies for different values of $D$

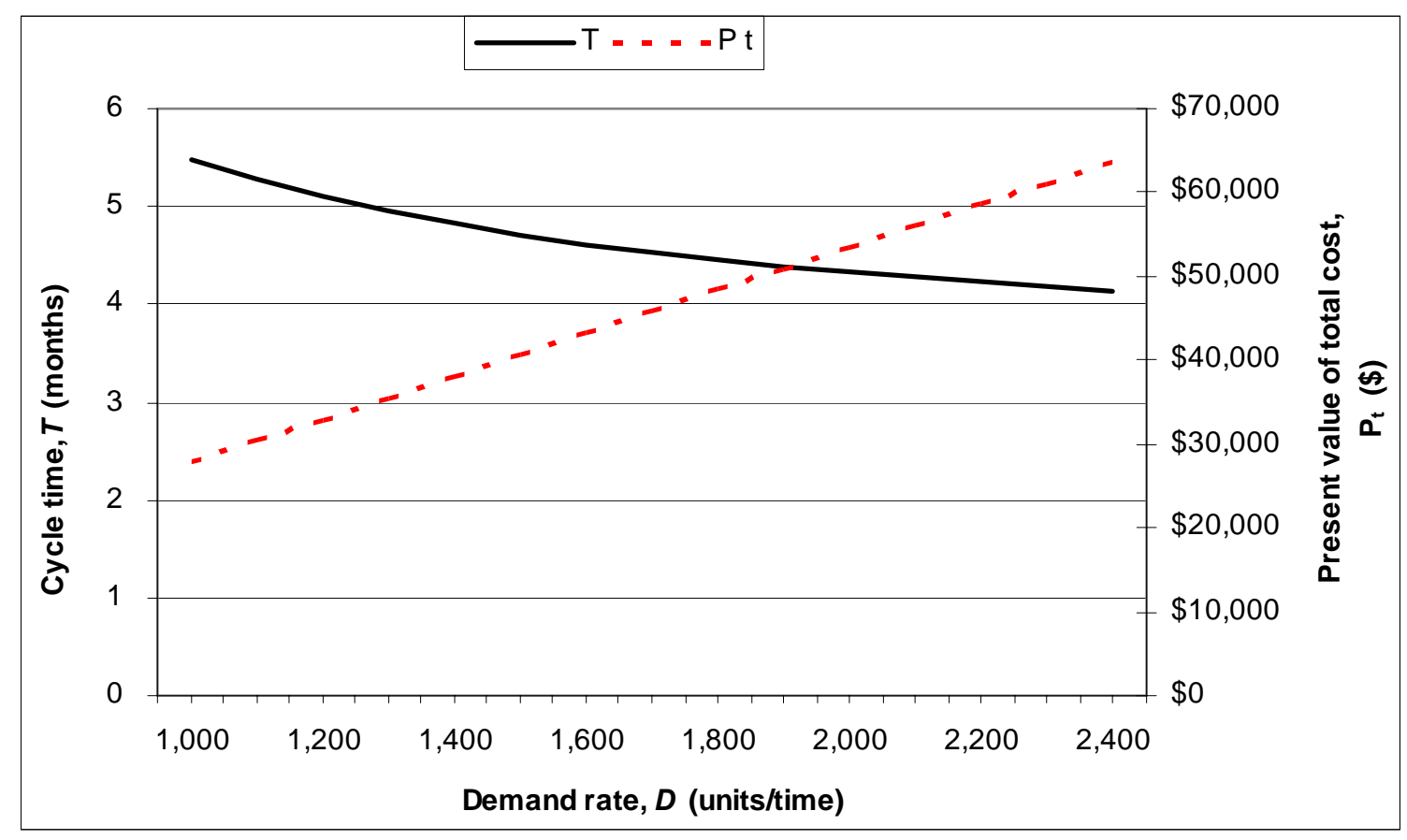

Figure 5.6 Effect of demand rate slope $b$ on cycle time $T$ and present value of the total cost $P_{t}$ 


\begin{tabular}{|c|c|c|c|c|}
\hline $\begin{array}{c}\text { Setup cost } \boldsymbol{A} \\
\text { (\$/order) }\end{array}$ & $\begin{array}{c}\boldsymbol{T} \\
\text { (months) }\end{array}$ & $\begin{array}{c}\boldsymbol{Q} \\
\text { (units) }\end{array}$ & $\begin{array}{c}\boldsymbol{I}_{\text {max }} \\
\text { (units) }\end{array}$ & $\begin{array}{c}\boldsymbol{P}_{\boldsymbol{t}} \\
\mathbf{( \$ )}\end{array}$ \\
\hline$\$ 20$ & 2.99 & 375.19 & 249.61 & $39,514.00$ \\
\hline$\$ 40$ & 4.22 & 530.55 & 352.66 & $40,356.43$ \\
\hline$\$ 60$ & 5.16 & 649.58 & 431.50 & $41,006.12$ \\
\hline$\$ 80$ & 5.95 & 750.07 & 497.97 & $41,556.03$ \\
\hline$\$ 100$ & 6.65 & 838.63 & 556.49 & $42,042.20$ \\
\hline$\$ 120$ & 7.28 & 919.07 & 609.60 & $42,483.07$ \\
\hline$\$ 140$ & 7.86 & 992.78 & 658.22 & $42,889.62$ \\
\hline$\$ 160$ & 8.39 & $1,061.23$ & 703.33 & $43,269.01$ \\
\hline$\$ 180$ & 8.89 & $1,125.44$ & 745.62 & $43,626.19$ \\
\hline$\$ 200$ & 9.37 & $1,186.54$ & 785.84 & $43,964.79$ \\
\hline$\$ 220$ & 9.82 & $1,244.56$ & 824.00 & $44,287.53$ \\
\hline$\$ 240$ & 10.25 & $1,299.85$ & 860.34 & $44,596.53$ \\
\hline$\$ 260$ & 10.67 & $1,352.90$ & 895.19 & $44,893.48$ \\
\hline$\$ 280$ & 11.06 & $1,403.92$ & 928.69 & $45,179.75$ \\
\hline$\$ 300$ & 11.45 & $1,453.38$ & 961.14 & $45,456.46$ \\
\hline
\end{tabular}

Table 5.5 Optimal ordering policies for different values of $\boldsymbol{A}$

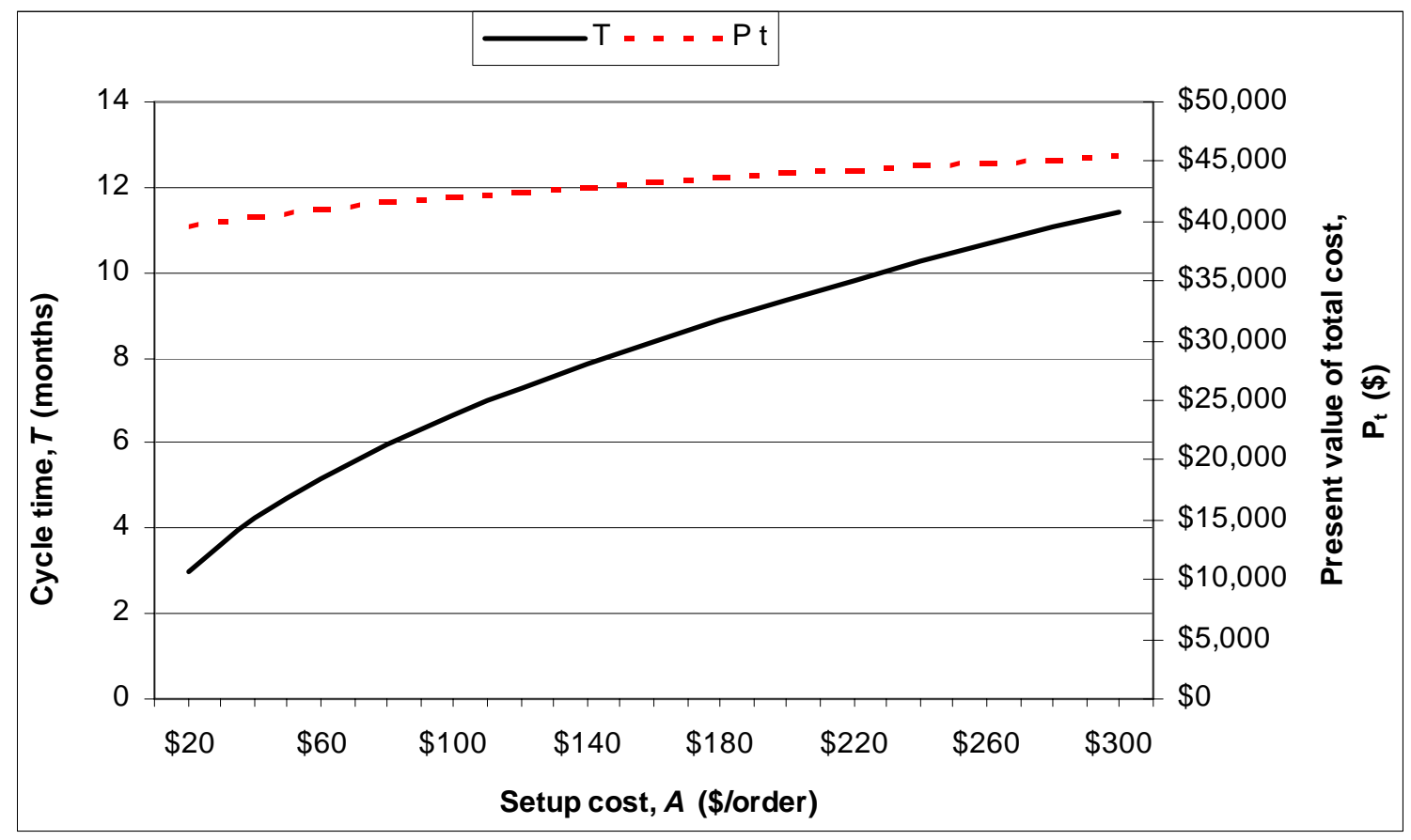

Figure 5.7 Effect of setup cost $A$ on cycle time $T$ and present value of the total $\operatorname{cost} \boldsymbol{P}_{t}$ 
For Case 2, the same example was used, with the same parameters, except that the production cost, $c$, was replaced with a raw material $\operatorname{cost} c_{1}=1.5 \$ /$ unit, and a labor cost $c_{2}=0.5$ \$/unit. The results obtained are summarized in Table 5.6. As in Case 1, the cycle time, order quantity, and maximum inventory on hand decrease as the real interest rate increases. The present value of the total cost also decreases as the real interest rate increases. The effects of all other parameters on the optimal policy are similar to Case 1 and are not repeated here.

\begin{tabular}{|c|c|c|c|c|c|}
\hline $\begin{array}{c}\text { Real interest } \\
\text { rate } \boldsymbol{r} \\
\mathbf{( \% )}\end{array}$ & $\begin{array}{c}\boldsymbol{T} \\
\text { (months) }\end{array}$ & $\begin{array}{c}\boldsymbol{Q} \\
\text { (units) }\end{array}$ & $\begin{array}{c}\boldsymbol{I}_{\text {max }} \\
\text { (units) }\end{array}$ & $\begin{array}{c}\boldsymbol{P}_{\boldsymbol{t}} \\
\mathbf{( \$ )}\end{array}$ & $\begin{array}{c}\text { PV for first } \\
\text { year, } \\
\mathbf{( \$ )}\end{array}$ \\
\hline $0 \%$ & 5.93 & 746.92 & 495.88 & - & $3,201.23$ \\
\hline $1 \%$ & 5.79 & 729.54 & 484.39 & $320,727.46$ & $3,191.06$ \\
\hline $2 \%$ & 5.61 & 706.38 & 469.08 & $160,706.64$ & $3,181.37$ \\
\hline $3 \%$ & 5.44 & 685.56 & 455.30 & $107,359.92$ & $3,171.41$ \\
\hline $4 \%$ & 5.29 & 666.45 & 442.66 & $80,682.13$ & $3,161.23$ \\
\hline $5 \%$ & 5.15 & 648.72 & 430.93 & $64,672.20$ & $3,150.97$ \\
\hline $6 \%$ & 5.02 & 632.21 & 420.00 & $53,996.39$ & $3,140.66$ \\
\hline $7 \%$ & 4.90 & 617.26 & 410.10 & $46,368.82$ & $3,130.43$ \\
\hline $8 \%$ & 4.79 & 603.20 & 400.79 & $40,646.51$ & $3,120.25$ \\
\hline $9 \%$ & 4.69 & 589.51 & 391.72 & $36,194.47$ & $3,110.17$ \\
\hline $10 \%$ & 4.59 & 577.16 & 383.54 & $32,631.69$ & $3,100.22$ \\
\hline $11 \%$ & 4.50 & 565.58 & 375.87 & $29,715.72$ & $3,090.30$ \\
\hline $12 \%$ & 4.41 & 554.45 & 368.50 & $27,284.90$ & $3,080.62$ \\
\hline $13 \%$ & 4.33 & 544.06 & 361.61 & $25,227.32$ & $3,071.01$ \\
\hline $14 \%$ & 4.25 & 534.19 & 355.07 & $23,463.04$ & $3,061.63$ \\
\hline $15 \%$ & 4.18 & 524.99 & 348.97 & $21,933.42$ & $3,052.28$ \\
\hline
\end{tabular}

Table 5.6 Optimal ordering policies for different values of $r$ and two separate costs

Table 5.7 and Figure 5.8 show the results obtained with simultaneous increases in raw material and labor costs, $c_{1}$ and $c_{2}$. As explained in the previous chapters, increases in these costs lead to a significant reduction in the cycle time and considerable increases in the present value of the total cost. 


\begin{tabular}{|c|c|c|c|c|c|c|}
\hline $\begin{array}{c}\text { Raw } \\
\text { material } \\
\text { cost } \boldsymbol{c}_{\mathbf{1}} \\
\mathbf{\$} \mathbf{\text { unit }}\end{array}$ & $\begin{array}{c}\text { Labor } \\
\text { cost } \boldsymbol{c}_{\mathbf{2}} \mathbf{2} \\
\mathbf{\$} / \mathbf{u n i t}\end{array}$ & $\boldsymbol{c}=\boldsymbol{c}_{\mathbf{1}}+\boldsymbol{c}_{\mathbf{2}}$ & $\begin{array}{c}\boldsymbol{T} \\
\text { (months) }\end{array}$ & $\begin{array}{c}\boldsymbol{Q} \\
\text { (units) }\end{array}$ & $\begin{array}{c}\boldsymbol{I}_{\mathbf{m a x}} \\
\text { (units) }\end{array}$ & $\begin{array}{c}\boldsymbol{P}_{\boldsymbol{t}} \\
\mathbf{( \$ )}\end{array}$ \\
\hline$\$ 0.30$ & $\$ 0.10$ & $\$ 0.40$ & 10.64 & $1,349.73$ & 893.11 & $8,926.04$ \\
\hline$\$ 0.60$ & $\$ 0.20$ & $\$ 0.80$ & 7.55 & 953.93 & 632.60 & $17,002.56$ \\
\hline$\$ 0.90$ & $\$ 0.30$ & $\$ 1.20$ & 6.17 & 778.47 & 516.74 & $24,944.96$ \\
\hline$\$ 1.20$ & $\$ 0.40$ & $\$ 1.60$ & 5.35 & 674.08 & 447.71 & $32,817.92$ \\
\hline$\$ 1.50$ & $\$ 0.50$ & $\$ 2.00$ & 4.79 & 603.21 & 400.79 & $40,646.51$ \\
\hline$\$ 1.80$ & $\$ 0.60$ & $\$ 2.40$ & 4.38 & 550.49 & 365.87 & $48,443.57$ \\
\hline$\$ 2.10$ & $\$ 0.70$ & $\$ 2.80$ & 4.05 & 509.57 & 338.75 & $56,216.75$ \\
\hline$\$ 2.40$ & $\$ 0.80$ & $\$ 3.20$ & 3.79 & 476.50 & 316.83 & $63,971.03$ \\
\hline$\$ 2.70$ & $\$ 0.90$ & $\$ 3.60$ & 3.58 & 449.34 & 298.81 & $71,709.84$ \\
\hline$\$ 3.00$ & $\$ 1.00$ & $\$ 4.00$ & 3.39 & 426.34 & 283.56 & $79,435.72$ \\
\hline$\$ 3.30$ & $\$ 1.10$ & $\$ 4.40$ & 3.24 & 406.46 & 270.36 & $87,150.56$ \\
\hline$\$ 3.60$ & $\$ 1.20$ & $\$ 4.80$ & 3.10 & 389.17 & 258.88 & $94,855.84$ \\
\hline$\$ 3.90$ & $\$ 1.30$ & $\$ 5.20$ & 2.98 & 373.80 & 248.68 & $102,552.73$ \\
\hline$\$ 4.20$ & $\$ 1.40$ & $\$ 5.60$ & 2.87 & 360.16 & 239.63 & $110,242.18$ \\
\hline$\$ 4.50$ & $\$ 1.50$ & $\$ 6.00$ & 2.77 & 348.06 & 231.59 & $117,924.98$ \\
\hline
\end{tabular}

Table 5.7 Optimal ordering policies for different values of $c_{1}$ and $c_{2}$

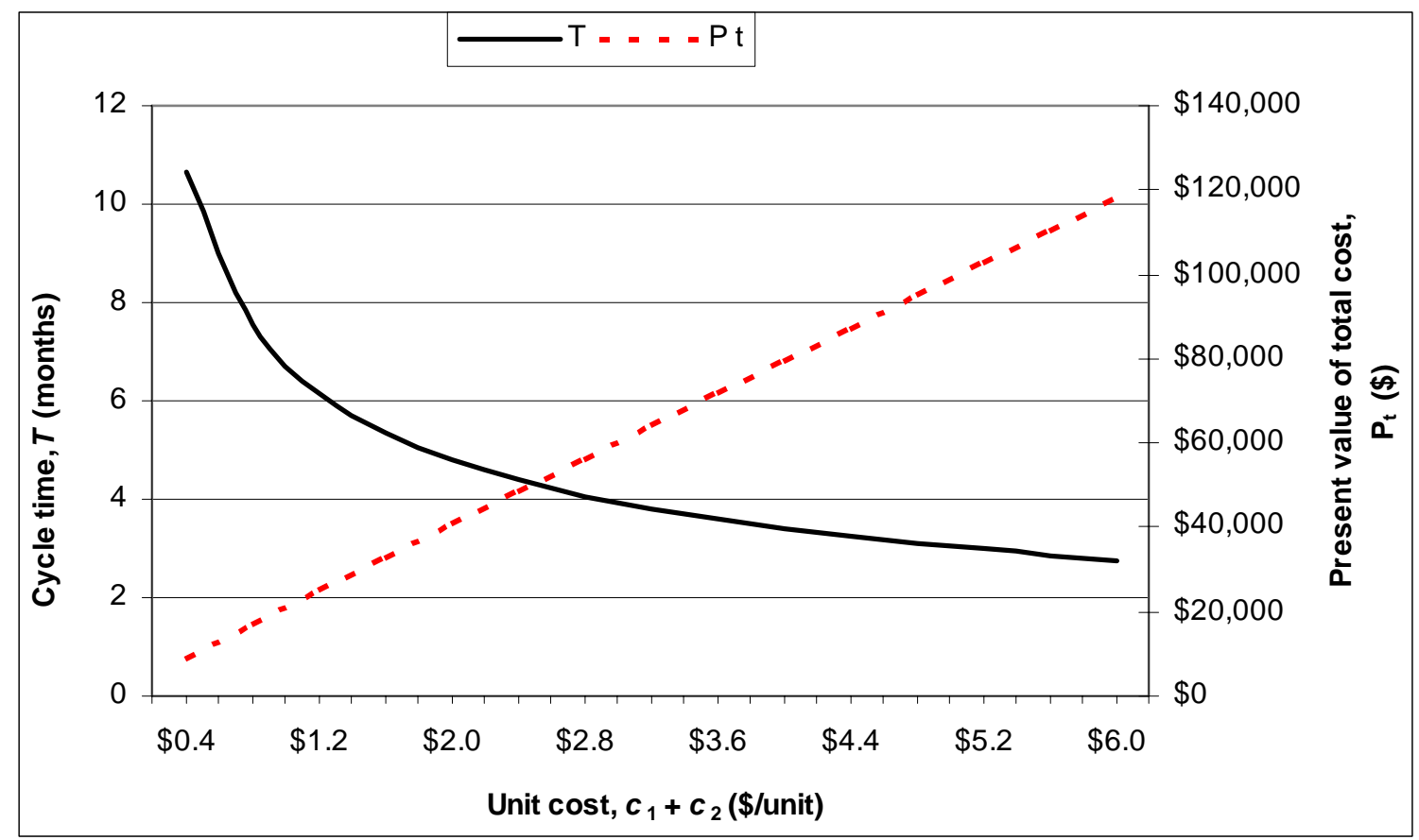

Figure 5.8 Effect of changes in unit costs $c_{1}$ and $c_{2}$ on cycle time $T$ and present value of the total $\operatorname{cost} P_{t}$ 


\subsection{Inventory Models with Shortage}

The objective of the inventory models where shortage is allowed is to determine the optimal cycle time and optimal quantity of allowed shortage in order to minimize the total relevant cost. Consequently, the production time and the maximum inventory level can be determined. The models are applied for an infinite planning horizon. Figure 5.9 gives a graphical representation of the first cycle in the system, when items deteriorate exponentially and shortage is allowed. The inventory production starts at time zero and increases with the rate $p-D$, which is production rate minus consumption rate, until time $t_{1}$. After $t_{1}$, it continues to increase with a rate that is equal to the difference between $p-D$ and the decay rate, $\theta$, and the inventory on hand starts building up until time $t_{p}$ when the production process stops and the inventory on hand reaches its maximum level. After time $t_{p}$, the inventory level decreases with the consumption rate, $D$, and the decay rate, $\theta$, until it becomes zero at time $t_{2}$. After $t_{2}$, the system is out of stock but the demand still exists, and backorders accumulate with the rate of $D$, until the end of the cycle, $T$, when the production process is resumed again.

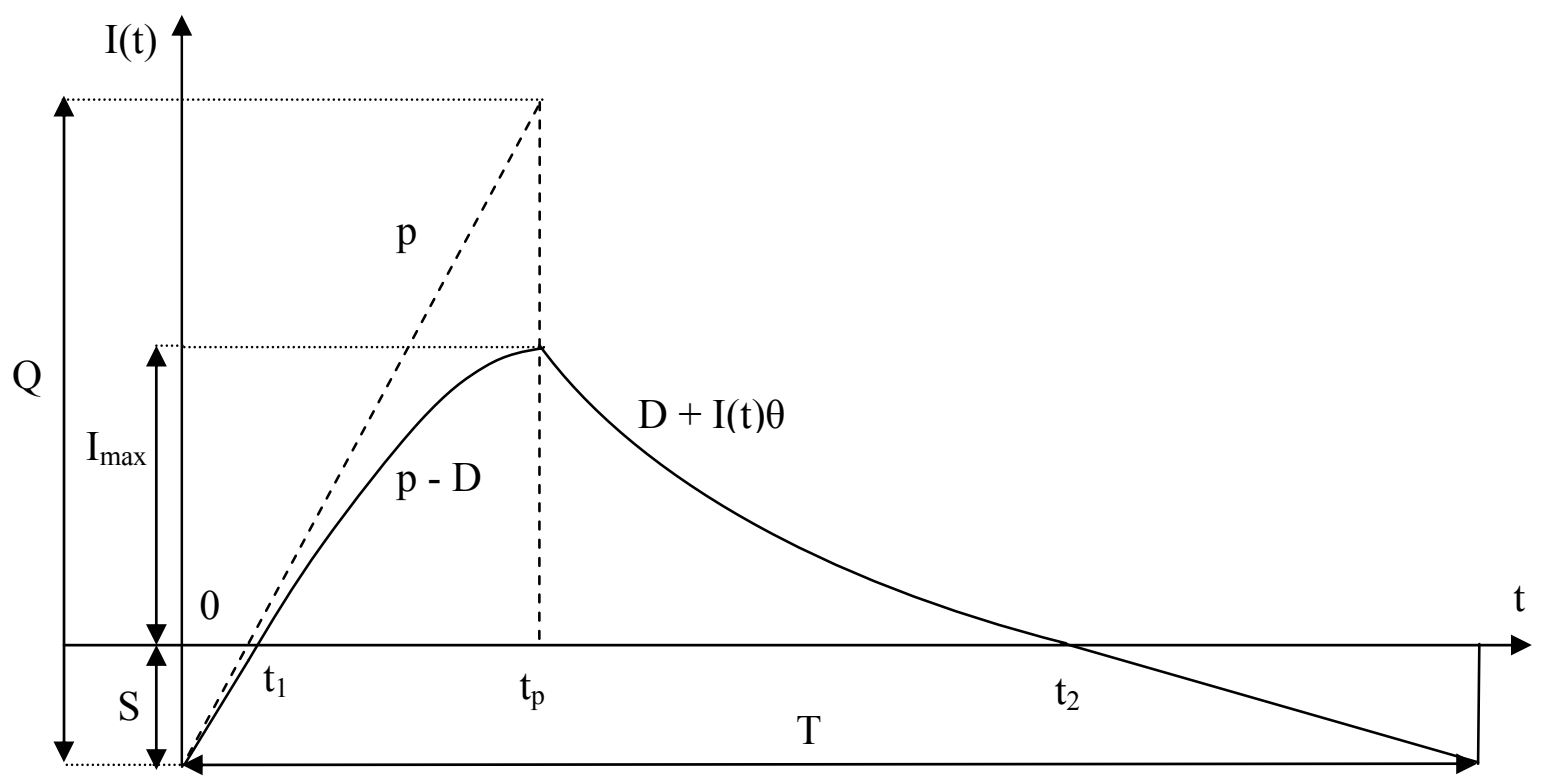

Figure 5.9 EPQ model with shortage for deteriorating items 
The total cost $T C$ for this EPQ model, consists of four elements:

$$
\mathrm{TC}=\text { Setup Cost }+ \text { Shortage Cost }+ \text { Production Cost }+ \text { Holding Cost }
$$

\subsubsection{Case 3}

For this case, the setup cost and the production cost are assumed to be incurred at the beginning of each cycle, and the inventory holding cost is incurred continuously during the cycle. A shortage cost will also be incurred and is addressed below.

The inventory level, $I(t)$, at time $t$ is equal to:

$$
\begin{aligned}
& -I_{1}(t)=S-t(p-D) \quad \text { for } 0<t<t_{1} \\
& I_{2}(t)=\frac{p-D}{\theta}\left(1-e^{-\theta\left(t-t_{1}\right)}\right) \quad \text { for } t_{1}<t<t_{p} \\
& I_{3}(t)=I_{t_{p}} e^{-\theta\left(t-t_{p}\right)}-\frac{D}{\theta}\left(1-e^{-\theta\left(t-t_{p}\right)}\right) \quad \text { for } t_{p}<t<t_{2} \\
& -I_{4}(t)=D\left(t-t_{2}\right) \quad \text { for } t_{2}<t<T
\end{aligned}
$$

where $\quad t_{1}=\frac{S}{p-D} ; \quad t_{2}=T-\frac{S}{D} ; \quad I_{t_{p}}=\frac{p-D}{\theta}\left(1-e^{-\theta\left(t_{p}-t_{1}\right)}\right)$

Assuming that the shortage cost consists of two components: $K_{0}$ times the maximum amount of shortage, $S$, which is incurred at the beginning of the cycle, and $K$ times duration of the shortage, for each unit short, and is incurred during the shortage time of the individual units, and assuming continuous compounding, the present value of the total cost of the inventory system for the first period can be expressed as:

$$
\begin{aligned}
P & =A+c p t_{p}+K \int_{0}^{t_{1}}[S-t(p-D)] e^{-r t} d t+F c \int_{t_{1}}^{t_{p}}\left[\frac{p-D}{\theta}\left(1-e^{-\theta\left(t-t_{1}\right)}\right)\right] e^{-r t} d t \\
& +F c \int_{t_{p}}^{t_{2}}\left[I_{t_{p}} e^{-\theta\left(t-t_{p}\right)}-\frac{D}{\theta}\left(1-e^{-\theta\left(t-t_{p}\right)}\right)\right] e^{-r t} d t+K \int_{t_{2}}^{T} D\left(t-t_{2}\right) e^{-r t} d t+K_{0} S
\end{aligned}
$$


To find the value of $t_{p}$, we equate the inventory level at time $t_{2}$ to zero and substitute for $I_{t_{p}}$ with its value (from Equation (5.4)):

$$
\begin{gathered}
I_{t_{2}}=I_{t_{p}} e^{-\theta\left(t_{2}-t_{p}\right)}-\frac{D}{\theta}\left(1-e^{-\theta\left(t_{2}-t_{p}\right)}\right)=\left[\frac{p-D}{\theta}\left(1-e^{-\theta\left(t_{p}-t_{1}\right)}\right)+\frac{D}{\theta}\right] e^{-\theta\left(t_{2}-t_{p}\right)}-\frac{D}{\theta}=0 \\
p e^{\theta t_{p}}-(p-D) e^{\theta t_{1}}-D e^{\theta t_{2}}=0
\end{gathered}
$$

In general, $e^{x}$ can be expressed as the following series:

$$
e^{x}=1+x+\frac{(x)^{2}}{2 !}+\frac{(x)^{3}}{3 !}+\frac{(x)^{4}}{4 !}+\cdots
$$

Applying this expansion to each of $e^{\theta_{1}}, e^{\theta_{p}}$ and $e^{\theta_{2}}$ and ignoring the cubic and higher terms, which are very close to zero, especially when $\theta<1$, and $t_{1}<t_{p}<t_{2}<1$, Equation (5.19) becomes:

$$
p\left(1+t_{p} \theta+\frac{t_{p}^{2} \theta^{2}}{2}\right)-(p-D)\left(1+t_{1} \theta+\frac{t_{1}^{2} \theta^{2}}{2}\right)-D\left(1+t_{2} \theta+\frac{t_{2}^{2} \theta^{2}}{2}\right)=0
$$

The solution to this quadratic equation is:

$$
t_{p}=-\frac{1}{\theta}+\sqrt{\frac{1}{\theta^{2}}-\frac{2 D}{p \theta}\left(t_{1}-t_{2}\right)-\frac{D}{p}\left(t_{1}^{2}-t_{2}^{2}\right)+\frac{2 t_{1}}{\theta}+t_{1}^{2}}
$$

Since the present value, $P$, for the first period is repeated at the beginning of each of the following cycles, the present value of the total cost for $N$ cycles, $P_{t}$, can be calculated as follows:

$$
P_{t}=P\left(1+e^{-r T}+e^{-2 r T}+\cdots+e^{-(N-1) r T}\right)
$$

For an infinite planning horizon, $N \rightarrow \infty, P_{t}$ can be expressed as:

$$
P_{t}=P\left(\frac{1}{1-e^{-r T}}\right)
$$


Solving for $P$ in Equation (5.18) after performing the integrations and simplifying, and substituting for it in the above equation, we get the present value, $P_{t}$, of the total cost:

$$
\begin{aligned}
P_{t}= & \left(\frac{1}{1-e^{-r T}}\right)\left\{A+c p t_{p}+\frac{K(p-D)}{r}\left[t_{1}+\frac{1}{r}\left(e^{-r t_{1}}-1\right)\right]+\right. \\
& \frac{F c(p-D)}{\theta}\left[\frac{1}{r}-\frac{e^{-r t_{1}}}{\theta+r}\left(1-e^{-t_{p}(\theta+r)}\right)\right]+\frac{\left(F c p e^{\theta t_{p}}-F c(p-D) e^{\theta t_{1}}\right)}{\theta(\theta+r)}\left(e^{-t_{p}(\theta+r)}-e^{-t_{2}(\theta+r)}\right)+ \\
& \left.\frac{F c}{r \theta}\left(D e^{-r t_{2}}-p e^{-r t_{p}}\right)+K_{0} t_{1}(p-D)+\frac{K D}{r}\left(e^{-r T}\left(t_{2}-\frac{1}{r}-T\right)+\frac{e^{-r t_{2}}}{r}\right)\right\}
\end{aligned}
$$

where $t_{1}=\frac{S}{p-D} ; \quad t_{2}=T-\frac{S}{D} ; \quad t_{p}=-\frac{1}{\theta}+\sqrt{\frac{1}{\theta^{2}}-\frac{2 D}{p \theta}\left(t_{1}-t_{2}\right)-\frac{D}{p}\left(t_{1}{ }^{2}-t_{2}{ }^{2}\right)+\frac{2 t_{1}}{\theta}+t_{1}{ }^{2}}$

The total inventory cost in Equation (5.21) is a function of the cycle time, $T$, and the shortage, $S$. Closed formulas could not be obtained for the optimal values of $T$ and $S$. A search technique needs to be applied to find the optimal policy. The same iterative search procedure described in Chapter 3, which uses a combination of a modified version of the Simplex Evolutionary Operation (EVOP) and a Univariate Walk is used to find the optimal policy. In order for the search procedure to work more efficiently, variables are normalized in order for them to have comparable ranges.

\subsubsection{Case 4}

For this case, as in the models without shortage, the production cost, $c$, has two components. A cost, $c_{1}$, that is incurred at the beginning of each cycle and is applied to the total quantity produced during the production period and a second cost, $c_{2}$, which is incurred as the production process takes place. 
The main difference between the two cases is in the production cost. Equation (5.12) is applicable for the model with shortages as well. In addition, the unit production cost is replaced with the sum of the components, $c_{1}$ and $c_{2}$.

The present value of the total cost for the first period for the inventory system where shortages are allowed becomes:

$$
\begin{aligned}
P= & A+c_{1} Q+c_{2} p \int_{0}^{t_{p}} e^{-r t} d t+K \int_{0}^{t_{1}} I_{1}(t) e^{-r t} d t+F c_{3} \int_{t_{1}}^{t_{p}} I_{2}(t) e^{-r t} d t+F c_{3} \int_{t_{p}}^{t_{2}} I_{3}(t) e^{-r t} d t+ \\
& K \int_{t_{2}}^{T} I_{4}(t) e^{-r t} d t+K_{0} S
\end{aligned}
$$

where $c_{3}=c_{1}+c_{2}$

The procedure followed in Case 3 is repeated and leads to the following value for the total cost for all cycles:

$$
\begin{aligned}
P_{t}= & \left(\frac{1}{1-e^{-r T}}\right)\left\{A+c_{1} p t_{p}+\frac{c_{2} p}{r}\left(1-e^{-r t_{p}}\right)+\frac{K(p-D)}{r}\left[t_{1}+\frac{1}{r}\left(e^{-r t_{1}}-1\right)\right]+\right. \\
& \frac{F\left(c_{1}+c_{2}\right)(p-D)}{\theta}\left[\frac{1}{r}-\frac{e^{-r t_{1}}}{\theta+r}\left(1-e^{-t_{p}(\theta+r)}\right)\right]+ \\
& \frac{\left(F\left(c_{1}+c_{2}\right) p e^{\theta t_{p}}-F\left(c_{1}+c_{2}\right)(p-D) e^{\theta t_{1}}\right)}{\theta(\theta+r)}\left(e^{-t_{p}(\theta+r)}-e^{-t_{2}(\theta+r)}\right)+ \\
& \frac{F\left(c_{1}+c_{2}\right)}{r \theta}\left(D e^{-r t_{2}}-p e^{-r t_{p}}\right)+ \\
& \left.K_{0} t_{1}(p-D)+\frac{K D}{r}\left[e^{-r T}\left(t_{2}-\frac{1}{r}-T\right)+\frac{e^{-r t_{2}}}{r}\right]\right\}
\end{aligned}
$$

where $t_{1}=\frac{S}{p-D} ; \quad t_{2}=T-\frac{S}{D} ; \quad t_{p}=-\frac{1}{\theta}+\sqrt{\frac{1}{\theta^{2}}-\frac{2 D}{p \theta}\left(t_{1}-t_{2}\right)-\frac{D}{p}\left(t_{1}{ }^{2}-t_{2}{ }^{2}\right)+\frac{2 t_{1}}{\theta}+t_{1}{ }^{2}}$ 
Similar to Case 3, the total inventory cost is a function of $T$ and $S$ and a search procedure is used to find the minimum total inventory cost. Other inventory variables can be calculated based on the values of $T$ and $S$ obtained with the search technique.

\subsection{Numerical Example and Sensitivity Analysis}

A numerical example is presented to illustrate the application of the models developed for the inventory system where shortage is allowed and items are fully backordered. A software was developed, using Visual Basic Applications, to apply the search technique that was developed based on the modified EVOP and a Univariate Walk. Consider an inventory system with the following data:

$$
\begin{aligned}
p=4500 \text { units/yr, } \quad D=1500 \text { units/yr }, \quad A=50 \$ / \text { order }, \quad F=0.15 \$ / \$ / \mathrm{yr}, \quad c=2 \$ / \text { unit } \\
\theta=0.05 \text { unit/unit/yr }, \quad K=1 \$ / \text { unit } / \mathrm{yr}, \quad K_{0}=0 \$ \text { unit. }
\end{aligned}
$$

The model was applied for Case 3, using different values of real interest rate, and the results obtained are summarized in Table 5.8. This table shows the relations between the optimal values of the cycle time, order quantity, shortage, maximum inventory on hand, and the real interest rate. As expected, the cycle time decreases as the real interest rate increases. Accordingly, the optimal production quantity, $Q$, shortage, $S$, and maximum inventory on hand, $I_{\max }$, decrease with higher real interest rates. The present value of the total cost also decreases as the real interest rate increases.

Figure 5.10 shows the effects of real interest rate, $r$, on the optimal production quantity, $Q$, shortage, $S$, and present value of the total cost. Table 5.9 and Figure 5.11 illustrate the effect of the deterioration rate, $\theta$, on the optimal policy. Increases in the deterioration rate result in 
decreases in production quantity and increases in shortage. The present value of the total cost also increases but at a very slow rate.

\begin{tabular}{|c|c|c|c|c|c|}
\hline $\begin{array}{c}\text { Real interest } \\
\text { rate } \boldsymbol{r} \\
(\%)\end{array}$ & $\begin{array}{c}\boldsymbol{T} \\
\text { (months) }\end{array}$ & $\begin{array}{c}\boldsymbol{Q} \\
\text { (units) }\end{array}$ & $\begin{array}{c}\boldsymbol{S} \\
\text { (units) }\end{array}$ & $\begin{array}{c}\boldsymbol{I}_{\text {max }} \\
\text { (units) }\end{array}$ & $\begin{array}{c}\boldsymbol{P}_{\boldsymbol{t}} \\
\text { (\$) }\end{array}$ \\
\hline $1 \%$ & 6.00 & 754.52 & 77.11 & 424.40 & $320,014.31$ \\
\hline $2 \%$ & 5.78 & 726.98 & 74.39 & 408.86 & $160,392.72$ \\
\hline $3 \%$ & 5.59 & 702.03 & 71.76 & 394.95 & $107,177.07$ \\
\hline $4 \%$ & 5.41 & 679.85 & 69.64 & 382.37 & $80,563.50$ \\
\hline $5 \%$ & 5.25 & 659.18 & 67.57 & 370.73 & $64,591.19$ \\
\hline $6 \%$ & 5.10 & 640.53 & 65.73 & 360.20 & $53,939.81$ \\
\hline $7 \%$ & 4.96 & 623.29 & 63.88 & 350.62 & $46,329.17$ \\
\hline $8 \%$ & 4.83 & 607.20 & 62.12 & 341.71 & $40,619.17$ \\
\hline $9 \%$ & 4.72 & 592.34 & 60.65 & 333.32 & $36,176.40$ \\
\hline $10 \%$ & 4.61 & 578.53 & 59.22 & 325.58 & $32,620.79$ \\
\hline $11 \%$ & 4.50 & 565.55 & 57.83 & 318.36 & $29,710.46$ \\
\hline $12 \%$ & 4.41 & 553.68 & 56.77 & 311.54 & $27,284.18$ \\
\hline $13 \%$ & 4.32 & 542.22 & 55.53 & 305.17 & $25,230.29$ \\
\hline $14 \%$ & 4.24 & 531.61 & 54.42 & 299.24 & $23,469.05$ \\
\hline $15 \%$ & 4.15 & 521.46 & 53.31 & 293.61 & $21,941.96$ \\
\hline
\end{tabular}

Table 5.8 Optimal ordering policies for different values of $r$ when shortages are allowed

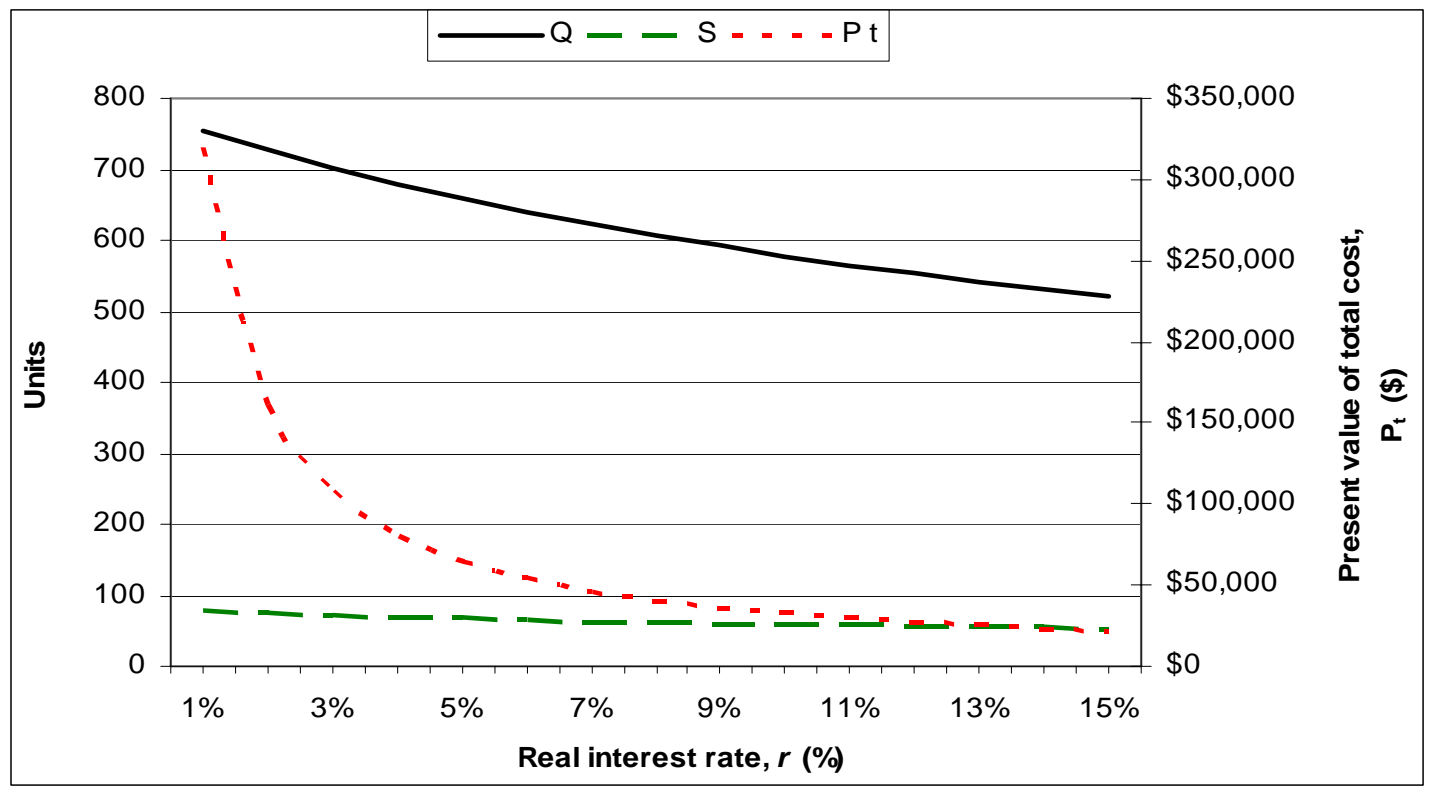

Figure 5.10 Effect of real interest rate $r$ on ordering quantity $Q$, shortage $S$ and present value of the total $\operatorname{cost} \boldsymbol{P}_{t}$ 


\begin{tabular}{|c|c|c|c|c|c|}
\hline $\begin{array}{c}\text { Deterioration } \\
\text { rate } \boldsymbol{\theta} \\
\text { (\%) }\end{array}$ & $\begin{array}{c}\boldsymbol{T} \\
\text { (months) }\end{array}$ & $\begin{array}{c}\boldsymbol{Q} \\
\text { (units) }\end{array}$ & $\begin{array}{c}\boldsymbol{S} \\
\text { (units) }\end{array}$ & $\begin{array}{c}\boldsymbol{I}_{\max } \\
\text { (units) }\end{array}$ & $\begin{array}{c}\boldsymbol{P}_{\boldsymbol{t}} \\
\text { (\$) }\end{array}$ \\
\hline $1 \%$ & 5.10 & 638.32 & 41.54 & 383.76 & $40,458.94$ \\
\hline $2 \%$ & 5.03 & 629.64 & 47.03 & 372.27 & $40,502.02$ \\
\hline $3 \%$ & 4.96 & 621.58 & 52.48 & 361.25 & $40,542.98$ \\
\hline $4 \%$ & 4.89 & 614.06 & 57.49 & 351.06 & $40,581.98$ \\
\hline $5 \%$ & 4.83 & 607.20 & 62.12 & 341.71 & $40,619.17$ \\
\hline $6 \%$ & 4.78 & 600.74 & 66.73 & 332.65 & $40,654.70$ \\
\hline $7 \%$ & 4.73 & 594.80 & 70.83 & 324.46 & $40,688.67$ \\
\hline $8 \%$ & 4.68 & 589.00 & 74.93 & 316.39 & $40,721.19$ \\
\hline $9 \%$ & 4.64 & 583.82 & 78.91 & 308.86 & $40,752.36$ \\
\hline $10 \%$ & 4.59 & 578.79 & 82.47 & 301.87 & $40,782.28$ \\
\hline $11 \%$ & 4.56 & 574.19 & 86.10 & 295.09 & $40,811.01$ \\
\hline $12 \%$ & 4.52 & 569.58 & 89.16 & 288.88 & $40,838.63$ \\
\hline $13 \%$ & 4.48 & 565.18 & 92.32 & 282.72 & $40,865.20$ \\
\hline $14 \%$ & 4.45 & 561.25 & 95.46 & 276.90 & $40,890.80$ \\
\hline $15 \%$ & 4.42 & 557.29 & 98.26 & 271.41 & $40,915.47$ \\
\hline
\end{tabular}

Table 5.9 Optimal ordering policies for different values of $\theta$ when shortages are allowed

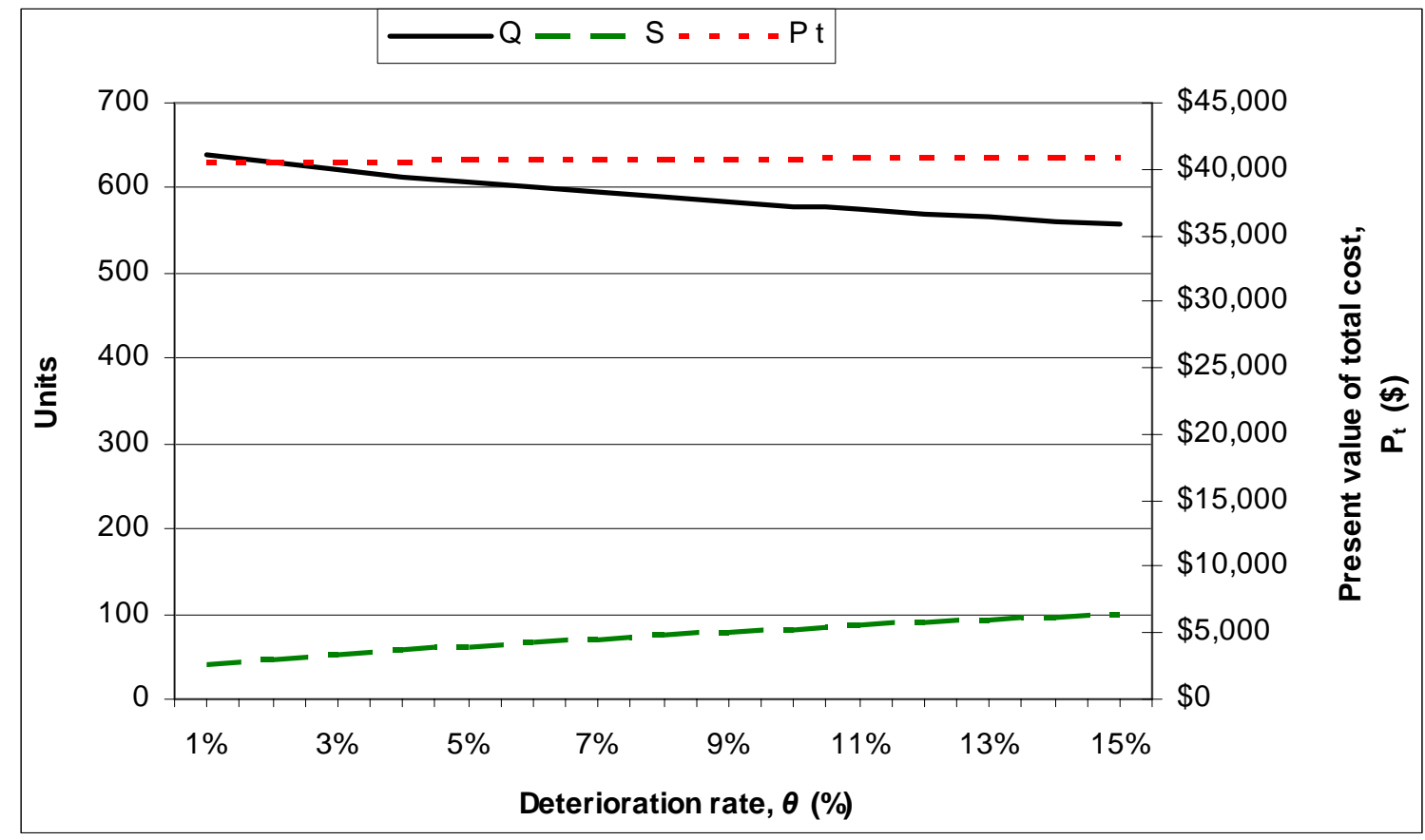

Figure 5.11 Effect of deterioration rate $\theta$ on ordering quantity $Q$, shortage $S$ and present value of the total $\operatorname{cost} \boldsymbol{P}_{t}$ 
Tables 5.10 through 5.13 along with Figures 5.12 through 5.15 present the optimal values obtained for $Q, S$, and $P_{t}$ for different values of carrying rate, $F$, demand rate, $D$, shortage cost, $K$, and setup cost, $A$. Increases in $F$ result in decreases in the production quantity, $Q$, while increases in $D$ or $A$ result in increases in its value. The amount of shortage, $S$, increases with increases in carrying rate and setup cost. It also decreases when the shortage cost increases. The increase in demand, $D$, results in an increase in the shortage at the beginning, but after some point, the shortage starts decreasing. The present value of the total cost behaves in a way similar to the model without shortage.

\begin{tabular}{|c|c|c|c|c|c|}
\hline $\begin{array}{c}\text { Carrying rate } \boldsymbol{F} \\
(\%)\end{array}$ & $\begin{array}{c}\boldsymbol{T} \\
\text { (months) }\end{array}$ & $\begin{array}{c}\boldsymbol{Q} \\
\text { (units) }\end{array}$ & $\begin{array}{c}\boldsymbol{S} \\
\text { (units) }\end{array}$ & $\begin{array}{c}\boldsymbol{I}_{\text {max }} \\
\text { (units) }\end{array}$ & $\begin{array}{c}\boldsymbol{P}_{\boldsymbol{t}} \\
\mathbf{( \$ )}\end{array}$ \\
\hline $4 \%$ & 5.91 & 743.88 & 54.67 & 439.64 & $40,053.12$ \\
\hline $5 \%$ & 5.78 & 727.28 & 55.62 & 427.71 & $40,110.31$ \\
\hline $6 \%$ & 5.66 & 711.75 & 56.36 & 416.69 & $40,166.14$ \\
\hline $7 \%$ & 5.55 & 697.47 & 57.26 & 406.34 & $40,220.69$ \\
\hline $8 \%$ & 5.44 & 683.89 & 57.93 & 396.68 & $40,274.04$ \\
\hline $9 \%$ & 5.34 & 671.06 & 58.66 & 387.46 & $40,326.26$ \\
\hline $10 \%$ & 5.24 & 658.94 & 59.27 & 378.82 & $40,377.42$ \\
\hline $11 \%$ & 5.15 & 647.50 & 60.08 & 370.44 & $40,427.57$ \\
\hline $12 \%$ & 5.07 & 636.62 & 60.74 & 362.57 & $40,476.78$ \\
\hline $13 \%$ & 4.99 & 626.34 & 61.21 & 355.29 & $40,525.08$ \\
\hline $14 \%$ & 4.91 & 616.51 & 61.58 & 348.40 & $40,572.53$ \\
\hline $15 \%$ & 4.83 & 607.20 & 62.12 & 341.71 & $40,619.17$ \\
\hline $16 \%$ & 4.77 & 598.41 & 62.74 & 335.26 & $40,665.04$ \\
\hline $17 \%$ & 4.70 & 589.85 & 63.24 & 329.09 & $40,710.17$ \\
\hline $18 \%$ & 4.63 & 581.48 & 63.43 & 323.34 & $40,754.59$ \\
\hline $19 \%$ & 4.57 & 573.79 & 64.05 & 317.64 & $40,798.34$ \\
\hline $20 \%$ & 4.51 & 566.39 & 64.21 & 312.57 & $40,841.44$ \\
\hline
\end{tabular}

Table 5.10 Optimal ordering policies for different values of $\boldsymbol{F}$ when shortages are allowed 


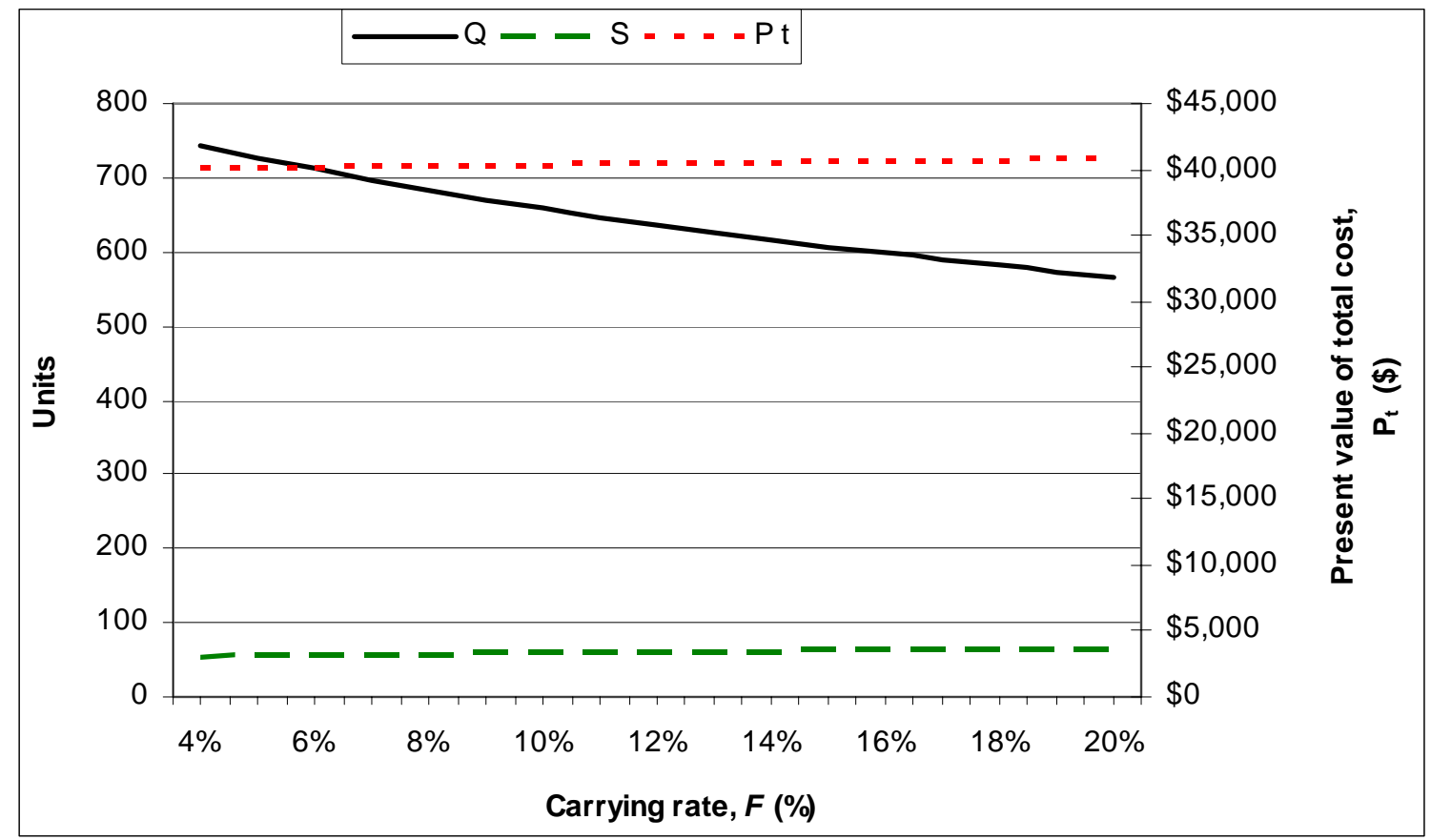

Figure 5.12 Effect of carrying rate $F$ on ordering quantity $Q$, shortage $S$ and present value of the total cost $\boldsymbol{P}_{t}$

\begin{tabular}{|c|c|c|c|c|c|}
\hline $\begin{array}{c}\text { Demand rate } \boldsymbol{D} \\
\text { (units/time) }\end{array}$ & $\begin{array}{c}\boldsymbol{T} \\
\text { (months) }\end{array}$ & $\begin{array}{c}\boldsymbol{Q} \\
\text { (units) }\end{array}$ & $\begin{array}{c}\boldsymbol{S} \\
\text { (units) }\end{array}$ & $\begin{array}{c}\boldsymbol{I}_{\text {max }} \\
\text { (units) }\end{array}$ & $\begin{array}{c}\boldsymbol{P}_{\boldsymbol{t}} \\
\mathbf{( \$ )}\end{array}$ \\
\hline 100 & 17.58 & 149.07 & 42.16 & 103.55 & $3,369.67$ \\
\hline 300 & 10.23 & 258.58 & 64.29 & 176.86 & $8,980.78$ \\
\hline 500 & 7.97 & 334.87 & 73.61 & 223.74 & $14,396.70$ \\
\hline 700 & 6.78 & 398.22 & 76.90 & 258.93 & $19,727.26$ \\
\hline 900 & 6.03 & 454.87 & 76.49 & 286.84 & $25,003.72$ \\
\hline 1,100 & 5.51 & 507.48 & 73.45 & 309.28 & $30,240.00$ \\
\hline 1,300 & 5.12 & 557.90 & 68.51 & 327.39 & $35,443.63$ \\
\hline 1,500 & 4.84 & 607.29 & 62.16 & 341.72 & $40,619.17$ \\
\hline 1,700 & 4.61 & 656.24 & 54.74 & 352.47 & $45,769.58$ \\
\hline 1,900 & 4.44 & 705.74 & 46.62 & 359.89 & $50,896.89$ \\
\hline 2,100 & 4.31 & 756.46 & 37.98 & 364.08 & $56,002.59$ \\
\hline 2,300 & 4.20 & 808.68 & 29.14 & 364.69 & $61,087.78$ \\
\hline 2,500 & 4.13 & 863.12 & 20.26 & 361.71 & $66,153.35$ \\
\hline
\end{tabular}

Table 5.11 Optimal ordering policies for different values of $D$ when shortages are allowed 


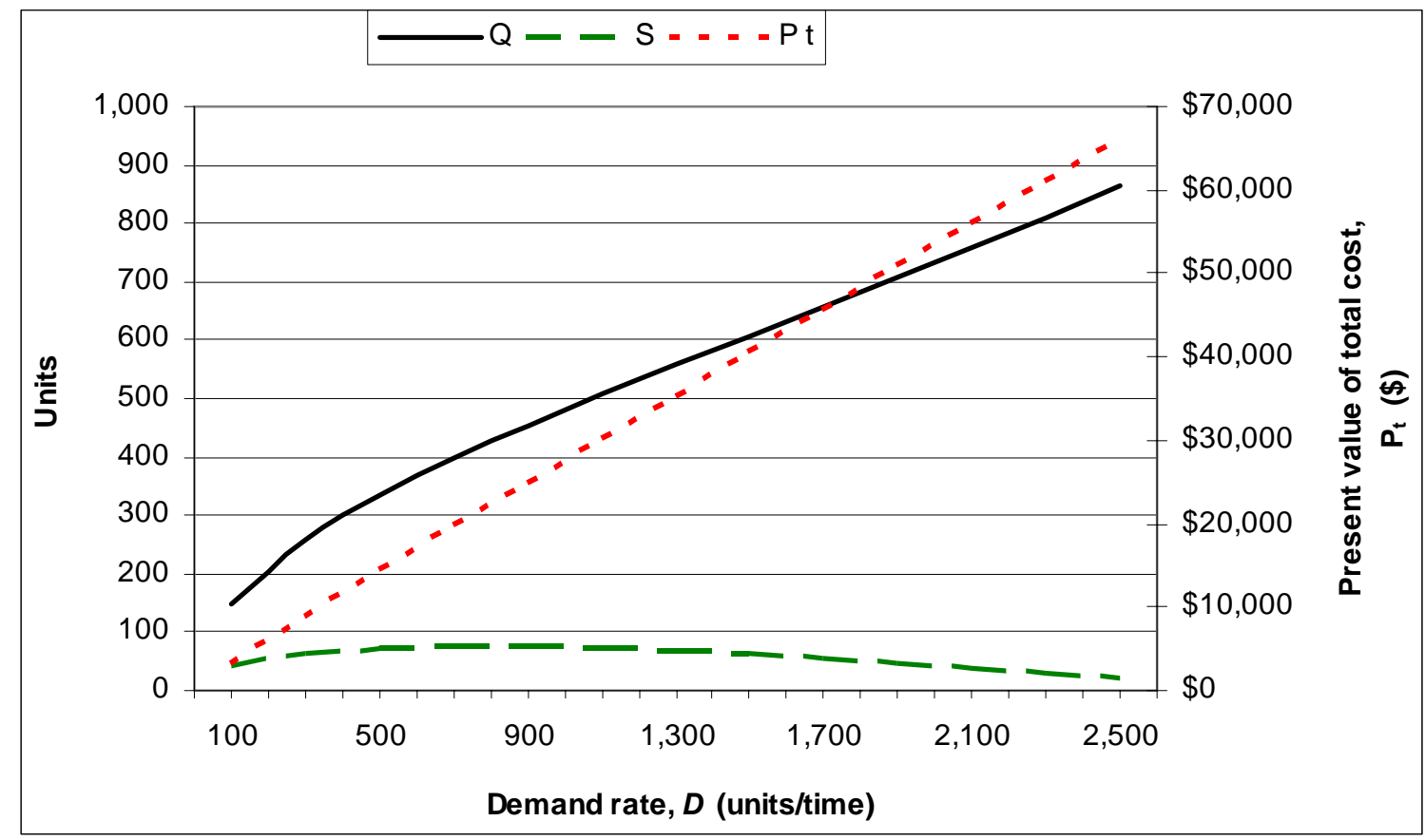

Figure 5.13 Effect of demand rate $D$ on ordering quantity $Q$, shortage $S$ and present value of the total $\operatorname{cost} \boldsymbol{P}_{t}$

\begin{tabular}{|c|c|c|c|c|c|}
\hline $\begin{array}{c}\text { Shortage cost } \boldsymbol{K} \\
\text { (\$/unit/time) }\end{array}$ & $\begin{array}{c}\boldsymbol{T} \\
\text { (months) }\end{array}$ & $\begin{array}{c}\boldsymbol{Q} \\
\text { (units) }\end{array}$ & $\begin{array}{c}\boldsymbol{S} \\
\text { (units) }\end{array}$ & $\begin{array}{c}\boldsymbol{I}_{\text {max }} \\
\text { (units) }\end{array}$ & $\begin{array}{c}\boldsymbol{P}_{\boldsymbol{t}} \\
\mathbf{( \$ )}\end{array}$ \\
\hline 1 & 4.83 & 607.20 & 62.12 & 341.71 & $40,619.17$ \\
\hline 2 & 4.78 & 601.29 & 34.79 & 364.95 & $40,652.67$ \\
\hline 3 & 4.76 & 599.04 & 24.20 & 374.00 & $40,665.75$ \\
\hline 4 & 4.75 & 597.85 & 18.66 & 378.71 & $40,672.72$ \\
\hline 5 & 4.75 & 596.90 & 15.14 & 381.58 & $40,677.05$ \\
\hline 6 & 4.74 & 596.45 & 12.55 & 383.85 & $40,680.00$ \\
\hline 7 & 4.74 & 596.11 & 11.03 & 385.13 & $40,682.15$ \\
\hline 8 & 4.74 & 595.69 & 9.50 & 386.38 & $40,683.77$ \\
\hline 9 & 4.73 & 595.49 & 8.49 & 387.25 & $40,685.04$ \\
\hline 10 & 4.73 & 595.36 & 7.68 & 387.97 & $40,686.07$ \\
\hline
\end{tabular}

Table 5.12 Optimal ordering policies for different values of $K$ when shortages are allowed 


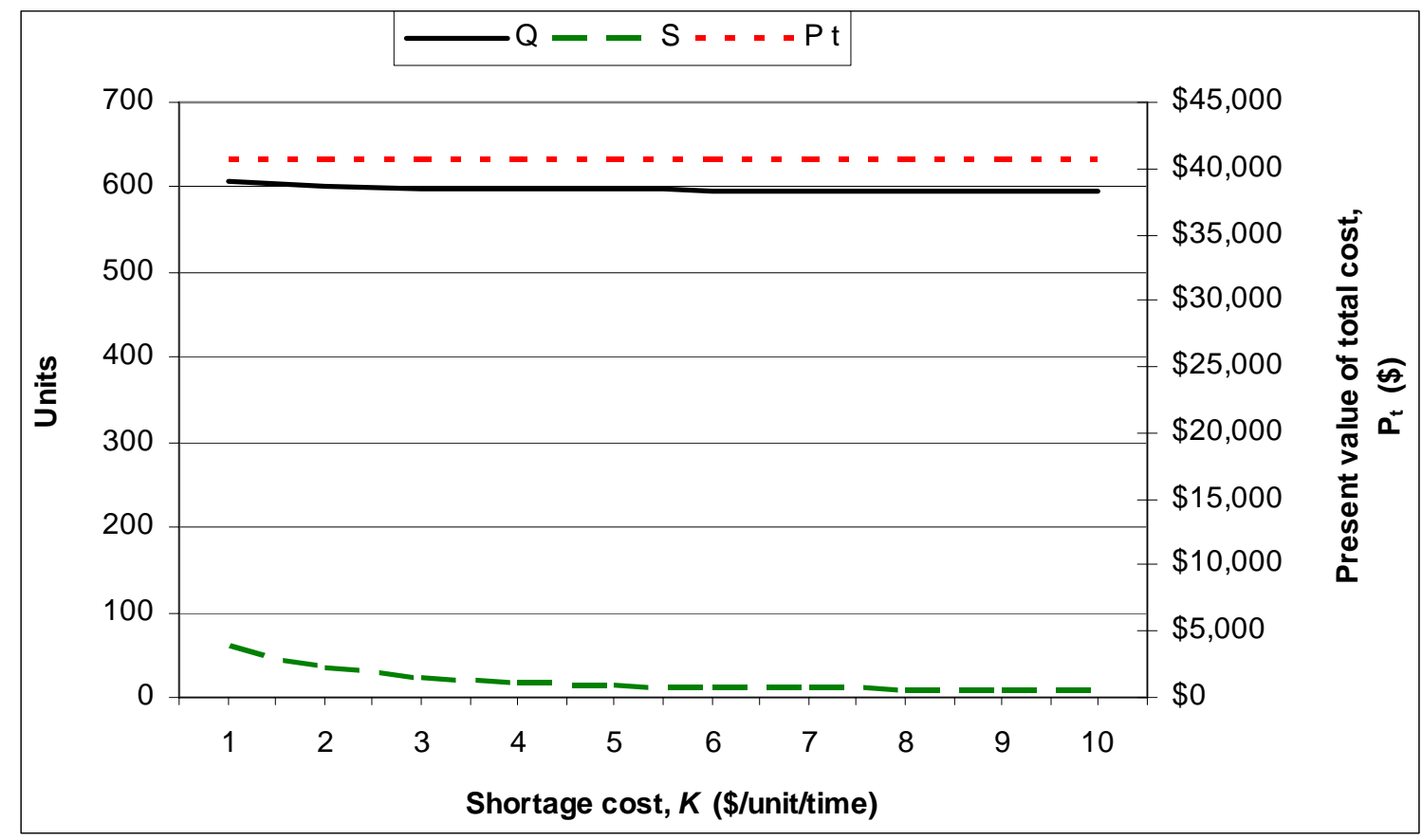

Figure 5.14 Effect of shortage cost $K$ on ordering quantity $Q$, shortage $S$ and present value of the total $\operatorname{cost} \boldsymbol{P}_{\boldsymbol{t}}$

\begin{tabular}{|c|c|c|c|c|c|}
\hline $\begin{array}{c}\text { Setup cost } \boldsymbol{A} \\
\text { (\$/order) }\end{array}$ & $\begin{array}{c}\boldsymbol{T} \\
\text { (months) }\end{array}$ & $\begin{array}{c}\boldsymbol{Q} \\
\text { (units) }\end{array}$ & $\begin{array}{c}\boldsymbol{S} \\
\text { (units) }\end{array}$ & $\begin{array}{c}\boldsymbol{I}_{\max } \\
\text { (units) }\end{array}$ & $\begin{array}{c}\boldsymbol{P}_{\boldsymbol{t}} \\
\text { (\$) }\end{array}$ \\
\hline 40 & 4.33 & 543.16 & 55.51 & 305.82 & $40,286.68$ \\
\hline 50 & 4.83 & 607.20 & 62.12 & 341.71 & $40,619.17$ \\
\hline 60 & 5.29 & 665.07 & 68.14 & 374.07 & $40,920.42$ \\
\hline 70 & 5.71 & 718.19 & 73.40 & 404.02 & $41,198.00$ \\
\hline 80 & 6.11 & 767.72 & 78.44 & 431.81 & $41,456.83$ \\
\hline 90 & 6.47 & 814.49 & 83.40 & 457.84 & $41,700.33$ \\
\hline 100 & 6.82 & 858.53 & 87.94 & 482.47 & $41,931.02$ \\
\hline 110 & 7.15 & 900.23 & 92.20 & 505.81 & $42,150.76$ \\
\hline 120 & 7.47 & 940.13 & 96.02 & 528.40 & $42,361.02$ \\
\hline 130 & 7.77 & 978.72 & 100.15 & 549.79 & $42,562.97$ \\
\hline 140 & 8.06 & $1,015.50$ & 103.84 & 570.43 & $42,757.54$ \\
\hline 150 & 8.34 & $1,051.24$ & 107.61 & 590.30 & $42,945.52$ \\
\hline 160 & 8.61 & $1,085.46$ & 111.02 & 609.50 & $43,127.55$ \\
\hline 170 & 8.87 & $1,118.85$ & 114.40 & 628.19 & $43,304.18$ \\
\hline 180 & 9.13 & $1,151.15$ & 117.55 & 646.38 & $43,475.89$ \\
\hline 190 & 9.38 & $1,182.84$ & 120.98 & 663.88 & $43,643.08$ \\
\hline 200 & 9.62 & $1,213.42$ & 123.98 & 681.08 & $43,806.10$ \\
\hline
\end{tabular}

Table 5.13 Optimal ordering policies for different values of $A$ when shortages are allowed 


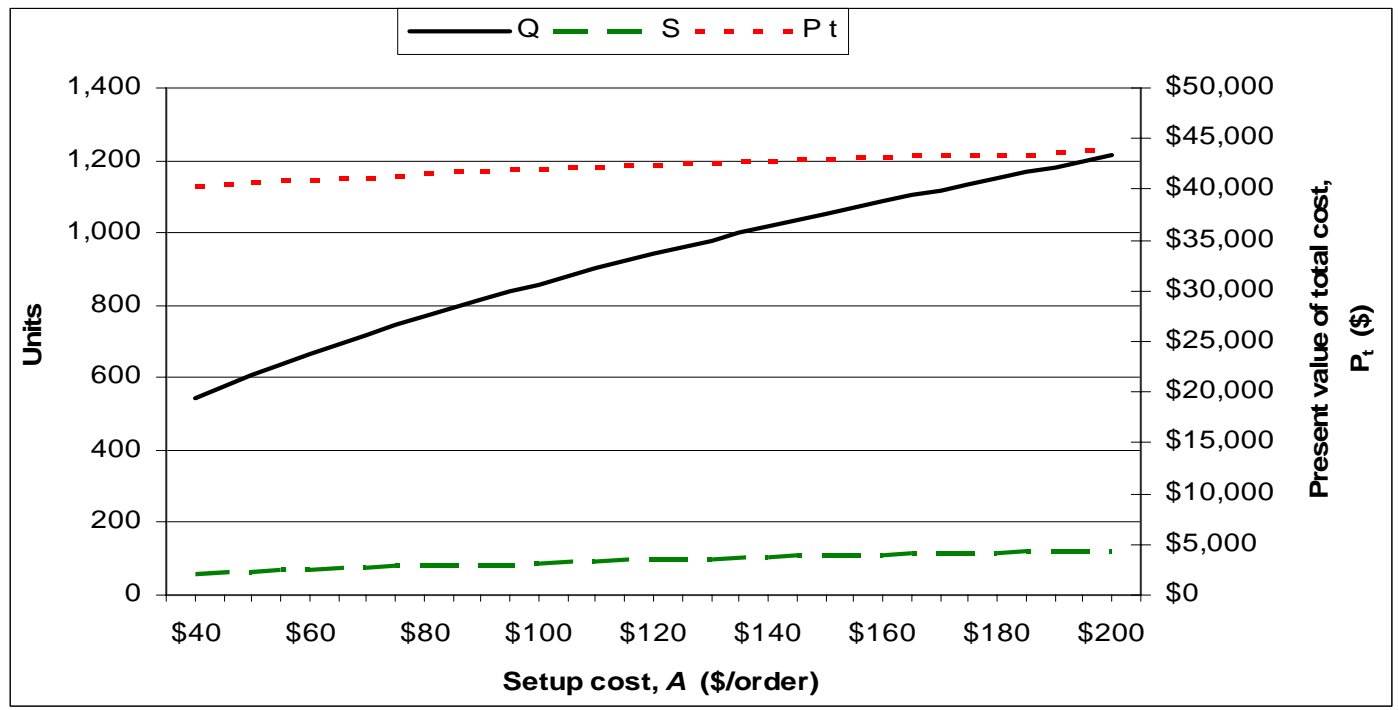

Figure 5.15 Effect of setup cost $A$ on ordering quantity $Q$, shortage $S$ and present value of the total $\operatorname{cost} \boldsymbol{P}_{t}$

For Case 4, the same example was used with the same parameters, except that the production cost, $c$, was replaced with a raw material cost $c_{1}=1.5 \$ /$ unit, and a labor cost $c_{2}=0.5$ \$/unit. The results are summarized in Table 5.14.

\begin{tabular}{|c|c|c|c|c|c|c|}
\hline $\begin{array}{c}\text { Real interest } \\
\text { rate } \boldsymbol{r} \\
\mathbf{( \% )}\end{array}$ & $\begin{array}{c}\boldsymbol{t}_{\mathbf{1}} \\
\text { (months) }\end{array}$ & $\begin{array}{c}\boldsymbol{T} \\
\text { (months) }\end{array}$ & $\begin{array}{c}\boldsymbol{Q} \\
\text { (units) }\end{array}$ & $\begin{array}{c}\boldsymbol{S} \\
\text { (units) }\end{array}$ & $\begin{array}{c}\boldsymbol{I}_{\boldsymbol{m a x}} \\
\text { (units) }\end{array}$ & $\begin{array}{c}\boldsymbol{P}_{\boldsymbol{t}} \\
\mathbf{( \$ )}\end{array}$ \\
\hline $1 \%$ & 0.31 & 6.02 & 757.28 & 77.53 & 425.81 & $319,950.84$ \\
\hline $2 \%$ & 0.30 & 5.82 & 731.39 & 74.89 & 411.29 & $160,331.39$ \\
\hline $3 \%$ & 0.29 & 5.63 & 708.18 & 72.41 & 398.38 & $107,117.66$ \\
\hline $4 \%$ & 0.28 & 5.47 & 686.91 & 70.19 & 386.5 & $80,505.85$ \\
\hline $5 \%$ & 0.27 & 5.31 & 667.53 & 68.15 & 375.69 & $64,535.15$ \\
\hline $6 \%$ & 0.27 & 5.17 & 649.63 & 66.59 & 365.37 & $53,885.25$ \\
\hline $7 \%$ & 0.26 & 5.04 & 633.09 & 64.84 & 356.16 & $46,275.98$ \\
\hline $8 \%$ & 0.25 & 4.92 & 617.76 & 63.36 & 347.46 & $40,567.24$ \\
\hline $9 \%$ & 0.25 & 4.81 & 603.56 & 61.69 & 339.72 & $36,125.65$ \\
\hline $10 \%$ & 0.24 & 4.70 & 590.02 & 60.45 & 331.98 & $32,571.13$ \\
\hline $11 \%$ & 0.24 & 4.60 & 577.53 & 59.26 & 324.88 & $29,661.84$ \\
\hline $12 \%$ & 0.23 & 4.51 & 565.79 & 57.71 & 318.64 & $27,236.52$ \\
\hline $13 \%$ & 0.23 & 4.42 & 554.61 & 56.65 & 312.27 & $25,183.55$ \\
\hline $14 \%$ & 0.22 & 4.34 & 544.23 & 55.54 & 306.49 & $23,423.16$ \\
\hline $15 \%$ & 0.22 & 4.26 & 534.37 & 54.71 & 300.77 & $21,896.88$ \\
\hline
\end{tabular}

Table 5.14 Optimal ordering policies for different values of $\boldsymbol{r}$ and two separate costs when shortages are allowed 
As in Case 3, the optimal values of the cycle time, order quantity, shortage, and maximum inventory on hand decrease as the real interest rate increases. The present value of the total cost also decreases as the real interest rate increases.

\begin{tabular}{|c|c|c|c|c|c|c|c|}
\hline $\begin{array}{c}\text { Raw } \\
\text { material } \\
\text { cost } \boldsymbol{c}_{\mathbf{1}} \\
\$ / \mathbf{u n i t}\end{array}$ & $\begin{array}{c}\text { Labor } \\
\text { cost } \boldsymbol{c}_{\mathbf{2}} \text {, } \\
\$ / \mathbf{u n i t}\end{array}$ & $\boldsymbol{c}=\boldsymbol{c}_{\mathbf{1}}+\boldsymbol{c}_{\mathbf{2}}$ & $\begin{array}{c}\boldsymbol{T} \\
\text { (months) }\end{array}$ & $\begin{array}{c}\boldsymbol{Q} \\
\text { (units) }\end{array}$ & $\begin{array}{c}\boldsymbol{S} \\
\text { (units) }\end{array}$ & $\begin{array}{c}\boldsymbol{I}_{\text {max }} \\
\text { (units) }\end{array}$ & $\begin{array}{c}\boldsymbol{P}_{\boldsymbol{t}} \\
\mathbf{\$} \text { ) }\end{array}$ \\
\hline$\$ 0.30$ & $\$ 0.10$ & $\$ 0.40$ & 10.73 & $1,359.64$ & 33.70 & 866.41 & $8,915.92$ \\
\hline$\$ 0.60$ & $\$ 0.20$ & $\$ 0.80$ & 7.65 & 964.91 & 45.52 & 594.78 & $16,978.34$ \\
\hline$\$ 0.90$ & $\$ 0.30$ & $\$ 1.20$ & 6.29 & 791.27 & 53.46 & 472.18 & $24,903.82$ \\
\hline$\$ 1.20$ & $\$ 0.40$ & $\$ 1.60$ & 5.47 & 688.06 & 58.90 & 398.48 & $32,758.22$ \\
\hline$\$ 1.50$ & $\$ 0.50$ & $\$ 2.00$ & 4.92 & 617.76 & 63.36 & 347.46 & $40,567.24$ \\
\hline$\$ 1.80$ & $\$ 0.60$ & $\$ 2.40$ & 4.51 & 565.99 & 66.62 & 309.90 & $48,344.14$ \\
\hline$\$ 2.10$ & $\$ 0.70$ & $\$ 2.80$ & 4.19 & 525.73 & 69.03 & 280.80 & $56,096.81$ \\
\hline$\$ 2.40$ & $\$ 0.80$ & $\$ 3.20$ & 3.93 & 493.26 & 70.99 & 257.30 & $63,830.41$ \\
\hline$\$ 2.70$ & $\$ 0.90$ & $\$ 3.60$ & 3.72 & 466.54 & 72.73 & 237.82 & $71,548.52$ \\
\hline$\$ 3.00$ & $\$ 1.00$ & $\$ 4.00$ & 3.54 & 443.74 & 73.85 & 221.57 & $79,253.75$ \\
\hline$\$ 3.30$ & $\$ 1.10$ & $\$ 4.40$ & 3.39 & 424.27 & 74.96 & 207.53 & $86,948.08$ \\
\hline$\$ 3.60$ & $\$ 1.20$ & $\$ 4.80$ & 3.25 & 407.09 & 75.58 & 195.49 & $94,633.01$ \\
\hline$\$ 3.90$ & $\$ 1.30$ & $\$ 5.20$ & 3.13 & 392.14 & 76.52 & 184.62 & $102,309.76$ \\
\hline$\$ 4.20$ & $\$ 1.40$ & $\$ 5.60$ & 3.02 & 378.67 & 76.73 & 175.46 & $109,979.29$ \\
\hline$\$ 4.50$ & $\$ 1.50$ & $\$ 6.00$ & 2.93 & 366.41 & 77.09 & 166.95 & $117,642.42$ \\
\hline
\end{tabular}

Table 5.15 Optimal ordering policies for different values of $c_{1}$ and $c_{2}$ when shortages are allowed

Table 5.15 and Figure 5.16 show the changes in the optimal policy corresponding to changes in the unit costs. The order quantity and the present value of the total cost behave the same way as in the previous model where no shortage is allowed, while the shortage increases with an increase in the combined unit cost, although at a slow rate. 


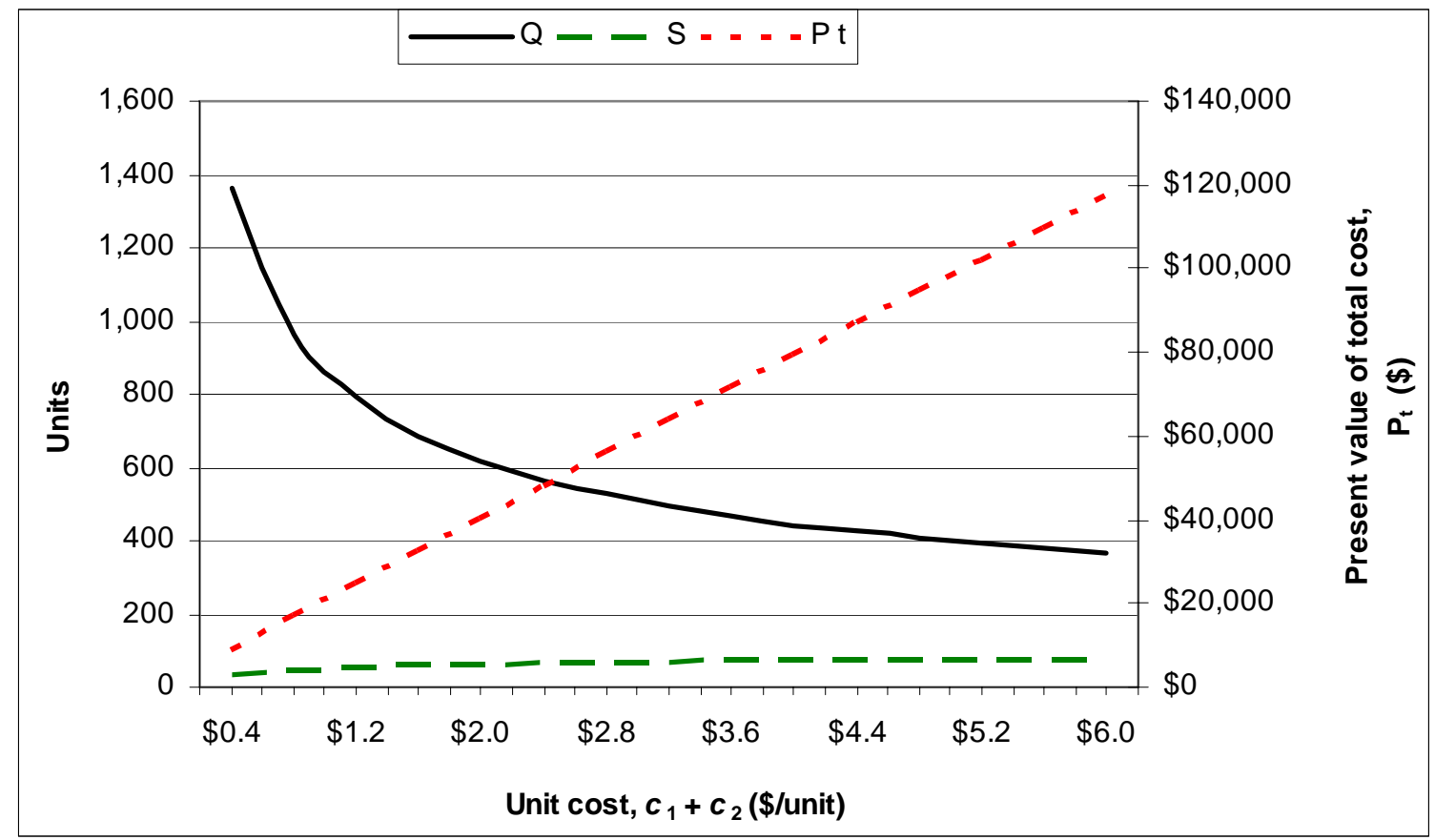

Figure 5.16 Effect of changes in unit $\operatorname{costs} c_{1}$ and $c_{2}$ on ordering quantity $Q$, shortage $S$ and present value of the total $\operatorname{cost} \boldsymbol{P}_{t}$ 


\section{Chapter 6}

\section{Summary and Future Research}

\subsection{Summary}

In Chapter 3, the deterministic inventory control problem was considered for the determination of optimal production quantities for items with constant demand rate, while considering the effect of time value of money. Two different models were developed. In the first model, no shortage was allowed, while the second model allowed for shortages. In each model, two different cost functions were considered. In the first function, the production cost is incurred at the beginning of the cycle, while in the second, the production cost consists of two parts: An initial cost, which is incurred at the beginning of the cycle and is applied to the entire quantity produced during the cycle, and a running cost that is incurred as production progresses and is applied to the individual units produced. Closed formulas were obtained for the optimal cycle time and the corresponding optimal production quantity for the models without shortage. For the models where shortage is allowed, a search technique was developed which applies a combination of a modified Simplex EVOP and a Univariate Walk to find the optimal cycle time and the amount of shortage allowed. Numerical examples were presented and sensitivity analyses were performed.

In Chapter 4, optimal production cycle times are determined for deterministic inventory problems with linear demand rate over time, while considering the effect of time value of money. The optimal policies are determined over a finite planning horizon. Similar to Chapter 3, two different models were developed, one without shortage, and the other with shortages. In each model, two different cost functions were considered, depending on when the production cost occurs. Modified Golden Search techniques were developed to find the optimal number of 
inventory production cycles and the amount of shortage allowed (when applicable), for each of the production cost functions. A proof of the existence of a unique optimum for the cost function was given for the models where shortages are not allowed. Numerical examples were presented and sensitivity analyses were performed.

Optimal cycle times were determined in Chapter 5 for deterministic inventory problems with constant demand rate, and exponentially decaying inventory while considering the effect of time value of money over an infinite planning horizon. As in the previous chapters, models were developed with and without shortage. For each system, two different cases were considered. The existence of a unique optimum for the cost function was shown for the models where shortages are not allowed. Two different search techniques were used to find the optimal policies. The first uses the Golden Search to find the optimal cycle time for the models without shortage. For the models where shortage is allowed, a search technique was developed, which applies a combination of a modified Simplex EVOP and a Univariate Walk to find the optimal cycle time and amount of shortage allowed. As for the previous models, numerical examples were presented and sensitivity analyses were performed.

\subsection{Future Research}

Several extensions can be made to this research:

1. In the first problem, a closed formula was developed for the model without shortage. For the rest of the models search techniques were used to find optimal policies. One extension to this study would be to attempt to develop closed formulas for the rest of the models. 
2. In developing the models, only one concept was introduced at a time, along with time value of money. One may want to investigate models with combination of several concepts and determine the optimal polices for these cases.

3. Another extension to this research could be to attempt to prove the convexity of the total cost function where interest rate is included in the total cost function.

4. The models developed in this research were considered for a single item. One may relax this assumption and consider models with multiple items.

5. The production rate in all the models was constant and the demand rate was either constant or increasing linearly over time. Other extension to this research could be to consider probabilistic demand or production rate. 


\section{Bibliography}

Aggarwal, S. P. and C. K. Jaggi. 1995. Ordering policies of deteriorating items under permissible delay in payments. Journal of Operational Research Society 46: 458-662.

Balkhi, Z. T. 2001. On a finite horizon production lot size inventory model for deteriorating items: An optimal solution. European Journal of Operational Research 132: 210-223.

Balkhi, Z. T. and L. Benkherouf. 1996. On the optimal replenishment schedule for an inventory system with deteriorating items and time-varying demand and production rates. Computers \& Industrial Engineering 30: 823-829.

Bazaraa, M. S. and S. M. Shetty. 1979. Nonlinear Programming: Theory and Algorithms. New York: John Wiley and Sons, Inc.

Bhunia, A. K. and M. Maiti. 1999. An inventory model of deteriorating items with lot-size dependent replenishment cost and a linear trend in demand. Applied Mathematical Modeling 23: 301-308.

Bronshtein, I. N. and K. A. Semendyaev. 1980. Handbook of Mathematics for Engineers and College Students. (in Russian) Moscow, Russia: Nauka.

Buzacott, J. A. 1975. Economic order quantities with inflation. Operational Research Quarterly 26: $553-558$.

Chandra, J. M. and M. L. Bahner. 1985. The effects of inflation and time value of money on some inventory systems. International Journal of Production Research 23: 723-730.

Chen, J. 1998. An inventory model for deteriorating items with time-proportional demand and shortages under inflation and time discounting. International Journal of Production Economics 55: $21-30$.

Chu, P., K. J. Chung, and S. Lan. 1998. Economic order quantity of deteriorating items under permissible delay in payments. Computers \& Operations Research 25: 817-824.

Chung, K. J. 1996. Optimal ordering time interval taking account of time value. Production Planning and Control 7: 264-267.

Chung, K. J. 1998. A theorem on the determination of economic order quantity under conditions of permissible delay in payments. Computers \& Operations Research 25: 49-52.

Chung, K. J., S. D. Lin, P. Chu, and S. P. Lan. 1998. The production and inventory systems taking account of time value. Production Planning and Control 9: 580-584. 
Chung, K. J. and S. Tsai. 2001. Inventory systems for deteriorating items with shortages and a linear trend in demand taking account of time value. Computers \& Operations Research 28: 915-934.

Donaldson, W. A. 1977. Inventory replenishment policy for a linear trend in demand an analytical solution. Journal of the Operational Research Society 28: 123-137.

Dohi, T., N. Kaio, and S. Osaki. 1992. A note on optimal inventory policies taking account of time value. RAIRO - Operations Research 26: 1-14.

Giri, B. C., A. K. Jalan, and K. S. Chaudhuri. 2005. An economic production lot size model with increasing demand, shortages and partial backlogging. International Transactions in Operational Research 12: 235-245.

Ghare, P. M. and G. F. Schrader. 1963. A Model for an Exponentially Decaying Inventory. The Journal of Industrial Engineering 14: 238-243.

Goyal, S. K. 1985. Economic order quantity under conditions of permissible delay in payments. Journal of the Operational Research Society 36: 335-338.

Hadley, G. and T. M. Whitin. 1963. Analysis of Inventory Systems. Englewood Cliffs, N.J.: Prentice-Hall, Inc.

Haley, C. W. and R. C. Higgins. 1973. Inventory policy and trade credit financing. Management Science 20: 464-471.

Hariga, M. A. and M. Ben-Daya. 1996. Optimal time varying lot-sizing models under inflationary conditions. European Journal of Operational Research 89: 313-325.

Heizer, J. and B. Render. 2001. Operations Management. 6-th Edition, Englewood Cliffs, N.J.: Prentice-Hall, Inc.

Hong, J. D., R. R. Sandrapaty, and J. C. Hayya. 1990. On production policies for a linearly increasing demand and finite, uniform production rate. Computers \& Industrial Engineering 18: $119-127$.

Hou, K. 2006. An inventory model for deteriorating items with stock-dependent consumption rate and shortages under inflation and time discounting. European Journal of Operational Research 168: 463-474.

Liao, H., C. Tsai, and C. Su. 2000. An inventory model with deteriorating items under inflation when a delay in payment is permissible. International Journal of Production Economics 63: 207-214. 
Moon, I. and S. Lee. 2000. The effects of inflation and time value of money on an economic order quantity model with a random product life cycle. European Journal of Operational Research 125: 588-601.

Ray, J. and K.S. Chaudhuri. 1997. An EOQ model with stock-dependent demand, shortage, inflation and time discounting. International Journal of Production Economics 53: 171-180.

Sarker, B.R., A.M.M. Jamal, and S. Wang. 2000. Supply chain models for perishable products under inflation and permissible delay in payment. Computers \& Operations Research 27: 59-75.

Skouri, K. and S. Papachristos. 2002. Note on "Deterministic Inventory Lot-Size Models under inflation with Shortages and Deterioration for Fluctuating Demand" by Yang et al. Naval Research Logistics 49: 527-529.

Starr, M. K. and D. W. Miller. 1962. Inventory Control: Theory and Practice", Englewood Cliffs, N.J.: Prentice-Hall, Inc.

Teng, J. T. and C. T. Chang. 2005. Economic production quantity models for deteriorating items with price- and stock-dependent demand. Computers \& Operations Research 32: 297-308.

Tersine, T. J. 1994. Principles of Inventory and Materials Management. 4-th Edition, Englewood Cliffs, N. J.: Prentice-Hall, Inc.

Teunter, R. 2001. Economic ordering quantities for recoverable item inventory system. Naval Research Logistics 48: 484-485.

Wang, S. 2002. An inventory replenishment policy for deteriorating items with shortages and partial backlogging. Computers \& Operations Research 29: 2043-2051.

Wee, H. and S. Law. 1999. Economic production lot size for deteriorating items taking account of the time value of money. Computers \& Operations Research 26: 545-558.

Yang, H., J. Teng, and M. Chern. 2001. Deterministic inventory lot-size models under inflation with shortages and deterioration for fluctuating demand. Naval Research Logistics 48: 144-158. 


\section{Appendix A. Computer program used for EPQ model with shortages and time value of money}

Note: The same program is used for the EPQ model with shortages, deterioration and time value of money. The total cost function is changed for the different models.

Dim A, p, c, c1, c2, F, InflRate, NomRate, r, D, L As Double

Dim k, p_, q, R_, K_, K0, Z As Double

Dim i, j, inew, Div As Integer

Dim flag, flag1, flag2, found As Boolean

Dim X(2), V(3, 3), VV(3) As Double

Dim TotCost1, TotCost2 As Double

Dim Total_cost, max_TC As Double

Dim TCnew, TCB, TC(3) As Double

Private Sub cmdCalculate_Click()

$\mathrm{A}=$ Val(txtSetup_A.Text)

$\mathrm{p}=$ Val(txtProdRate_p.Text)

$\mathrm{c}=\operatorname{Val}($ txtProdCost_c.Text)

$\mathrm{c} 1=$ Val(txtRawCost_c1.Text)

c2 $=$ Val(txtLaborCost_c2.Text)

$\mathrm{F}=$ Val(txtCarryingRate_F.Text) $/ 100$

InflRate $=$ Val(txtInflRate. Text $) / 100$

NomRate $=$ Val (txtNomRate. Text) $/ 100$

$\mathrm{r}=$ NomRate - InflRate

$\mathrm{D}=$ Val(txtDemand_D.Text)

$\mathrm{K} 0=\mathrm{Val}($ txtShortCost_K0.Text)

$\mathrm{K}_{-}=$Val(txtShortCost_K.Text)

$\mathrm{L}=$ Val(txtLength_L.Text)

Div $=$ Val(txtDivisor_Div.Text)

$\mathrm{Z}=$ Val(txtStopping_Z.Text)

$\mathrm{X}(1)=\operatorname{Val}(\mathrm{txtVariable}(0) \cdot$ Text $)$

$\mathrm{X}(2)=\operatorname{Val}(\mathrm{txtVariable}(1) \cdot$ Text $)$

$\mathrm{k}=2$

$\mathrm{p}_{-}=((\mathrm{k}-1)+\operatorname{Sqr}(\mathrm{k}+1)) /(\mathrm{k} * \operatorname{Sqr}(2))$

$\mathrm{q}=(\operatorname{Sqr}(\mathrm{k}+1)-1) /(\mathrm{k} * \operatorname{Sqr}(2))$

$\mathrm{R}_{-}=\left(\mathrm{p}_{-} * \mathrm{~L}+(\mathrm{k}-1) * \mathrm{q} * \mathrm{~L}\right) /(\mathrm{k}+1)$

For $\mathrm{j}=1$ To $\mathrm{k}$ Step 1

Next $\mathrm{j}$

For $\mathrm{j}=1$ To $\mathrm{k}$ Step 1

For $\mathrm{i}=2$ To $\mathrm{k}+1$ Step 1

If $\mathrm{i}-1=\mathrm{j}$ Then

Else

$\mathrm{V}(\mathrm{i}, \mathrm{j})=\mathrm{X}(\mathrm{j})-\mathrm{R}_{-}+\mathrm{p}_{-} * \mathrm{~L}$

$V(i, j)=X(j)-R_{-}+q * L$

$$
\text { End If }
$$

Next i

Next j

For $\mathrm{i}=1$ To $\mathrm{k}+1$ Step 1

If $V(i, 1)>V(i, 2)$ And $V(i, 2)>0$ Then 


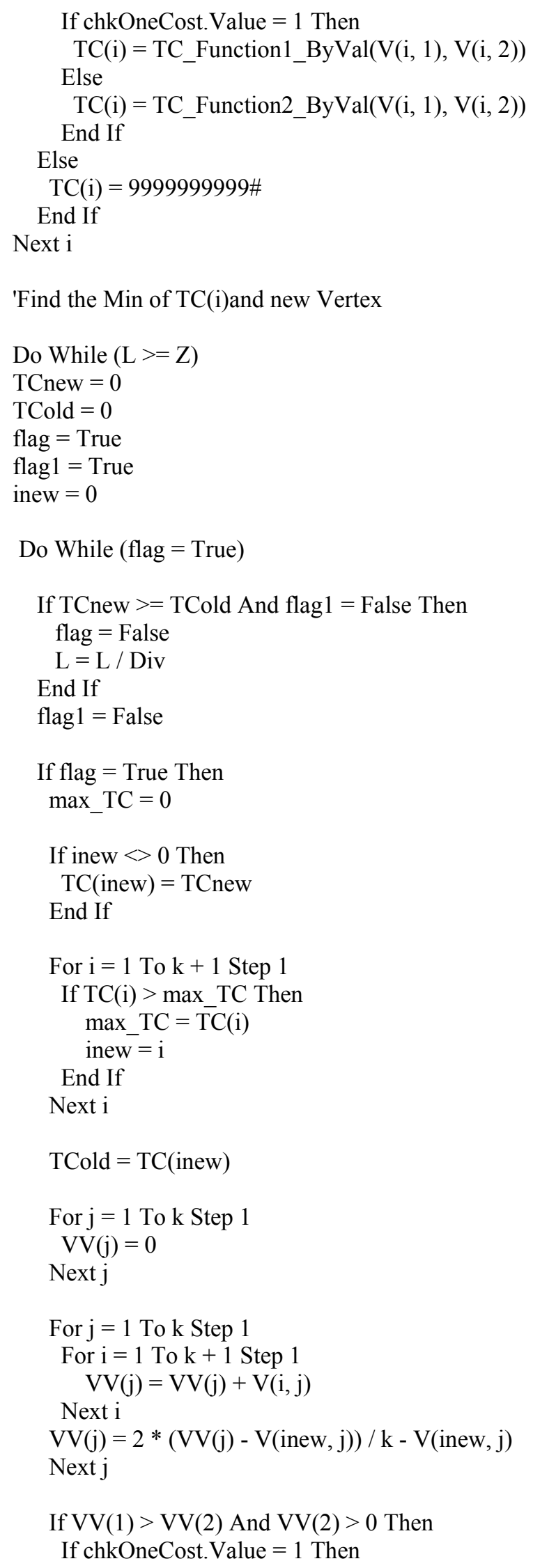




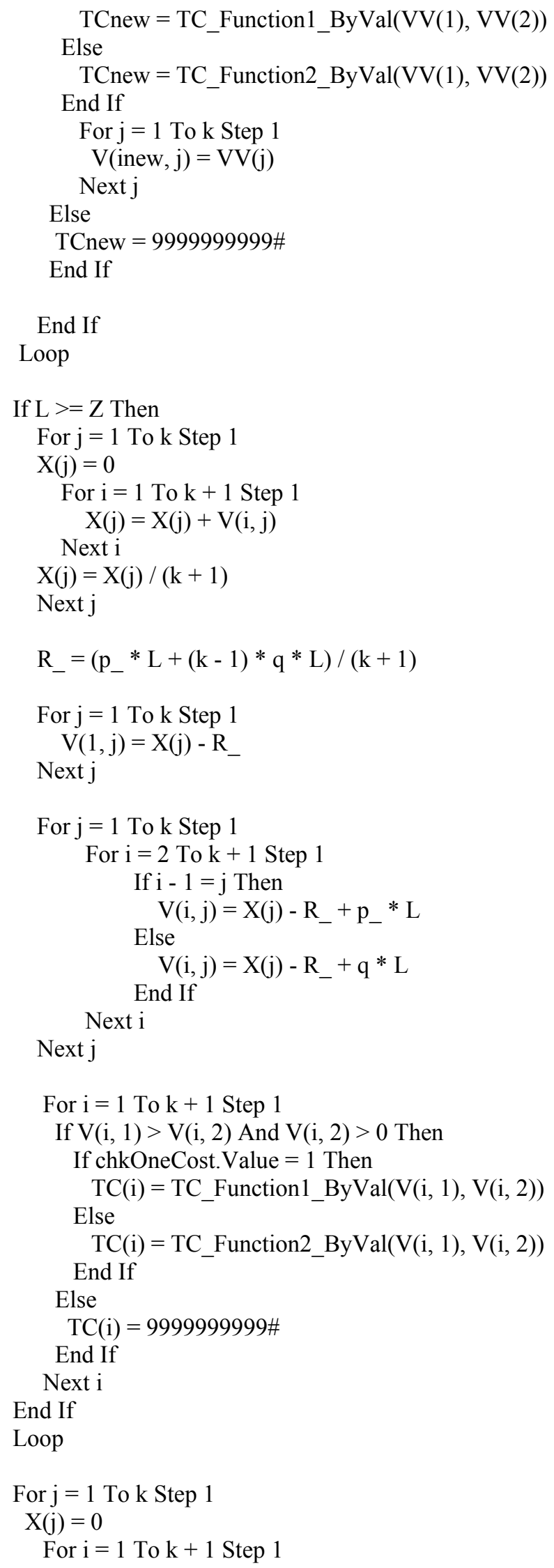




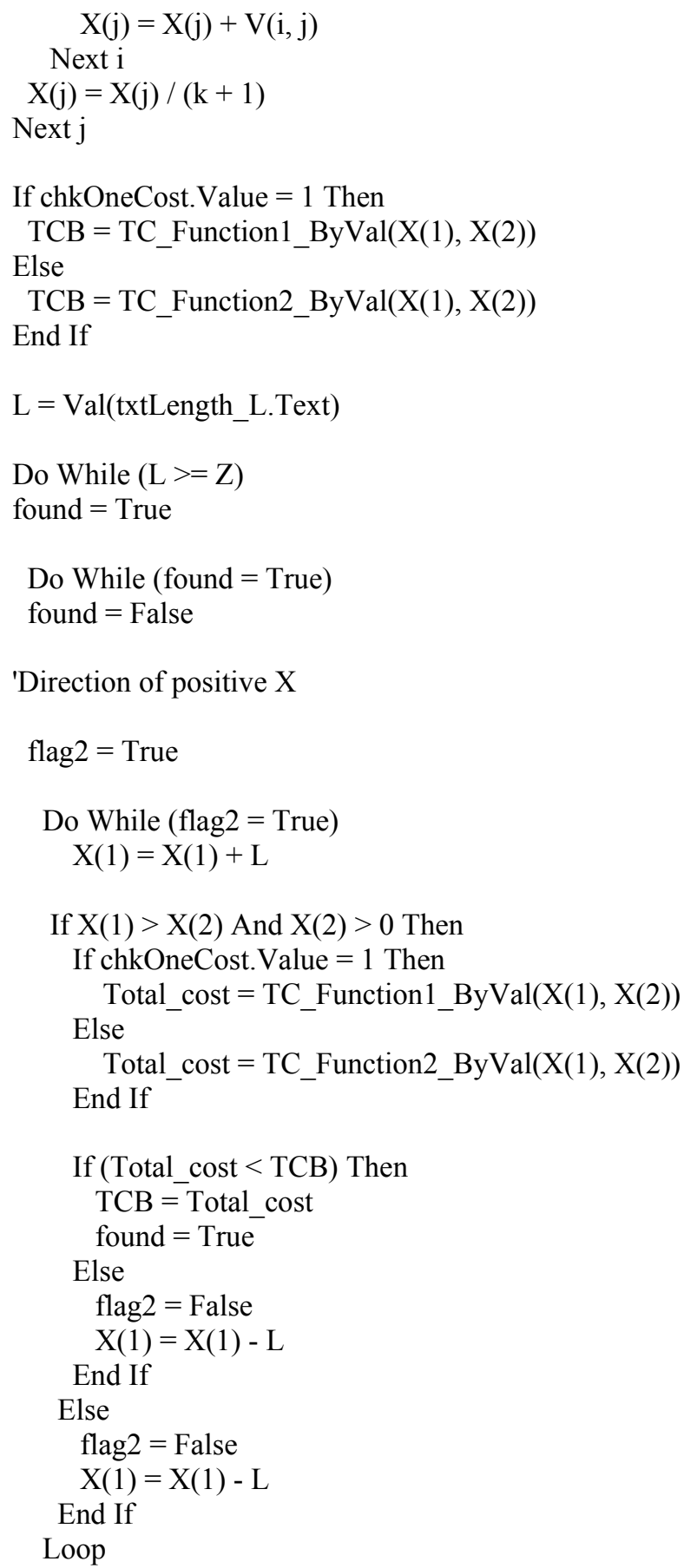

'Direction of positive Y

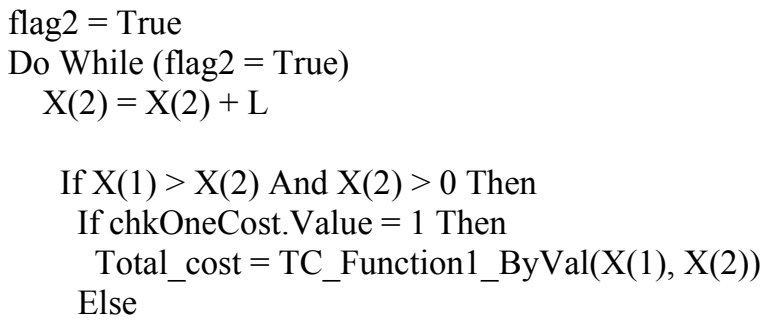


Total_cost $=$ TC_Function2_ByVal(X(1), X(2))

End If

If (Total_cost $<$ TCB) Then

TCB $=$ Total_cost

found $=$ True

Else

flag $2=$ False

$\mathrm{X}(2)=\mathrm{X}(2)-\mathrm{L}$

End If

Else

flag2 $=$ False

$\mathrm{X}(2)=\mathrm{X}(2)-\mathrm{L}$

End If

Loop

'Direction of negative X

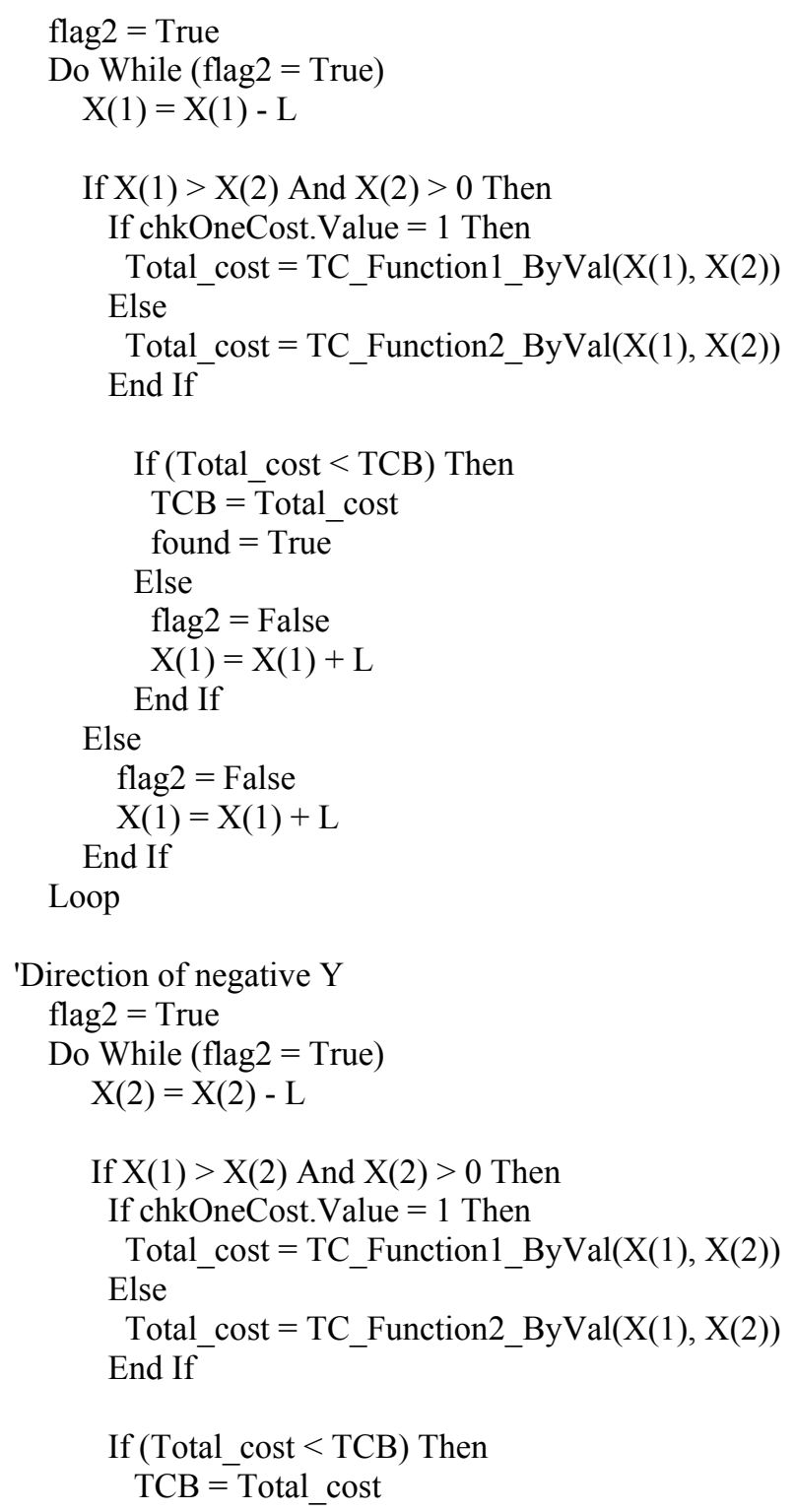




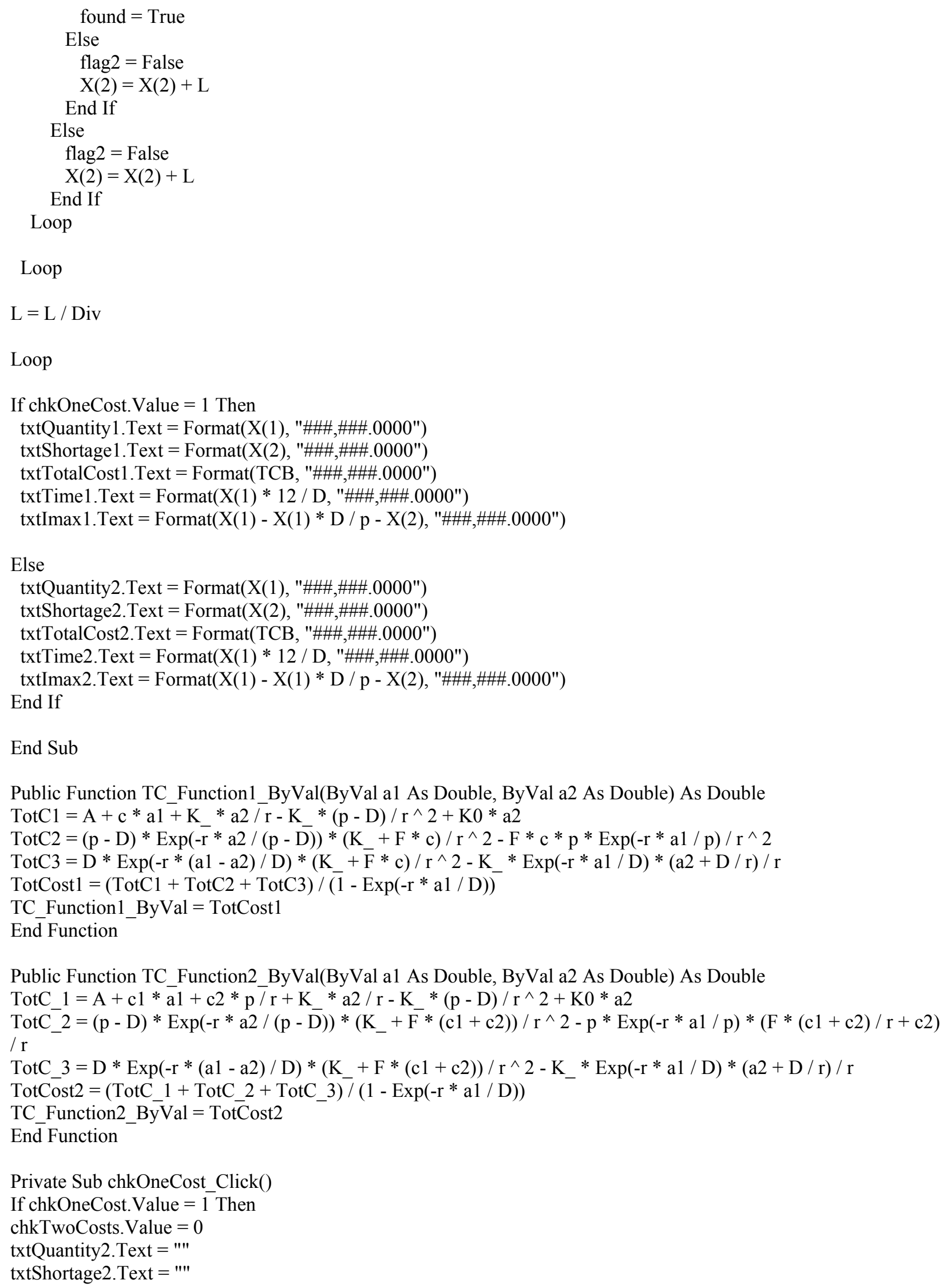




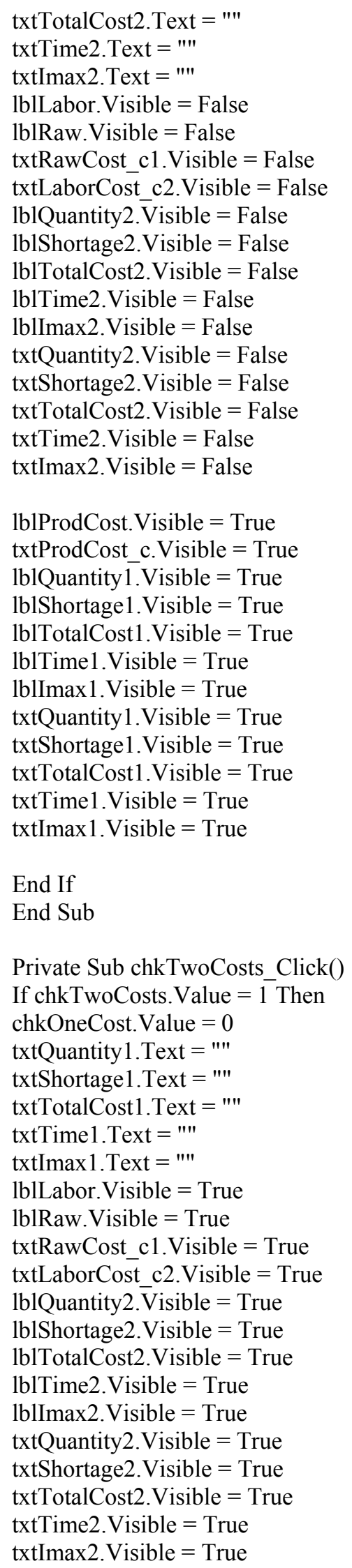

End If

End Sub

Private Sub chkTwoCosts_Click() If chkTwoCosts. Value $=1$ Then chkOneCost.Value $=0$ txtQuantity1.Text = "" 
lblProdCost. Visible $=$ False

txtProdCost c.Visible $=$ False

lblQuantity1. Visible $=$ False

lblShortage 1 .Visible $=$ False

lblTotalCost 1 .Visible $=$ False

lblTime1. Visible $=$ False

lblImax 1. Visible $=$ False

txtQuantity 1. Visible $=$ False

txtShortage 1 .Visible $=$ False

txtTotalCost 1 .Visible $=$ False

txtTime1.Visible $=$ False

txtImax 1. Visible $=$ False

End If

End Sub

Private Sub cmdEnd_Click()

End

End Sub 


\section{Appendix B. Computer program for EPQ model without shortages, with linear demand and time value of money}

Note: Similar programs with minor changes are used for the EPQ model without shortages, deterioration and time value of money. The total cost function is changed for the different models.

Dim A_, p, c, c1, c2, F, r, H, b0, b1, m As Double

Dim NomRate, InflRate As Double

Dim a(100), b(100), Lyam(100), Myu(100) As Double

Dim TC_M(100), TC_L(100), Sum1, Sum2 As Double

Dim TotCost1, TotCost2 As Double

Private Sub cmdCalculate_Click()

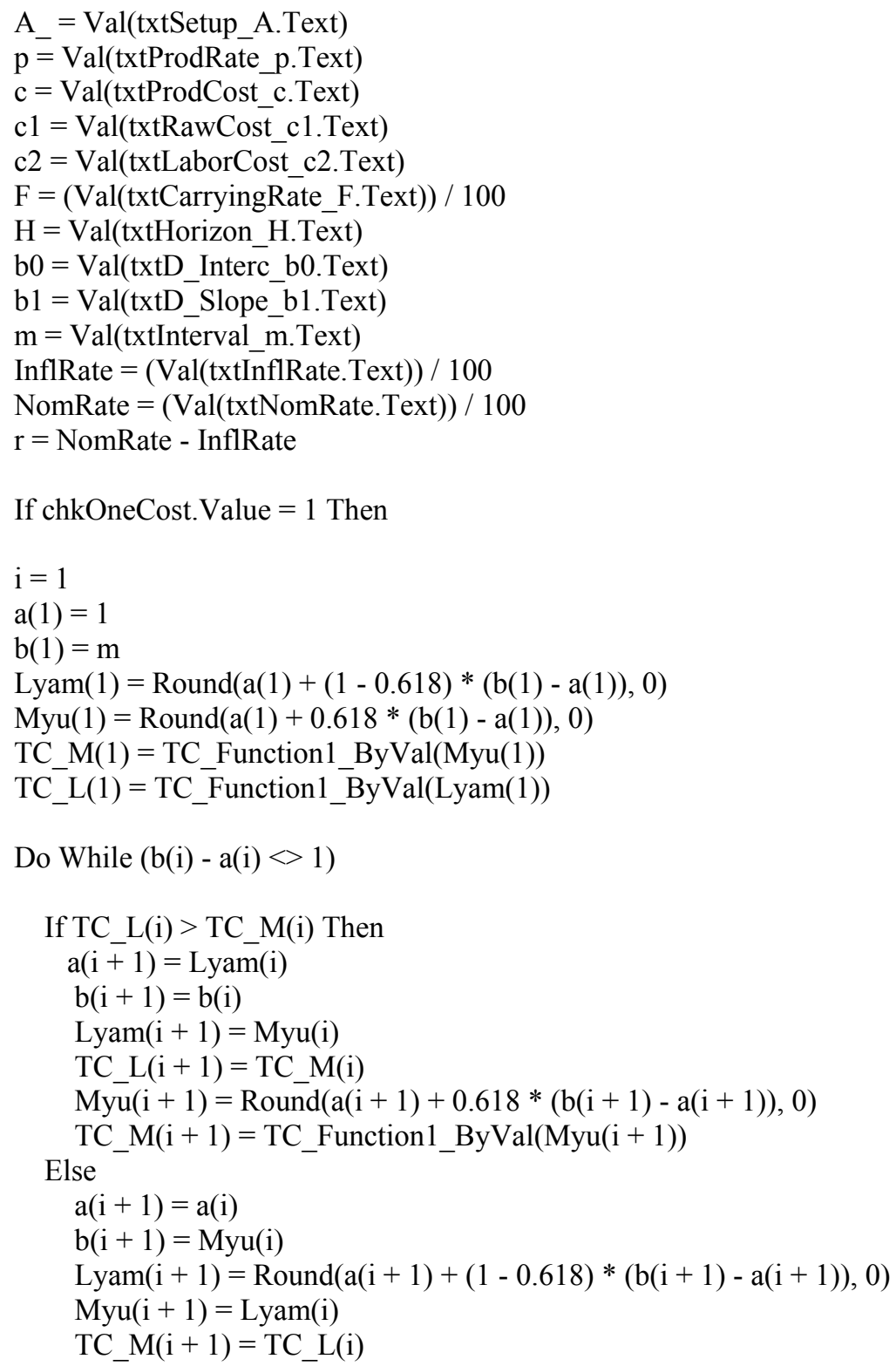




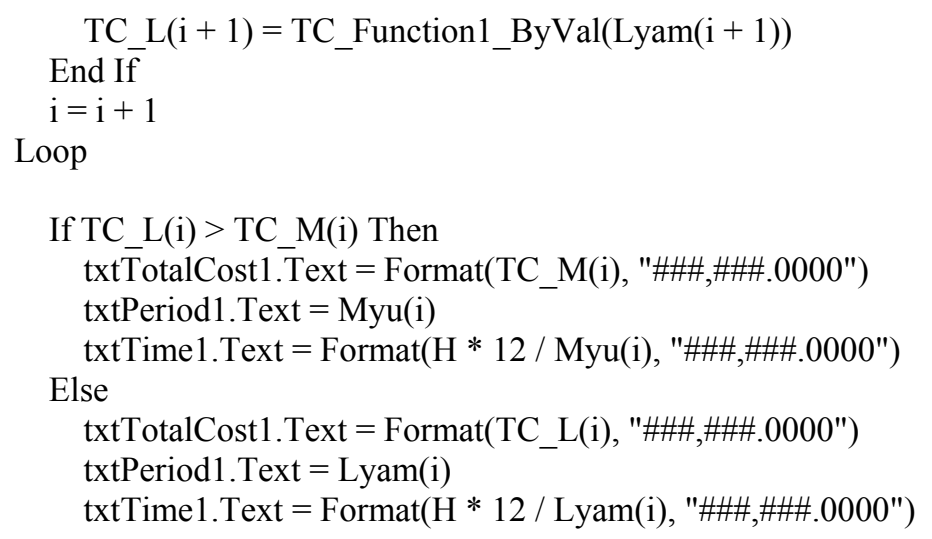

End If

Else

$\mathrm{i}=1$

$\mathrm{a}(1)=1$

$\mathrm{b}(1)=\mathrm{m}$

$\operatorname{Lyam}(1)=\operatorname{Round}(\mathrm{a}(1)+(1-0.618) *(\mathrm{~b}(1)-\mathrm{a}(1)), 0)$

$\operatorname{Myu}(1)=\operatorname{Round}(\mathrm{a}(1)+0.618 *(\mathrm{~b}(1)-\mathrm{a}(1)), 0)$

TC_M(1) = TC Function2_ByVal(Myu(1))

TC_L(1) = TC_Function2_ByVal $($ Lyam $(1))$

Do While (b(i) - a(i) $<>1$ )

If TC L(i) > TC M(i) Then

$\mathrm{a}(\mathrm{i}+\mathbf{+})=\operatorname{Lyam}(\mathrm{i})$

$\mathrm{b}(\mathrm{i}+1)=\mathrm{b}(\mathrm{i})$

$\operatorname{Lyam}(i+1)=\operatorname{Myu}(i)$

TC_L $(\mathrm{i}+1)=$ TC_M(i)

$\operatorname{Myu}(i+1)=\operatorname{Round}(a(i+1)+0.618 *(b(i+1)-a(i+1)), 0)$

TC_M $(i+1)=$ TC_Function2_ByVal $(\operatorname{Myu}(i+1))$

Else

$a(i+1)=a(i)$

$\mathrm{b}(\mathrm{i}+1)=\operatorname{Myu}(\mathrm{i})$

$\operatorname{Lyam}(\mathrm{i}+1)=\operatorname{Round}(\mathrm{a}(\mathrm{i}+1)+(1-0.618) *(\mathrm{~b}(\mathrm{i}+1)-\mathrm{a}(\mathrm{i}+1)), 0)$

$\operatorname{Myu}(i+1)=\operatorname{Lyam}(i)$

TC_M $(\mathrm{i}+1)=\mathrm{TC} \_$L(i)

TC_L $(i+1)=$ TC_Function2_ByVal $(\operatorname{Lyam}(i+1))$

End If

$\mathrm{i}=\mathrm{i}+1$

Loop

If $\mathrm{TC} \_\mathrm{L}(\mathrm{i})>\mathrm{TC} \_\mathrm{M}(\mathrm{i})$ Then txtTotalCost2.Text $=$ Format(TC M(i), "\#\#\#,\#\#\#.0000") txtPeriod2.Text $=$ Myu(i) txtTime2.Text = Format(H * 12 / Myu(i), "\#\#\#,\#\#\#.0000")

Else

txtTotalCost2.Text $=$ Format(TC_L(i), "\#\#\#,\#\#\#.0000") txtPeriod2.Text $=$ Lyam $(\mathrm{i})$

txtTime2.Text $=$ Format(H * 12 / Lyam(i), "\#\#\#,\#\#\#.0000")

End If 
End If

End Sub

Public Function TC_Function1_ByVal(ByVal X1 As Double) As Double

Sum $1=0$

$\mathrm{TC} 1=\left(2 * \mathrm{~A}_{-} * \mathrm{X} 1 \wedge 2+2 * \mathrm{c} * \mathrm{~b} 0 * \mathrm{H} * \mathrm{X} 1+\mathrm{c} * \mathrm{~b} 1 * \mathrm{H}^{\wedge} 2\right) *(\operatorname{Exp}(-\mathrm{r} * \mathrm{H})-1) /(2 * \mathrm{X} 1 \wedge 2 *(\operatorname{Exp}(-\mathrm{r} * \mathrm{H} / \mathrm{X} 1)$ - 1))

$\mathrm{TC} 2=\mathrm{F} * \mathrm{c} * \mathrm{p} * \operatorname{Exp}(-\mathrm{r} * \mathrm{H} *(2 * \mathrm{~b} 0 * \mathrm{X} 1+\mathrm{b} 1 * \mathrm{H}) /(2 * \mathrm{p} * \mathrm{X} 1 \wedge 2)) *(\operatorname{Exp}(-\mathrm{r} * \mathrm{H} *(\mathrm{p} * \mathrm{X} 1+\mathrm{b} 1 * \mathrm{H}) /(\mathrm{p} *$

$\mathrm{X} 1))-1) /(\mathrm{r} \wedge 2 *(\operatorname{Exp}(-\mathrm{r} * \mathrm{H} *(\mathrm{p} * \mathrm{X} 1+\mathrm{b} 1 * \mathrm{H}) /(\mathrm{p} * \mathrm{X} 1 \wedge 2))-1))$

$\mathrm{TC} 3=\mathrm{F} * \mathrm{c} *((\mathrm{~b} 0+\mathrm{b} 1 / \mathrm{r}) *(\operatorname{Exp}(-\mathrm{r} * \mathrm{H} / \mathrm{X} 1)-1) * \mathrm{X} 1+\mathrm{b} 1 * \mathrm{H} * \operatorname{Exp}(-\mathrm{r} * \mathrm{H} / \mathrm{X} 1)+\mathrm{p} * \mathrm{X} 1) *(\operatorname{Exp}(-\mathrm{r} * \mathrm{H})-1) /$

$\left(\mathrm{X} 1 * \mathrm{r}^{\wedge} 2 *(\operatorname{Exp}(-\mathrm{r} * \mathrm{H} / \mathrm{X} 1)-1)\right)$

For $\mathrm{j}=0$ To $(\mathrm{X} 1-1)$ Step 1

$\operatorname{Sum} 1=\operatorname{Sum} 1+\mathrm{j} * \operatorname{Exp}(-\mathrm{r} * \mathrm{j} * \mathrm{H} / \mathrm{X} 1)$

Next j

$\mathrm{TC} 4=\left(\mathrm{H} * \mathrm{c} * \mathrm{~b} 1 /\left(\mathrm{X} 1 \wedge 2 * \mathrm{r}^{\wedge} 2\right)\right) *\left(\mathrm{H}^{*} \mathrm{r}^{\wedge} 2+\mathrm{F} * \mathrm{X} 1 *(\operatorname{Exp}(-\mathrm{r} * \mathrm{H} / \mathrm{X} 1)-1)\right) * \operatorname{Sum} 1$

TotCost $1=\mathrm{TC} 1-\mathrm{TC} 2+\mathrm{TC} 3+\mathrm{TC} 4$

TC_Function1_ByVal $=$ TotCost1

End Function

Public Function TC_Function2_ByVal(ByVal X1 As Double) As Double

Sum2 $=0$

$\mathrm{TC} 1=\left(2 * \mathrm{r} * \mathrm{~A} \_* \mathrm{X} 1 \wedge 2+2 * \mathrm{c} 1 * \mathrm{~b} 0 * \mathrm{H} * \mathrm{r} * \mathrm{X} 1+\mathrm{c} 1 * \mathrm{~b} 1 * \mathrm{H}^{\wedge} 2 * \mathrm{r}+2 * \mathrm{c} 2 * \mathrm{p} * \mathrm{X} 1 \wedge 2\right) *(\mathrm{Exp}(-\mathrm{r} * \mathrm{H})-$

1) $/(2 * \mathrm{r} * \mathrm{X} 1 \wedge 2 *(\operatorname{Exp}(-\mathrm{r} * \mathrm{H} / \mathrm{X} 1)-1))$

$\mathrm{TC} 2=\mathrm{p} * \operatorname{Exp}(-\mathrm{r} * \mathrm{H} *(2 * \mathrm{~b} 0 * \mathrm{X} 1+\mathrm{b} 1 * \mathrm{H}) /(2 * \mathrm{p} * \mathrm{X} 1 \wedge 2)) *(\operatorname{Exp}(-\mathrm{r} * \mathrm{H} *(\mathrm{p} * \mathrm{X} 1+\mathrm{b} 1 * \mathrm{H}) /(\mathrm{p} * \mathrm{X} 1))-$

$1) *(\mathrm{c} 2 * \mathrm{r}+\mathrm{F} * \mathrm{c} 1+\mathrm{F} * \mathrm{c} 2) /(\mathrm{r} \wedge 2 *(\operatorname{Exp}(-\mathrm{r} * \mathrm{H} *(\mathrm{p} * \mathrm{X} 1+\mathrm{b} 1 * \mathrm{H}) /(\mathrm{p} * \mathrm{X} 1 \wedge 2))-1))$

$\mathrm{TC} 3=\mathrm{F} *(\mathrm{c} 1+\mathrm{c} 2) *((\mathrm{~b} 0+\mathrm{b} 1 / \mathrm{r}) *(\operatorname{Exp}(-\mathrm{r} * \mathrm{H} / \mathrm{X} 1)-1) * \mathrm{X} 1+\mathrm{b} 1 * \mathrm{H} * \operatorname{Exp}(-\mathrm{r} * \mathrm{H} / \mathrm{X} 1)+\mathrm{p} * \mathrm{X} 1) *(\operatorname{Exp}(-\mathrm{r}$

$* \mathrm{H})-1) /\left(\mathrm{X} 1 * \mathrm{r}^{\wedge} 2 *(\operatorname{Exp}(-\mathrm{r} * \mathrm{H} / \mathrm{X} 1)-1)\right)$

For $\mathrm{j}=0$ To $(\mathrm{X} 1-1)$ Step 1

$\operatorname{Sum} 2=\operatorname{Sum} 2+\mathrm{j} * \operatorname{Exp}(-\mathrm{r} * \mathrm{j} * \mathrm{H} / \mathrm{X} 1)$

Next j

$\mathrm{TC} 4=\left(\mathrm{b} 1 * \mathrm{H} /\left(\mathrm{r}^{\wedge} 2 * \mathrm{X} 1 \wedge 2\right)\right) *\left(\mathrm{H}^{*} \mathrm{c} 1 * \mathrm{r}^{\wedge} 2+\mathrm{X} 1 * \mathrm{~F} *(\mathrm{c} 1+\mathrm{c} 2) *(\operatorname{Exp}(-\mathrm{r} * \mathrm{H} / \mathrm{X} 1)-1)\right) * \mathrm{Sum} 2$

TotCost $2=\mathrm{TC} 1-\mathrm{TC} 2+\mathrm{TC} 3+\mathrm{TC} 4$

$\mathrm{TC}$ Function2_ByVal $=$ TotCost 2

End Function

Private Sub chkOneCost_Click()

If chkOneCost. Value $=1$ Then

chkTwoCosts. Value $=0$

txtTotalCost2. Text $=$ ""

txtPeriod2.Text $=" "$

txtTime2.Text $=$ ""

lblLabor.Visible $=$ False

lblRaw. Visible $=$ False

txtRawCost c1. Visible $=$ False

txtLaborCost_c2. Visible $=$ False

lblMinTotal2. Visible $=$ False

lblNumber2. Visible $=$ False

lblTime2. Visible $=$ False

txtTotalCost2. Visible $=$ False

txtPeriod2. Visible $=$ False

txtTime2. Visible $=$ False

lblProdCost. Visible $=$ True

txtProdCost_c.Visible $=$ True 


\author{
lblMinTotal1. Visible $=$ True \\ lblNumber1.Visible $=$ True \\ lblTime1. Visible $=$ True \\ txtTotalCost1. Visible $=$ True \\ txtPeriod 1 .Visible $=$ True \\ txtTime1.Visible $=$ True \\ End If \\ End Sub \\ Private Sub chkTwoCosts_Click() \\ If chkTwoCosts. Value $=1$ Then \\ chkOneCost.Value $=0$ \\ txtTotalCost1.Text $=" "$ \\ txtPeriod1.Text $=$ "" \\ txtTime1.Text $=$ "" \\ lblLabor.Visible $=$ True \\ lblRaw.Visible $=$ True \\ txtRawCost_c1.Visible $=$ True \\ txtLaborCost_c2.Visible $=$ True \\ lblMinTotal2. Visible $=$ True \\ lblNumber2. Visible $=$ True \\ lblTime2. Visible $=$ True \\ txtTotalCost2. Visible $=$ True \\ txtPeriod2.Visible $=$ True \\ txtTime2. Visible $=$ True \\ lblProdCost. Visible $=$ False \\ txtProdCost_c.Visible $=$ False \\ lblMinTotal 1 . Visible $=$ False \\ lblNumber1.Visible $=$ False \\ lblTime1.Visible $=$ False \\ txtTotalCost 1. Visible $=$ False \\ txtPeriod1 . Visible $=$ False \\ txtTime1.Visible $=$ False \\ End If \\ End Sub \\ Private Sub cmdExit_Click() \\ End \\ End Sub
}




\section{Appendix C. Computer program for EPQ model with shortages, linear demand, and time value of money:}

Dim A_, p, c, F, InflRate, NomRate, r, m, H As Double

Dim b0, b1, c1, c2, K, K0, S, S_starL, S_starM As Double

Dim a(1000), b(1000), Lyam_m(1000), Myu_m(1000), Lyam_S(1000), Myu_S(1000) As Double

Dim a2L(1000), b2L(1000), Lyam_SL(1000), Myu_SL(1000) As Double

Dim a2M(1000), b2M(1000), Lyam_SM(1000), Myu_SM(1000) As Double

Dim TC_LL(1000), TC_LM(1000), TC_ML(1000), TC_MM(1000) As Double

Dim t1(1000), tp(1000), t2(1000), TotCost1, Short As Double

Dim t_1(1000), t_p(1000), t_2(1000), TotCost2 As Double

Dim X1, X2, X3, i, j, y, TC_M(1000), TC_L(1000) As Double

Private Sub cmdCalculate_Click()

A $=$ Val(txtSetup_A.Text)

$\mathrm{p}=\operatorname{Val}($ txtProdRate_p.Text)

$\mathrm{c}=$ Val(txtProdCost_c.Text)

$\mathrm{c} 1=\operatorname{Val}($ txtRawCost_c1.Text)

c2 $=$ Val(txtLaborCost_c2.Text)

$\mathrm{F}=(\mathrm{Val}($ txtCarryingRate F.Text $)) / 100$

InflRate $=($ Val $($ txtInflRate.Text $)) / 100$

NomRate $=(\operatorname{Val}($ txtNomRate.Text $)) / 100$

$\mathrm{r}=$ NomRate - InflRate

b0 $=\operatorname{Val}($ txtD Interc b0.Text)

$\mathrm{b} 1=\mathrm{Val}(\mathrm{txtD}$ Slope_b1.Text)

$\mathrm{K} 0=$ Val(txtShortCost_K0.Text)

$\mathrm{K}=\mathrm{Val}($ txtShortCost_K.Text)

$\mathrm{H}=$ Val(txtHorizon_H.Text)

$\mathrm{m}=$ Val(txtPeriod_m.Text)

$\mathrm{S}=$ Val(txtInitShortage_S.Text)

If chkOneCost. Value $=1$ Then

$\mathrm{i}=1$

$\mathrm{a}(1)=1$

$\mathrm{b}(1)=\mathrm{m}$

Lyam_m $(1)=\operatorname{Round}(\mathrm{a}(1)+(1-0.618) *(\mathrm{~b}(1)-\mathrm{a}(1)), 0)$

Myu_m(1) $=\operatorname{Round}(\mathrm{a}(1)+0.618 *(\mathrm{~b}(1)-\mathrm{a}(1)), 0)$

S_starL $=$ Function3_ByVal(Lyam_m(1))

S_starM = Function3_ByVal(Myu_m(1))

$$
\begin{aligned}
& \mathrm{j}=1 \\
& \mathrm{a} 2 \mathrm{~L}(1)=0 \\
& \text { If S_starL }<\text { S Then } \\
& \mathrm{b} 2 \mathrm{~L}(1)=\mathrm{S} \text { _starL } \\
& \text { Else } \\
& \mathrm{b} 2 \mathrm{~L}(1)=\mathrm{S} \\
& \text { End If } \\
& \text { a2M(1) =0 } \\
& \text { If S_starM }<\mathrm{S} \text { Then } \\
& \text { b2M }(1)=\mathrm{S} \text { starM } \\
& \text { Else } \\
& \text { b2M(1) }=\mathrm{S} \\
& \text { End If }
\end{aligned}
$$




$$
\begin{aligned}
& \text { Lyam_SL(1) = a2L(1) + }(1-0.618) *(\mathrm{~b} 2 \mathrm{~L}(1)-\mathrm{a} 2 \mathrm{~L}(1)) \\
& \text { Myu_SL(1) } \mathrm{a} 2 \mathrm{~L}(1)+0.618 *(\mathrm{~b} 2 \mathrm{~L}(1)-\mathrm{a} 2 \mathrm{~L}(1)) \\
& \mathrm{Lyam} \_\mathrm{SM}(1)=\mathrm{a} 2 \mathrm{M}(1)+(1-0.618) *(\mathrm{~b} 2 \mathrm{M}(1)-\mathrm{a} 2 \mathrm{M}(1)) \\
& \text { Myu_SM(1) }=\mathrm{a} 2 \mathrm{M}(1)+0.618 *(\mathrm{~b} 2 \mathrm{M}(1)-\mathrm{a} 2 \mathrm{M}(1)) \\
& \text { TC_LL(1) }=\text { TC_Function1_ByVal(Lyam_m(1), Lyam_SL(1)) } \\
& \text { TC_LM(1) = TC_Function1_ByVal(Lyam_m(1), Myu_SL(1)) } \\
& \text { TC_ML(1) = TC_Function1_ByVal(Myu_m(1), Lyam_SM(1)) } \\
& \text { TC_MM(1) = TC_Function1_ByVal(Myu_m(1), Myu_SM(1)) }
\end{aligned}
$$

Do While (b2L(j) - a2L(j) > 0.001)

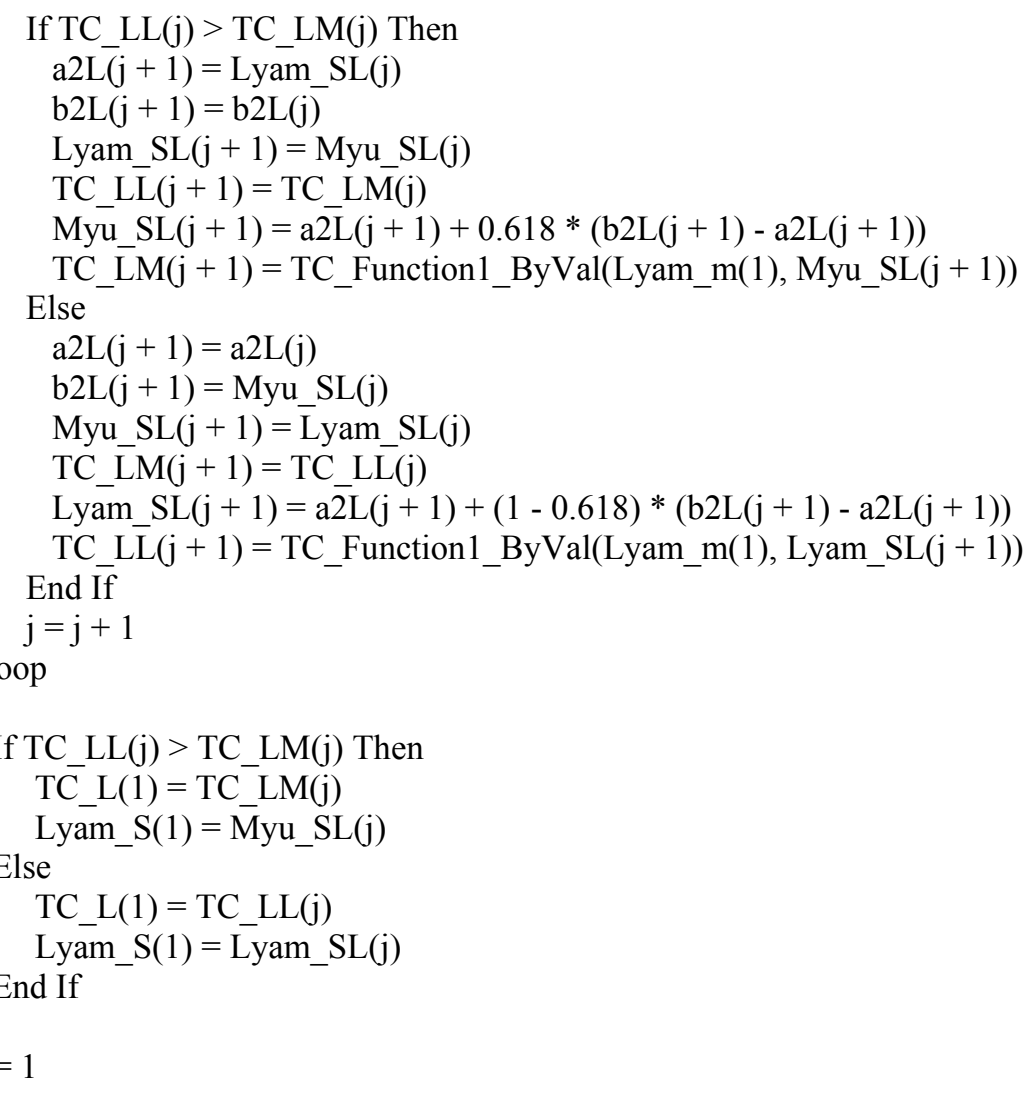

Do While (b2M(j) - a2M(j) > 0.001)

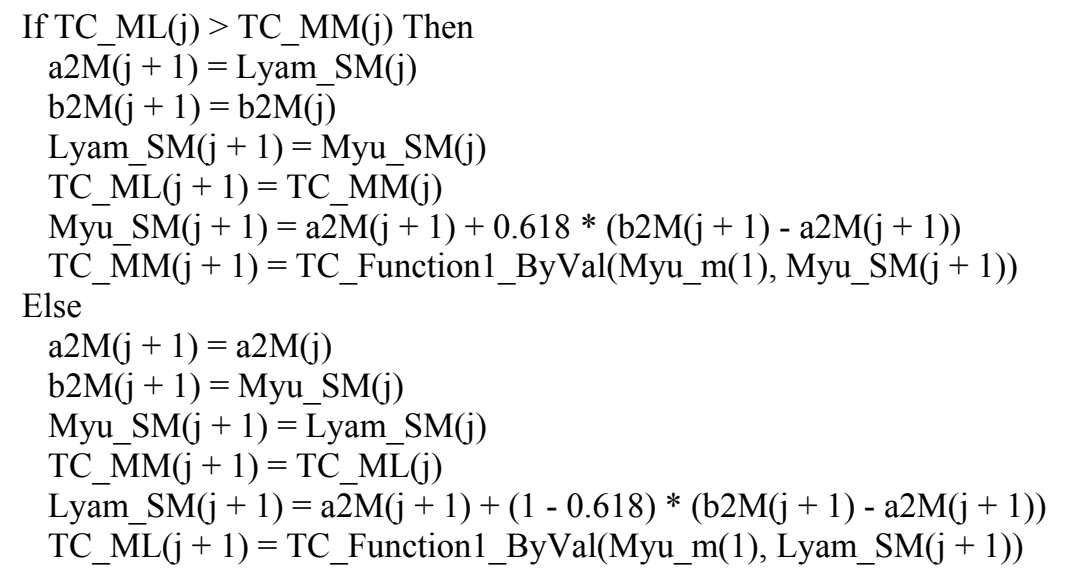




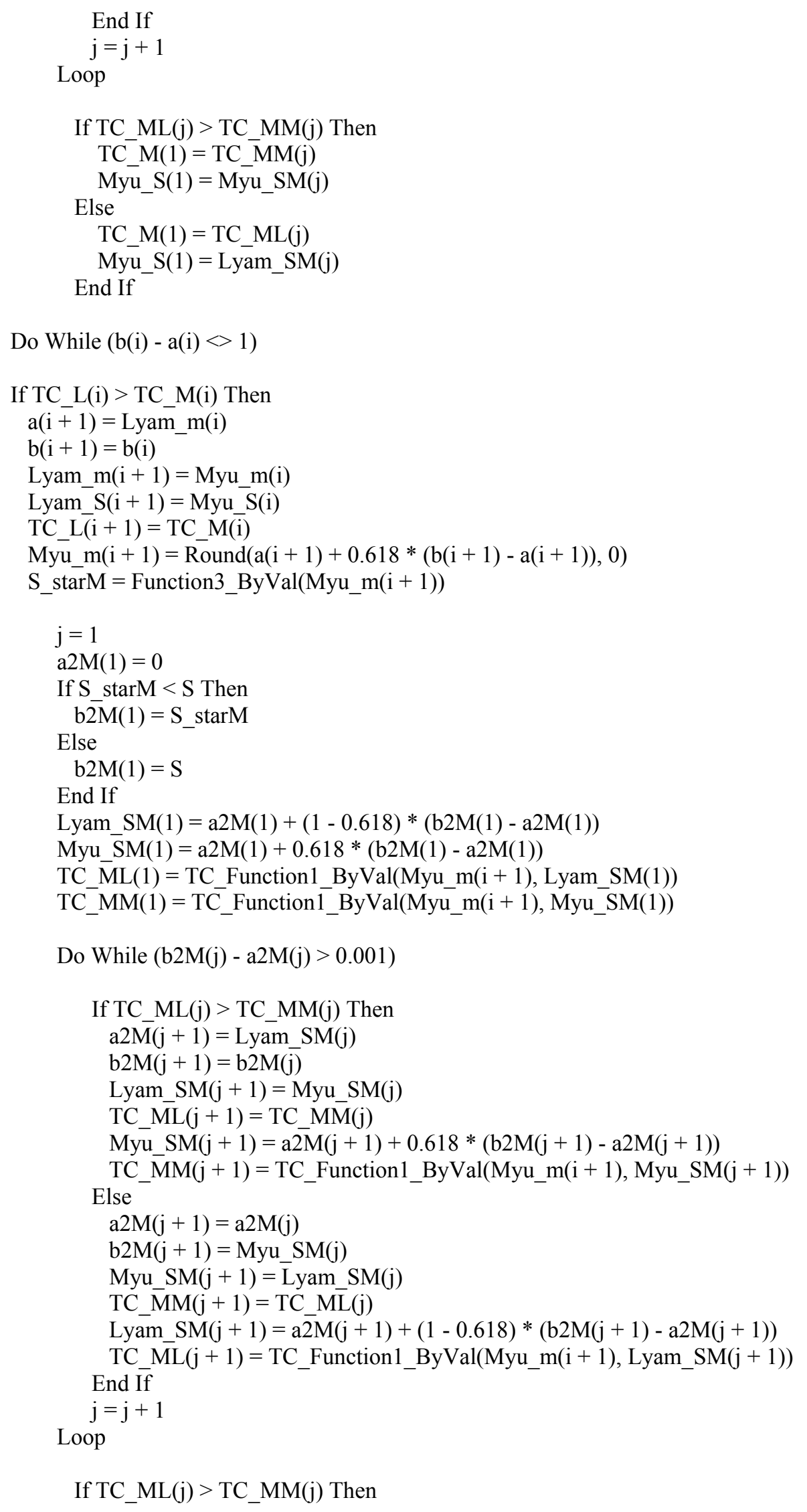




$$
\begin{aligned}
& \text { Myu_S(i+1) }=\text { Myu_SM }(j) \\
& \text { Else } \\
& \text { Myu_S(i }+1)=\text { Lyam_SM }(j) \\
& \text { End If }
\end{aligned}
$$

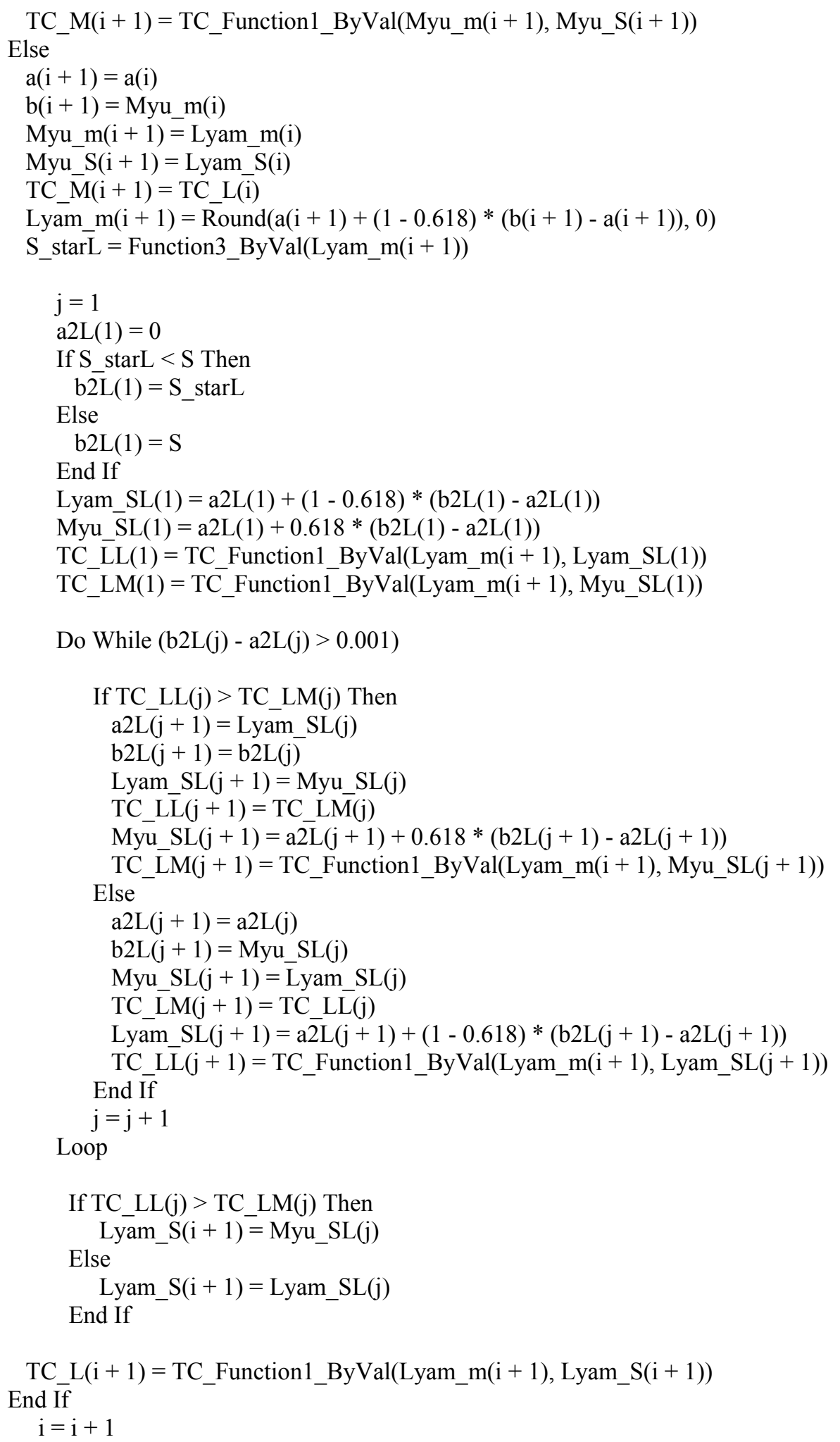


Loop

If TC_L(i) $>$ TC_M(i) Then txtTotalCost1.Text = Format(TC_M(i), "\#\#\#,\#\#\#.0000") txtPeriod1.Text $=$ Myu_m(i)

txtShortage1.Text = Format(Myu_S(i), "\#\#\#,\#\#\#.0000")

txtTime1.Text $=$ Format $(H * 12 /$ Myu_m(i), "\#\#\#,\#\#\#.0000")

Else

txtTotalCost1.Text $=$ Format(TC_L(i), "\#\#\#,\#\#\#.0000")

txtPeriod1.Text $=$ Lyam $\mathrm{m}(\mathrm{i})$

txtShortage1.Text = Format(Lyam_S(i), "\#\#\#,\#\#\#.0000")

txtTime1.Text $=$ Format(H * 12 / Lyam_m(i), "\#\#\#,\#\#\#.0000")

End If

Else

$\mathrm{i}=1$

$\mathrm{a}(1)=1$

$b(1)=m$

Lyam_m(1) = Round $(\mathrm{a}(1)+(1-0.618) *(\mathrm{~b}(1)-\mathrm{a}(1)), 0)$

Myu_m(1) $=$ Round $(\mathrm{a}(1)+0.618 *(\mathrm{~b}(1)-\mathrm{a}(1)), 0)$

S_starL = Function3_ByVal(Lyam_m(1))

S_starM = Function3_ByVal(Myu_m(1))

$$
\begin{aligned}
& \mathrm{j}=1 \\
& \mathrm{a} 2 \mathrm{~L}(1)=0 \\
& \text { If } \mathrm{S} \text { _starL }<\mathrm{S} \text { Then } \\
& \text { b } 2 \mathrm{~L}(1)=\mathrm{S} \_ \text {starL } \\
& \text { Else } \\
& \text { b2L }(1)=\mathrm{S} \\
& \text { If TC LL(j) > TC LM(j) Then } \\
& \text { a2L }(j+1)=\text { Lyam_SL }(j) \\
& \mathrm{b} 2 \mathrm{~L}(\mathrm{j}+1)=\mathrm{b} 2 \mathrm{~L}(\mathrm{j}) \\
& \text { Lyam_SL }(j+1)=\text { Myu_SL(j) }
\end{aligned}
$$

Lyam_SL(1) $=\mathrm{a} 2 \mathrm{~L}(1)+(1-0.618) *(\mathrm{~b} 2 \mathrm{~L}(1)-\mathrm{a} 2 \mathrm{~L}(1))$

Myu_SL(1) $=\mathrm{a} 2 \mathrm{~L}(1)+0.618 *(\mathrm{~b} 2 \mathrm{~L}(1)-\mathrm{a} 2 \mathrm{~L}(1))$

Lyam_SM(1) =a2M(1) + (1 - 0.618)*(b2M(1) - a2M(1))

Myu_SM(1) $=\mathrm{a} 2 \mathrm{M}(1)+0.618 *(\mathrm{~b} 2 \mathrm{M}(1)-\mathrm{a} 2 \mathrm{M}(1))$

TC_LL(1) = TC_Function2_ByVal(Lyam_m(1), Lyam_SL(1))

TC_LM(1) $=$ TC_Function2_ByVal(Lyam_m(1), Myu_SL(1))

TC_ML(1) $=$ TC_Function2_ByVal(Myu_m(1), Lyam_SM(1))

TC_MM(1) $=$ TC_Function2_ByVal(Myu_m(1), Myu_SM(1)) 


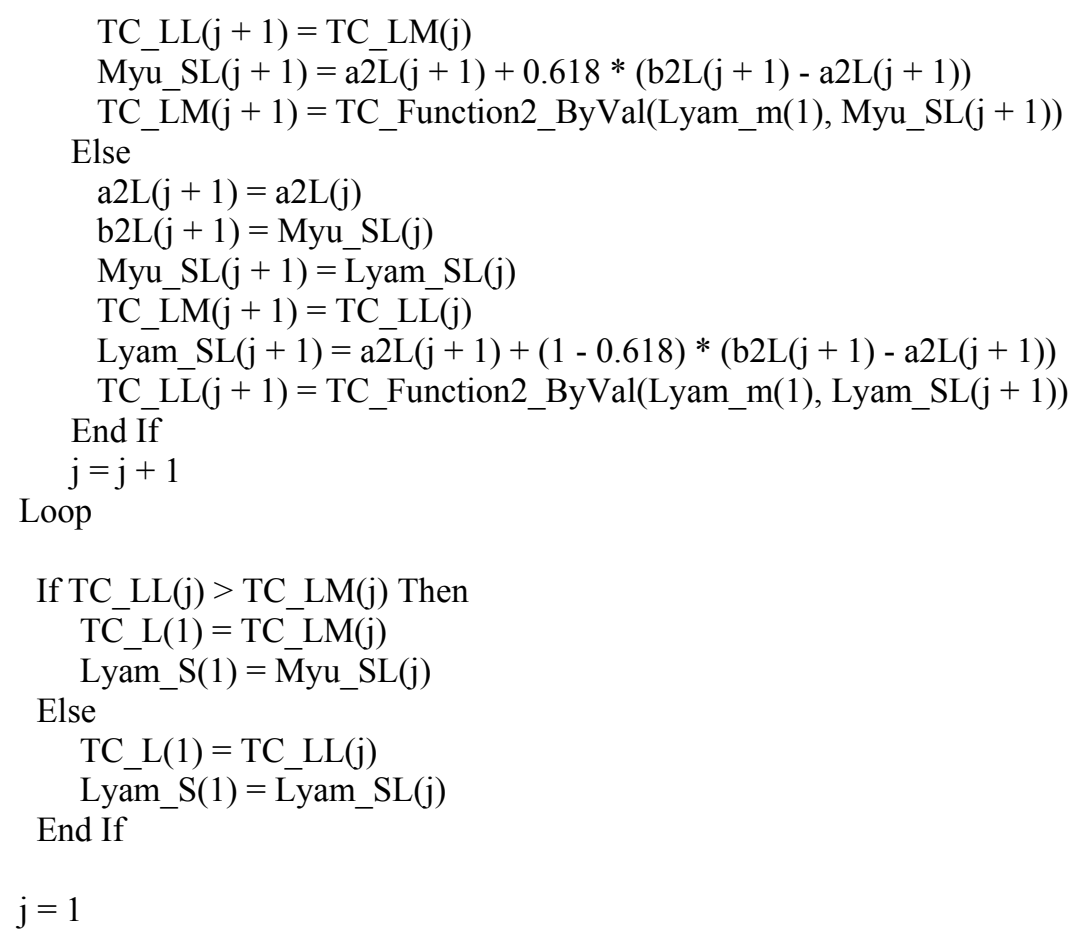




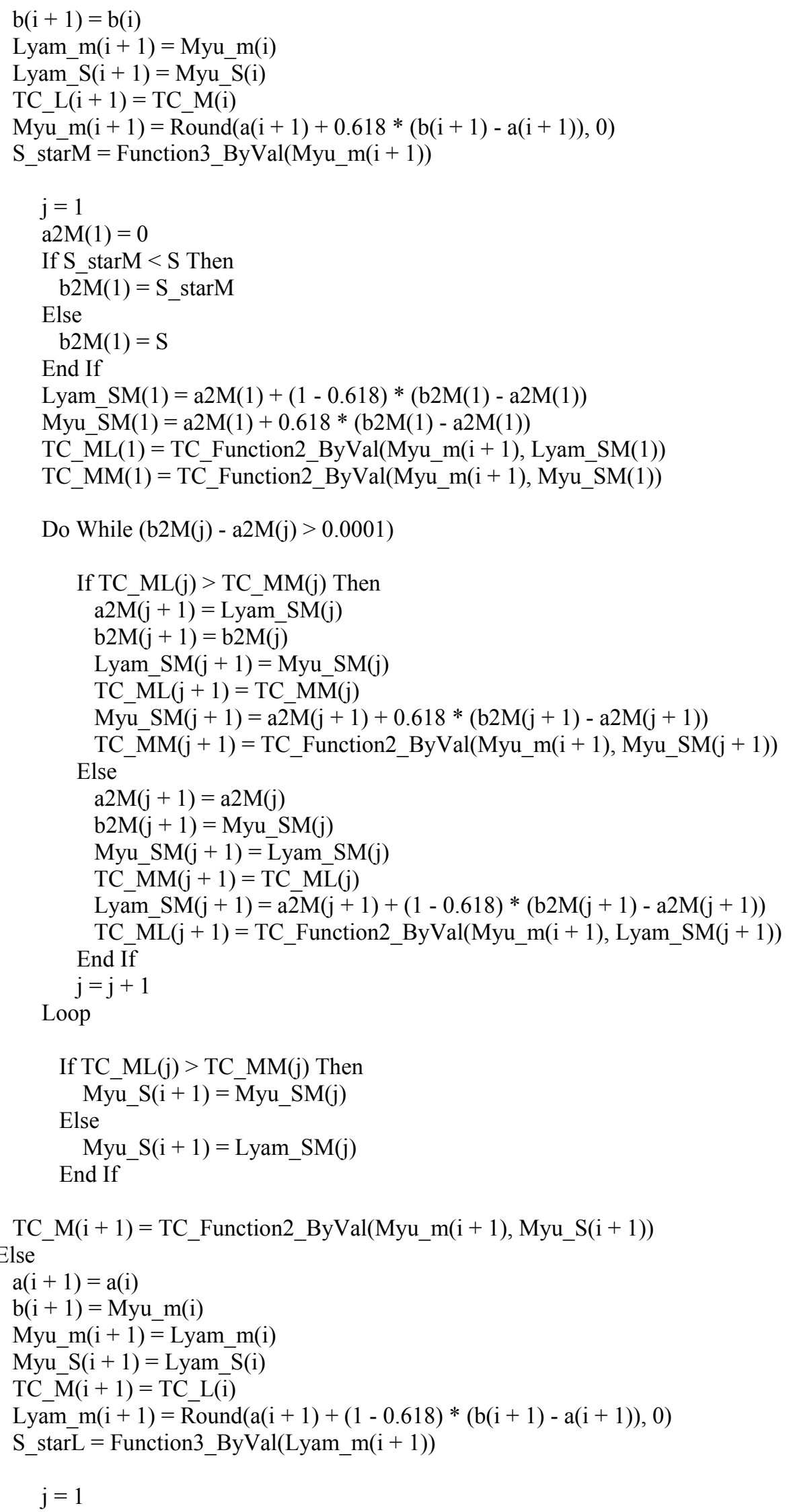




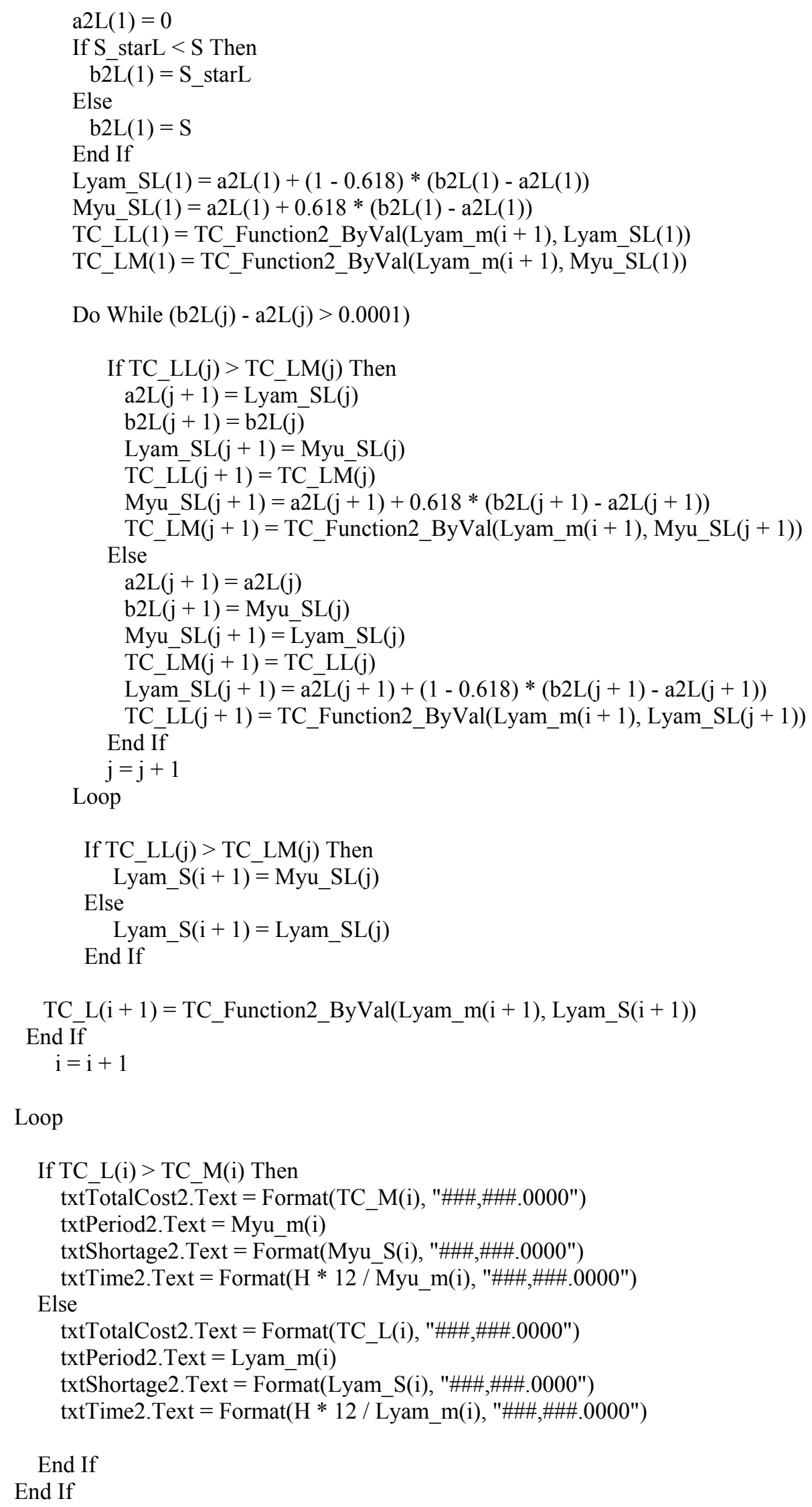


End Sub

Public Function TC_Function1_ByVal(ByVal X1 As Double, ByVal X2 As Double) As Double PCExp $=0$

$\mathrm{BC} 1=0$

$\mathrm{BC} 2=0$

$\mathrm{BC} 3=0$

$\mathrm{HC} 1=0$

$\mathrm{HC} 2=0$

For $\mathrm{y}=0$ To X1 - 1 Step 1

PCExp $=$ PCExp $+\mathrm{y} * \operatorname{Exp}(-\mathrm{r} * \mathrm{y} * \mathrm{H} / \mathrm{X} 1)$

$\mathrm{t} 1(\mathrm{y})=(\mathrm{p}-\mathrm{b} 0) / \mathrm{b} 1-\operatorname{Sqr}\left((\mathrm{p}-\mathrm{b} 0)^{\wedge} 2-2 * \mathrm{y} * \mathrm{H} * \mathrm{~b} 1 *(\mathrm{p}-\mathrm{b} 0) / \mathrm{X} 1+\mathrm{b} 1 *\left(\mathrm{y}^{\wedge} 2 * \mathrm{H}^{\wedge} 2 * \mathrm{~b} 1 / \mathrm{X} 1 \wedge 2-2 *\right.\right.$ $\mathrm{X} 2)) / \mathrm{b} 1$

$\operatorname{tp}(\mathrm{y})=\mathrm{y} * \mathrm{H} / \mathrm{X} 1+\mathrm{b} 0 * \mathrm{H} /(\mathrm{X} 1 * \mathrm{p})+\mathrm{b} 1 * \mathrm{H}^{\wedge} 2 *(2 * \mathrm{y}+1) /(2 * \mathrm{p} * \mathrm{X} 1 \wedge 2)$

b1)

$\mathrm{t} 2(\mathrm{y})=-\mathrm{b} 0 / \mathrm{b} 1+\operatorname{Sqr}\left(\mathrm{b} 0 \wedge 2 / \mathrm{b} 1 \wedge 2+2 * \mathrm{~b} 0 * \mathrm{H}^{*}(\mathrm{y}+1) /(\mathrm{b} 1 * \mathrm{X} 1)+\mathrm{H}^{\wedge} 2 *(\mathrm{y}+1) \wedge 2 / \mathrm{X} 1 \wedge 2-2 * \mathrm{X} 2 /\right.$

$\mathrm{BC} 1=\mathrm{BC} 1+\operatorname{Exp}(-\mathrm{r} * \mathrm{t} 1(\mathrm{y})) *(-\mathrm{X} 2-\mathrm{p} * \mathrm{y} * \mathrm{H} / \mathrm{X} 1+\mathrm{b} 0 * \mathrm{y} * \mathrm{H} / \mathrm{X} 1+\mathrm{b} 1 * \mathrm{y} \wedge 2 * \mathrm{H} \wedge 2 /(2 * \mathrm{X} 1 \wedge 2)-\mathrm{b} 0 *$ $\left.\mathrm{t} 1(\mathrm{y})-\mathrm{b} 0 / \mathrm{r}+\mathrm{p} * \mathrm{t} 1(\mathrm{y})+\mathrm{p} / \mathrm{r}-\mathrm{b} 1 * \mathrm{t} 1(\mathrm{y}) \wedge 2 / 2-\mathrm{b} 1 * \mathrm{t} 1(\mathrm{y}) / \mathrm{r}-\mathrm{b} 1 / \mathrm{r}^{\wedge} 2\right)$

$\mathrm{BC} 2=\mathrm{BC} 2+\operatorname{Exp}(-\mathrm{r} * \mathrm{t} 2(\mathrm{y})) *\left(-\mathrm{b} 0 * \mathrm{y} * \mathrm{H} / \mathrm{X} 1-\mathrm{b} 0 * \mathrm{H} / \mathrm{X} 1-\mathrm{b} 1 * \mathrm{y} \wedge 2 * \mathrm{H}^{\wedge} 2 /(2 * \mathrm{X} 1 \wedge 2)-\mathrm{b} 1 * \mathrm{y} * \mathrm{H} \wedge 2\right.$ $\left./ \mathrm{X} 1 \wedge 2-\mathrm{b} 1 * \mathrm{H}^{\wedge} 2 /(2 * \mathrm{X} 1 \wedge 2)+\mathrm{b} 0 * \mathrm{t} 2(\mathrm{y})+\mathrm{b} 0 / \mathrm{r}+\mathrm{b} 1 * \mathrm{t} 2(\mathrm{y}) \wedge 2 / 2+\mathrm{b} 1 * \mathrm{t} 2(\mathrm{y}) / \mathrm{r}+\mathrm{b} 1 / \mathrm{r} \wedge 2+\mathrm{X} 2\right)$

$\mathrm{BC} 3=\mathrm{BC} 3+\operatorname{Exp}(-\mathrm{r} * \mathrm{y} * \mathrm{H} / \mathrm{X} 1) *(\mathrm{X} 2+\mathrm{b} 0 / \mathrm{r}-\mathrm{p} / \mathrm{r}+\mathrm{b} 1 * \mathrm{y} * \mathrm{H} /(\mathrm{X} 1 * \mathrm{r})+\mathrm{b} 1 / \mathrm{r} \wedge 2-\mathrm{b} 0 * \operatorname{Exp}(-\mathrm{r} * \mathrm{H} /$ $\mathrm{X} 1) / \mathrm{r}-\mathrm{b} 1 * \mathrm{H} *(\mathrm{y}+1) * \operatorname{Exp}(-\mathrm{r} * \mathrm{H} / \mathrm{X} 1) /(\mathrm{X} 1 * \mathrm{r})-\mathrm{b} 1 * \operatorname{Exp}(-\mathrm{r} * \mathrm{H} / \mathrm{X} 1) / \mathrm{r} \wedge 2-\mathrm{X} 2 * \operatorname{Exp}(-\mathrm{r} * \mathrm{H} / \mathrm{X} 1))$

$\mathrm{HC} 1=\mathrm{HC} 1+\operatorname{Exp}(-\mathrm{r} * \operatorname{tp}(\mathrm{y})) *(\mathrm{~b} 0 * \mathrm{t} 2(\mathrm{y})+\mathrm{b} 1 * \mathrm{t} 2(\mathrm{y}) \wedge 2 / 2+\mathrm{p} * \mathrm{t} 1(\mathrm{y})-\mathrm{b} 0 * \mathrm{t} 1(\mathrm{y})-\mathrm{b} 1 * \mathrm{t} 1(\mathrm{y}) \wedge 2 / 2-\mathrm{p} *$ $\operatorname{tp}(\mathrm{y})-\mathrm{p} / \mathrm{r})$

$\mathrm{HC} 2=\mathrm{HC} 2+\operatorname{Exp}(-\mathrm{r} * \mathrm{t} 2(\mathrm{y})) *(\mathrm{~b} 0+\mathrm{b} 1 * \mathrm{t} 2(\mathrm{y})+\mathrm{b} 1 / \mathrm{r}) / \mathrm{r}+\operatorname{Exp}(-\mathrm{r} * \mathrm{t} 1(\mathrm{y})) *(\mathrm{p}-\mathrm{b} 0-\mathrm{b} 1 * \mathrm{t} 1(\mathrm{y})-\mathrm{b} 1 / \mathrm{r}) / \mathrm{r}$ Next y

$\mathrm{SC}=\mathrm{A}_{-} *(\operatorname{Exp}(-\mathrm{r} * \mathrm{H})-1) /(\operatorname{Exp}(-\mathrm{r} * \mathrm{H} / \mathrm{X} 1)-1)$

$\mathrm{PC}=\mathrm{c} * \mathrm{~b} 0 * \mathrm{H} *(\operatorname{Exp}(-\mathrm{r} * \mathrm{H})-1) /(\mathrm{X} 1 *(\operatorname{Exp}(-\mathrm{r} * \mathrm{H} / \mathrm{X} 1)-1))+\mathrm{c} * \mathrm{~b} 1 * \mathrm{H}^{\wedge} 2 *(\operatorname{Exp}(-\mathrm{r} * \mathrm{H})-1) /(2 * \mathrm{X} 1 \wedge 2$

$*(\operatorname{Exp}(-\mathrm{r} * \mathrm{H} / \mathrm{X} 1)-1))+\mathrm{c} * \mathrm{~b} 1 * \mathrm{H}^{\wedge} 2 * \mathrm{PCExp} / \mathrm{X} 1 \wedge 2$

$\mathrm{BC}=\mathrm{K} *(\mathrm{BC} 1+\mathrm{BC} 2+\mathrm{BC} 3) / \mathrm{r}+\mathrm{K} 0 * \mathrm{X} 2 *(1-\operatorname{Exp}(-\mathrm{r} * \mathrm{H})) /(1-\operatorname{Exp}(-\mathrm{r} * \mathrm{H} / \mathrm{X} 1))$

$\mathrm{HC}=\mathrm{F} * \mathrm{c} *(\mathrm{HC} 1+\mathrm{HC} 2) / \mathrm{r}$

TotCost $1=\mathrm{SC}+\mathrm{PC}+\mathrm{BC}+\mathrm{HC}$

TC_Function1_ByVal $=$ TotCost1

End Function

Public Function TC_Function2_ByVal(ByVal X1 As Double, ByVal X2 As Double) As Double

PCExp_2 $=0$

BC_1 $1=0$

$\mathrm{BC}^{-} 2=0$

$\mathrm{BC} 3=0$

$\mathrm{HC} 1=0$

$\mathrm{HC} 2=0$

For $\mathrm{y}=0$ To X1 - 1 Step 1

PCExp_2 = PCExp_2 $+\mathrm{y} * \operatorname{Exp}(-\mathrm{r} * \mathrm{y} * \mathrm{H} / \mathrm{X} 1)$

$\mathrm{t} 1(\mathrm{y})=(\mathrm{p}-\mathrm{b} 0) / \mathrm{b} 1-\operatorname{Sqr}\left((\mathrm{p}-\mathrm{b} 0)^{\wedge} 2-2 * \mathrm{y} * \mathrm{H} * \mathrm{~b} 1 *(\mathrm{p}-\mathrm{b} 0) / \mathrm{X} 1+\mathrm{b} 1 *\left(\mathrm{y} \wedge 2 * \mathrm{H}^{\wedge} 2 * \mathrm{~b} 1 / \mathrm{X} 1 \wedge 2-2 *\right.\right.$ $\mathrm{X} 2)) / \mathrm{b} 1$

$\mathrm{t} \mathrm{p}(\mathrm{y})=\mathrm{y} * \mathrm{H} / \mathrm{X} 1+\mathrm{b} 0 * \mathrm{H} /(\mathrm{X} 1 * \mathrm{p})+\mathrm{b} 1 * \mathrm{H}^{\wedge} 2 *(2 * \mathrm{y}+1) /(2 * \mathrm{p} * \mathrm{X} 1 \wedge 2)$

b1)

$\mathrm{t} \_2(\mathrm{y})=-\mathrm{b} 0 / \mathrm{b} 1+\mathrm{Sqr}\left(\mathrm{b} 0 \wedge 2 / \mathrm{b} 1 \wedge 2+2 * \mathrm{~b} 0 * \mathrm{H} *(\mathrm{y}+1) /(\mathrm{b} 1 * \mathrm{X} 1)+\mathrm{H}^{\wedge} 2 *(\mathrm{y}+1) \wedge 2 / \mathrm{X} 1 \wedge 2-2 * \mathrm{X} 2 /\right.$

$\mathrm{BC}_{-} 1=\mathrm{BC}_{-} 1+\operatorname{Exp}\left(-\mathrm{r} * \mathrm{t} \_1(\mathrm{y})\right) *(-\mathrm{X} 2-\mathrm{p} * \mathrm{y} * \mathrm{H} / \mathrm{X} 1+\mathrm{b} 0 * \mathrm{y} * \mathrm{H} / \mathrm{X} 1+\mathrm{b} 1 * \mathrm{y} \wedge 2 * \mathrm{H} \wedge 2 /(2 * \mathrm{X} 1 \wedge 2)-$ $\left.\mathrm{b} 0 * \mathrm{t} \_1(\mathrm{y})-\mathrm{b} 0 / \mathrm{r}+\mathrm{p} * \mathrm{t} \_1(\mathrm{y})+\mathrm{p} / \mathrm{r}-\mathrm{b} 1 * \mathrm{t} \_1(\mathrm{y}) \wedge 2 / 2-\mathrm{b} 1 * \mathrm{t} \_1(\mathrm{y}) / \mathrm{r}-\mathrm{b} 1 / \mathrm{r} \wedge 2\right)$

$\mathrm{BC} 22=\mathrm{BC} \_2+\operatorname{Exp}\left(-\mathrm{r} * \mathrm{t} \_2(\mathrm{y})\right) *(-\mathrm{b} 0 * \mathrm{y} * \mathrm{H} / \mathrm{X} 1-\mathrm{b} 0 * \mathrm{H} / \mathrm{X} 1-\mathrm{b} 1 * \mathrm{y} \wedge 2 * \mathrm{H} \wedge 2 /(2 * \mathrm{X} 1 \wedge 2)-\mathrm{b} 1 * \mathrm{y} * \mathrm{H}$ $\left.\wedge 2 / \mathrm{X}^{\wedge} \wedge 2-\mathrm{b} 1 * \mathrm{H}^{\wedge} 2 /(2 * \mathrm{X} 1 \wedge 2)+\mathrm{b} 0 * \mathrm{t} \_2(\mathrm{y})+\mathrm{b} 0 / \mathrm{r}+\mathrm{b} 1 * \mathrm{t} \_2(\mathrm{y}) \wedge 2 / 2+\mathrm{b} 1 * \mathrm{t} \_2(\mathrm{y}) / \mathrm{r}+\mathrm{b} 1 / \mathrm{r} \wedge 2+\mathrm{X} 2\right)$ 


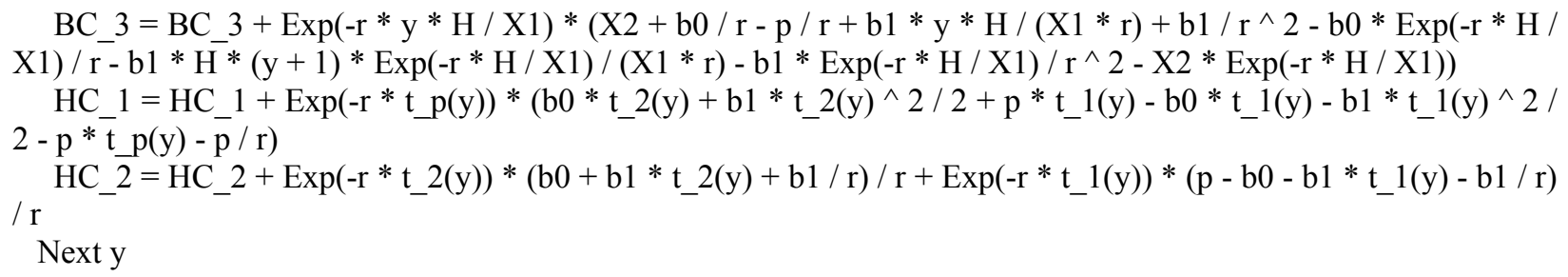

Public Function Function3 ByVal(ByVal X3 As Double) As Double

Short $=\mathrm{b} 0 * \mathrm{H} *(1-\mathrm{b} 0 / \overline{\mathrm{p}}) / \mathrm{X} 3-\mathrm{b} 1 * \mathrm{H}^{\wedge} 2 *(\mathrm{~b} 0 /(\mathrm{p} * \mathrm{X} 3)-\mathrm{b} 0 /(2 * \mathrm{p} * \mathrm{X} 3 \wedge 2)-1 / 2)-\mathrm{b} 1 * \mathrm{H} \wedge 2 *(1-1 /$ $\mathrm{X} 3+\mathrm{b} 0 /(\mathrm{p} * \mathrm{X} 3)+\mathrm{b} 1 * \mathrm{H} /(\mathrm{p} * \mathrm{X} 3)-\mathrm{b} 1 * \mathrm{H} /(2 * \mathrm{p} * \mathrm{X} 3 \wedge 2)) \wedge 2 / 2$

Function3 ByVal $=$ Short

End Function

Private Sub chkOneCost_Click()

If chkOneCost. Value $=1$ Then

chkTwoCosts. Value $=0$

txtTotalCost2. Text $=$ ""

txtPeriod2.Text $=" "$

txtTime2. Text $=" "$

txtShortage2. Text = "'"

lblLabor.Visible $=$ False

lblRaw. Visible $=$ False

txtRawCost_c1. Visible $=$ False

txtLaborCost_c2. Visible $=$ False

lblMinTotal2. Visible $=$ False

lblNumber2. Visible $=$ False

lblTime2. Visible $=$ False

lblShortage2. Visible $=$ False

txtTotalCost2. Visible $=$ False

txtPeriod2. Visible $=$ False

txtTime2. Visible $=$ False

txtShortage2. Visible $=$ False

lblProdCost. Visible $=$ True txtProdCost_c. Visible $=$ True lblMinTotal $\overline{1}$. Visible $=$ True lblNumber1. Visible $=$ True lblTime1. Visible $=$ True lblShortage1. Visible $=$ True txtTotalCost 1 . Visible $=$ True txtPeriod 1. Visible $=$ True txtTime1. Visible $=$ True txtShortage1. Visible $=$ True 
End If

End Sub

Private Sub chkTwoCosts_Click()

If chkTwoCosts. Value $=1$ Then

chkOneCost. Value $=0$

txtTotalCost1.Text $=$ ""

txtPeriod1.Text $=" "$

txtTime1.Text $=" "$

txtShortage1.Text = ""

lblLabor.Visible $=$ True

lblRaw. Visible $=$ True

txtRawCost c1. Visible $=$ True

txtLaborCost $c 2$.Visible $=$ True

lblMinTotal2. Visible $=$ True

lblNumber 2 . Visible $=$ True

lblTime2. Visible $=$ True

lblShortage2. Visible $=$ True

txtTotalCost2. Visible $=$ True

txtPeriod2. Visible $=$ True

txtTime2. Visible $=$ True

txtShortage2. Visible $=$ True

lblProdCost. Visible $=$ False

txtProdCost_c. Visible $=$ False

lblMinTotal $\overline{1}$. Visible $=$ False

lblNumber1. Visible $=$ False

lblTime1. Visible $=$ False

lblShortage 1. Visible $=$ False

txtTotalCost1 . Visible $=$ False

txtPeriod1.Visible $=$ False

txtTime1. Visible $=$ False

txtShortage 1. Visible $=$ False

End If

End Sub

Private Sub cmdExit_Click()

End

End Sub 